\title{
A new giant sauropod, Australotitan cooperensis gen. et sp. nov., from the mid-Cretaceous of Australia
}

\author{
Scott A Hocknull ${ }^{\text {Corresp., }, 2, \text {, Melville Wilkinson }}{ }^{3}$, Rochelle Ann Lawrence ${ }^{1}$, Vladislav Konstantinov ${ }^{4}$, Stuart \\ Mackenzie $^{3}$, Robyn Mackenzie ${ }^{3}$ \\ ${ }^{1}$ Geosciences, Queensland Museum, Hendra, Brisbane City, Australia \\ 2 Biosciences, University of Melbourne, Melbourne, Victoria, Australia \\ 3 Eromanga Natural History Museum, Eromanga, Queensland, Australia \\ 4 Unaffiliated, Oktyabrskaya, Ryazan, Russian Federation \\ Corresponding Author: Scott A Hocknull \\ Email address: scott.hocknull@qm.qld.gov.au
}

A new giant sauropod, Australotitan cooperensis gen. et sp. nov., represents the first record of dinosaurs from the southern-central Winton Formation of the Eromanga Basin, Australia. We estimate the type locality to be $270-300 \mathrm{~m}$ from the base of the Winton Formation and compare this to the semi-contemporaneous sauropod taxa, Diamantinasaurus matildae Hocknull et al. 2009, Wintonotitan wattsi Hocknull et al. 2009 and Savannasaurus elliottorum Poropat et al. 2016. The new titanosaurian is the largest dinosaur from Australia as represented by osteological remains and based on limb-size comparisons it reached a size similar to that of the giant titanosaurians from South America. Using 3-D surface scan models we compare features of the appendicular skeleton that differentiate Australotitan cooperensis gen. et sp. nov. as a new taxon. A key limitation to the study of sauropods is the inability to easily and directly compare specimens. Therefore, 3-D cybertypes have become a more standard way to undertake direct comparative assessments. Uncoloured, low resolution, and uncharacterized 3-D surface models can lead to misinterpretations, in particular identification of pre-, syn- and post-depositional distortion. We propose a method for identifying, documenting and illustrating these distortions directly onto the 3-D geometric surface of the models using a colour reference scheme. This new method is repeatable for researchers when observing and documenting specimens including taphonomic alterations and geometric differences. A detailed comparative and preliminary computational phylogenetic assessment supports a shared ancestry for all four Winton Formation taxa, albeit with limited statistical support. Palaeobiogeographical interpretations from these resultant phylogenetic hypotheses remain equivocal due to contrary Asian and South American relationships with the Australian taxa. Temporal and palaeoenvironmental differences between the northern and southern-central sauropod locations are considered to explain the taxonomic and Peerj reviewing PDF | (2020:11:55594:2:1:NEW 28 Mar 2021) 
morphological diversity of sauropods from the Winton Formation. Interpretations for this diversity are explored, including an eco-morphocline and/or chronocline across newly developed terrestrial environments as the basin fills. 
1 A new giant sauropod, Australotitan cooperensis gen. et sp. nov., from the mid-Cretaceous 2 of Australia.

3

4 Scott Alexander Hocknull ${ }^{1,2}$, Melville Wilkinson ${ }^{3}$, Rochelle Ann Lawrence ${ }^{1}$, Vlad

5 Konstantinov $^{4}$, Stuart Mackenzie ${ }^{3}$, Robyn Mackenzie ${ }^{3}$

6

8

9

10

11

12 13

${ }^{1}$ Geosciences Queensland Museum, 122 Gerler Rd. Hendra, Brisbane, Queensland, Australia 4011.

${ }^{2}$ Biosciences, University of Melbourne, Melbourne, Victoria, 3010

${ }^{3}$ Eromanga Natural History Museum, 1 Dinosaur Drive, Eromanga, Queensland, Australia 4480.

${ }^{4}$ 65/168 Oktyabrskaya Street, Ryazan, Russia, 390010.

Corresponding Author:

Scott Hocknull ${ }^{1}$

122 Gerler Rd. Hendra, Brisbane, Queensland, 4011, Australia.

Email address: scott.hocknull@qm.qld.gov.au

\section{Abstract}

A new giant sauropod, Australotitan cooperensis gen. et sp. nov., represents the first record of dinosaurs from the southern-central Winton Formation of the Eromanga Basin, Australia. We estimate the type locality to be $270-300 \mathrm{~m}$ from the base of the Winton Formation and compare this to the semicontemporaneous sauropod taxa, Diamantinasaurus matildae Hocknull et al. 2009, Wintonotitan wattsi Hocknull et al. 2009 and Savannasaurus elliottorum Poropat et al. 2016. The new titanosaurian is the largest dinosaur from Australia as represented by osteological remains and based on limb-size comparisons it reached a size similar to that of the giant titanosaurians from South America. Using 3-D surface scan models we compare features of the appendicular skeleton that differentiate Australotitan cooperensis gen. et sp. nov. as a new taxon. A key limitation to the study of sauropods is the inability to easily and directly compare specimens. Therefore, 3-D cybertypes have become a more standard way to undertake direct comparative assessments. Uncoloured, low resolution, and uncharacterized 3-D surface models can lead to misinterpretations, in particular identification of pre-, syn- and post-depositional distortion. We propose a method for identifying, documenting and illustrating these distortions directly onto the 3-D geometric surface of the models using a colour reference scheme. This new method is repeatable for researchers when observing and documenting specimens including taphonomic alterations and geometric differences. A detailed comparative and preliminary computational phylogenetic assessment supports a shared ancestry for all four Winton Formation taxa, albeit with limited statistical 
support. Palaeobiogeographical interpretations from these resultant phylogenetic hypotheses remain equivocal due to contrary Asian and South American relationships with the Australian taxa. Temporal and palaeoenvironmental differences between the northern and southern-central sauropod locations are considered to explain the taxonomic and morphological diversity of sauropods from the Winton Formation. Interpretations for this diversity are explored, including an eco-morphocline and/or chronocline across newly developed terrestrial environments as the basin fills.

\section{Introduction}

Australian dinosaur palaeontology has experienced somewhat of a resurgence of research over the last decade or so with several new taxa recorded from Cretaceous-aged localities across Australia, including Wintonotitan wattsi, Diamantinasaurus matildae, Australovenator wintonensis (Hocknull et al. 2009) and Savannasaurus elliottorum (Poropat et al. 2016) from Winton, Queensland; Kunburrasaurus ieversi (Leahey et al. 2015) from Richmond, Queensland; Weewarrasaurus pobeni (Bell et al. 2018) and Fostoria dhimbangunmal (Bell et al. 2019a) from Lightning Ridge, New South Wales; Diluvicursor pickeringi (Herne et al. 2018) and Galleonosaurus dorisae (Herne et al. 2019) from coastal Victoria; and six new ichnotaxa from Broome, Western Australia (Salisbury et al. 2016).

This increased naming of new taxa has mostly occurred due to more intensive study of previously described specimens and already established fossil collections, alongside a moderate increase in new discoveries from known fossil fields. Although a new 'wave' of research focus on Australian dinosaurs is underway, large regions of prospect for Cretaceous-aged fauna remain. Developing this potential both in terms of fauna and their geochronological context is crucial to better understand the palaeobiogeography and biochronology of the Cretaceous-aged terrestrial faunal assemblages.

In the Winton Formation the dinosaurian fossil record is concentrated to a small number of sites near Winton and Isisford, located in the northern portion of the Eromanga Basin (Figures $1 \&$ 2, A). This concentrated research effort is in spite of vast areas of mapped Winton Formation occurring throughout the central, southern and western Eromanga Basin, including much of western Queensland (QLD), large areas of interior and north-eastern South Australia (SA), south-eastern Northern Territory (NT) and north-western New South Wales (NSW) (Figures $1 \&$ 
72 2, A). These poorly developed regions comprise an area of approximately two thirds of the

73 Eromanga Basin, but have currently only yielded isolated vertebrate faunal remains (Table 1). As

74 such, major palaeobiogeographic gaps occur in our knowledge of these mid- to Late Cretaceous

75 faunas, paralleling the vast gaps occurring in other high profile Australian vertebrate fossil

76 records, such as the Quaternary megafauna (Hocknull et al. 2020).

77 New fossil sites from the southwest Queensland portion of the Winton Formation, near the

78 townships of Eromanga and Quilpie have recorded floral, faunal and ichnofossils, including the

79 remains of sauropod dinosaurs (Hocknull et al. 2019) (Figure 2, A \& B). Dinosaurian vertebrate

80 fossils were first discovered in this area in 2004 by property owners of Plevna Downs Station.

81 Subsequent excavations undertaken by Queensland Museum from 2006, and then between the

82 newly established Eromanga Natural History Museum and Queensland Museum, have recovered

83 vertebrate fossil remains that include the fossils described here. The new specimens described

84 are lodged in the Eromanga Natural History Museum, a not-for-profit museum with a publicly

85 accessible palaeontological collection that represents vertebrate fossils from the southwest region

86 of Queensland.

87 We describe a new taxon based on associated sauropod limb and girdle elements along with

88 isolated remains referable to this new taxon. We compare these new finds with other sauropods

89 world-wide sharing similar geological age and body-size, but we pay particular attention to

90 comparisons with the previously described taxa from the northern Winton Formation;

91 Wintonotitan wattsi Hocknull et al. 2009, Diamantinasaurus matildae Hocknull et al. 2009 and

92 Savannasaurus elliottorum Poropat et al. 2016. We do not undertake comparisons to the only

93 other Australian Cretaceous sauropod, Austrosaurus mckillopi Longman 1933, because it does

94 not preserve comparable appendicular remains. The new taxon represents the largest dinosaur so

95 far found in Australia represented by osteological remains.

96

97 Institutional Abbreviations. AODF (Australian Age of Dinosaurs Museum of Natural History

98 Fossil), AODL (Australian Age of Dinosaurs Museum of Natural History Locality)

99 EMF (Eromanga Natural History Museum Fossil), EML (Eromanga Natural History Museum

100 Locality), QMF (Queensland Museum Fossil), QML (Queensland Museum Locality).

101

102 Geological Settings

Peer) reviewing PDF | (2020:11:55594:2:1:NEW 28 Mar 2021) 
103 The new dinosaur sites reported here are located within the central Eromanga Basin as part of the 104 southern-central Winton Formation. The sites occur 80-90 kilometres $(\mathrm{km})$ west of the township 105 of Eromanga on Plevna Downs Station (Figure 2, B). These new sites are approximately 500-600 $106 \mathrm{~km}$ south of the Winton district, which represents the locations for all currently named 107 dinosaurian taxa from the Winton Formation (Hocknull et al. 2009; Poropat et al. 2016) (Figure 108 2, A). Approximately $300 \mathrm{~km}$ to the north-east of Eromanga, an unnamed ornithopod has been 109 reported from Isisford, representing the first central-eastern Winton Formation dinosaur 110 (Salisbury et al. 2019) (Figure 2, A). As yet, no dinosaurian fossils from the south-western or 111 western extremities of the Winton Formation have been found, excepting for a weathered bone 112 from Munga-Thirri (Simpson Desert) that may be dinosaurian (Hocknull pers. obs. 2002; 2011; $113 \&$ Yates pers. comms. 2019). A newly dated, now considered semi-contemporaneous

114 dinosaurian fauna, from the Surat Basin Griman Creek Formation, occurs approximately $600 \mathrm{~km}$ 115 southeast of Eromanga (Bell et al. 2019b) (Figure 2, A).

116 The new southern-central Winton Formation dinosaur sites are structurally dominated by the Mt.

117 Howitt Anticline, a large anticline with associated Cooper Syncline that produces variable 118 surface exposures of Winton Formation sediments, with a relatively thin cover of Cenozoic 119 alluvium. Each fossil site is located on an alluvial plain with gullies and creeks that drain 120 westward to form part of the greater Cooper Creek channel system. The floodplain forms part of 121 the western portion of the Mount Howitt Anticline (Figure 2, B) and is surrounded by erosion122 resistant flat-top hills comprised of Cenozoic silcretes and Glendower Formation that overlie 123 extensively chemically-weathered Winton Formation sediments (Ingram 1971; Senior 1970; 124 Senior 1968) (Figure 2, A).

125 Outcrop of Winton Formation is sparse and confined to resistant sandstones and calcite cemented 126 siltstone-claystone concretions that form part of the resultant deeply weathered regolith (Figure 1273, A). A relatively thin, 1 metre $(\mathrm{m})$ to $2 \mathrm{~m}$ thick, soil profile containing a deflation lag of the 128 Cenozoic-aged silcretes and Glendower Formation pebbles, covers most of the available Winton 129 Formation (Draper 2002) (Figure 3, B). Faunal remains and silicified wood are initially found at 130 the surface of this soil profile and are usually associated with broken up cemented concretions or 131 rarely within sandstones.

132 The 'self-mulching' actions of the vertosol soils through the expansion and contraction of the 133 smectite-rich clays (Grant \& Blackmore 1991) offers a likely mechanism that evidently brings 
134 hard material from within the underlying Winton Formation up to the soil surface (e.g. fossilized 135 bones, petrified wood and cemented rock). The vertosol profile itself is derived from the 136 weathering of the underlying Winton Formation, as part of a wider process of cracking clays 137 weathering the Rolling Downs Group surface expression (Vanderstaay 2000). Therefore, over 138 time, as the Winton Formation weathers into a soil profile, the fossil remains rise and concentrate 139 at the surface, breaking into pieces. This same mechanism was originally observed around the 140 township of Winton and led to the discoveries of vertebrate remains at depth and the subsequent 141 new dinosaur discoveries (Hocknull et al. 2009). This same process was observed at the 142 Eromanga sites and subsequent excavations proved an essentially identical process yielding 143 similar levels of success for recovering vertebrate fossils and discovering intact bonebeds 144 subsurface.

145 Inclusions within the soil profile include alluvial sands, clays and gravels derived from major 146 flooding of the Cooper Creek channel system that incorporates the material from the surrounding 147 topographically higher Cenozoic cap rock. Therefore, the soil profile at most sites derives 148 material from two separate sources.

149 Unlike the northern Winton Formation sites, buried Neogene-Holocene palaeochannels have 150 been observed to cut and erode some of the southern-central Winton Formation dinosaur fossil 151 sites. Therefore, at some time in the past, possibly during wetter periods of the Pliocene or 152 Pleistocene, active channel down cutting likely exposed significant areas of Winton Formation at 153 the surface. Subsequent to this, possibly during the intensifying aridity of the Late Pleistocene, 154 burial of these palaeochannels occurred and vertosols dominated the landscape. 155

\section{Winton Formation}

The Winton Formation consists of interbedded volcanolithic sandstones, siltstones, mudstones, minor coals and intraformational conglomerates (Gray et al. 2002). Calcite cemented concretions are common and in places the top approximate $90 \mathrm{~m}$ of preserved Winton Formation is highly chemically altered (kaolonitised and ferrugunised). The present-day thickness of the Winton Formation ranges from surface exposure on the basin margins that is associated with uplifted structures, to at least $1100 \mathrm{~m}$ of thickness toward the west-southwestern parts of the basin (Cook et al. 2013; Hall 2015). 
164 The present-day surface expression, distribution and thickness of the Winton Formation is 165 residual, reflecting modifications of its original distribution and thickness through multiple post166 depositional structural and erosional events (Gray et al. 2002). It represents one of the largest 167 formations (both in terms of thickness and areal extent) from the Cretaceous part of the Rolling 168 Downs Group within the Eromanga Basin and occurs across three States (QLD, NSW, SA) and 169 one Territory (NT) (Figures $1 \& 2$ ).

170 The Winton Formation forms the uppermost unit of the Rolling Downs Group and the Late 171 Triassic to Cretaceous-aged Eromanga Basin (Exon \& Senior 1976). It conformably and 172 transitionally overlies the Mackunda Formation, however, due to the transitional nature of the 173 Mackunda to Winton Formation it is difficult to establish the base of the Winton Formation, both 174 in outcrop and in the subsurface (Cook et al. 2013; Draper 2002). In some successions in SA 175 where these two formations are more difficult to differentiate, the superseded name 176 Blanchewater Formation (Forbes 1966) was used in the past for the combined undifferentiated 177 interval (Moore \& Pitt 1985).

178 An informal convention has previously been used to define the base of the Winton Formation, 179 using the first appearance of coals or rhizomiferous sediments to define the base (Draper 2002;

180 Gray et al. 2002). However, coals are not always present and the majority of these transitions are 181 only observable in cores and do not manifest in surface outcrop. This means there is uncertainty 182 when determining the vertical and spatial distribution of the first appearance of coals or 183 palaeosols and thus the base of the Winton Formation. Likewise, the last occurrences of marine 184 shells, such as Inoceramus, are considered in numerous stratigraphic and petroleum well logs to 185 be good indicators of the transition from the marine and tidally influenced Mackunda Formation 186 to the freshwater fluvial and lacustrine deposits of the Winton Formation. However, in core 187 samples, it is very difficult to confidently discern the difference between Inoceramus, or other 188 marine invertebrate shells, in comparison to the freshwater-restricted invertebrate taxa, such as 189 unionoid bivalves. Therefore, whether using the last presence of marine-tidal invertebrate taxa $190 \mathrm{and} /$ or the first indications of palaeosols, freshwater taxa or coals, the clear distinction of the 191 Winton Formation base remains equivocal. 192

193 Stratigraphic position of dinosaur sites. Due to the lack of contiguous Winton Formation 194 outcrop it is practically impossible to directly trace and define the relative local stratigraphic 
195 position between any one of the many dinosaurian body-fossil sites found throughout the Winton 196 Formation. Even at sites in relative close proximity to one another where the surface expression 197 of fossilized bones is spaced 10s to 100s of meters apart it is impractical to define a local 198 stratigraphic succession. Heavy earth-moving machinery must be used to create long and deep (4 $\mathrm{m}+$ ) stratigraphic trenches that remove the $1 \mathrm{~m}+$ soil and weathered vertosol-Winton Formation covering to expose enough primary sedimentological structure to enable bonebed layers to be

201

202 203

204

205

206

207

208

209

210

211

212

213

214

215

216

217

218

219

220

221

222

223

224

225 traced laterally. This is both impractical and unrealistic in terms of developing a good understanding of local stratigraphic control between dinosaur bonebeds and site clusters. Ground penetrating radar has been tried in places but with limited results. The clay-rich vertosol soil is variably moist at depth and possesses large voids and cracks, all of which impact the resistivity profiles and thus potential for accurate subsurface interpretations. The uniform sedimentological signature of the Winton Formation itself, being mostly siltstones to finegrained sandstones, with small to large cemented concretionary zones also obscures lateral continuity.

Within the local context, the overall dip of strata is generally low; however, sites occur 100s of meters to several kilometers apart and are mostly associated close to poorly defined structural features such as concealed faults or the crests of anticlines (Figures 2, 4 and 5). Therefore, these local and poorly mapped structural features potentially create differences in vertical profile position of $10 \mathrm{~s}$ to $100 \mathrm{~s}$ of meters between individual fossil sites. Although the sites may be regarded as topographically similar and assumed to be contemporaneous, this is unverified, and concealed stratigraphic differences could be greater than expected. Such unverified stratigraphic position makes determining whether the taxa recovered from one or more sites are sympatric near impossible. This is especially relevant for the Winton Formation where there is no control on relative positions of bonebeds or the sedimentation rate of these deposits and the Winton Formation unit as a whole.

Regionally, defining the relative stratigraphic position of dinosaur fossil sites is equally difficult with the added complexity of; 1) regional subsurface structuring (Exon \& Senior 1976; Hoffmann 1989); 2) rapid exhumation and pre-Cenozoic erosion of the Winton Formation (Keany et al. 2016; Rodgers et al. 1991); 3) Cenozoic basin filling (Cook \& Jell 2013; Day et al. 1983; Krieg et al. 1990); 4) deep Winton Formation chemical weathering (Idnurm \& Senoir 1978; Senior \& Mabbutt 1979); 5) broadly defined palynomorph zones with no refinement 
226 within the Winton Formation (Monteil 2006); and 6) considerable geographical distance between

227 localities ranging from $\sim 105 \mathrm{~km}$ to over $500 \mathrm{~km}$ apart.

228 The multiple levels of uncertainty at both local and regional scales, over such an extensive and

229 thick geological formation, renders the level of stratigraphic accuracy needed for meaningful

230 chronological comparisons between faunas difficult, and even more so when comparing fauna

231 from semi-contemporaneous formations from separate basins. Such uncertainty requires a greater

232 future effort to place each fauna within a local and regional context, currently leaving only

233 broad-sweeping generalisations possible (Wilkinson et al. 2019).

234 We have attempted here to place the type localities of all four sauropod taxa into a regional

235 stratigraphic context, but local stratigraphic context for each site is near impossible to ascertain.

236 For the southern-central Winton Formation sauropod sites we begin by using a published

237 interpretation of seismic and well data that produced an approximation of Winton Formation

238 thickness (Hall 2015) (Figure 4, A). Importantly, it provides a NW-SE cross-sectional

239 interpretation across the crest of the Mt. Howitt anticline, the key geological structure associated

240 with all new dinosaur sites described here.

241 All of the new dinosaur sites occur within $5 \mathrm{~km}$ of the western flank of the Mt. Howitt anticline

242 with one locality (EML019) located close to the Mt. Howitt 1 well (Delhi Petroleum 1966). The

243 thickness of the Winton Formation at Mt. Howitt 1 approximates $300 \mathrm{~m}$, with thicker sections

244 preserved on the flanks of the Mt. Howitt anticline (Figure 4, A).

245 Next, we used well and seismic data proximal to the sites to estimate the thickness of the Winton

246 Formation closest to the dinosaur sites. The stratigraphic position of the type locality for

247 Australotitan cooperensis. (EML011(a)) relative to the base of the Winton Formation was

248 estimated by examining data from nearby petroleum well bores, Wareena 1-5 (Gauld 1981;

249 Lawrence 1998; Lowman 2010; Robinson 1988; Turner 1997) and Navalla 1 (Boothby 1989)

250 with Wareena 4 located approximately $1.33 \mathrm{~km}$ to the east of EML011. In addition to this,

251 seismic data was investigated to determine the influence of faulting and structural features within

252 the vicinity of the dinosaur localities (Delhi Petroleum 1991; Finlayson 1984; Flynn 1985;

253 Garrad \& Russel 2014; Seedsman 1998).

254 Data from the petroleum well bores is limited, as no cores were taken, and the lithological

255 descriptions do not indicate the clear presence of coal or palaeosols, thus determining the base of

256 the Winton Formation or top of the Mackunda Formation was not possible. The closest 
257 stratigraphic core, GSQ Eromanga 1, occurs $130 \mathrm{~km}$ to the east, where the base of the Winton

258 Formation is interpreted to be $164 \mathrm{~m}$ below ground surface (Almond 1983).

259 Without a good lithological control, we considered wireline petrophysical logs to interpret the

260 base of the Winton Formation. Changes in petrophysical character of the gamma-ray, sonic,

261 resistivity and self-potential wireline logs have previously been used to define the Mackunda and

262 Winton Formations in the subsurface (Gray et al. 2002; Moore et al. 1986). We used these same

263 features to pick the base of the Winton Formation with a thickness of 270-300 $\mathrm{m}$ for the Wareena

264 and Mt. Howitt wells.

265 We correlated the petrophysically interpreted base of the Winton Formation at Wareena 1 and

266 Mt. Howitt 1 wells with the uppermost prominent seismic reflection event for seismic line 83-

267 NJZ (Figure 4, B). This seismic line includes the Mt. Howitt 1 and Wareena 1 wells and runs in a

268 NNE-SSW direction close to the axis of the Mt. Howitt anticline (Figure 2, B). This seismic

269 reflection event is not continuous which is likely due to small scale faulting. This again reflects

270 the uncertainty likely to pervade local stratigraphic differences mentioned above. Interpretation

271 of the seismic line indicates that the Wareena 1 and Mt. Howitt 1 wells are located near to the

272 crest of the Mt. Howitt anticline and are therefore likely to contain the thinnest section of

273 preserved Winton Formation. Therefore, on the basis of the four dinosaur localities (EML010-

274013 ) being located in close proximity to the Wareena 1 well on the crest of the Mt. Howitt

275 anticline, the sites are likely to be $270-300 \mathrm{~m}$ from the base of the Winton Formation (Wilkinson

276 et al. 2019). This is supported by previous interpretations (Hall 2015) (Figure 4, A).

277 Applying similar methods to the northern Winton Formation sauropod type localities, we

278 focused our assessment of the Winton Formation base and thickness by assessing stratigraphic

279 and petroleum wells found closest to the type localities of Diamantinasaurus matildae and

280 Australovenator wintonensis at AODL85 (Hocknull et al. 2009); Wintonotitan wattsi at QML313

281 (Hocknull et al. 2009); Savannasaurus elliottorum at AODL82 (Poropat et al. 2016); and the

282 referred specimen of Diamantinasaurus matildae at QML1333 / AODL127 (Poropat et al. 2016)

283 (Figure 5, A).

284 The type localities of $D$. matildae and $W$. wattsi are close to one another ( $\sim 3.5 \mathrm{~km}$ apart) and

285 occur $2.6 \mathrm{~km}$ and $1.1 \mathrm{~km}$ east of a concealed (unnamed) fault respectively. The closest petroleum

286 wells are Minion 9 (Pangaea Resources 2013) to the west of the concealed fault and fossil sites, 
287 and Lovelle Downs 1 (Watson 1973) that occurs east of the concealed fault and east of the type 288 localities. Lovelle Downs 1 is $4 \mathrm{~km}$ due east of the type locality for D. matildae.

289 At Lovelle Downs 1, the base of the Winton Formation was assessed to be 880 feet (268 m)

290 (Watson 1973); however, lithological descriptions indicate first coal at 1210 feet (368 m);

291 therefore, we agree that the base of the Winton Formation is at least $268 \mathrm{~m}$ from surface but it is 292 more likely to be $368 \mathrm{~m}$ or more from the surface. At Minion 9, west of the type localities and 293 the unnamed fault, the base of the Winton Formation was assessed on first coals to be $352 \mathrm{~m}$ 294 from the surface but with $31.6 \mathrm{~m}$ of overlying Cenozoic sediments; thus a thickness of $316 \mathrm{~m}$ 295 (Pangaea Resources 2013). We agree with this assessment (Figure 5).

296 Both type localities are situated over a structural low termed the Lovelle Syncline / Depression, 297 and occur about 18-20 km west and downthrown of a major fault, termed the Cork Fault, which 298 would provide the structural means for a relatively thick Winton Formation across this area.

299 Therefore, we propose a Winton Formation base from surface for the type localities of $D$. 300 matildae and $W$. wattsi of at least $350 \mathrm{~m}$ (Figure 2, A).

301 The closest stratigraphic core to the type localities of $D$. matildae and $W$. wattsi comes from 302 GSQ McKinlay 1 (Hoffman \& Brain 1991), $70 \mathrm{~km}$ to the northwest and very close to the Winton 303 Formation outcrop edge (Figure 5). The Winton Formation base at GSQ McKinlay 1 is 304 interpreted to be approximately $112 \mathrm{~m}$ from the surface although no coals are present. 305 Inoceramus shell is identified at $\sim 125 \mathrm{~m}$, therefore, we agree that the base of the Winton 306 Formation is at around $112 \mathrm{~m}$, but it could be higher in the core. Therefore, there is a difference 307 of over 200-250 m of Winton Formation thickness between the Minion 9 and Lovelle Downs 1 308 wells (and type localities), relative to the closest stratigraphic core (GSQ McKinlay 1).

309 In contrast, the type locality of S. elliottorum and another sauropod locality preserving a 310 specimen referred to D. matildae (QML1333) occur approximately $70 \mathrm{~km}$ to the east of the Cork 311 Fault on the upthrown section, and approximately $18 \mathrm{~km}$ west of the Eyriewald Anticline. These 312 sites are located closer to the Winton Formation outcrop edge than the type locations for $D$. 313 matildae and $W$. wattsi and therefore we would expect them to be closer to the base of the 314 Winton Formation.

315 The closest petroleum well is Wardoo 1 (Exoma Energy 2013), positioned 6-7 km south and 316 southwest of the S. elliottorum type locality and QML1333 respectively. The base of the Winton 317 Formation at Wardoo 1 is reported as $311 \mathrm{~m}$, however, the first coals are indicated at $90 \mathrm{~m}$ 
318 (Exoma Energy 2013). Therefore, we treat the reported depth and thickness of the Winton

319 Formation at Wardoo 1 with some caution and propose that it is more likely closer to $100 \mathrm{~m}$

320 (Figure 5). Wardoo 1 and the dinosaur localities are close to the Winton Formation outcrop edge, 321 which is similar to that seen in the stratigraphic cores of GSQ McKinlay 1 (Winton Formation 322 base at $112 \mathrm{~m}$ ) (Hoffman \& Brain 1991) and GSQ Manuka 1 (Winton Formation base at $~ 92 \mathrm{~m}$ ) 323 (Balfe 1978); therefore, we propose a $90 \mathrm{~m}$ depth based on the first appearances of coals as a 324 more realistic estimate for the base of the Winton Formation at Wardoo 1. Therefore, we propose 325 a depth to base of Winton Formation for the S. elliottorum type locality and QML1333 to be less 326 than $100 \mathrm{~m}$. (Figure 5).

327

328 Summary of the stratigraphy of the Winton Formation sauropods. Taken together, our 329 assessment of the depth to base of Winton Formation in relation to the four sauropod type 330 localities illustrates the uncertainty discussed above in relation to a lack of clear delineation for 331 the base of the Winton Formation, and the relative stratigraphic positions of the sites both locally 332 and regionally. On the available published data from stratigraphic cores, wells and seismic lines 333 located closest to the type localities, we propose that; 1) the S. elliottorum type locality and 334 QML1333 site with a referred specimen to D. matildae are positioned less than $100 \mathrm{~m}$ above the 335 base of the Winton Formation; 2) the new type locality for A. cooperensis is positioned 336 somewhere between 270 and $300 \mathrm{~m}$ above the base of the Winton Formation; and 3) the type 337 localities of D. matildae and $W$. wattsi are positioned approximately $350 \mathrm{~m}$ (or somewhere 338 between 316 and $368 \mathrm{~m}$ ) above the base of the Winton Formation (Figure 5).

339 Although this proposed series of positions above the base of the Winton Formation likely 340 constitute real stratigraphic, and thus chronological differences between the sauropod type 341 localities, we urge caution in using this proposed stratigraphic sequence for palaeontological 342 interpretations due to the diachronous uncertainty of it and the unknown spatiotemporal 343 sedimentation rates across the entire Winton Formation.

345 Winton Formation Age

346 The Winton Formation was assigned a Late Albian to Cenomanian chronostratigraphic age on 347 the basis of spore-pollen zonation (Monteil 2006). The presence of Late Albian index species 348 Phimopollenites pannosus to Cenomanian index species Hoegisporis uniforma 
349 (=Appendicisporites distocarinatus) within the Winton Formation reflects this assessed

350 chronostratigraphic age range (Helby et al. 1987). On the basis of well-preserved palynomorphs

351 indicating the Coptospora paradoxa and Phimopollenites pannosus zones, a latest Albian age

352 was interpreted for a surface locality located close to the type localities of Diamantinasaurus

353 matildae, Wintonotitan wattsi and Australovenator wintonensis (Dettmann et al. 2009). The

354 palynomorphs from this site indicated an age of no older than Late Albian. With the absence of

355 Cenomanian indicator species such as Hoegisporis uniforma and Appendicisporites

356 distocarinatus a Cenomanian age could not be given. The type localities for three dinosaurian

357 taxa (D. matildae, W. wattsi and A. wintonensis) from nearby sites were thus considered to be

358 latest Albian in age (Hocknull et al. 2009).

359 Subsequent to this, two independent age assessments of the Winton Formation were conducted

360 using modelled U-Pb radiometric assessments of detrital zircons, and calculated age probability

361 distributions, to determine the maximum depositional age of dinosaurian fossil sites (Bryan et al.

362 2012; Tucker et al. 2013). Modelled interpretations from these probability distributions were

363 used to propose true depositional ages for the layers from where the zircons were sampled and to

364 construct an age profile for the Winton Formation, defined into lower, middle and upper Winton

365 Formation (Tucker et al. 2017; Tucker et al. 2016). See Tucker (Tucker et al. 2016; Tucker et al.

366 2013) for explanations of each age model type and methodology used.

367 The reliability of the detrital zircon dating technique for sedimentary sequences will not be

368 reviewed here, having been discussed and assessed by many others who have identified biases,

369 methodological issues, and interpretative problems with detrital zircons (Allen \& Campbell

370 2012; Andersen et al. 2019; Coutts et al. 2019; Horstwood et al. 2016; Johnstone et al. 2019;

371 Klötzli et al. 2009; Košler et al. 2013; Sharman \& Malkowski 2020).

372 Considering this uncertainty, the results so far produced for the Winton Formation need to be

373 treated cautiously. Nevertheless, they all indicate a probable temporal age range of between 103

374 to 92 million years ago (Late Albian to earliest Turonian) for the maximal depositional ages of

375 portions of the Winton Formation.

376 Key to determining the depositional age and age range for the Winton Formation is the source of

377 the youngest zircon grains that likely came from eastern Australian volcanicity that continued

378 throughout the Early to mid-Cretaceous (Bryan et al. 2012; Tucker et al. 2017). Substantial

379 volumes of mostly silicic pyroclastic material and coeval first cycle volcanogenic sediment 
380 accumulated in the Eromanga Basin during deposition of the Winton Formation (Bryan et al.

381 2012). This material was transported over very large distances along with the semi-

382 contemporaneous development of a southwest draining river system dubbed the 'Ceduna River'.

383 The 'Ceduna River' depocentre was the Ceduna delta, a very large deltaic lobe that filled the

384 tectonically subsiding southern Australian Bight Basin, which formed the contemporaneous

385 paralic White Pointer supersequence (Espurt et al. 2009; King \& Mee 2004; Lloyd et al. 2016;

386 Sauermilch et al. 2019; Totterdell \& Krassay 2003).

387 However, it is unclear, not only of the magnitude and continuity of explosive events, but also the 388 ultimate cessation of volcanicity. If volcanicity ceased before the end of Winton Formation 389 deposition, this raises the possibility of erosion and reworking of older zircons within the Winton 390 Formation without the arrival of new zircons entering the system, which could obscure a more 391 refined true depositional age, and this may impact the ages of the four type locality deposits. 392

393 Age of the dinosaur sites. A single population of detrital zircons has been published for the $D$. 394 matildae type locality (Bryan et al. 2012), but no detrital zircon populations have been published 395 for the other three type localities. The closest stratigraphically controlled detrital zircon 396 populations for all three northern sauropod taxa, D. matildae, W. wattsi and S. elliottorum, comes 397 from GSQ McKinlay 1 (2 samples) (Tucker et al. 2016). Whilst for the southern-central Winton 398 Formation sites, the closest stratigraphically controlled detrital zircon population comes from 399 GSQ Eromanga 1 (1 sample) (Tucker et al. 2016).

400 Of these four zircon populations recovered closest to our type localities, the two GSQ McKinlay 4011 samples were taken closest to the Winton Formation base, at $102.7 \mathrm{~m}$ and $58 \mathrm{~m}$ from the 402 Winton Formation base respectively. The lowest sample was defined to represent the 'middle' 403 Winton Formation and the higher sample the 'uppermost' Winton Formation (Tucker et al. 2017; 404 Tucker et al. 2016). The stratigraphically lower sample returned modelled zircon ages of 405 between $92.1 \pm 1.8 \mathrm{Ma}(\mathrm{YCl} \sigma(+3)$ to $95 \mathrm{Ma}(\mathrm{YPP})$, whilst the stratigraphically higher sample 406 returned discordant older ages of between $93.5 \pm 4.4 \mathrm{Ma}$ (Weighted average (+3)) and $98 \mathrm{Ma}$ $407+0.9 /-4.1 \mathrm{Ma}$ (TuffZirc (+6) (see Tucker et al. 2016 for model descriptions).

408 The next highest zircon population was taken from GSQ Eromanga 1 within the core, at 409 approximately $146 \mathrm{~m}$ above the Winton Formation base and defined as the 'lower' Winton 410 Formation (Tucker et al. 2017; Tucker et al. 2016), $44 \mathrm{~m}$ higher than the 'uppermost' Winton 
411 Formation of GSQ McKinlay 1. This sample returned modelled maximum depositional ages 412 ranging between 93.1 $\pm 1.1 \mathrm{Ma}(\mathrm{YSG})$ and 101.1 +1.3/-1.4 Ma (TuffZirc (+6), representing a 413 similar modelled age range compared to the 'uppermost' Winton Formation of GSQ McKinlay 1. 414 Of note, a similar age range was also given for a sample taken between 20.8-35.8 $\mathrm{m}$ below 415 surface at GSQ Blackall 2 stratigraphic core, to the north east of GSQ Eromanga 1 (Tucker et al. 416 2016). This sample comes from the 'lower' Winton Formation, taken between 113-128 m from 417 the Winton Formation base ( 149 m below surface) (Coote 1987). This zircon population 418 returned modelled ages ranging between 93.4 $\pm 1.8 \mathrm{Ma}$ (YPP) and 98.7 +2.2/-5.3 Ma (TuffZirc $419(+6))$.

420 Finally, the highest zircon population was sampled at the D. matildae type locality, which sits at 421 least $350 \mathrm{~m}$ from the Winton Formation base. This sample sits twice to three times higher in the 422 Winton Formation when compared to the 'lower' Winton Formation GSQ Eromanga 1 and GSQ 423 Blackall 2 and 'middle' to 'uppermost' Winton Formation of GSQ McKinlay 1 (Tucker et al. 424 2017; Tucker et al. 2016). The ages for the type locality include a single youngest grain age of $42594.29 \pm 2.8 \mathrm{Ma}$ and two youngest age peaks at $\sim 95 \mathrm{Ma}$ and $\sim 102 \mathrm{Ma}$ (Bryan et al. 2012; 426 Greentree 2011).

427 Considering each zircon sample's stratigraphic position above the base of the Winton Formation 428 with each sample's youngest single grain age, it would be expected that the sample taken closest 429 to the base of the Winton Formation would return the oldest youngest single grain age, and that 430 the sample taken furthest from the Winton Formation base would have the youngest single grain 431 age. This is not the case, the lowest sample, taken $58 \mathrm{~m}$ from the Winton Formation base has a 432 single grain age of $93.4 \pm 1.5 \mathrm{Ma}$, which is within the error of the highest sample $(350 \mathrm{~m}+)$ 433 single grain age of $94.29 \pm 2.8 \mathrm{Ma}$. The youngest single grain ages for the intermediate samples 434 are also within error of the lowest and highest zircon populations; therefore, the maximal 435 depositional age based on youngest single grain detrital zircons is similar throughout the $350 \mathrm{~m}+$ 436 sampled Winton Formation and does not indicate a change in age with stratigraphic position. 437 Taking the youngest age peak for the zircon populations, a similar situation exists, with the 438 sample taken closest to the base of the Winton Formation returning an age of $95 \mathrm{Ma}$ and the 439 sample taken furthest from the base of the Winton Formation also returning an age of $95 \mathrm{Ma}$. 440 Such similarities in ages across $350 \mathrm{~m}+$ of Winton Formation can potentially be reconciled in 441 several ways. 
442 The similarities in ages could represent the loss of new zircons entering the system after the 443 cessation of volcanicity, resulting in reworking of the youngest available grains up the profile. 444 Or, the sedimentation rate across the Winton Formation was exceptionally variable across the 445 basin producing considerable differences in depositional thicknesses across relatively small 446 geographical areas. Alternatively, the base of the Winton Formation may be diachronous across 447 the basin, resulting in areas with similar positions relative to the base of the Winton Formation 448 being of dissimilar ages. It is conceivable that one or more, or even all, of these processes were 449 operating during deposition of the Winton Formation. We note that all samples within the 450 Winton Formation contain recycled detrital zircons and as yet no in situ pyroclastic beds have 451 been recorded.

452 The detrital zircon samples taken closest to our new dinosaur sites is GSQ Eromanga 1 (Almond 453 1983) and as discussed above the sample comes from close to the base of the Winton Formation 454 ( 146 m). The type locality for Australotitan cooperensis is estimated to occur 270-300 m above 455 the base of the Winton Formation, therefore, twice as high within the sequence relative to GSQ 456 Eromanga 1, located $130 \mathrm{~km}$ east of it. The age range for this detrital zircon population is also 457 within the error of the samples from the northern Winton Formation, with a youngest single grain 458 of $93 \pm 1.1 \mathrm{Ma}$, and ranging up to $101.1+1.3 /-1.4 \mathrm{Ma}$ (Tucker et al. 2016). The youngest 459 population peak sits at $96 \mathrm{Ma}$, slightly older than the lowest samples from the northern Winton 460 Formation stratigraphic cores. We therefore consider that the age of the type locality EML011(a) 461 and other associated localities have a maximum depositional age of between 93-96 Ma.

462 Summary of the age of the Winton Formation sauropods. The combined uncertainties

463 464 465 466 467 468 469 470 471 $47296 \mathrm{Ma})$. expressed above in regards to the stratigraphic positions of all of the type localities, uncertainties with detrital zircon dating, and the lack of other techniques to better refine the absolute ages of the deposits, the actual age of all four taxa remains equivocal. A maximum depositional age of mid-Cenomanian ( $95-96 \mathrm{Ma}$ ) for the four type localities discussed here is favoured but with the caveat that all four type localities could be considerably different in relative and absolute age. Any further refinement will require much greater control of both stratigraphy and chronometric age. We note that the uncertainty of the maximum depositional age has been suggested to range for the 'lower', 'middle' and 'upper' Winton Formation of between 92-94 Ma (Tucker et al.

47 2016). We generally agree with this level of uncertainty but propose a slightly greater range (92- 
473 The uncertainty surrounding the chronometric dates for the maximum depositional age of either

474 portions of, or the whole, Winton Formation presents significant difficulties when proposing

475 testable hypotheses focused on local or regional sauropod biogeography, palaeoecology and

476 evolution. Additionally, these stratigraphic and age uncertainties further render chronological

477 comparisons of the Winton Formation dinosaurian fauna with the semi-contemporaneous Griman

478 Creek Formation at Lightning Ridge (Bell et al. 2019b) of limited value.

479

480 Depositional \& Taphonomic Settings

481 The dinosaurian skeletal remains from these southern-central Winton Formation sites are

482 exclusively represented by sauropods. In spite of a large number of sites having been excavated

483 over the last decade, only the remains of a freshwater turtle (?chelid) and an isolated poorly

484 preserved hyriid bivalve represent fauna not attributable to sauropods (Hocknull et al. 2019).

485 There is a distinct lack of higher taxonomic representation relative to the fauna from the northern

486 Winton Formation sites. Currently missing fauna from the southern-central Winton Formation

487 include gastropods, insects, teleost fish, lungfish, crocodilians, pterosaurs, theropods,

488 ornithopods, and ankylosaurs (Table 1).

489 Preservation of sauropod remains range from isolated, fragmentary remains that have undergone

490 considerable pre- and post-depositional modifications through to articulated partial skeletons

491 preserved within thick cemented siltstone concretions (Figures 6, I \& K). Preserved alongside

492 these sauropod remains are macrofloral remains ranging from isolated leaves to thick layers of

493 woody debris (Figures 6, A-I). In addition, ichnological evidence points to considerable

494 bioturbation (dinoturbation) at EML011, which includes the type locality of Australotitan

495 cooperensis. (Figure 6, J; Figure 7, C \& D and Figure 8, A-N). One such feature is a near $100 \mathrm{~m}$

496 long trampled silt and bonebed unit, also preserving a partial associated skeleton.

497

498 Site Descriptions

499 At least fourteen dinosaur bone-bearing fossil sites have so far been discovered in the southern-

500 central Winton Formation. These sites are divided into two areas of northern and southern Plevna

501 Downs Station, located $85 \mathrm{~km}$ west of the Eromanga Township (Figure 2, B). The type locality

502 for type specimen of Australotitan cooperensis comes from the southern Plevna Downs Station,

503 EML011(a), with referred remains from EML010 and EML013. 
504

505 EML 010. Material; EMF106 \& EMF164. EML010 surface scatter was discovered in 2005

506 within the present-day anastomosing channeled creek system. The bones occur between two

507 weathered units of resistant siltstone-mudstone cemented rock both running in a general East-

508 West direction. The bone scatter occurs between these two units with no surface bone found to

509 the north or south of them. It represents a discrete site with the entire deposit being confined to a

510 single area of surface scatter approximately $1500 \mathrm{~m}^{2}$. The majority of the surface scatter was

511 made up of fragmented, rounded and winnowed cortical and cancellous bone fragments

512 indicating a long period of surface exposure, but relatively little distal transport from its

513 subsurface source matrix.

514 Bone preserved with adhering cemented siltstone-mudstone indicates that the bones originated

515 from one of the cemented units and subsequent surface exposure and weathering has broken up

516 the remains into small pieces. Collections of surface specimens in 2005, 2006, 2010 and 2014

517 along with excavated subsurface collections in 2006 and 2014 revealed a large number of bone

518 fragments representing pieces from sauropod axial and appendicular elements.

519 There is no obvious element duplication; however, some remains indicate the presence of two

520 different-sized sauropod individuals within the deposit. At this point, we have separated the

521 identifiable elements of the large individual from those that are from a smaller individual, or

522 those pieces that are unidentifiable. The identifiable remains from the large individual include

523 pieces of a massive femur, pieces of at least one very large somphospondylous presacral

524 vertebra, fragments of appendicular limb (ulna) and rib shaft pieces. The putative smaller

525 individual is represented by a partial caudal vertebra and fragments of podial elements.

526 Few fragments could be pieced together with most suspected joins having long weathered away

527 due to long-term exposure. Most are of limited morphological use due to their poor preservation;

528 however, on comparison with other better-preserved specimens from other sites, the large

529 individual represents the largest sauropod specimen so far recorded.

530 Winnowing and rounding through sand-blasting of the internal cancellous bone is present in

531 most surface collected elements. At depth, the bone fragments are found within a lag of

532 Paleogene-aged silcrete gibber stones close to the transition between the vertosol and underlying

533 Winton Formation siltstone. These gibber stones most likely became incorporated within the

534 vertosol during soil formation processes as lag and channel fill. Therefore, the bone deposit can 
535 be considered to be a lag and redeposit derived from the breaking down of the cemented Winton

536 Formation siltstone unit containing the vertebrate fossil remains. Subsequent mixing within the

537 channel has concentrated bone fragments within the vertosol profile, and recycling of these

538 fragments within the soil profile makes it impossible to determine the original relationship of the

539 bones to one another within the siltstone unit itself. However, the total confined spread of the

540 fragments and uniform preservation indicates no secondary bone mixing from other localities.

541 We conclude from this that an in situ siltstone shelf preserving the dinosaur skeletal remains was

542 broken apart through the combined weathering and development of the vertosol with the

543 recycling actions of a small palaeochannel sometime during the Quaternary.

544 One additional possible taphonomic agent at this particular site is bioturbation of the deposit by

545 wombats. A tooth of a wombat, probably a species of Lasiorhinus (Hairy-nosed Wombat), was

546 recovered within the vertosol during initial excavations in 2005. Although there are no preserved

547 indications of burrows, the presence of wombats in the area in the past does offer an alternative

548 mechanism for dislocation of fossil remains at depth and transport of these remains to the

549 surface. The burrowing behaviour of wombats may have also contributed to the surface

550 expression and bone fragments in Winton, at QML1333 (Hocknull 2005).

551 Once exposed at the surface, lateral movement of the bone fragments has been limited due to the

552 very low topographic relief and channel velocity during flooding events. It was observed in 2011

553 that exposed bone fragments can withstand high volume flow during large-scale flood events,

554 whereby the specimens move very little during the event and remain exposed at the surface on

555 pedestals of sediment. So although flooding occurs within the channel system, the impact of this

556 on the surface expression of dinosaur bones seems minimal. Together, these observations suggest

557 that EML010 represents the longest-term surface expression of dinosaur fossils so far found in

558 the region.

559 EML010 is unique within the sites so far recovered from Eromanga having experienced the

560 greatest amount of surface weathering of any of the sites and the only site demonstrating the

561 impact of winnowing by windblown abrasion. This form of bone weathering is unique in all of

562 the sites so far observed in the Queensland section of the Winton Formation. Thus, EML010

563 probably represents one of the most weathered dinosaur localities from the Winton Formation

564 that still preserves bone at the surface. 
565 Fossil bone observed by SAH in 2002 and 2011 at the Museum of Central Australia, Alice

566 Springs, Northern Territory, and via Yates pers. comm. (2019), represent vertebrate fossil

567 remains from the Winton Formation located in the Munga-Thirri (Simpson) Desert. These bone

568 fragments show similar levels of surface weathering and wind-blown sand abrasion. The

569 proximity of the Eromanga and Northern Territory sites to the sand dunes of the Munga-Thirri

570 Desert provides adequate mechanisms for sand abrasive conditions to be present especially

571 throughout the intensified aridity of the late Quaternary (Hocknull et al. 2007; Hollands et al.

572 2006; Maroulis et al. 2007). In comparison, the dinosaur localities of Winton and Isisford to the

573 north and east are distal to these dunes and probably did not experience this kind of abrasive

574 surface weathering.

575

576 EML011(a-c). Material; EMF102, EMF103 \& EMF111. EML011 was first thought to be a

577 single large surface scatter over an area of $5000 \mathrm{~m}^{2}$. It was treated as a singular entity whilst

578 excavations proceeded from 2007-2010. However, during this period, three discrete subsurface

579 fossil beds were recognised representing semi-contemporaneous deposits, but containing

580 different associated skeletons representing three individual sauropod specimens and including

581 unusual ichnological features that indicate a trampled surface (Figures 6-8).

582 The trampling is localized to EML011 and is not observed in other northern or southern Plevna

583 Downs sites. EMF102 from EML011(a) and EMF103 from EML011(b) are two associated

584 skeletons recovered $72 \mathrm{~m}$ apart, and are divided by an approximately $100 \mathrm{~m}$ linear ichnological

585 feature interpreted to be a sauropod 'trample zone'. Silty sediments have been turbated and

586 compressed by the footsteps of numerous heavy tetrapods, likely sauropods walking single file,

587 creating a trodden 'pathway' or 'pad' (Hocknull et al. 2019). Partial tracks are discernable, and

588 resemble sauropod footprints, along with clear deformation structures and subsurface sediment

589 deformation. However, complete tracks or trackways are difficult to decipher due to the

590 similarity of the siltstone matrix infilling the depressions made within the trampled sediment.

591 The siltstone has preferentially cemented along the compressed 'pathway' as seen in Figure 6, J.

592 This feature, along with other ichnological features, will be fully described elsewhere.

593 EMF103 was located within the middle of this linear trampled features and is represented by a

594 series of associated dorsal vertebrae and isolated teeth. The vertebrae are heavily compressed 
595 from trampling, making referral of it to known sauropod taxa difficult, and erection of a new 596 taxon is premature at this stage. It will be described fully in a future study.

597

598

599

EML011(a) (Figure 7). Material; EMF102, Holotype of Australotitan cooperensis EML011(a) was located in 2005 as a small surface scatter of bone fragments that were able to be joined with

600 unweathered fits indicating that this locality was likely to preserve in situ fossil remains that

601 were better preserved in comparison to the heavily weathered remains $1 \mathrm{~km}$ to the south at

602 EML010. The total area of EML011(a) is approximately $480 \mathrm{~m}^{2}$.

603 Excavations produced several massive sauropod appendicular elements including a partial left

604 scapula, partial left and complete right humeri, a complete right ulna, partial left and near

605 complete right femora, both pubes and ischia and indeterminate corticocancellous bone that was

606 originally suspected to be of osteoderm origin. In total, ten elements were recovered in

607 association with the pelvic elements in semi-articulation. No duplicate bones were found and

608 each element corresponds to a sauropod individual of comparable size. Therefore, these elements

609 are treated as the same individual and thus can represent a describable holotype specimen

610 (EMF102) and new taxon, Australotitan cooperensis.

611 The upward-facing surface of each bone has experienced a greater degree of cortical bone

612 weathering than the downward-facing bone surfaces due to the actions of the vertosol soil-

613 forming processes active at the site. The bone surfaces are split into a mosaic of pieces,

614 superficially resembling the mosaic weathering stages of exposed bone (Behrensmeyer 1978;

615 Lyman 1994).

616 Instead of cracking occurring prior to fossilisation, the surface splitting of the cortical bone

617 observed on these specimens occurred after fossilisation and during the period of weathering at

618 the vertosol-Winton Formation transitional zone. The cracking vertosol penetrated the cemented

619 mudstone matrix encasing the surface bone. Expansion and contraction of theses clays split the

620 cemented matrix into quadrangular sections. The surface cortical bone is indurated with the

621 matrix above it which indicates that when these cracks penetrated the cemented matrix, they also

622 cracked the surface bone, lifting these sections off of the main body of the specimen. The weaker

623 corticocancellous bone layer is a region of weakness and splits before the matrix-cortical bone

624 interface does. 
625 Subsequent infilling of these cracks with vertosol sediment widens the cracks and eventually lifts

626 the cemented matrix with surface bone off of the main body, exposing cancellous bone from

627 inside. As the matrix lifts, sediment penetrates below the surface bone and forms a soft clay

628 infill. Subsequent gypsum precipitation within this clay infill creates a crystalline surface

629 between the lifted matrix-surface bone and the underlying corticocancellous bone. Preparation of

630 the matrix removes the cemented matrix from the thin adhering surface bone, and removal of the

631 gypsiferous layer allows the original cortical bone surface to be repositioned back onto a cleaned

632 surface. These quadrangular pieces present themselves as a mosaic-like pattern across the surface

633 of the bone in a similar way to sauropod remains reported from Argentina (González Riga \&

634 Astini 2007).

635 Most of the bones show post-burial to pre-induration distortion created by localised directional 636 compression forces exerted from above the bone and specifically focused above the area of

637 distortion. These distortions do not occur uniformly across all of the bones or across the entire

638 surface of a single bone. Therefore, the distortion is not a result of diagenetic and lithostatic

639 compression. Instead, the bones are crushed in localised areas and this direction of crushing is

640 from above and locally generated by forces orthogonal to the in situ horizontal orientation of the

641 bones (Figures $7 \& 8$ ). The best interpretation of these distortions is as a result of crushing

642 through dinoturbation, which involves the actions of trampling by dinosaurs, likely sauropods

643 (Britt et al. 2009). Clear evidence of this crushing has been observed in the right femur, which

644 preserves a well-delineated sauropod manus-shaped crush mark within the proximal diaphyseal

645 shaft (Figure 8, A-H).

646 The forelimb elements (scapular blade, humeri and ulna) were all found together with each

647 element touching one of the other elements. Their long axes were oriented in a NW-SE direction

648 for the humeri and ulna and in a N-S direction for the scapular blade. The hind limb elements

649 (puboischial complex and right femur) were found close to one another, whilst the left proximal

650 femoral head was found disassociated from this group, at the surface and downslope from the

651 right femur's position. Between the two appendicular bone groups, a small patch of

652 indeterminate corticocancellous bone was recovered, likely the internal corticocancellous

653 remains derived from within the femur nearby.

654 The orientation of the in situ bones shows a degree of skeletal sorting by water flow with the

655 long axis of the bones oriented horizontally in either a NW-SE, or a near-normal to this (N/NE- 
$656 \mathrm{~S} / \mathrm{SW}$ ), direction. The right femur was oriented with a NE-SW long axis direction whilst the 657 pelvis was oriented in a NW-SE long axis direction.

658 Due to the flat aspect of these broad bone elements, they are oriented either with their long axis 659 in the direction of flow or perpendicular to it, indicating the direction of water flow was the key 660 driver of their final orientations (Kreutzer 1988; Lyman 1994; Voorhies 1969). Based on the 661 dominant direction of orientation, the palaeocurrent was in a NW-SE direction.

662 Much of the fine primary sedimentary structure has been destroyed by the cementation and 663 concretion formed around the bones, along with significant post diagenetic growth of gypsum 664 throughout the sediment. The bones are preserved in a fine siltstone-mudstone matrix which is 665 cemented, predominantly on the undersides of the bones. There is very little structure to the 666 sediment surrounding the bones other than gross horizontal laminations. These laminations have 667 been compressed in parts, likely through dinoturbation (Figure 7, D).

668 Below the bonebed, a very thin lens $(<10 \mathrm{~cm})$ of cross-laminated yellow-orange coloured 669 sandstone occurs with a scoured top surface that is filled with the overlying siltstone that 670 preserves the bones. This layer was most evident underneath the preserved pelvic elements but 671 was also observed below the ulna and scapula (Figure 7, D-F).

672 The cross-laminations indicate a palaeocurrent parallel to the long axis of the pelvic elements 673 (NW-SE) suggesting higher energy flow which was followed by a scouring event with the 674 subsequent deposition of silts along with sparse plant remains and bones. Settling of finer muds 675 produced the gross horizontally laminated siltstone-mudstone matrix which entrained the bones. 676 Following deposition of this thick silty-mud unit with the entrained bones, the water-saturated 677 soft bones were deformed via trampling (dinoturbation) of the sediment. This, along with post678 depositional processes, destroyed much of the primary sedimentary structures available.

679 Small-sized pieces of woody plant debris covered the top surface of the bones, having settled out 680 with and onto the exposed bone surfaces prior to burial. The largest pieces of wood debris have a 681 preferred long axis orientation of a NW-SE direction, therefore, supporting the dominant NW-SE 682 palaeocurrent direction.

683 The woody debris is found in close proximity to the surface bone and was most evident during 684 preparation of the femur and scapula, suggesting that these elements formed an obstacle for 685 water flow allowing woody debris to settle. Both these limb elements are oriented normal to the 
686 main axis of flow providing a leading edge that would have slowed flow and provided an

687 opportunity for the woody plant remains to settle out.

688

689

690 EML013. Material; EMF105 (femur), EMF165 (humerus), EMF166 (metacarpal).

691 EML013 was discovered in 2007 and is located $860 \mathrm{~m}$ northwest of EML011. A small patch of

692 bones within cemented mudstone was found at the surface including a fragmented anterior

693 caudal vertebra and partial ribs. There was no immediate subsurface connection of this scatter to

694 a bonebed; however, after extensive excavation, a line of bones was discovered at depth and

695 within the Winton Formation. This bonebed lay just below a thick rock unit preserving densely

696 packed woody debris, that was well-sorted with a dominant long-axis orientation, NW-SE.

697 The rock unit shows sorting of the plant debris from large log-jams with directional orientation,

698 with isolated and broken bones, at the base, overlain by smaller suspended plant pieces in matrix,

699 and densely packed woody fragments in the upper-most section (Figure 6, G \& H). The entire

700 unit has been cemented within a siltstone-mudstone that sits above the underlying bonebed.

701 Isolated and broken bones were found at the base of this cemented woody debris unit (Figure 6,

702 I). Transitioning below this level into the un-cemented Winton Formation a series of well-

703 preserved sauropod bones was found. Four limb elements were found lying side-by-side, offset

704 to one another in an east-west direction by approximately $20-40 \mathrm{~cm}$. Each bone was similarly

705 oriented in a NW-SE direction, parallel with the observed orientations of the overlying woody

706 debris.

707 The bones include a partial humerus, femur, metacarpal and yet-to-be prepared large limb

708 element. Each of these elements was differentially cemented but clearly isolated within the

709 uncemented Winton Formation siltstone layer below the main debris level. Stratigraphically

710 below and south of this bonebed a thin fine mudstone lens ranging from $5-15 \mathrm{~cm}$ in thickness

711 preserved leaf and cone scale impressions. The floral remains exclusively preserve leaves and

712 cone scales from gymnosperms, and pinnae and pinnules of pteridophytes and a possible

713 bennetitalean (Figure 6, A-F).

714

715 Macrofloral fossils occur at all of the southern-central Winton Formation sites associated with

716 the sauropod bonebeds, and are predominantly represented by thick plant debris strands of well- 
717 sorted woody remains. Occasional clay lenses exclusively preserve pteridophytes and

718 gymnosperm leafy remains with no indication of equisetaleans, ginkophytes, angiosperms or 719 cycadales macroflora typical of northern Winton Formation sites.

720 The combination of predominantly thick sections of well-sorted woody remains with rare near-

721 monospecific leaf deposits has not been observed by us from any of the faunal or floral sites in

722 the northern Winton Formation, or the Surat Basin Griman Creek Formation.

723 The combined depositional, taphonomic and ichnological observations here represent a distinct

724 departure from what would be expected based on observations from the northern Winton

725 Formation sites. The combined bias to sauropod skeletal remains, disturbance by trampling over

726 large areas, and the low diversity of flora, indicates either a unique taphonomic bias that has

727 removed those remains from preservation potential, or it establishes the base for

728 palaeoenvironmental differences observed between northern and southern Winton Formation

729 sites. Palaeoenvironmental differences between the two regions are likely the reasons for these

730 differences and will be discussed later.

731

732

733

\section{Materials \& Methods}

734

735

Fossil Preparation. The sauropod remains described herein were prepared using pneumatic airscribes and pneumatic chisels. All remains were preserved within varying thicknesses of siltstone-cemented matrix that also included layers of gypsum-rich mineral precipitation. Mechanical preparation was used to prepare the holotype using a variety of pneumatic air scribes and an electric high-speed diamond wheel cutter. A combination of air scribes were used, including, a WEN pen, HW50, HW10, No 6 \& 4 microjacks and Aro. The preserved elements

741 were partially encased in the concretionary mudstone and buried in the surrounding clays.

742 Gypsum crystals had fractured the surface of some of the preserved elements, and in some areas, 743 a thin iron-oxide crust covered the bone surface.

744

745 Specimen 3-D Surface Geometry Creation. Undertaking comparative assessments of 746 morphology for the key taxa during this work came with specific difficulties because of the 747 specimen's geographical location, physical attributes and conservation considerations. In this 
748 particular work, three museum collections house the four holotypes referring to the taxa of 749 specific interest here. Wintonotitan wattsi QMF7287 is reposited in the collection of the 750 Queensland Museum, Brisbane, southeast Queensland; Diamantinasaurus matildae AODF603 751 and Savannasaurus elliottorum AODF660 are reposited in the collection of the Australian Age 752 of Dinosaurs Museum of Natural History, Winton, central Queensland, and the proposed 753 holotype of the new taxon described here, EMF102, is reposited in the collection of the 754 Eromanga Natural History Museum, Eromanga, southwest Queensland. From Brisbane, each 755 location is around $1000 \mathrm{~km}$ apart, representing a next to impossible logistical means for direct 756 specimen comparisons. Traditional plaster or polyurethane replicas do not exist.

757 Each type specimen presents its own specific difficulties when undertaking comparative work 758 because of their physical location, very large size and great mass, fragility, and conservation 759 needs. For such large specimens simply viewing individual elements from multiple sides (e.g. 760 proximal, distal, anterior and posterior) can be a fraught process both for the specimen, the 761 researcher and the collection staff. These difficulties in comparative analysis have been manifest 762 since the discovery of dinosaurs, and since then, concessions have had to be made based on the 763 primary protection and conservation of the type specimens relative to access for assessment by 764 researchers.

765 Advances in three-dimensional (3-D) scanning technology, in particular, the relatively easily 766 learned and affordable process of photogrammetry (Bates et al. 2010; Falkingham 2012; Otero et 767 al. 2020b), have allowed many of these limitations of comparative work to be resolved by 768 creating three-dimensional models of specimens. Digital 3-D models allow multiple comparisons 769 with multiple specimens in a virtual sense, helping to augment direct observations, and more 770 frequently superseding them.

771 Since 2011, we (SAH \& RAL) have collected photogrammetric data of the four taxa used in this 772 work which has allowed regions of morphological interest to be directly compared between the 773 taxa. During this process, it has become evident that changes and damage sustained to the 774 specimens during events occurring pre- and post-deposition, during preservation, exposure and 775 weathering, during excavation and throughout preparation and display, have all altered the 776 specimens and have influenced comparative capabilities and interpretations.

777 In the past, many of these taphonomic and preparatory changes to the specimens have been 778 unintentionally or intentionally 'rectified' and 'restored', resulting in what might be considered 
779 to be a more realistic representation of the specimen prior to alteration. Thus, providing the 780 researcher with a different morphological starting point for comparisons versus what was 781 originally preserved. Many intentional restorations occur in response to display or by connecting 782 isolated portions of a specimen together to estimate a whole. Restorations of this manner can 783 preclude morphological features or unintentionally fabricate morphology that did not exist in the 784 original element.

785 Such restorations occurred to the holotype specimen of $W$. wattsi (QMF7292), prior to its 786 establishment as a holotype, which included plaster-based restoration of bones and bolting of 787 elements for display armature. Such restorative work was removed for the purposes of 788 description of $W$. wattsi, although this process also meant the loss of some surface bone. This 789 type of specimen alteration is not uncommon, but it does serve to alter the specimens, sometimes 790 irreversibly from what it was in situ in the field. 3-D digital reconstruction and restoration allow 791 a reversible and testable way of assessing and restoring alterations evident in the specimens so 792 that more meaningful comparative assessments can be made. Demonstrating that a feature does 793 or does not exist, or potentially could, but has been altered from some taphonomic or preparatory 794 reason, impacts all interpretations and needs to be communicated in some way.

795 3-D digital reconstruction, retrodeformation and restoration is becoming a more common 796 element in palaeontology, whereby a 3-D digital restoration or reconstruction is used to assist in 797 morphological, ichnological, body-size and biomechanical studies (Otero et al. 2020b). Whilst 798 this process is becoming more commonplace, new standards of reporting are required when 799 utilizing these datasets, especially considering the initial limitations that come with accessing 800 specimens to undertake scanning in the first place. In particular, digital capture and restoration 801 requires several tradeoffs including capacity of hardware, software and personnel, along with 802 financial and time constraints.

803 Tradeoffs also include ease of access to capture the specimens in the first instance, which 804 includes lighting, physical location, speed of capture and ultimately resolution and fidelity of the 805 final digital 3-D geometry. This has led to the development of some standards and procedures of 806 capture that may assist collection managers, curators and researchers when deciding about the 807 relative advantages and disadvantages of different scanning procedures and taking into account 808 these tradeoffs (Bitelli et al. 2020; Brecko \& Mathys 2020; Lautenschlager 2016; Le Cabec \& 
809 Toussaint 2017; Otero et al. 2020b; Vidal \& Díez Díaz 2017). However, it is unlikely that all

810 standards can be met at all times, and in our present experience, this was the case.

811 Here we will take the opportunity to describe the methods and processes used as a way to

812 describe the limitations of resulting 3-D models, but also how they provide clear advantages over

813 traditional methods of morphological comparison.

814 We generated 3-D surface models of the fossil specimens using digital photogrammetry and

815 surface rendering from Computed Tomography (CT) X-ray scans. The process of 3-D model

816 creation using photogrammetry and CT data is well documented across many disciplines and

817 readily available through software manuals, online tutorials, YouTube demonstrations and

818 simple, but iterative, trial and error.

819 From 2011-2014 specimens in this study were captured using two Panasonic Lumix DMC-TZ30

820 cameras. These cameras were chosen due to their portability, affordable price, rapid shooting,

821 tough body, and image LED review screen. This allowed them to serve multiple purposes for

822 capturing specimen and field site photogrammetry. Their small compact size with LED review

823 screen allowed us to position and focus on specimens quickly and evenly, and in very awkward

824 and tight positions, such as on darkly-lit shelves, within fiberglass cradles in preparation

825 laboratories, on display, or in very small spaces within cramped working spaces.

826 The settings were set to 'Fine JPG' resolution, using f-stop settings between F12-18, ISO Auto

827 or 100, under autofocus. Lighting was balanced as best possible during each shooting session;

828 however, individual bones may have been captured over a period of several months or years

829 depending on the point of preparation of each available side of the specimen. The difference in

830 lighting and colour can be seen on a number of specimens where the shooting occurred at

831 different times with different lighting arrangements, creating dissimilar coloured surfaces. This

832 did not affect the geometric reconstruction.

833 Rapid and close-range images were taken of each specimen with the user moving around the

834 specimen. Foreground and background elements were initially recorded for alignment control,

835 and then later removed from the dense point cloud. We also opted to 'over-shoot' each specimen, 836 focusing on capturing as much fine surface detail as possible.

837 Due to the massive size and impossibility of building a large enough turn-table, undertaking

838 standard turn-table techniques were not employed. In addition, due to the location of many of the 839 specimens occurring either in a preparation facility or within close range to very dusty 
840 environments, it was impossible to control dust and therefore, creating a uniform coloured

841 background was not possible. Instead, we opted to include the foreground and background

842 elements within the photograms, so that although the main focus of the reconstruction was on the

843 specimen, the shooting included elements that would assist in alignment and would be removed

844 later. We found the more irregular these features, the better the overall alignment. Therefore, in

845 future, if a uniform clean background and stage with turntable is not possible, we suggest

846 creating a very geometrically complex stage and remove unwanted dense point cloud data after

847 this phase of reconstruction.

848 Although we understood the tradeoff of the number of images taken relative to additional

849 geometry, digital storage space, and processing time, we opted to 'over-shoot' each specimen.

850 This created close to two or three times as many images as was generally required for a usual

851 turn-table approach where all factors such as light, camera stability, camera resolution and

852 processing time are all controllable. We also focused on capturing as much fine surface detail as

853 possible each session within the timeframes available.

854 Due to the large number of images captured per specimen and long processing time, subset

855 image batches were processed in Agisoft Photoscan Standard versions 0.8.2 (June 2011) to 1.0.4

856 (April 2014 and then in Agisoft Metashape 1.6.1 build 10009 (20 January 2020)), retrieved from

857 http://agisoft.com. All images of each specimen were reprocessed in Reality Capture software,

858 retrieved from http://capturingreality.com (beta 2014 onwards) due to its faster processing speed

859 of greater numbers of images whilst using the same processing power. This new process returned

860 a greater detail of surface geometry, especially in areas with detailed image clusters.

861 Each specimen needed to be captured from at least two sides due to their large size, fragility and

862 housing cradle. If possible, a significant overlap of an area was captured from each side so that

863 both could be neatly aligned later. Images were aligned and positions reconstructed in the

864 software, with a dense point cloud generated from these positions. Surface geometry was

865 reconstructed in Reality Capture using Normal Settings with vertex and polygon colouration. All

866 outputs were exported as Stanford Triangle Format (i.e. .ply files).

867 Removal of unwanted geometry, such as background structures and specimen housing was

868 undertaken in Reality Capture and Agisoft Photoscan at the dense point cloud stage, leaving only

869 the geometry representing the specimen and the included scale bar. If poorly reconstructed

870 geometry was observed, usually below the edges of specimens where there was overhang or 
871 shadowing, this geometry was also removed to reduce the production of inaccurate additional

872 geometry when the surface models were aligned to one another.

873 The scanned components of the specimen were scaled to real-world dimension in Meshlab

874 (Callieri et al. 2012; Cignoni et al. 2008), by measuring the included scale bar or a known

875 distance on the specimen using the measuring tool. The real-world measurement was then

876 divided by the measurement given in Meshlab, thereby providing a scaling factor. This scaling

877 factor was then used to scale the object in Meshlab using the Scaling option, whereby the scaling

878 factor occurred in all directions ( $\mathrm{x}, \mathrm{y}$ and $\mathrm{z}$ ). The scale of the specimen was then re-checked by

879 measuring within Meshlab the included scale bar or known length. We then 'Freeze the Current

880 Matrix' so that the new scaling factor is coordinated to the vertex positions. Finally, the model is

881 exported as a .ply file.

882 Each component of the specimen model is then aligned together in Meshlab (Cignoni et al. 1998;

883 Pietroni et al. 2009) using the alignment tool by point picking multiple corresponding positions

884 of overlap on each component and adjusting this alignment for maximum best fit. Ideally,

885 specifically corresponding geometries or specimen numbering written on the specimen are

886 chosen to allow for quick and accurate point picking to occur. The two aligned meshes are more

887 precisely aligned using the default alignment parameters within Meshlab. If alignment is not

888 clear, we cross-check this in Cloud Compare software (Girardeau-Montaut 2016), using the

889 alignment tools of this software. Once aligned, the two separate components (layers), are merged

890 using the 'Flatten Visible Layers' tool and exported, creating a single model.

891 This combined, merged model is re-meshed using the Poisson Surface Mesh reconstruction tool

892 with the Reconstruction Depth set to 12, and the Adaptive Octree Depth set to 8 (Cignoni et al.

893 2008; Kazhdan \& Hoppe 2013). We have found that these meshing parameters produce the most

894 accurate resulting full surface geometry. However, some components may create additional

895 geometry along the seams between two parts that had limited overlap. For example, the large

896 limb elements that are fixed within firm housing fibreglass cradles are missing approximately 5-

$89710 \mathrm{~mm}$ of overlap due to the obscuring nature of the cradle. Therefore, alignment needed to take

898 this into account, and the Reconstruction Depth using the Poisson reconstruction method may

899 need to be reduced to 10 or 8 . Although this reduces the overall detail in the surface geometry, it

900 also removes the false geometry. A tradeoff is required to attain the best re-meshed model. 
901 Finally, the fully aligned and re-meshed model is colourised by transferring the vertex colour

902 attributes from the original components onto the new uncoloured mesh geometry. We do this

903 using the Vertex Attribute Transfer tool in Meshlab (Cignoni et al. 1999). The finalized,

904 coloured model is then exported as a .ply model. We once again take measurements from the

905 included scale bar or known distances to verify correct scaling. We then remove the scale bar

906 from the model and undertake a final model clean using the 'Remove Isolated Pieces' tool in

907 Meshlab (Cignoni et al. 2008). We then re-align the model to the correct bounding box position

908 and use the manipulator tool to reorient the model so that the dorsal anatomical direction is

909 aligned to the $\mathrm{z}$-axis within the 3-D model space, and the anteroposterior anatomical direction is

910 in the $\mathrm{x}$-axis plane. The final model is exported again as a .ply file.

911 In addition to photogrammetry data, where possible we collected CT scan data for the holotype

912 of $W$. wattsi and particular remains associated with EMF102. The ischium of $W$. wattsi was

913 digitized using CT scan data that was aligned and processed in Dragonfly 3.6 (Computer

914 software), from Object Research Systems (ORS) Inc., Montreal, Canada, 2018 retrieved from

915 http://www.theobjects.com/dragonfly.

916 The ischium was too large to be scanned as one piece, so we scanned the specimen twice,

917 moving it across the gantry to allow all of it to be captured. These two scan datasets were then

918 aligned in Dragonfly 3.6 using the image stack alignment tool. A surface model was then

919 generated from these aligned CT scan datasets.

920

921

Specimen 3-D digital restoration, retrodeformation, reconstruction and annotation. A

922 benefit of 3-D digital geometry of specimens in palaeontology is the capacity to manipulate these

923 specimens in a way not possible with the original specimen. In addition, digital techniques can

924 help restore bones to reflect the known and predicted original shape (Lautenschlager 2016; Vidal

925 \& Díez Díaz 2017). In particular, skeletal remains when components of the right and left

926 elements are preserved, but are not complete, can be used together to restore a whole single

927 bone. Here we undertook similar processes to assist in reconstructing the bones we compared.

928 Before restoration or reconstruction can be accomplished the specimens need to be assessed for

929 matrix obscuration, bone damage and loss, along with deformation. High fidelity models that

930 possess realistic and detailed colour allow the user to see features and textures with the geometry

931 that colourless surface scans cannot, which is a distinct advantage of photogrammetry. 
932 Specimens that are digitized in pieces provide an extra level of data if each individual piece is

933 reconstructed, because they can provide cross-sectional information such as cortical and

934 cancellous bone thickness that a completed bone may not reveal.

935 Computed Tomographic (CT) scans provide another level of detail that can show difficult to

936 distinguish matrix coverage or bone damage, surface corrosion and loss. Together, using these

937 different lines of evidence, each bone can be restored. However, prior to any restoration, the

938 obscured, altered, missing or damaged areas need to be clearly identified on the 3-D model

939 geometry.

940 To do this, we colourised a duplicate 3-D model of each specimen and digitally painted onto the

941 surface geometry areas of alteration, damage and deformation using a pre-defined colour scheme

942 (Figure 8, O). Meshlab (Cignoni et al. 2008) was used to undertake this surface geometry

943 painting, including singular colour choices without gradation or feathering, with the brush set to

$944100 \%$ opacity and $100 \%$ hardness. This provided a clear distinction between a painted surface

945 and the colour data from the original surface scan, thereby indicating clearly what has been

946 intentionally coloured and what has not.

947 The colour scheme used the following preferences using the Meshlab (Callieri et al. 2012;

948 Cignoni et al. 2008; Cignoni et al. 1999) standard HTML HEX colour coding: Brown (\#aa5500)

949 indicating obscuring matrix; Purple (\#aa55ff) indicating bone deformation; Red (\#ff0000)

950 indicating significantly broken/missing surfaces; Magenta (\#ff55ff) indicating corroded surfaces;

951 Dark Green (\#55aa00) indicating loss of cortical bone surface; Very light orange (\#ffaa7f)

952 indicating mosaic broken surface (cortical bone); White (\#ffffff) indicating plaster fill; Yellow

953 (\#ffff00) indicating poorly rendered 3-d model geometry (Figure 8, P); Light Blue (\#55aaff)

954 indicating pneumatic pores and cavities. All images rendered from these models for the figures

955 used herein were produced in Meshlab using natural vertex colour, ambient occlusion, x-ray or

956 radiance scaling rendering (Cignoni et al. 2008; Vergne et al. 2010), or by using the edge detect

957 feature in Dragonfly 3.6 with the 3-D model placed in orthogonal projection and 100\%

958 transparent.

959 After completion of the 3-D specimen model, the regions of deformation and alteration were

960 identified and segmented into separate components using the model cutting tool in Agisoft

961 Metashape. The lasso cutting tool was used to trace the line of deformation, which then broke the

962 model into at least two components. If this region was deformed further, additional segments 
963 were created. Each segmented piece was saved as a separate model to be re-aligned in Meshlab.

964 After identifying the greatest degree of deformation, usually in the downward direction relative

965 to the field site position, the segmented components were rotated in the $\mathrm{x}$ - or $\mathrm{y}$-axis to align to

966 the un-deformed portion of the model. Once the new alignment was determined, all of the

967 components were merged using the 'Flatten Visible Layer' tool in Meshlab. The resulting

968 merged model was then re-meshed using the same process described above and the resulting

969 closed mesh exported as a new model.

970 Bone retrodeformation was undertaken by SAH where such deformation would clearly influence

971 comparative understanding. The focus of this procedure was to retrodeform the surface scan

972 models of EMF102 elements so that they could be compared to other taxa without the influence

973 of distortions leading to misinterpretation of similarities or differences between taxa (Figure 8).

974 If the bone was undeformed, or the deformation features did not alter the overall shape of the

975 element substantially, or a better preserved contralateral pair existed, comparative assessments

976 were undertaken directly between these elements as preserved. These regions included the

977 scapula (excluding the acromion plate), humerus, (excluding the deltopectoral crest), ulna

978 (excluding the diaphyseal curvature), pubes and ischia (excluding the right ischium) and femur

979 (excluding the proximal half of the diaphysis).

980 Retrodeformation was applied to the humerus to restore the deformed deltopectoral crest of the

981 left humerus. The deltopectoral crest was deformed during removal at the point of excavation

982 where the crest relaxed outward from its original position due to the compressive weight of the

983 specimen and lack of reinforcement of the plaster jacket. The preserved extent of the right

984 humerus (digitally mirrored) provided a guide to the direction of the distal end of the

985 deltopectoral crest for the left humerus. Field images prior to removal provided additional

986 guidance as to the shape of the overall element. Finally, each segment could not overlap each

987 other, which provided the key limitation to the overall shape of the crest and the proximal

988 margin.

989 The right ulna diaphysis was clearly bent downwards in the site, through the processes of

990 trampling. The diaphysis was segmented into components and realigned so that the shaft was

991 straightened. The pubes and ischia were segmented apart due to each element being slightly

992 dislocated from their articular margins. They were then relocated, re-articulated along their

993 articular margins. It was evident that the right pubis and ischium had suffered most deformation 
994 and crushing so the left puboischium (and its duplicate mirror) was used as the base model for

995 the reconstruction of the pelvic floor and comparisons of this element.

996 The right femur was deformed downwards in the site having also been crushed from trampling.

997 The proximal half of the shaft was segmented into components and realigned so that the shaft

998 was straightened. The distal end was not deformed but some areas of the condyles had been lost 999 post-deposition. To restore the proximal region of the femur, the isolated and associated left 1000 femoral head of EMF102 along with a referred proximal femoral head (EMF164) were used to 1001 reconstruct an entire femur. We subsequently used the referred complete femur (EMF105) to 1002 compare our resulting reconstruction.

1003 With the elements of EMF102 retrodeformed and/or reconstructed using specimens referable to 1004 the new taxon VK undertook to digitally sculpt complete bones using these retrodeformed 1005 elements as the basis for the models. VK used ZBrush digital sculpting software retrieved from 1006 https://pixologic.com/ to generate a new geometry for each element, using the retrodeformed 1007 models as a subtool basis for this new geometry. Also at this stage, any additional small 1008 deformations, weathering features or cracked surfaces were digitally 'repaired'. The overall 1009 geometric shape and size were not altered. Where areas of articulation were missing articular 1010 surfaces, these were estimated based on the preserved trajectory of such features in the 1011 reconstructed models or by reference to better-preserved titanosaurians from the literature. To be 1012 clear, these sculpted ZBrush models were not used in any comparative assessments between 1013 taxa, or for the establishment of the diagnostic characteristics of the taxon. They serve only as a 1014 guide to the overall shape and size of the reconstructed bones, allowing us to produce 3-D 1015 printed 1:1 scale versions of them and to assist in recreating a skeleton for exhibition.

1016

1017 Phylogenetic Assessment

1018 A preliminary phylogenetic assessment is undertaken using recently published datasets,

1019 including those that included the three previously described Australian taxa (Poropat et al. 2021; 1020 Royo-Torres et al. 2020). The phylogenetic dataset (Mannion et al. 2019b) used in both of these 1021 recent analyses included the three Australian taxa of interest here, each adding new taxa and 1022 characters.

1023 Using these two recent assessments (Poropat et al. 2021; Royo-Torres et al. 2020), we score the 1024 character states for Australotitan cooperensis, along with revised character state scores for the 
1025 Australian taxa, where needed. In particular, we observed a number of characteristics of

1026 Wintonotitan wattsi that are poorly preserved or not preserved, making some of the previously

1027 scored states equivocal, in our opinion. We could, however, make direct comparisons and

1028 estimates of these states using 3-D cybertypes created from the holotypes of each Australian

1029 taxon. All character state score changes are provided as Supplementary Information and we

1030 indicate where scores have changed and whether estimated scores are used. The updated datasets

1031 were entered into MESQUITE 3.61 software (Maddison \& Maddison 2019) and analysed using

1032 TNT 1. 5 software (Goloboff et al. 2008) (Supplementary Information).

1033 In both assessments we ran a series of computations using the same protocols and parameters as

1034 previously set out (Mannion et al. 2019b; Poropat et al. 2021; Royo-Torres et al. 2020). These

1035 included a priori exclusion of fragmentary and unstable taxa, although we note that at least two,

1036 perhaps three, of the Australian taxa would fit within this similar protocol based on the level of

1037 preservation and unstable nature of their phylogenetic position. However, for the purposes of this

1038 preliminary assessment of Australian taxa, we did not exclude them. The excluded taxa were

1039 Astrophocaudia, Australodocus, Brontomerus, Fukuititan, Fusuisaurus, Liubangosaurus,

1040 Malarguesaurus, the Cloverly titanosauriform, and Ruyangosaurus. Multi-state characters that

1041 were previously ordered, were retained as ordered. No new characters were added, numbering

1042542 (Royo-Torres et al. 2020) and 552 (Poropat et al. 2021) characters. For all assessments the

1043 maximum number of trees saved was set to 99,999 (TNT 1.5, Windows no taxon limit).

1044 The first assessment included all of the remaining taxa from each previous study, assigning

1045 Shunosaurus as the outgroup taxon. First, a New Technology Search was undertaken using

1046 sectorial, drift and tree fusing with the stabilize consensus set to 5 times. Weighting for all

1047 characters was equal. The resulting most parsimonious trees were then saved and subjected to a

1048 strict consensus to produce a single tree that we then used in the discussion. Bootstrapping and

1049 Bremer support were trialed on all analyses, however, all results returned very poor results with

1050 Bremer support of $<1$ and bootstrap support of $<50$ for all clades. However, the resulting strict

1051 consensus trees provided some areas for discussion.

1052 We undertook a second assessment using identical parameters to the first, except we changed the

1053 character weightings. Following previously developed protocols for weighting characters in

1054 sauropod phylogenetic analyses we increased the implied weighting k value to 9.0 (Tschopp \&

1055 Upchurch 2019). As with the unweighted analysis, we saved all most parsimonious trees and 
1056 subjected them to a strict consensus. Again, Bremer support and Bootstrapping were

1057 unsuccessful in returning useful supporting statistics.

1058 We then undertook a 'Traditional Search' using the Tree Bisection-Reconnection (TBR)

1059 algorithm, a method traditionally used in maximum likelihood phylogenetic analyses (Swofford

1060 2003). We set the number of replicates to 1000 and number of trees saved per replicate to 100 ,

1061 totaling a possible 100,000 maximum trees to be retained. Both analyses used equal weighting

1062 for characters.

1063 To assess whether the non-Macronarian taxa were potentially influencing the tree topology, we

1064 excluded all taxa, retaining only those considered to be within Macronaria (Mannion et al.

1065 2019b), and placed Camarasaurus as the outgroup taxon. With such a large reduction in taxa, we

1066 opted to use the TBR 'Traditional Search' with 1000 replicates and 100 trees saved per replicate.

1067 We weighted the characters using a $\mathrm{k}$ value of 9.0.

1068 Next, to assess the possible influence of a lack of non-appendicular characters in A. cooperensis

1069 on its phylogenetic position, we excluded all non-appendicular characters from the assessment.

1070 Differing from all of the previous assessments, we did not exclude any taxon, including the

1071 fragmentary or unstable taxa, because many of these are known from appendicular elements and

1072 thus could be useful in comparisons. Shunosaurus was selected as the outgroup and we

1073 undertook a TBR 'Traditional Search' with 1000 replicates and 100 trees saved per replicate. We

1074 weighted the characters using a $\mathrm{k}$ value of 9.0 .

1075 Finally, we undertook to exclude unstable taxa and taxa aged younger than the Turonian, whilst 1076 retaining all characters. We chose to do this as an exploration of the data by excluding taxa that

1077 are temporally unrelated to our target group. By excluding younger taxa, we expected this would 1078 reduce potential descendant homoplasy. We ran two analyses for each dataset, using a TBR

1079 'Traditional Search' with 1000 replicates, saving 100 trees per replication, undertaking both 1080 equal character weighting and implied character weighting with a $\mathrm{k}$ value of 9.0.

1081

1082 Body-size estimation

1083 Body mass estimation is a fraught exercise for fragmentary skeletons (Bates et al. 2015; Bates et 1084 al. 2009; Bates et al. 2016; Campione \& Evans 2012; Campione \& Evans 2020; Paul 2019).

1085 Recent body mass estimates of giant sauropods (Carballido et al. 2017; Lacovara et al. 2014)

1086 using humeral and femoral circumferences (Benson et al. 2014; Campione \& Evans 2012; 
1087 Campione \& Evans 2020) have come under scrutiny and are shown to be implausible or

1088

1089

1090

1091

1092

1093

1094

1095

1096

1097

1098

1099

1100

1101

1102

1103

1104

1105

1106

1107

1108

1109

1110

1111

1112

1113

1114

1115

1116

1117

1118 inaccurate (Bates et al. 2015; Otero et al. 2020a; Paul 2019). However, a recent review of these inaccuracies has suggested that the estimation methods themselves can be reconciled, albeit with reservations when dealing with particular groups of tetrapods, like giant sauropods (Campione \& Evans 2020). Therefore, although it is tempting to produce an estimate of body mass for $A$. cooperensis based on the preserved and reconstructed stylopodial circumferences we consider that this will not add significant interpretative value to our main purpose of describing this taxon, and comparing it to other members of the Titanosauria from the Winton Formation and semicontemporaneous faunas.

Based on limb-size, a feature that is easily comparable, we can compare A. cooperensis to other sauropods of similar size globally. We used the limb element sizes provided in (Benson et al. 2014) for our comparisons to A. cooperensis.

Humerus and femur lengths, along with humerus and femur circumferences from known taxa were plotted against the type specimen of $A$. cooperensis (EMF102) and a reconstructed femur (EMF164) to see where this new Australian taxon falls in regards to the largest sauropods known from femora and humeri (Supporting Information).

\section{New Taxonomic Name}

The electronic version of this article in Portable Document Format (PDF) will represent a published work according to the International Commission on Zoological Nomenclature (ICZN), and hence the new names contained in the electronic version are effectively published under that Code from the electronic edition alone. This published work and the nomenclatural acts it contains have been registered in ZooBank, the online registration system for the ICZN. The ZooBank LSIDs (Life Science Identifiers) can be resolved and the associated information viewed through any standard web browser by appending the LSID to the prefix http://zoobank.org/. The LSID for this publication is urn:Isid:zoobank.org:pub:AF1FA65A-5351-45B1-B0CB-

EC1225590A0F. The online version of this work is archived and available from the following digital repositories: PeerJ, PubMed Central and CLOCKSS. 
1119 Results

1120

1121 Systematic Palaeontology

1122 Dinosauria Owen, 1842

1123 Saurischia Seeley, 1887

1124 Sauropodomorpha von Huene, 1932

1125 Sauropoda Marsh, 1878

1126 Eusauropoda Upchurch, 1995

1127 Neosauropoda Bonaparte, 1986

1128 Macronaria Wilson and Sereno, 1998

1129 Titanosauriformes Salgado et al., 1997a

1130 Somphospondyli Wilson and Sereno, 1998

1131 Titanosauria Bonaparte and Coria, 1993

1132

1133 Australotitan gen. nov.

1134 Type Species. Australotitan cooperensis gen. et sp. nov.

1135

1136 Diagnosis. As for species.

1137

1138 Australotitan cooperensis gen. et sp. nov.

1139

1140 Material. Holotype: EMF102, consists of ten appendicular elements and pieces of

1141 corticocancellous internal bone. The appendicular elements include a partial left scapula, partial

1142 left and complete right humerus, right ulna, right and left pubes and ischia, and partial right and 1143 left femora.

1144 Referred Specimens: EMF164, a fragmented femur, a fragmented ulna, presacral vertebral

1145 centrum fragments and rib fragments. EMF105, a complete femur and EMF165, a distal 1146 humerus.

1147

1148 Age \& Horizon. Cenomanian-? Turonian, Winton Formation.

1149 Type Locality. EML011(a). Referred Specimen Localities, EML010 \& EML013. 
1150 Etymology. Australo - meaning southern in Greek and in reference to the southern continent of

1151 Australia; titan - from the Greek mythological Titan gods and in reference to its gigantic size;

1152 cooperensis - being from the Cooper-Eromanga Basin, Cooper Creek system \& “Cooper

1153 Country".

1154

1155 Diagnosis

1156 A large titanosaurian sauropod with the following combination of characters that differentiate

1157 this new taxon from all others. Proposed autapomorphies indicated by an asterisk. Scapular

1158 blade, narrow and straight with sub-parallel dorsal and ventral margins with lateral ridge situated

1159 near the ventral margin. Humerus with a rounded ridge that extends from the distal end of the

1160 deltopectoral crest to just proximal of a tri-lobate distal epiphysis. Ulna with heavily reduced

1161 anterolateral and olecranon processes relative to much enlarged and elongate anteromedial

1162 process. Ulna with a distinct radial interosseous ridge within the distal half of the radial fossa*.

1163 Anterolateral process of the ulna with a distal accessory projection* proximal to a proximally

1164 beveled distal epiphysis*. Pubes and ischia broad and contact each other medially forming a

1165 cohesive pelvic floor. Distal ischial blades curve ventrally to produce a dorsal face that is

1166 posteriorly directed. Femur with a medially sloped proximolateral margin, diaphysis narrow

1167 anteroposteriorly, and distal condyles directed anterolaterally to posteromedially.

1168

1169 Description

1170 Holotype, EMF102. Scapula (Figures 9 \& 10; Table 2). The scapula will be described with the

1171 long axis of the blade held horizontal and the short axis of the blade held vertically

1172 (dorsoventrally) with the acromion process vertical (dorsally oriented). A partial left scapula is

1173 represented in the holotype preserving from the mid-section of the anterior supracoracoideus

1174 fossa, including the acromion ridge and process, to a large proximal portion of the scapular

1175 blade. The anterior portion of scapular plate that articulates with the coracoid, including the

1176 proximal portion of the supracoracoideus fossa, coracoid suture (articulation), glenoid fossa and

1177 proximal portion of the supraglenoid buttress is not preserved having been broken off before

1178 fossilisation. It is missing the distal portion of the scapular blade including the distal-most

1179 margin. The proximoventral margin of the scapular blade base has been crushed and pushed

1180 dorsomedially into the medial side of the scapular blade.

Peer] reviewing PDF | (2020:11:55594:2:1:NEW 28 Mar 2021) 
1181 The surface cortical bone of the scapular plate and blade is broken into a mosaic-like fracture 1182 pattern with minor distortions due to collapse and some crushing from trampling; however, the 1183 overall morphology is intact.

1184 The preserved section of the scapular plate proximal of the acromion ridge is very thin in 1185 mediolateral thickness and is deflected medially. This makes what would have been the anterior 1186 fossa very shallow and angled medially, thus the coracoid articulation was also most-likely 1187 medially positioned and coracoid angled medially. The bone is very thin along the exposed 1188 (broken) margins of the proximal and proximoventral regions of the scapular plate, indicating 1189 that these missing regions making up the supracoracoideus fossa, coracoid suture (articulation) 1190 and glenoid were gracile.

1191 The proximal dorsoventral expansion of the acromion region is hard to estimate; however, the 1192 thickness of the bone at the preserved proximal margin suggests that it wasn't expanded to a 1193 level seen in similarly large and gracile scapulae like that of Dreadnoughtus schrani (see Figure 11942 in (Ullmann \& Lacovara 2016)). Instead, it is most similar to the scapula of Yongjinglong 1195 datangi (see Figure 11 in (Li et al. 2014)).

1196

1197 Lateral View. The acromion is not fully preserved, with the ventral margin missing, therefore, 1198 the relative acromion dorsoventral height to minimum dorsoventral height of the scapular blade 1199 is not precisely known. However, based on the preserved extremities, the proximal region of the 1200 acromion at its broadest part was not significantly expanded dorsoventrally. Based on our 1201 reconstruction, the ratio of minimum scapular blade dorsoventral height to acromial plate 1202 dorsoventral height would be 0.48 for $A$. cooperensis (Table 2). Y. datangi (see Figure 11 in (Li 1203 et al. 2014)) approaches this with a ratio of 0.5 derived from a minimum scapular blade 1204 dorsoventral height of $230 \mathrm{~mm}$ and an acromial plate dorsoventral height of $460 \mathrm{~mm}$. Comparing 1205 this ratio across other titanosauriform sauropods, there is variation from 0.29 to 0.5 (e.g. 1206 Muyelensaurus pecheni: 0.29 (Calvo et al. 2007a); Elaltitan lilloi: 0.30 (Mannion \& Otero 2012); 1207 Dr. schrani: 0.34 (Ullmann \& Lacovara 2016); Patagotitan mayorum: 0.38 (Carballido et al. 1208 2017); Saltasaurus loricatus: 0.4 (González Riga et al. 2019); W. wattsi: 0.42 (Hocknull et al. 1209 2009; Poropat et al. 2015a); Jiangshanosaurus lixianensis: 0.42 (Mannion et al. 2019a); 1210 Suuwassea emilieae: 0.43 (Harris 2007); Vouivria daparisensis: 0.45 (Mannion et al. 2017)), and 1211 Y. datangi: 0.5$)$. 
1212 The dorsal process of the acromion is short, straight and oriented perpendicular to the long axis

1213 of the scapular blade. The acromion ridge is nearly straight along its dorsoventral length 1214 expressed as a low and rounded lateral face. The ventral-most portion of the acromion ridge is 1215 missing; however, what is preserved is a broad low rise that becomes slightly steeper along its 1216 dorsal length where it terminates at the dorsal-most region comprised of roughened surface bone 1217 texture. This may be interpreted as a tuberosity; however, we cannot exclude taphonomic 1218 alteration of the dorsal margin. The posterior surface of the acromion process is a flat plate 1219 running from the acromion ridge to the scapular blade base. There is no posterior acromion fossa 1220 or notch present. The posteroventral corner of the acromion is not preserved in the holotype so it 1221 is not possible to determine whether it possessed a subtriangular posteroventral process, similar to that seen in D. matildae (Figures 9, E, F, I and 10, B; see also Figure 4, A in (Hocknull et al. 1223 2009) and Figure 8, B in (Poropat et al. 2015b)), and W. wattsi (Figures 9, C, D, H and 10, C; see also Figure 16, G-H in (Hocknull et al. 2009) and Figure 7, B in (Poropat et al. 2015a)). The scapular blade is dorsoventrally narrowest just distal of the scapular blade base where it meets the acromion plate; in comparison with $W$. wattsi and $D$. matildae where the narrowest point is further distally along the blade. The entire scapular blade is narrow along its entire length with sub-parallel dorsal and ventral blade margins with only a slight expansion of the preserved distal portion of the blade. The distal-most end is not preserved and there is no indication of significant expansion relative to the main blade plate; therefore, it is likely that there is a significant portion of the distal blade missing (Figure 10, A). On comparison with sauropods possessing mediolaterally thin scapulae with parallel dorsal and ventral margins such as $Y$. datangi (Li et al. 2014) and Lirainosaurus astibiae (Díaz et al. 2013) the scapular blade could conceivably be much longer than is preserved. D. matildae (Hocknull et al. 2009; Poropat et al. 2015b) and W. wattsi (Hocknull et al. 2009; Poropat et al. 2015a) have shorter, robust, and distally expanded scapular blades by comparison. A ventral ridge runs along the lateral side of the blade (Figures 9, A \& 10, A). This feature is most prominent toward the distal half of the blade. A similar ridge is seen in L. astibiae (Díaz et al. 2013) in comparison to the centrally located scapular blade ridge of $D$. matildae (Hocknull et al. 2009; Poropat et al. 2015b) (Figures 9, E \& 10, B) and W. wattsi (Hocknull et al. 2009;

1241 Poropat et al. 2015a) (Figures 9, C \& 10, C), which runs close to the midline of the blade, as 1242 observed in many titanosaurians (González Riga et al. 2019). 
1243 In $A$. cooperensis the acromion ridge is near straight, curving only slightly at its ventral extent.

1244 Both $W$. wattsi and D. matildae partially preserve the acromion plate; however, the acromion

1245 ridge is only observable in $W$. wattsi. In W. wattsi it is curved anteriorly toward its ventral

1246 margin and terminates about the midline of the scapular plate and blade. The posterior margin of

1247 the acromion process is rounded and narrower in $W$. wattsi compared to the flat and relatively

1248 broad region of $A$. cooperensis. In both $W$. wattsi and D. matildae the acromion plate is thicker

1249 mediolaterally and less medially deflected compared to A. cooperensis.

1250

1251

Medial View. The scapular plate preserves a deep fossa created by the medial curvature of the

1252 scapular plate and an excavated medial side of the acromial ridge and scapular blade base. This large fossa is interpreted to be a proximal location for the M. subscapularis (Figure 9, B). The fossa in D. matildae (Hocknull et al. 2009; Poropat et al. 2015b) (Figure 9, F) and W. wattsi (Hocknull et al. 2009; Poropat et al. 2015a) (Figure 9, D) is not as deep, and in both of these taxa there exists a small and distinct medial tuberosity muscle scar distal to the fossa near the midline of the scapular blade. This feature has not been observed in other taxa illustrating the medial view of the scapula, so it could be considered a shared characteristic of these two taxa. Such a medial tuberosity is missing from A. cooperensis and helps differentiate it from D. matildae and W. wattsi.

The bone making up the acromion process is thin and excavated from the medial side of the scapular plate to be level with the dorsal margin of the scapular blade. The bone then thickens mediolaterally toward the dorsal margin of the acromion process, forming a rounded buttress for the process. The scapular blade base is straight with sub-parallel dorsal and ventral margins. The ventral margin has been crushed and the bone making up the proximoventral margin of the scapular blade has been deformed vertically and medially. The ventral margin of the blade is rounded and slightly thicker than the dorsal margin toward the scapular blade base, which on the lateral side, forms a slightly raised ridge running along the ventrolateral margin of the blade. There is no indication of this ridge occurring on the medial side; therefore, the ridge is a lateral expansion of bone only along this lateral margin.

1272 Distal View. The scapular blade bends only slightly laterally along its length toward the distal 1273 end. Half way along the shaft, the blade is slightly laterally deformed. However, this does not 
1274 alter the overall form of the blade being very straight and only slightly curved laterally. The 1275 distal end of the blade is not preserved, so it is difficult to estimate the distance from the broken 1276 margin to the scapular blade's distal extremity. The bone thickness does not alter significantly 1277 along its length suggesting the blade could have continued significantly further than what is 1278 preserved, especially when comparison is made to the same area of cross-sectional shape in $D$. 1279 matildae and $W$. wattsi (Figure 10), and in comparing the distal cross-sectional shape of $Y$. 1280 datangi (see Figure 11, E in ( $\mathrm{Li}$ et al. 2014)). The cross-sectional shape along the length of the 1281 scapular blade is shallowly curved and sub-rectangular with no distinct lateral ridge along the 1282 midline of the scapular blade or any medial excavation or fossa (Figures 9, G-I \& 10, A-C). 1283 Although not completely preserved, the scapula possesses a combination of features that warrant 1284 comparison across titanosauriforms. The taxa that exhibit some of the suite of features seen in 1285 the scapula of A. cooperensis include Y. datangi,(Li et al. 2014), L. astibiae (Díaz et al. 2013), 1286 Dr. schrani (Ullmann \& Lacovara 2016), Chubutisaurus insignis (Carballido et al. 2011a) and V. 1287 daparisensis (Mannion et al. 2017). They all possess relatively narrow scapular blades that have 1288 close to parallel dorsal and ventral margins with poorly expanded distal margins and lack a 1289 central scapular blade ridge.

1290 Considering the diversity of scapulae shapes across Titanosauriformes, taxa tend to possess 1291 either; 1) a dorsoventrally broad acromion plate with a dorsoventrally narrow scapular blade that 1292 is markedly expanded posteriorly (e.g. Tehuelchesaurus benitezii, see Figure 14 in (Carballido et 1293 al. 2011b); 2) a broad acromion plate with a dorsoventrally narrow scapular blade that is not 1294 expanded posteriorly with sub-parallel dorsal and ventral margins (e.g. Dr. schrani, see Figure 2 1295 1296 in (Ullmann \& Lacovara 2016); 3) a broad acromion plate with a dorsoventrally deep scapular blade that is expanded posteriorly (e.g. P. mayorum, see Figure 2, h in (González Riga et al. 2019); 4) a dorsoventrally narrow acromion plate with a dorsoventrally narrow scapular blade that is not expanded posteriorly with subparallel dorsal and ventral margins (e.g. Y. datangi, see 1299 Figure 11, E in (Li et al. 2014)); and 5) a narrow acromion plate with dorsoventrally broad scapular blade that is expanded posteriorly (e.g. Mendozasaurus neguyelap, Figure 2, g in (González Riga et al. 2019)). A. cooperensis shares features most closely with the titanosaurians similar to $Y$. datangi in scapular morphology, whilst the other Winton Formation taxa that have comparative scapulae ( $W$. wattsi and $D$. matildae) more closely resemble each other and titanosaurians with scapulae like M. neguyelap. 
1306 Humeri (Figures 11-16) (Table 3). The humerus will be described with the diaphysis long axis 1307 oriented vertically and the distal condyles horizontal and perpendicular to the diaphysis long 1308 axis. The holotype preserves both humeri; a partial left and a nearly complete right humerus. The 1309 left humerus is missing the proximal epiphysis and much of the medial margin of the diaphysis. 1310 Most of the lateral margin of the limb is preserved from just distal of the proximolateral corner 1311 along the deltopectoral crest, including the distal portion of the diaphysis and distal epiphysis, 1312 from the distolateral flange and ectepicondyle to the distomedial flange and entepicondyle. The 1313 cortical bone is heavily split, forming three main sections that join together. Portions of the 1314 deltopectoral crest were collected as surface scatter, having been dislodged from the main distal 1315 epiphysis and weathered and exposed at the ground surface. These elements cleanly fit together 1316 and also fit to the main piece recovered within the transitional horizon between the overlying 1317 vertosol and the underlying Winton Formation.

1318 The right humerus is relatively well preserved although the cortical surface bone is heavily split 1319 into a mosaic-like pattern similar to the left humerus. A thin crust of cemented siltstone with 1320 woody debris covered the element prior to preparation. The posterior side of the right humerus 1321 was facing up in the deposit as the top surface and has suffered significant weathering of the 1322 surface bone through the actions of the vertosol. The anterior face was oriented downwards and 1323 had been somewhat protected from this weathering. The right deltopectoral crest is flattened 1324 laterally due to collapse that occurred during plaster jacket removal during excavation. However, 1325 the relative positions of each distorted region are identifiable and this enables us to reconstruct 1326 the pre-collapsed state of the deltopectoral crest and thus understand the shape of the 1327 proximolateral corner. By combining the 3-D photogrammetric models created from both 1328 humeri, we retrodeformed the deltopectoral crest so that accurate description of the humerus 1329 would be possible (see Methods) (Figures 8, K-N \& 11, H). 1330 Anterior view. The proximal and distal epiphyses are widely expanded relative to a narrow 1332 midshaft, as seen in most sauropod humeri, but further expanded mediolaterally as seen in 1333 titanosauriform sauropods. The proximal epiphysis is rounded, with the humeral head 1334 proximomedially directed and the proximolateral corner is rounded, similar to $V$. daparisensis 1335 (Mannion et al. 2017), Zby atlanticus (Mateus et al. 2014) and Alamosaurus sanjuanensis 
1336 (Lehman \& Coulson 2002), in comparison to a distinct right-angled 'corner' that is seen in the 1337 outlines of D. matildae, Sa. loricatus, Epachthosaurus sciuttoi, Neuquensaurus australis and M. 1338 neguyelap compared with the same feature in Panamericansaurus schroederi, Tornieria africana 1339 and Kotasaurus yamanpalliensis (see Figure 16 in (González Riga \& David 2014)).

1340 The distorted (flattened) proximolateral margin makes the specimen look like it possesses a 1341 distinct proximolateral corner; however, this is an artefact of deformation. When reorienting the 1342 deltopectoral crest the proximolateral margin exhibits a more rounded appearance in comparison 1343 to taxa showing the distinct proximolateral corner. The proximal anterior fossa forms a shallow 1344 and broad depression from the proximomedial margin of the deltopectoral crest to the 1345 proximolateral margin of the humeral head. A small raised rugosity is just medial to the center of 1346 the proximal anterior fossa.

1347 The deltopectoral crest rises anteriorly from the proximolateral corner, thickens toward the 1348 midshaft of the diaphysis and is thickest at approximately a third the maximum proximodistal 1349 length measured from the proximal margin. This thickening at the apex of the deltopectoral crest 1350 is rugose and forms a tuberosity on the crest. The deltopectoral crest forms a shallow curve 1351 originating from the proximolateral margin in a distomedial direction onto the anterior face of 1352 the diaphysis where it expands into a shallowly rounded ridge that continues distally and expands 1353 mediolaterally toward the medial condyle of the radial-ectepicondylar region.

1354 The medial margin distal to the humeral head curves laterally toward the midshaft of the 1355 diaphysis, then straightens along the midshaft and curves medially toward a medially expanded 1356 entepicondylar margin of the distal epiphysis. At the midshaft of the diaphysis the lateral margin 1357 extends distolaterally from underneath the deltopectoral crest into a broad ectepicondylar flange 1358 that curves slightly laterally toward the rounded distolateral corner. The distal epiphysis is broad 1359 due to both the medial and lateral margins expanding distally to respective epicondylar regions. 1360 The ectepicondylar region comprises two main articular regions, the radial condyle and the 1361 flattened ectepicondyle. The radial condyle consists of two small condyles coalesced on the 1362 distal articular surface. The medial condyle is rounded and smaller than the sub-triangular lateral 1363 condyle, they are split apart by a crack. The ectepicondyle is separated from the radial condyles 1364 by a shallow distal anterior fossa; however, it too is connected to the radial condyles through the 1365 distal articular surface. The distal articular surface is anteroposteriorly convex curving up onto 1366 the distal margin of the distoanterior face. The entepicondylar region comprises a large rounded 
1367 ulnar condyle that is mediolaterally expanded and rounded medially. The distal articular surface 1368 curves anteroposteriorly onto the anterior face, but not to the extent seen in the radial condyle. A 1369 shallow and elongate fossa divides the anterior face of the ulnar condyle from the radial condyle 1370 and the low central ridge that extends from the deltopectoral crest.

1371

1372 Posterior view. The proximal epiphysis is poorly preserved, missing portions of the humeral 1373 head; however, based on the distribution of the surface bone preserved it indicates a relatively 1374 thick posterior expansion of the humeral head, thicker than the anterior humeral head bulge.

1375 There is a large, broad and rounded posterior ridge that expands from the medial flange laterally 1376 to approximately the midline of the shaft. The medial fossa (medial fossa for the M.

1377 scapulohumeralis) is significantly reduced to a small flat region along the medial flange. The 1378 lateral fossa (lateral fossa for the M. scapulohumeralis) is large, broad and shallow. The lateral 1379 margin of the diaphysis, distal to the level of the deltopectoral crest, is curved medially and 1380 expanded distolaterally to the ectepicondylar region. This region lacks any representation of a 1381 tuberosity or strong bulge as seen in Opisthocoelicaudia skarzynskii (see Figure 7 in (Borsuk1382 Bialynicka 1977)), but could be preservational loss.

1383 The medial margin of the diaphysis has been distorted by internal collapse to form a narrow 1384 fissure along the mid-length of the shaft in a proximodistal orientation. The surface cortical bone 1385 is still traceable along the margins of this fissure and shows that the fissure is an artefact of 1386 preservation. The olecranon (=anconeal) fossa is elongate and subtriangular in shape with the 1387 tallest apex starting at the level of the midshaft of the diaphysis, just distal to the level of the 1388 deltopectoral crest termination. The fossa broadens distally and is shallow along its length. The 1389 distolateral expansion for the distal condyles creates a steep medial margin for the fossa, whilst 1390 the medial side of the fossa remains broadly shallow.

1391

1392

Proximal view. Proximal epiphysis cross-section through the mid-level of the anterior fossa is anteroposteriorly narrow, elliptical, and slightly curved posteriorly. Midshaft diaphysis crosssection is bi-lobed subrectangular in shape, taking into account the internal collapse along the medial margin and distal extremity of the deltopectoral crest. The distal epiphysis cross-section through epicondylar region is tri-lobed with shallow fossae dividing each lobe. The anterior portion of the humeral head is anteroposteriorly moderately expanded and rounded 
1398 anteromedially. The posterior face of the humeral head is poorly preserved with indications of 1399 thickening in a posterior direction to form a relatively broad humeral head. The deltopectoral 1400 crest is near perpendicular to the proximal anterior fossa and curved medially. The deltopectoral 1401 crest remains vertical along its length and its base curves medially toward the center of the 1402 anterior face of the diaphysis. The vertical projection and apex of the crest remains vertical and 1403 does not curve medially to project across the anterior face of the humerus.

1404

1405 Distal view. The distal condylar region is tri-lobed and sub-equal in size. The radial condylar 1406 region is made up of a rounded radial condyle, which is divided into two small condyles, and a 1407 large ectepicondyle that is similar in size to the radial condyle itself. The ulnar condyle is offset 1408 posteromedially from the radial condylar region via a shallow groove. The ulnar condyle is 1409 similar in size to the radial condyle. The entepicondylar region is rounded and not as expanded 1410 relative to the ectepicondylar corner.

1411 Three of the four currently recognised Australian Cretaceous sauropod taxa possess humeri: $D$. 1412 matildae (Figure 12), W. wattsi (Figure 13), and S. elliottorum (Figure 14) do, whilst 1413 Austrosaurus mckillopi does not. Only D. matildae is complete enough with minimal 1414 deformation for good comparisons. Both $W$. wattsi and S. elliottorum can only be compared for 1415 central diaphysis shape and relative proportions (Figures 12-16, Table 3). Both are missing the 1416 proximal and distal epiphyses due to significant pre-depositional breakage and surface 1417 weathering (i.e., W. wattsi) or pre-diagenetic loss and crushing (i.e., S. elliottorum).

1418 The proximal region of the humerus in A. cooperensis differs from D. matildae by possessing: a 1419 more rounded proximolateral corner; a more rounded proximal articular margin in anterior view; 1420 a relatively thinner, more vertically oriented and more distally terminating deltopectoral crest; a 1421 relatively narrower humeral head and shallower proximal anterior fossa. Posteriorly, the 1422 posterior ridge is broader medially, and the medial fossa is reduced in A. cooperensis. A. 1423 cooperensis has more laterally and medially flared distal condyles (Figures 15 \& 16). 1424 The diaphysis of A. cooperensis differs from $W$. wattsi and S. elliottorum by being considerably 1425 more elliptical in cross-sectional shape where $W$. wattsi and $S$. elliottorum present a much more 1426 ovo-rectangular cross-sectional shape relative to A. cooperensis and D. matildae (Figure 16).

1427 The humerus is hour-glass shaped, as is typical of most sauropods. The proximal margin 1428 compares most favorably with Al. sanjuanensis (Gilmore 1946; Lehman \& Coulson 2002), 
1429 Turiasaurus riodevensis (Royo-Torres et al. 2006), V. daparisensis (Mannion et al. 2017), 1430 Haestasaurus becklesii (Upchurch et al. 2015) and Z. atlanticus (Mateus et al. 2014). These 1431 similarities are based on the outline curvature in anterior view of the proximal margin, differing 1432 from the 'sigmoidal' or 'sinuous' outline characterising other sauropods with similarly broad 1433 proximal epiphyses (e.g. D. matildae, Sa. loricatus, N. australis and O. skarzynskii).

1434 The distal epiphysis in distal view forms a tri-lobate articular cross-sectional profile which is not 1435 seen in D. matildae (Figures 11, 12 \& 16), but is similar to E. lilloi (see Figure 6, E in (Mannion 1436 \& Otero 2012), Giraffatitan brancai and Ep. sciuttoi (see Figure 4, F-G in (Upchurch et al. 1437 2015). Contributing to the tri-lobate distal epiphysis is a deep olecranon fossa which is longer 1438 and deeper than in D. matildae but is similar to that of E. lilloi.

1439 Considerable variation exists across titanosauriformes in regards to the overall shape of the

1440 humerus as illustrated by the outline drawings in Figure 7 of (Lehman \& Coulson 2002), Figure 144116 of (González Riga \& David 2014) \& Figure 4 of (González Riga et al. 2019). The humeri of 1442 A. cooperensis share a combination of characteristics that are missing from more derived 1443 titanosaurians. The gently curved proximodorsally convex outline of the epiphyseal head is 1444 similar to that seen in Tehuelchesaurus benitezii and $V$. daparisensis and differs from the 1445 proximodorsally projecting sub-quadrangular outline typical of many titanosaurians like $C$. 1446 insignis, D. matildae, N. australis, Notocolossus gonzalezparejasi and Paralititan stromeri. 1447 The distal epiphyses of $A$. cooperensis is mediolaterally broad, with clearly defined articular 1448 condylar areas that are anteroposteriorly compressed. This overall shape is similar to that seen in 1449 Dr. schrani, Pa. stromeri and Malawisaurus dixeyi, but differs from titanosaurians like $D$. 1450 matildae, N. australis, E. lilloi, and No. gonzalezparejasi, that possess a more rotund humerus 1451 that is not mediolaterally expanded, but anteroposteriorly deep.

1454 Ulna (Figures 17-19) (Table 4). The ulna will be described with the longest proximodistal 1455 length, taken from the distal articular surface to the olecranon process, oriented vertically. The 1456 main processes of the ulna are oriented anterolaterally and anteromedially with the radial fossa 1457 considered anterior. The holotype preserves a single almost complete right ulna. It is one of the 1458 best preserved and distinctive bones of the holotype specimen. The proximal region has 1459 experienced some weathering; however, much of the articular surfaces remain. The cortical bone 
1460 of the anteromedial process and anterior and posterior faces of the diaphysis are heavily split into 1461 mosaic-like pieces; however, they are tightly arranged and have not moved significantly post1462 burial and excavation. The diaphysis has been deformed, bent downwards in situ, producing an

1463

1464

1465

1466

1467

1468

1469

1470

1471

1472

1473

1474

1475

1476

1477

1478

1479

1480

1481

1482

1483

1484

1485

1486

1487

1488

1489

1490 anterolateral bend. This deformation is unlikely a result of subsurface vertical movement through soil action because the bend was downwards, or post-fossilisation turbation (e.g. wombats) because no evidence of sediment disturbance or infill with soil profile was observed at this site. A more likely conclusion is that this downward bend was a result of pre-fossilisation trampling. Digital retro-deformation of the shaft was possible and allowed a more accurate description of the bone and its dimensions. Referred ulna fragments from EMF164 include parts of the proximal diaphysis and the interosseous ridge of the distoanterior face.

Anterior view. Three distinct processes extend from the proximal epiphysis, the anterolateral, anteromedial and olecranon processes, in an arrangement typical of sauropods. The anterolateral and olecranon processes are of similar length with the anteromedial process being much longer than either of these. The anteromedial process is shallowly concave along its length ending at its extremity as a triangular point. The anterolateral process is short and broad with a rounded extremity whilst the olecranon process is constricted mediolaterally and angled proximally into a tapered articular surface. Between the anterolateral and anteromedial processes, a deep radial fossa extends distally toward a distinct radial interosseous ridge. The lateral side of the fossa is steep, made up by the medial face of the anterolateral process. The medial side of the fossa is shallow and slightly curved, made up by the broad lateral face of the anteromedial process. The radial fossa extends distally to the beginning of the distal epiphysis.

The distal half of the fossa is shallow and a distinct and thick proximodistally oriented interosseous ridge extends along its center, terminating just proximal of the distal articular end.

This feature is present in fragments of a large ulna of EMF164; therefore, such a unique feature allows us to confirm referral of EMF164 to this same taxon.

The anterolateral process is broader proximally, but is not a thick process. It extends the length of the diaphysis tapering along its length into a tall thin crest and terminates just proximal of the distal articular end. At the distal end of the anterolateral process a distinct crest of bone, an interosseous crest, smaller than the process itself extends slightly posterolaterally with a small rounded tuberosity at its apex. This tuberosity sits above another ridge of bone that extends 
1491 anteriorly along the distal edge of the diaphysis and connects anteriorly to the distal articular 1492 region. There is no indication on the surface of the bone or surrounding this region to suggest 1493 that this unique set of features is distortion through preservation or from pathology.

1494 Lateral to the anterolateral process is a narrow and deep posterolateral fossa bounded by the 1495 lateral face of the anterolateral process and the anterolateral face of the olecranon process. The 1496 fossa is broadest proximally and extends distally to about the midshaft level where it tapers to a 1497 shallow point before meeting the distal epiphysis. The anteromedial process curves steeply from 1498 its proximomedial extremity to the distal articular surface. The olecranon process is the highest 1499 of the three processes with its articular face oriented anteroproximally.

1500

1501

1502

1503

1504

1505 1506

1507

1508

1509

1510

1511 1512

1513

1514

1515

1516

1517

1518

1519 Overall, the ulna possesses the characteristic shape seen in many sauropod taxa. The stout nature 1520 1521

Posterior view. The anteromedial process is broad and flat with a shallow medial fossa extending across the process and distally to approximately two thirds of the proximodistal length. The olecranon process extends distally making a shallow sigmoidal curve, convex proximally and concave distally to the distal articular surface. The anterolateral process is straight in profile and sharply tapers distally to the distal tuberosity and accessory process and ridge.

Proximal view. Tri-radiate proximal end made up of an anterolateral, anteromedial and an olecranon process. Olecranon process smallest of the three, anterolateral process second largest whilst the anteromedial process is much longer than both extending approximately two and a half times the length of the anterolateral process. The angle created between the long axes of the anteromedial and anterolateral processes is approximately $50^{\circ}$.

Distal view. The distal articular surface is beveled proximally, and made of two clear lobes, a posteriorly placed mediolateral lobe and a small anterolateral lobe. The overall shape in distal view is oblong for the posterior lobe and rounded for the anterior lobe. The whole articular area is compressed anteroposteriorly so that the posterior region is not prominently expanded and more 'comma' shaped. of the ulna is similar to many titanosaurians like D. matildae, Sa. loricatus, N. australis, Y. datangi and O. skarzynskii. The presence of an accessory interosseous crest on the mediolateral 
1522 process and an interosseous ridge within the radial fossa is unique to this taxon. An accessory 1523 interosseous crest has been recently observed in the brachiosaur $V$. daparisensis (see Figure 20, 1524 A in (Mannion et al. 2017)); however, this feature does not originate from the anterolateral 1525 process as it does in A. cooperensis. Instead, the crest originates separately from it in a more 1526 medial position. Distinct interosseous ridges within the radial fossa of the ulna are observed in $Z$. 1527 atlanticus (Mateus et al. 2014), Rapetosaurus krausei (Curry Rogers 2009), Bonitasaura 1528 salgadoi (Gallina \& Apesteguía 2015) Narambuenatitan palomoi (Filippi et al. 2011); and to a 1529 lesser degree of development in N. robustus (Otero 2018) and Dr. schrani (Ullmann \& Lacovara 1530 2016). With the exceptions of $A$. cooperensis and $N$. robustus, the interosseous ridge originates at 1531 approximately one third distal of the proximal epiphysis. In A. cooperensis and N. robustus, the 1532 ridge originates in the distal third of the shaft.

1533 The ulna of D. matildae differ from A. cooperensis by both possessing a similar combination of 1534 features not present in A. cooperensis; including a relatively shorter anteromedial and relatively 1535 longer anterolateral and olecranon processes (in proximal view) (Figures 17, E-H, 18 \& 19); a 1536 taller and broader olecranon process; a less sinusoidal posterolateral ridge (in anterior view); the 1537 absence of an anterolateral distal interosseous crest or interosseous ridge within the distal radial 1538 fossa; a more inflated and rounded anterolateral and anteromedial margins of the distal epiphysis 1539 producing an inflated bean-shaped articular end in distal view; and a deeper fossa between the 1540 anteromedial and posterior processes.

1541 The ulnae of $W$. wattsi are both poorly preserved missing the proximal and distal epiphyses and 1542 cannot be easily compared with A. cooperensis (Figure 17). The reconstructed ulna (Figure 18, 1543 C) shows clear differences between $W$. wattsi and A. cooperensis along with D. matildae in 1544 regards to cross-sectional thickness of the anteromedial and anterolateral processes (Figures 18 1545 and 19). W. wattsi is distinctly more robust in cross-section. Previously it has been reported that 1546 the left ulna of $W$. wattsi preserves the proximal and distal epiphyses (Hocknull et al. 2009;

1547 Poropat et al. 2015a), however, on inspection, both the left and right ulnae lack preserved 1548 proximal or distal articular ends or preserved epiphyses (Figure 17-19). The proximal end of the 1549 left ulna is missing significant portions of the anteromedial and anterolateral processes. The 1550 olecranon is also missing the articular end with the surface exhibiting a pitted and corroded 1551 surface that can also be seen along the diaphyseal shaft (Figure 17, M \& O). The distal end is 1552 missing and there is some indication of plant-debris adhering to this broken surface. Therefore, 
1553 observations about the morphology of the ulnar condyles of $W$. wattsi are likely

1554 misinterpretations.

1555

1556 Pelvis. The right and left pubes and ischia were recovered together in semi-articulation and semi1557 life position with the dorsal side facing up in the deposit. The ilia were not found. Both pubes are 1558 well preserved; however, the cortical bone surface has been split into small mosaic-like pieces 1559 across the broad anterodorsal plates of the pubes and posterodorsal plates of the ischia. The 1560 pubes and ischia have split along the medial symphysis and reoriented sub-horizontally within 1561 the deposit, the cause of which is likely dinoturbation through trampling. The pubic blades are 1562 oriented slightly above horizontal. The ischial blades have been dislocated slightly from their life 1563 position relative to the pubes; however, remain in near contact along their articular surfaces 1564 between each ischium and pubis.

1565

1566 Pubes (Figures 20-22) (Table 5). Lateral view. The lateral (ventrolateral) views of both pubes 1567 represent the sides facing downward in the site resulting in this side being better preserved than 1568 the medial (dorsomedial) side. The left pubis is best preserved and will be used as the basis for 1569 most of the pubic description. The iliac peduncle sits dorsal of a shallow fossa that runs 1570 posteroventrally to the obturator foramen. Posterior of the obturator foramen the ischial peduncle 1571 is broken with matrix infill obscuring the lateral connection to the ischium. The anterior margin 1572 of the proximal blade extends ventrally from the iliac peduncle curving slightly ventrally toward 1573 the distal blade expansion. The ischial peduncle is connected and was co-ossified to the ischium 1574 along its entire length extending ventromedially to the midline, then joining with its contralateral 1575 pair. The ventral margin of the distal blade is divided into two regions of differing bone 1576 thickness with a line of collapsed bone forming an irregular groove from the ventral margin of 1577 the ischial peduncle across the pubic blade at about a third of the distance from the ventrolateral 1578 margin. This line of collapse indicates a distinct change in bone thickness from the main distal 1579 and proximal blade to the internal (medially directed) thin bone connection between the two 1580 contralateral elements.

1581

1582 Medial view. The medial (dorsomedial) view of both pubes represent the face exposed upwards 1583 in the site, therefore, the medial surface preserves a number of post-burial alterations to the bone 
1584 surface. The right pubis has been affected more so than the left, with the surface cortical bone 1585 fractured into a mosaic tile of pieces with some collapse of internal bone and compression 1586 observed. Both pubes have some distortion to the central portion of the distal blades having been 1587 affected by crushing through trampling.

1588 The iliac peduncle is better preserved in the left pubis. In medial view, it is broad and flat, taking 1589 up almost the entire proximal portion of the acetabulum. The peduncle is slightly expanded 1590 dorsally of the proximal blade plate which extends ventrally and curves medially to the central 1591 symphyseal surface. The posterior margin of the proximal blade is made up of the ischial 1592 peduncle which was fused to the pubic peduncle of the ischium along its entire length during life. 1593 In the left pubis the connection has been split and broken prior to fossilisation with the pubis 1594 medially and ischium laterally displaced relative to life position. The medial margin of the 1595 ischial peduncle has been split and dislodged vertically above the anterodistal margin of the 1596 pubic peduncle of the ischium. The opposite has occurred on the right side element with the 1597 pubis displaced laterally and the ischium medially.

1598 Ventral of the posterior margin of the iliac peduncle and anterior of the ischial peduncle is an 1599 enclosed ovoid obturator foramen with a long axis oriented posterodorsally to anteroventrally.

1600 The symphyseal margin is thickest at both the posterior and anterior ends and has broken away 1601 from its contralateral pair exposing broken and open internal bone along its length, indicating 1602 that both blades were originally fused together. The bone connecting the contralateral elements is 1603 very thin along their length and curves ventrally to the massively expanded distal articular 1604 surface.

1605 The distal articular surface is dorsoventrally thickened with a central fossa (preserved best in the 1606 left pubis). A shallow fossa runs along the distomedial surface behind the distal expansion. The 1607 lateral margin of the proximal blade begins lateral to the anterior margin of the iliac peduncle 1608 and curves ventrally at a very low angle toward the distal blade and distal expansion. In the left 1609 pubis, two abnormal indentations occur at the junction of the proximal and distal blades and just 1610 proximal of the distal expansion. These indentations appear to be the result of bone trampling.

1611 The original lateral margin would have been a smooth curved surface along its length as seen in 1612 the right pubis.

1613 Based on the better-preserved left pubis, the iliac peduncle is oval in shape with tapered anterior 1614 and posterior margins, thickest in an anteromedial to distolateral direction. The region for the 
1615 ambiens process is indistinct as the pubic blade runs directly ventral of the base of the iliac 1616 peduncle. Only a short acetabular surface is present posterior of the iliac peduncle on the pubis. 1617

1618 Ischia (Figures 20-22) (Table 6). The left ischium is the least deformed of the ischia, preserving 1619 good and near complete margins and iliac and pubic peduncles. The iliac peduncle of the ischium 1620 is teardrop shaped with a rounded posterior and tapered anterior margin that runs into the 1621 acetabular surface. The acetabular surface is shallowly concave and approximately the same 1622 length as the iliac peduncle.

1623 The anterior corner of the acetabular surface where it meets the pubic peduncle is dislocated 1624 posterodorsally from the corresponding puboischial articular surfaces, offsetting this articulation 1625 in a dorsoventral and mediolateral direction. The distal ischial symphysis is broken along its 1626 anteromedial margin indicating that these two elements were connected in life. However, 1627 complete bone is observed close to the central connection of both paired elements, suggesting 1628 that the four elements were fused along their respective articular surfaces except for the central 1629 point where all four elements meet (Figure 21).

1630 Instead, we reconstruct this area as having a slight opening that would have resembled a 1631 diamond-shaped gap between the four elements or exceptionally thin bone that has not 1632 preserved. The posteroventral margin of the ischium is unfused, but when mirrored form a 1633 distinct ' $v$ ' shaped margin (notch) between the mediodistal ends of each ischium when viewed 1634 dorsally. The proximal ischial plate is anteroposteriorly broad along its entire length and 1635 continues to retain this breadth distal of the pubic articulation, creating a broad posterodistal, but 1636 ventromedially projecting ischial shaft. A lateral tuberosity along the middle of the posterior 1637 ischial margin is a long thin buttress of bone.

1638 When compared to other sauropods, the preserved portions of the pelvis are closest in 1639 morphology to all three previously described Winton Formation taxa (i.e. D. matildae, W. wattsi 1640 and $S$. elliottorum). The ischium is preserved for all taxa and warrants specific comparison 1641 (Figure 22). The articular surface of the iliac peduncle is poorly preserved in all taxa; however, 1642 the shaft just ventral of this articular surface indicates that all taxa bear a similar tear drop-shaped 1643 process that was anteroposteriorly longer than mediolaterally wide. The iliac peduncle is 1644 dorsoventrally elongate in D. matildae, W. wattsi and A. cooperensis, with that of W. wattsi 1645 being the most elongate. However, this could be a reflection of the significant bone loss around 
1646 the peduncle in $W$. wattsi, creating an illusion of a more elongate feature (Figure 22). This 1647 feature is fore-shortened in S. elliottorum and seems real. However, the iliac peduncles of both 1648 the pubis and ischium are somewhat dorsoventrally compressed, suggesting this feature might be 1649 due to taphonomic crushing.

1650 The proximal ischial plate is broad anteroposteriorly with a ventromedially curved posterior 1651 margin in all taxa, following the curvature of the pubic articulation and co-ossified fusion.

1652 Ventromedially the ischial shaft is indistinct from the proximal plate and is best described as a 1653 distal plate because it is broad anteroposteriorly along its entire length, and is not differentiated 1654 into a posterior process as seen in O. skarzynskii (Borsuk-Bialynicka 1977). The distal ischial 1655 plate contacts its co-lateral partner medially and was clearly fused to one another in all of the 1656 Australian taxa, although broken apart during fossilization in W. wattsi, D. matildae and A. 1657 cooperensis. This fusion is clearly preserved in S. elliottorum, and partially observable in $D$. 1658 matildae and A. cooperensis. This feature is likely to have been present in $W$. wattsi as well 1659 because the distal ischial plate is similarly broad along its entire length and posteriorly 1660 foreshortened, with no sign of a completed medial margin. This indicates that bone co1661 ossification likely occurred with its contralateral pair. Although the medial margin is missing, the 1662 thickness of bone suggests a significant area of missing distal ischial plate in $W$. wattsi.

1663 A broad and foreshortened distal ischial plate without a posteriorly projecting blade-like process 1664 is not well defined in titanosauriformes; however, Ma. dixeyi, Al. sanjuanensis and possibly 1665 Uberabatitan ribeiroi approach this morphology (Gomani 2005; Silva et al. 2019; Tykoski \& 1666 Fiorillo 2016). However, they still retain a posterior process of the ischium shaft blade. $O$. 1667 skarzynskii possesses a similar central fusion and broad distal ischial plate, although the distal 1668 plate continues posteriorly to form a distinct straight and posteriorly projecting blade-like 1669 process (Borsuk-Bialynicka 1977). We therefore consider this combination of features of the 1670 ischium a potential synapomorphy for D. matildae, S. elliottorum and A. cooperensis, with the 1671 possibility of this feature also uniting the only other Winton Formation taxon, W. wattsi, within 1672 this group (see Discussion).

1673 When viewed posteriorly, the distal ischial plate retains a gentle medial curvature to meet and 1674 fuse medially with its contra-lateral partner in D. matildae. However, in S. elliottorum, A. 1675 cooperensis and possibly in $W$. wattsi, the distal plate curves medially to meet its partner, as in 
1676 D. matildae, but before doing this the distal ischial plate curves steeply ventrally creating a 1677 posteriorly facing dorsal surface of the distal ischial plate (Figure 22).

1678

1679

1680 Femur (Figures 23-26) (Table 7). The femur will be described with the long axis of the shaft 1681 vertical and the distal condyles orientated so that they lie flat along a mediolateral horizontal 1682 plane. Portions of both the right and left femur are preserved in the holotype. The right femur 1683 preserves the diaphysis and distal epiphysis. It is missing the proximal epiphysis and the 1684 proximal section of the diaphysis is crushed and distorted, having been pushed downwards from 1685 a horizontal position (Figure 8). This vertical displacement and crushing has distorted the diaphysis from about the midshaft proximally. The crushing is likely due to trampling as 1687 discussed above (Hocknull et al. 2019) (Figure 8) and has distorted the longitudinal axis of the diaphysis. The distal half of the diaphysis and distal epiphysis remain undistorted, although the distal medial condyle is damaged with loss of structure on both the anterior and posterior 1690 surfaces.

1691 The left femur was recovered on the surface in a large number of fragments and was pieced back 1692 together. Surface exposure has removed much of the surface cortical bone; therefore, the femoral 1693 head would have been larger and had more of the bulbous femoral head articular surface than 1694 what is preserved. Reconstruction of these fragments recovered the proximal epiphysis and the 1695 proximal region of the diaphysis to just above the lateral bulge. Both elements preserve 1696 overlapping regions of the proximal diaphysis, which allows reconstruction of the femur (Figure $169723 \& 24)$.

1698 In addition to EMF102 (holotype), two other femora, EMF164 and EMF 105, are referred to $A$. 1699 cooperensis due to significant shared overlap in morphology. EMF164 is highly fragmented but 1700 represents a larger femur preserving the proximomedial margin of the proximal epiphysis, along 1701 with portions of the lateral bulge, diaphysis, fourth trochanter and medial and lateral condyles. 1702 The proximal epiphyseal portion (greater trochanter) has been useful when reconstructing the 1703 femur. EMF105 is a complete femur, with some loss of cortical bone around the proximal 1704 epiphysis and medial distal condyle. This femur, although smaller than the holotype, provides an 1705 accurate independent guide for overall femoral shape when scaled isometrically to the size of 1706 EMF102 (Bonnan 2004; Bonnan 2007; Kilbourne \& Makovicky 2010). It also provides the best 
1707 guide to the shape of the dorsomedial portion of the femoral head. The following descriptions of

1708 the femur will be based on the holotype but will reference the referred femora where appropriate.

1709

1710 Anterior view. The proximal epiphyseal head is rounded and projects proximomedially with

1711 preserved articular surface extending across the proximal-most margin from just above the

1712 greater trochanter and is assumed to include the missing femoral head. The fourth trochanter is

1713 positioned slightly more proximally than the medial margin of the femoral head. The lateral

1714 margin of the femur is shallowly sigmoidal in overall outline shape, made up of the abductor

1715 crest (lateral bulge) that curves laterally in a shallow convex outline, distally from the greater

1716 trochanter, encompassing approximately a third of the proximal length of the entire lateral

1717 margin of the diaphysis. Distal of this, the lateral margin of the diaphysis then curves medially in

1718 a shallow concave outline along the remaining two thirds of the shaft where it meets the lateral

1719 epicondyle. The medial margin curves laterally in a shallow concave outline from the medial

1720 margin of the femoral head position to the fourth trochanter and then curves laterally again in

1721 another shallow concave outline from the distal margin of the fourth trochanter to the tibial

1722 (medial) condyle.

1723 The distal condylar region is mediolaterally wide with an anteroposteriorly narrow distal

1724 epiphysis with the lateral condyle mediolaterally broader than the medial condyle. The articular

1725 surface of both condyles extends onto the anterior face of the diaphysis and both condylar

1726 articular surfaces on the anterior face are dorsolateral to ventromedially directed, the medial

1727 condyle more so than the lateral condyle.

1728

1729 Posterior view. A low rounded ridge (lesser trochanter + trochanteric shelf) runs from the greater

1730 trochanter along to the lateral bulge and merges with the diaphysis approximately $1 / 3$ the length

1731 of the shaft. The fourth trochanter is best visible in posterior view and is proximodistally ovoid

1732 in shape and positioned on the posteromedial face of the diaphysis. The distal end of the

1733 diaphysis expands mediolaterally and houses a shallow broad fossa proximal to the distal

1734 epiphysis. The distal articular region is divided into two regions, the tibial (medial) condyle and

1735 the fibular (lateral) condyle, which includes the lateral epicondyle. The posterior origin of the

1736 fibular condyle and lateral epicondyle extends further proximally on the posterior face than the

1737 tibial condyle. The fibular condyle and lateral epicondyle are divided by a distinct and deep 
1738 fossa. The lateral margin of the lateral epicondyle expands from the main articular surface

1739 creating a small shallow fossa on the distolateral corner. The tibial and fibular condyles are

1740 divided by a deep and wide intercondylar fossa.

1741

1742 Proximal view. Although poorly preserved, the femoral head is expanded anteroposteriorly and

1743 rounded medially. The greater trochanter is constricted anteroposteriorly with a mediolaterally

1744 tapered articular region. A shallow 'D'-shaped transverse cross-sectional outlines the proximal

1745 diaphysis, being broad mediolaterally and very narrow anteroposteriorly. The midshaft

1746 transverse cross-section outline is anteroposteriorly deeper forming a more distinct ' $\mathrm{D}$ '-shape.

1747

1748 Distal view. The long axes of the tibial and fibular condyles in distal view are oriented

1749 anterolaterally to posteromedially. The tibial (medial) condyle is anteroposteriorly longer than

1750 the fibular (lateral) condyle. The crural extensor fossa on the anterior side of the distal epiphysis

1751 is broad and similarly as deep to the intercondylar fossa of the posterior side. The anterolateral to

1752 posteromedial orientation of the condyles is similar to the distal condyles described for

1753 Daxiatitan binglingi (You et al. 2008), Dr. schrani (Ullmann \& Lacovara 2016), L. astibiae

1754 (Díaz et al. 2013) and cf. L. astibiae (Vila et al. 2012). In Da. binglingi, a combination of this

1755 feature with dorsolateral bevelling of the distal condyles was considered both unique features of

1756 this taxon (You et al. 2008). This feature was considered to be one of a number of features that

1757 could identify femora to L. astibiae (Vila et al. 2012). However, in Dr. schrani (Ullmann \&

1758 Lacovara 2016) the medially oriented distal condyles were considered to be oriented in this plane

1759 due to taphonomic distortion through lithostatic compression. Therefore, in some taxa this seems

1760 to be a real feature, whilst in others it is taphonomic. The anterolateral to posteromedially

1761 directed condyles in A. cooperensis are unlikely to be taphonomic, although there has been loss

1762 of surface bone to the condyles indicating some damage but crushing is restricted to the proximal

1763 half of the holotype femur. The same condylar feature is observed in the referred femur

1764 EMF112, which has not been crushed.

1765 When comparing the distal condyles of specimens referred to A. cooperensis with other femora

1766 from the Winton Formation there are clear differences in distal epiphyseal shape (Figures 23-26).

1767 Other than the considerable larger size, the femur of A. cooperensis also differs from the femur

1768 of D. matildae, the only described Winton Formation taxon to preserve a femur, in a number of 
1769 ways. These differences are also observed when comparing several additional isolated femoral 1770 elements from the Winton Formation not currently assigned to a taxon (Figures $25 \& 26$ ), and 1771 include: 1) A more proximomedially directed femoral head; a mediolaterally broader and 1772 anteroposteriorly narrower diaphysis along the entire length; 2) A relatively larger and more 1773 posteriorly positioned fourth trochanter; 3) a less sigmoidal lateral margin and more convex 1774 medial margin; and 4) Anterolateral to posteromedially oriented distal condyles (in distal view). 1775 These features not only differentiate the two taxa possessing femora, but also differentiate the 1776 southern-central from the northern Winton Formation femoral specimens. Therefore, the femur 1777 may be of taxonomic value when differentiating taxa between regions. This also suggests closer 1778 morphological similarities to those taxa found within a particular region, relative to between 1779 regions. These differences do not seem to relate to overall element size because the differences 1780 are seen in specimens from Eromanga and Winton that are very different in size (Figures $24 \&$ $178126)$.

1782 Overall, the femur of $A$. cooperensis is similar to titanosauriform sauropods and more derived 1783 titanosaurians. Comparing the outline shape of the anterior and posterior views across 1784 titanosauriform sauropods similarities in overall shape are found in Dr. schrani (Ullmann \& 1785 Lacovara 2016), Traukutitan eocaudata (González Riga et al. 2019), L. astibiae (Díaz et al. 1786 2013), Aegyptosaurus baharijensis (Stromer 1932) and Ampelosaurus atacis (Le Loeuff 2005).

1787 These similarities reflect a broad femoral shaft relative to proximal and distal condylar breadths, 1788 along with a long shallowly curved lateral bulge and less bulbous proximal femoral head. The 1789 femora are also narrow anteroposteriorly along the diaphyseal length, but possess expanded 1790 proximal and distal epiphyseal regions.

1791 The northern Winton Formation femora, including D. matildae, all have narrower and deeper 1792 diaphyseal shafts, more bulbous proximal femoral heads, anteroposteriorly thicker lesser 1793 trochanter, and anteroposteriorly rotund distal epiphyses (Figures $25 \& 26$ ). The femoral shaft is 1794 relatively narrower and dorsoventrally straightened in the northern Winton Formation sauropods 1795 compared to the southern-central specimens. Such variation in femoral shaft morphology is 1796 present in several titanosaurians, ranging from stout and robust diaphyses in taxa like N. robustus 1797 (Otero 2010), Sa. loricatus, Ep. sciuttoi (Martínez et al. 2004) and Bonatitan reigi (González 1798 Riga et al. 2019), to straight and deep diaphyses in taxa like P. mayorum (Carballido et al. 2017), 
1799 to anteroposteriorly compressed and mediolaterally broad, sinuous diaphyses in taxa like $A$. 1800 cooperensis, L. astibiae (Díaz 2013) and Dr. schrani (Ullmann \& Lacovara 2016).

1801

1802

1803 Referred Specimens

1804 EMF164. Axial remains. The type specimen for A. cooperensis does not possess associated 1805 vertebrae; however, the referred specimen EMF164 from EML010 includes isolated pieces of 1806 presacral vertebrae preserving distinctly camellate somphospondylous internal centrum bone.

1807 The internal cavities filled with matrix are large and indicate derived somphospondylous 1808 architecture similar to that seen in all other Cretaceous-aged sauropods from Australia. The 1809 camellate bone structure is very thin, reticulated, thin bone struts held within a mudstone matrix, 1810 approximating the same degree of camellate structuring seen in the holotype dorsal vertebrae of 1811 Austrosaurus mckillopi, D. matildae, W. wattsi and S. elliottorum. The thickness of the 1812 trabeculae and the size of the vacuities observed in the isolated pieces of EMF164 are larger than 1813 those from these previously described taxa, thus indicating that the vertebrae were much larger in 1814 overall size. Large pieces of plank-like rib shafts are also present, although no proximal rib 1815 articular ends have been identified.

1816

1817 Appendicular remains. Identifiable pieces of ulna include sections of diaphysis and a fragment 1818 preserving a thick ridge that represents the prominent interosseous ridge of the radius, similar to 1819 that present in holotype (EMF102). These ulna fragments are too poorly preserved to provide 1820 additional information that the holotype provides; however, the thickness of the cortical bone 1821 seen in cross-section of EMF164 when compared to that of the holotype (EMF102) indicates that 1822 EMF164 was a larger individual.

1823 The larger size of EMF164 is best represented by the fragments of a right femur. A large number 1824 of fragments represent diaphyseal pieces of the femur that are clearly anteroposteriorly narrow 1825 indicating a broad, but narrow diaphysis for the femur, similar to that seen in EMF102. However, 1826 these pieces have much thicker cortical bone in cross-sectional comparison. As with the ulna 1827 pieces, this thickness of cortical bone indicates an individual of larger size than that of EMF102. 1828 The elements of the EMF164 femur do not provide any additional details of the femur from a 1829 comparative point of view, other than its larger size. Estimating the size of this larger femur 
1830 provides some additional information in regards to the overall variation in the size of these 1831 elements and estimates of body-size in this taxon. Therefore, we have undertaken three different 1832 estimations of the femur length of EMF164 and will report the average and range.

1833 We directly matched the largest fragments of the femur of EMF164 to the femora of the $A$. 1834 cooperensis holotype, EMF 102 and referred EMF 105. We first did this by sight and then 1835 digitally by aligning and scaling the 3-D surface meshes of the smaller femora (EMF102 \& 105) 1836 to match the size of the combined 3-D surface meshes of the EMF164 femoral pieces. This was 1837 achieved in Meshlab (Cignoni et al. 2008) and Cloud Compare (Girardeau-Montaut 2016) by 1838 point picking, rotation/translation, then isometrically scaling the 3-D surface mesh of EMF102 1839 and EMF105 to match the size and position of the EMF164 pieces.

1840 The resulting isometrically scaled reconstruction returned maximum total lengths of the femur 1841 when scaled to EMF102: maximum medial length of $2117 \mathrm{~mm}$; maximum central length of 2134 $1842 \mathrm{~mm}$; maximum lateral length of $2160 \mathrm{~mm}$. The reconstructed surface mesh of EMF102 does not 1843 include the proximal-most femoral head articular surface because this is missing portions of the 1844 proximal-most cortical bone, therefore, these estimates could be considered underestimations. 1845 Second, we undertook the same process, but this time we matched the 3-D restored femur that 1846 was based on the surface mesh of EMF102. Therefore, when scaling the reconstructed model 1847 isometrically, this universal scaling was automatically applied to the associated 3-D modelled 1848 femur. The resulting isometrically scaled model returned total lengths of the femur: maximum 1849 medial length of $2125 \mathrm{~mm}$; maximum central length of $2176 \mathrm{~mm}$ and; maximum lateral length of $18502140 \mathrm{~mm}$. The modelled surface mesh of EMF102 includes estimations of the proximal-most 1851 femoral head articular surface by continuation of the surface bone shape, therefore, these 1852 estimates could be considered accurate.

1853 Finally, we used the 3-D surface mesh created of the referred femur, EMF105, and aligned and 1854 scaled this mesh to match the surface meshes of EMF164 pieces. The resulting isometrically 1855 scaled model returned total lengths of the femur: maximum medial length of $2133 \mathrm{~mm}$; 1856 maximum central length of $2187 \mathrm{~mm}$ and; maximum lateral length of $2147 \mathrm{~mm}$. EMF105 is a 1857 complete femur missing some of the proximal and distal condyles making this estimate likely a 1858 slight underestimate.

1859 Together, taking all nine measurements we arrive at an average length of $2146 \mathrm{~mm}$ with a range 1860 of 2117-2187 mm. Considered together, this provides an estimated length of the EMF164 femur 
1861 of approximately $2150 \mathrm{~mm}$ in length, which is approximately $200 \mathrm{~mm}$ longer than the

1862 reconstructed femur of the holotype (EMF102).

1863

1864

EMF105 (Figure 23 \& 24, Table 7). EMF105 is a complete right femur, measuring $1412 \mathrm{~mm}$ in

1865

1866

1867

1868

1869

1870

1871

1872

1873

1874

1875

1876

1877

1878

1879

1880

1881

1882

1883

1884

1885

1886

1887

1888

1889

1890

1891

maximum proximodistal length. The femur conforms closely to the overall morphology of the

holotype femora EMF102; however, it is better preserved and includes a well-preserved proximal femoral head. Post-depositional scouring of the distal condyles has truncated them in the anteroposterior plane. Excavator damage during removal of overburden has occurred to the distal diaphysis shaft with loss of preserved bone in a triangular wedge-shape.

EMF165 (Figure 27). EMF165 is a portion of a distal humerus preserving a shallow and broad olecranon (= anconeal) fossa and a rounded anterior face. It is missing much of the distal epiphyseal articular surface, although it is broad relative to the diaphysis to a similar extent to that seen in EMF102. In distal view, the tri-lobate articular outline can be discerned, although the anterior and posterior extremities of the condyles are missing. Although not preserving considerable detail, the proportions of this distal humerus are similar to that of the holotype and not that of $D$. matildae, the only other Winton Formation sauropod to preserve a distal end of the humerus.

\section{Other titanosaurian specimens}

Currently, several titanosaurian specimens cannot as yet be directly referred to $A$. cooperensis due to their incompleteness or current state of preparation. These specimens are known from the northern and southern Plevna Downs sites and include isolated, associated and articulated remains.

Based on comparisons of these preserved elements with those from northern Winton Formation taxa, they share general features, but none possess features that definitively ally them with those taxa (i.e. D. matildae, W. wattsi or S. elliottorum). Therefore, we applied a conservative approach of provisionally allocating them to the local taxon, A. cooperensis, until sufficient overlap is found in skeletal remains to constitute a fully diagnostic allocation. EMF100, from EML01 is a small, poorly preserved ulna, missing the majority of the proximal and distal ends (Figure 28). However, comparison of the midshaft diaphyseal cross-section and 
1892 proximal and distal shape comparisons are possible between EMF100, A. cooperensis, $D$.

1893 matildae and $W$. wattsi. EMF100 is mediolaterally compressed as seen in A. cooperensis and not 1894 in D. matildae or W. wattsi. Furthermore, the shape of the shaft in distal and oblique-distal views 1895 is closer to A. cooperensis than it is to D. matildae or W. wattsi. In proximal view, the 1896 anteromedial process is proportionately more elongate relative to the proximolateral process, 1897 albeit missing the proximal portion of the process. However, by projecting the anteromedial and 1898 anterolateral processes proximally, the relative expansion of these processes is closer to that of $A$. 1899 cooperensis than it is to D. matildae or $W$. wattsi.

1900 EMF106 occurs at EML010 and is a collection of small sauropod remains found with EMF164. 1901 Identifiable remains of EMF 106 include a metapodial articular end and pieces of mid caudal 1902 centra. A portion of a caudal centrum is amphicoelous with dense non-pneumatic cancellous 1903 bone (Figure 29, G \& H).

1904 EMF103 occurs at EML011b and is a scattered series of cervical and dorsal vertebrae with a 1905 poorly preserved distal femur and isolated dental remains. Based on overall size similarities 1906 between the cervical and dorsal vertebrae, along with the femur, it is likely that this specimen 1907 represents a single individual. However, the distribution of the skeletal elements and the post1908 depositional scouring and trampling makes comparing this skeleton with other individuals 1909 difficult. The femur does overlap as an appendicular element with EMF102. However, the 1910 element is not well enough preserved to ally it, or separate it, from A. cooperensis. The cervical 1911 and dorsal vertebrae are well preserved on the surfaces that faced downward in the site. The 1912 upward projecting faces have been scoured and trampled which has dislocated and deformed the 1913 positions, and possible interpretations, of the vertebral laminae. Therefore, this precludes 1914 meaningful comparisons to the other Winton Formation taxa preserving cervical and dorsal 1915 vertebral laminae, until we can retrodeform and model the original positions of these features. 1916 EMF166 is an isolated metacarpal found with EMF165 and EMF105. The metacarpal is 1917 relatively small in comparison to what would be expected to be from the individual femur 1918 (EMF105) or the humerus (EMF165). Based on comparisons with the metacarpals of $D$. 1919 matildae, $W$. wattsi and S. elliottorum, EMF166 is a metacarpal IV. The proximal and distal ends 1920 are rounded through pre-depositional abrasion, marked by a thick layer of plant debris covering 1921 the bone prior to preparation. The proximal end describes a roughly tear-drop or rounded 1922 triangular shape with the broadest rounded margin being external and the narrowest margin 
1923 constricted internally. There are remnants of distinct internal condylar processes that have been 1924 rounded off through abrasion. The distal external margin is rounded with no distinct indication of 1925 distal articular surfaces on the external face suggestive of phalanges. However, the lack of these 1926 features could be preservational. In external view, the metacarpal differs from the northern 1927 Winton Formation taxa by being more elongate without the proximally and distally expanded 1928 and robust epiphyses seen in D. matildae, W. wattsi and S. elliottorum.

1929 EMF109 (EML012) (Figure 6, K \& 29, A) is an associated and articulated skeleton preserved 1930 within a massive siltstone concretion located $65 \mathrm{~m}$ to the southwest of EML013. Based on what 1931 skeletal elements were observable in the concretion this specimen preserves much of the torso 1932 and tail of the sauropod. The articulated caudal vertebrae were evident in the site, delineated by 1933 the concretion itself. However, the dorsal vertebrae, ribs and appendicular elements are mostly 1934 obscured by concretion. Until this concretion has been prepared, direct referral of it to a 1935 described taxon is precluded; however, the distal mid and distal caudal vertebrae have been 1936 prepared to a point that allows some initial comparison with the distal caudal vertebrae known 1937 from $W$. wattsi (Figure 29, B).

1938 Of the two known occurrences of distal caudal vertebrae known from the northern Winton 1939 Formation both are incipiently bi-convex as originally described (Hocknull et al. 2009), 1940 possessing articular ends but do not approach the true bi-convexity seen in Rinconsaurus (Calvo 1941 \& González Riga 2003). This feature is now considered to be a local autapomorphy for W. wattsi 1942 because it is known across several titanosauriforms (D'Emic 2012; Poropat et al. 2015a). Having 1943 said this, neither D. matildae or S. elliottorum have associated distal caudal vertebrae preserved, 1944 therefore, at this stage, the utility of this feature is equivocal and only useful to exclude $W$. wattsi 1945 from a possible candidate taxon for the southern-central Winton Formation specimen.

1946 The distal caudal vertebrae of EMF109 are not incipiently bi-convex, instead being 1947 amphicoelous to amphiplatyan, possessing similar morphology to all other anterior and middle 1948 caudal vertebrae found across sites in both the northern and southern-central Winton Formation 1949 (see Discussion). Therefore, we can exclude $W$. wattsi, as a candidate taxon, however due to the 1950 ubiquitous nature of amphicoelous caudal vertebrae of sauropods in the Winton Formation we 1951 cannot exclude any of the other three described taxa. Based on what is indicated from the 1952 specimen as currently visible, EMF109 will provide significant data to understand the anatomy 1953 of these sauropods, being the most complete southern Winton Formation specimen. 


\section{Discussion}

1957

1958

Comparison with other Winton Formation sauropod taxa. Australotitan cooperensis can be 1959 differentiated from the three semi-contemporaneous northern Winton Formation sauropods, Diamantinasaurus matildae, Wintonotitan wattsi and Savannasaurus elliottorum, in the following ways: A. cooperensis is larger than all the three taxa in the scapula, humerus, ulna, femur and pubis (Tables 2-7). The scapula differs from $D$. matildae and $W$. wattsi by possessing sub-parallel dorsal and ventral margins of the scapular blade; not possessing a medial scapular blade tuberosity and; not possessing a distinct lateral mid-ridge of the scapular blade. Instead, this ridge occurs along the ventral margin (Figures $10 \& 28$ ). The humerus differs from $D$. matildae by possessing a distinct tri-lobate distal articular epiphysis and a deltopectoral crest that terminates more distally (Figures $15,16 \& 30$ ). Neither $S$. elliottorum nor $W$. wattsi preserve the proximal or distal articular ends so are not directly comparable. The humerus further differs from both $W$. wattsi and S. elliottorum by the later taxa bearing an ovo-rectangular midshaft crosssectional shape (Figure 16). The ulna differs from $D$. matildae and $W$. wattsi by possessing a relatively longer proximal anteromedial process and a distinct interosseous ridge in the radial 1972 fossa (Figures 18, $19 \& 30)$.

1973 Pubes are known from D. matildae, S. elliottorum and A. cooperensis, but are unknown in $W$. 1974 wattsi. A. cooperensis differs from D. matildae by being larger; possessing dorsoventrally 1975 thinner pubic blades; possessing an obturator foramen closer to the proximal margin; and a 1976 slightly more mediolaterally expanded distal margin (Figures $22 \& 28$ ). The pubes of $A$. 1977 cooperensis differ from S. elliottorum by being larger, more ventrally directed; not possessing a 1978 lateral proximodistal mid-ridge (autapomorphy of S. elliottorum); and by possessing an obturator 1979 foramen that is dorsoventrally oblong instead of dorsoventrally compressed as in S. elliottorum 1980 (Figures $22 \& 28$ ). The latter feature may be due to taphonomic distortion in S. elliottorum where 1981 the pubis has possibly been compressed in the dorsoventral plane, but if so, the obturator 1982 foramen would then be much larger in S. elliottorum relative to A. cooperensis and D. matildae. 1983 The ischia of D. matildae, W. wattsi, S. elliottorum and A. cooperensis are known and all are 1984 near complete, making this element one of the best directly comparable elements between all 1985 four taxa. All taxa are similar in overall morphology, possessing a distinct 'tear-drop' shaped 
1986 iliac peduncle in dorsal view; concave acetabular articular region; long ventromedially curved 1987 pubic articular surface; and similarly ventromedially curved posterior puboischial blade margin.

1988 The ischial blade expands anteroposteriorly as it curves ventrally, then connects with its

1989 contralateral element in D. matildae, S. elliottorum and A. cooperensis.

1990 The distomedial margin of the ischium in $W$. wattsi is missing and precludes a definitive mid-line 1991 connection between the contralateral ischia. However, based on the close similarity in

1992 morphology and the curvature of this element with the other taxa, it is very likely that the ischia 1993 extended to contact its contralateral at the midline (Figures $22 \& 30$ ).

1994 In dorsal view, the posterior-most margin of each ischial blade occurs at near to two-thirds the 1995 dorsoventral length of the posterior blade margin. This produces a double-pointed posterior 1996 margin of the ischia in dorsal view with a ' $v$ '-shaped embayment at the posteromedial margin of 1997 the ischia. This embayment is shallowest in A. cooperensis and steepest in S. elliottorum, with $D$. 1998 matildae intermediate. Although this margin is not completely preserved in $W$. wattsi, it is likely 1999 to have been similar based on the close approximation of these elements to one another (Figure $200022 \& 30$ ). The posterior margin of the ischia in S. elliottorum and A. cooperensis curve ventrally 2001 along the distal plate margin angling the dorsal margin of this distal-most portion posteriorly. 2002 This does not occur in D. matildae, where the dorsal margin of the distal plate remains dorsally 2003 oriented. The orientation of the distal-most plate margin is unknown in $W$. wattsi, although at the 2004 preserved distal-most margin it begins to curve ventrally. If this curvature was to continue, it 2005 would produce a similar posteriorly directed distal plate, as seen in S. elliottorum and A. 2006 cooperensis.

2007 The ischium of A. cooperensis is larger than in both S. elliottorum and D. matildae, but smaller 2008 than $W$. wattsi. The ischium is the only comparable element across these taxa where $A$. 2009 cooperensis is not substantially larger. Both holotype specimens of A. cooperensis (EMF102) 2010 and $W$. wattsi (QMF7292) are known from associated and semi-articulated remains, which 2011 establishes the allocation of each ischium with other elements of each holotype, therefore the 2012 size discrepancy is unlikely an artefact of having come from multiple individuals.

2013 The greater size of the ischium in $W$. wattsi is contrary to the relatively smaller sizes of all other 2014 known appendicular elements in common with $A$. cooperensis. The preserved scapula of $A$. 2015 cooperensis indicates that it had a much longer scapular blade relative to both D. matildae and $2016 W$. wattsi. However, this element is much more gracile in A. cooperensis, having a 
2017 mediolaterally thin scapular blade (Figures $10 \& 30$ ). Although incomplete, the reconstructed 2018 humerus of $W$. wattsi is longer than that of D. matildae and S. elliottorum, but considerably 2019 smaller with a narrower midshaft breadth for length in comparison to A. cooperensis (Figure 15 2020 \& 30). In mid-diaphyseal cross-sectional shape, W. wattsi is ovo-rectangular like S. elliottorum, 2021 but compared to the mediolaterally oblong and anteroposteriorly compressed A. cooperensis and 2022 D. matildae (Figure 16). The ulna of $W$. wattsi has the most robust midshaft cross-sectional 2023 shape when compared to the smaller D. matildae and larger A. cooperensis (Figure 18). The 2024 proximal olecranon process is robust, broad and rounded in both D. matildae (complete) and $W$. 2025 wattsi (incomplete) compared with the gracile, narrow and acute process in A. cooperensis 2026 (Figures 18, $19 \& 30$ ).

2027 The femur of $A$. cooperensis differs from the femur of $D$. matildae by possessing a relatively 2028 anteroposteriorly narrower femoral shaft, including a narrower proximal femoral head. The distal 2029 condyles of $A$. cooperensis are beveled more medially in anterior and distal aspects relative to 2030 that of D. matildae, and all other northern Winton Formation femora compared (Figure 24-26 \& 2031 $30)$.

2032

\section{Comparison with non-Winton Formation semi-contemporaneous members of the}

Titanosauria worldwide (e.g. Latest Albian-early Turonian). Comparisons were not possible

with the following semi-contemporaneous titanosaurian taxa due to a lack of overlap in 2036 preserved elements: Austrosaurus mckillopi (Poropat et al. 2017), Sarmientosaurus musacchioi (Martinez et al. 2016), Drusilasaura deseadensis (Navarrete et al. 2011), Jiutaisaurus xidensis (Wu et al. 2006) and Borealosaurus wimani (Hailu et al. 2004). In addition, comparisons were not possible due to poor preservation or a lack of detailed descriptions or figures of the overlapping elements for the following taxa: Huanghetitan liujiaxiaensis and Huanghetitan ruyangensis (Junchang et al. 2007; You et al. 2006), Quetecsaurus rusconii (González Riga \& 2042 David 2014) and Choconsaurus baileywillisi (Simón et al. 2017).

2043 Several titanosaurians are only comparable by one or two overlapping appendicular elements, 2044 and in some cases, size differences are the clearest feature that differentiates these taxa apart. $A$. cooperensis differs from Pa. stromeri (Smith et al. 2001) and Andesaurus delgadoi (Mannion \& Calvo 2011) by possessing a rounded proximal humeral epiphysis without a distinct 
2048 with a mediolaterally narrower diaphysis. An. delgadoi is smaller and also has a mediolaterally 2049 narrower humeral diaphysis.

2050 A. cooperensis possesses a smaller femur compared to the specimen referred to as 2051 Argentinosaurus huinculensis (Bonaparte 1996). A. cooperensis differs from Aegyptosaurus 2052 baharijensis (Stromer 1932) by being larger and possessing a mediolaterally broad midshaft for 2053 both the femur and humerus. A. cooperensis differs from Dongyangosaurus sinensis by 2054 possessing a pubis that is much longer than the ischium (Junchang et al. 2008). A. cooperensis 2055 differs from Ruyangosaurus giganteus by possessing a more mediolaterally broad and robust 2056 femur relative to the long and gracile femur of $R$. giganteus (Lü et al. 2009).

2057 A. cooperensis differs from Ep. sciuttoi (Martínez et al. 2004) by being much larger in all 2058 comparative elements (i.e. humerus, ulna, femur, pubis and ischium). A. cooperensis possesses a 2059 less stocky and robust humerus, a distinct interosseous ridge and an accessory ridge on the distal 2060 end of the anterolateral process of the ulna. A. cooperensis differs from P. mayorum (Carballido 2061 2062 et al. 2017) by being much smaller in all comparative elements except for the ulna with which it is of similar length and anterior width. A. cooperensis lacks the dorsoventrally deep scapular 2063 blade with distinct mid-ridge of P. mayorum. Both the humerus and femur are more elongate in 2064 anterior outline in P. mayorum than in A. cooperensis, which is also reflected in a narrower 2065 anteroposterior, but broader mediolateral midshaft width.

2066 2067 Based on the shared elements (scapula, humerus and ulna) A. cooperensis is larger than 2068 Angolatitan adamastor (Mateus et al. 2011). The acromion plate of the scapula of An. adamastor 2069 is broader dorsoventrally with a distinct posteroventral process as seen in $W$. wattsi and $D$. matildae. The dorsal and ventral margins of the scapular blade are curved to an expanded distal end, similar to that seen in D. matildae and $W$. wattsi but not in A. cooperensis. The humerus of An. adamastor is an elongate element relative to A. cooperensis, D. matildae and S. elliottorum; however, it is comparatively closer to the reconstructed humerus of $W$. wattsi (Figure 15, Z). The proximolateral corner exhibits a greater angularity relative to $D$. matildae and A. cooperensis. The ulna is uninformative in An. adamastor, retaining the general titanosauriform shape and robust proximal tri-radiate epiphysis. The ulna does not possess accessory distal processes or the 2077 compare favourably with $A$. cooperensis in scapula, humerus and ulna morphology, it does 
2078 closely resemble the elements preserved for $W$. wattsi, warranting more detailed comparison of 2079 these two taxa in future comparative assessments.

2080 A. cooperensis is much larger than Mnyamawamtuka moyowamkia (Gorscak \& O'Connor 2019) 2081 in all preserved elements. A. cooperensis shares with Mn. moyowamkia the scapula, humerus, 2082 ulna, pubis, ischium and femur, but all elements, except for the scapula, are so poorly preserved 2083 that frustratingly they cannot be adequately compared. The scapula is similar to $A$. cooperensis 2084 by being a lightly built element with a relatively narrow acromion plate compared to the scapular 2085 blade. The blade is near straight with an absent posteroventral process, similar to that of $A$. 2086 cooperensis and $Y$. datangi.

2087 A. cooperensis is morphologically similar to E. lilloi (Mannion \& Otero 2012); however, it is 2088 larger in all comparative elements (i.e. scapula, humerus, ulna, femur and pubis). The distal 2089 epiphysis of the humerus approaches a similar cross-sectional shape, being nearly tri-lobate in 2090 distal view; however, A. cooperensis has a much greater mediolateral expansion of the distal 2091 epiphysis and a laterally flared ectepicondylar margin of the lateral condyle. The proximal 2092 epiphysis of the ulna in E. lilloi bears a similar reduction of the anterolateral and olecranon 2093 processes relative to the much longer anteromedial process; however, the radial fossa does not 2094 possess the distinct interosseous ridge or the distal anterolateral accessory ridge present in $A$. 2095 cooperensis. The pubes are similarly broadened anteroposteriorly along the pubic blade in both 2096 taxa. However, the iliac peduncle of E. lilloi is directed more anteriorly and flattened in 2097 comparison to the anterodorsally pointed peduncle of $A$. cooperensis. The distal margin of the 2098 pubic blade is broader and truncated in E. lilloi compared to the rounded distal blade margin in 2099 A. cooperensis.

2100

2101 Comparisons with other large-bodied titanosaurians. In addition to the above comparisons 2102 between semi-contemporaneous titanosaurians, it is also worthy to compare A. cooperensis with 2103 other large-bodied titanosaurians of comparable size of preserved elements. Futalognkosaurus 2104 dukei possesses a similar-sized humerus $(1510 \mathrm{~mm})$ and near similar femur (1945 mm) (Benson 2105 et al. 2014); however, morphological comparisons were not possible. The pubis and ischium can 2106 be compared (Calvo et al. 2007b) with the pubis having similar overall morphology, but differing 2107 from A. cooperensis by possessing a anteroposteriorly longer iliac peduncle, and by being thicker 2108 along the dorsoventral length of the pubic blade. A lateral ridge along the mid-line of the blade is 
2109 clearly visible in $F$. dukei, but not in A. cooperensis. A lateral ridge along the pubic blade is also 2110 present in S. elliottorum, and considered an autapomorphy (Poropat et al. 2016). The pubic 2111 articulation of the ischium in $F$. dukei is shorter than the long, medially curved articulation seen 2112 in A. cooperensis, D. matildae, S. elliottorum and W. wattsi.

2113 Both Antarctosaurus sp. and T. eocaudata (Juárez Valieri \& Calvo 2011) possess more elongate 2114 femora with a more bulbous and anteroposteriorly thicker greater trochanter and femoral head 2115 when compared to A. cooperensis. No. gonzalezparejasi possesses a longer humerus (1760 mm) 2116 (Benson et al. 2014) and unlike A. cooperensis has: a proximal humeral epiphysis with a distinct 2117 proximolateral corner that meets at right angles; a flattened lateral to bulbous medial humeral 2118 head profile in anterior view; a proximodistally reduced deltopectoral crest; and a narrower 2119 midshaft diaphysis (Gonzalez Riga et al. 2016). Al. sanjuanensis's referred humerus (D'Emic et 2120 al. 2011; Gilmore 1946) is the same size (1503 mm) (Benson et al. 2014), with a rounded 2121 proximal humeral epiphysis, similar to that of $A$. cooperensis. The referred ischia of $A l$. 2122 sanjuanensis (Tykoski \& Fiorillo 2016) are also similar to A. cooperensis including an extensive 2123 ischial contact with its contralateral element. Unlike $A$. cooperensis, the posterodistal margin of 2124 the ischial blades are directed posteriorly, past the position of the posterior margin of the iliac 2125 peduncle. The scapula of Al. sanjuanensis possesses a central ridge along the scapular blade that 2126 is not seen in A. cooperensis. Da. binglingi has a smaller femur (1770 mm) (Benson et al. 2014), 2127 but has similarly oriented distal condyles that are bevelled in an anterolateral to posteromedial 2128 orientation when viewed distally (You et al. 2008). Da. binglingi differs from A. cooperensis by 2129 possessing a narrower diaphysis and dorsolaterally beveled distal condyles in posterior view. 2130 Dr. schrani has a longer humerus (1760 mm) and femur (1910 mm) (Benson et al. 2014); 2131 however, is similar in overall appendicular morphology (Ullmann \& Lacovara 2016). The 2132 scapula shares with $A$. cooperensis: a long, straight scapular blade with subparallel dorsal and 2133 ventral margins; the absence of a central ridge of the scapular blade; and a mediolaterally thin 2134 blade. It also possesses a mediolaterally thin and gracile acromion plate. However, the acromion 2135 plate is massively expanded dorsoventrally in excess of that estimated in A. cooperensis. Similar 2136 to $A$. cooperensis, the humerus of Dr. schrani is proximally and distally broad across the 2137 epiphyses as well as being anteroposteriorly narrow and mediolaterally broad at the midshaft. $2138 D$. schrani differs from A. cooperensis by the deltopectoral crest neither reaching as far distally 2139 nor possessing the distinctly tri-lobate distal epiphysis present in $A$. cooperensis. The ulna of $D r$. 
2140 schrani differs from $A$. cooperensis by being more robust and stocky, with near-equal

2141 anterolateral and anteromedial processes and an oblong-shaped distal epiphysis. The pubis of $D r$.

2142 schrani differs from $A$. cooperensis by being considerably thicker along the pubic blade with a

2143 dorsoventrally short ischiadic peduncle. The ischium of $D r$. schrani differs from A. cooperensis

2144 by being near-vertically oriented, with the entire dorsal surface of the ischial blade directed

2145 posteriorly. As with the pubis, the pubic peduncle is dorsoventrally short. The femur of $\mathrm{Dr}$.

2146 schrani is similar to A. cooperensis, possessing an anteroposteriorly narrow and mediolaterally

2147 broad diaphyseal shaft that leads to mediolaterally expanded proximal and distal epiphyses. The

2148 distal epiphyses are bevelled in an anterolateral to posteromedial direction, a feature also seen in

2149 Da. binglingi (You et al. 2008), L. astibiae (Díaz et al. 2013) and cf. L. astibiae (Vila et al.

2150 2012). However, this feature has been considered to be taphonomic distortion in Dr. schrani

2151 created through lithostatic compression (Ullmann \& Lacovara 2016).

2152 Considered together, A. cooperensis possesses a mosaic of features shared with titanosaurians

2153 with similar geographical (Australia) and temporal range (Latest Albian to ?Turonian), as well as

2154 similar body-size. The previously described and comparable Australian taxa (D. matildae, $W$.

2155 wattsi and S. elliottorum) share closer morphological similarities of the pubis and ischium

2156 complex with $A$. cooperensis than they do to all other taxa compared. This observation alludes to 2157 a potential shared ancestry.

2158 Those taxa of similar geological age or similar limb size tend to share only isolated features of

2159 each element with $A$. cooperensis but this is also observed in titanosaurians from older and 2160 younger Cretaceous sites, such as the scapular similarities seen in Y. datangi from the Lower 2161 Cretaceous of China, or the humeral and ischial similarities of Al. sanjuanensis from the latest 2162 Cretaceous of North America. Such a mosaic of characteristics helps define and differentiate $A$. 2163 cooperensis from all other taxa and is especially useful in regards to those taxa found within the 2164 Winton Formation. However, the mosaic of similar and different features found in this taxon, 2165 which derive from a small number of representative appendicular elements, suggests that these 2166 characteristics will not add significantly to a phylogenetic analysis of similarly incomplete and 2167 variable taxa. The morphological similarities in titanosaurian limb morphology across multiple 2168 lineages has recently been considered, finding that potentially convergent morphologies could 2169 reflect morphofunctional similarities across lineages. However, without more detailed 2170 comparative assessments, likely by using 3-D models and geometric morphometrics this 
2171 potential influence on phylogenetic signal or ecomorphology is difficult to quantify (Páramo et 2172 al. 2020).

2173

2174

2175 Phylogenetic position. A preliminary phylogenetic assessment, which we provide as

2176 Supplementary Information, does not resolve the phylogeny of titanosauriformes with any

2177 statistical support. However, it does allude to a possible shared relationship of the four Winton

2178 Formation taxa, as discussed below.

2179 In the absence of such a resolved phylogeny, we can consider the phylogenetic position of $A$.

2180 cooperensis using a comparative approach, using published phylogenies and the spread of 2181 characteristics hypothesized to define particular clades. The phylogenetics of titanosaurians 2182 remains in a state of flux with multiple assessments appearing in recent years investigating the 2183 relative position of taxa in a global context, covering Late Jurassic to Late Cretaceous 2184 (Carballido et al. 2017; D'Emic 2012; González Riga et al. 2019; Gonzàlez Riga et al. 2018; 2185 Hechenleitner et al. 2020; Mannion et al. 2017; Mannion et al. 2013; Mannion et al. 2019a; 2186 Mannion et al. 2019b).

2187 For our comparative approach, we use a recent review of the appendicular skeletons of South 2188 American titanosaurians (González Riga et al. 2019) that focuses on the appendicular 2189 synapomorphies which are derived from two independent phylogenetic assessments of 2190 titanosaurians (D'Emic 2012; Mannion et al. 2013). We find the following features present in $A$. 2191 cooperensis that are considered to be synapomorphies of Titanosauria or clades within it: 1) The 2192 humerus length is less than $80 \%$ the femur length (= Saltasauridae) (79\% for $A$. cooperensis). 2193 The length of the femur of $A$. cooperensis has been estimated in multiple different ways. Because 2194 we cannot directly confirm the length of the femur in the holotype, and with this percentage 2195 being so close to the upper limit of the expected range for saltasaurids, we treat its use as a 2196 synapomorphy for $A$. cooperensis within the Saltasauridae as dubious. 2) The humeral 2197 deltopectoral crest extends medially across the anterior face of the humerus, but this is not well 2198 developed (= Titanosauria). 3) The humeral deltopectoral crest is not expanded distally ( $\neq$ 2199 Saltasauridae). 4) Humerus with a strong posterolateral bulge around the level of the 2200 deltopectoral crest area is not well preserved or discernible in A. cooperensis ( $\neq$ Saltasauridae). 2201 5) Humeral radial and ulnar condyles are undivided distally ( $\neq$ Alamosaurus + 'Saltasaurini'). 6) 2202 Anterior surface of the distal lateral condyle of the humerus seems to be divided by a notch in $A$. 
2203 cooperensis; however, this feature is poorly defined ( $\neq$ Lithostrotia). 7) Prominent ulnar 2204 olecranon process projecting well above proximal articulation is present in A. cooperensis (= 2205 Lithostrotia). 8) Anteroposterior to mediolateral width ratio of iliac articular surface of pubis is $2206 \geq 2.0$ (= Titanosauria). 9) Acetabular margin of ischium strongly concave in lateral view such that 2207 pubic articular surface forms a proximodorsal projection (= Titanosauria or Lithostrotia). 10) No 2208 emargination of ischium distal to pubic articulation (= Titanosauria). 11) Ratio of dorsoventral 2209 width of distal end of ischial shaft to minimum shaft dorsoventral greater than 1.5 ( $\neq$

2210 Titanosauria). 12) Femur with longitudinal ridge on anterior face of shaft (linea intermuscularis 2211 cranialis (Otero 2010)) is preserved on the anterior face of the distal diaphysis in the holotype 2212 EMF102 and is well preserved along the entire anterior face of the referred femur in EMF 105 (= 2213 Alamosaurus + 'Saltasaurini'). 13) Femoral distal condyles are bevelled $10^{\circ}$ dorsomedially 2214 relative to shaft (= Saltasauridae) with the slightly distally projected fibular condyle that is not as 2215 exaggerated as seen in Saltasaurus and Bonatitan (González Riga et al. 2019).

2216 Based on this assessment, A. cooperensis possesses a single synapomorphy of the Saltasauridae, 2217 being bevelled distal condyles of the femur. One character state supports and another does not 2218 support placement within the 'Saltaurini' clade (D'Emic 2012). Two character states support and 2219 2220 one does not support placement within the Lithostrotia. Finally, four character states support and two do not support placement within the Titanosauria (Table 8). Such a mosaic of

2221 synapomorphies makes any solid phylogenetic footing equivocal.

2222 However, the distribution of the combined synapomorphic features of the appendicular skeleton 2223 recovered from two independent phylogenetic assessments of titanosauriformes (D'Emic 2012; 2224 Mannion et al. 2013) at least supports our placement of A. cooperensis within Titanosauria and 2225 suggests that it could be part of the Lithostrotia. Whether or not A. cooperensis is a lithostrotian 2226 titanosaurian, or a non-lithostrotian titanosaurian is remarkably the same situation for two other 2227 Winton Formation taxa: S. elliottorum and D. matildae (Mannion et al. 2013; Poropat et al. 2228 2016).

2229 The most recent phylogenetic analyses that include the Winton Formation titanosaurians 2230 (González Riga et al. 2019; Gonzàlez Riga et al. 2018; Mannion et al. 2017; Mannion et al. 2231 2019a; Mannion et al. 2019b) provide context for our discussion in two important ways. Firstly, 2232 there is growing support for a nearly global distribution of most titanosaurian clades by the Early 2233 Cretaceous, and by extension, titanosaurians from Cretaceous Australia could potentially 
2234 represent one or more of those clades. However, there is also growing support for clades 2235 restricted to specific regions, such as Colossosauria, Rincosauria, and Lognkosauria of South 2236 America (González Riga et al. 2019). Therefore, the mosaic of features that A. cooperensis 2237 shares with taxa from older, semi-contemporaneous and geographically distant regions could 2238 potentially place it within any of these clades unless homoplasy has played a more significant 2239 role in the evolution of sauropod appendicular elements than previously thought (Upchurch 2240 1998).

2241 Secondly, the relative positions of the Australian taxa are unstable, changing position depending 2242 on the phylogenetic methodologies and taxa included within each assessment. The relative 2243 phylogenetic position of $W$. wattsi as basal to $D$. matildae has changed since the first 2244 phylogenetic assessment was undertaken (Hocknull et al. 2009) and further since the addition of 2245 S. elliottorum (Poropat et al. 2016). W. wattsi has been resolved as a non-titanosaurian 2246 somphospondylan (Hocknull et al. 2009; Poropat et al. 2015a), but has also been recovered 2247 outside of titanosauriformes (Carballido et al. 2011b; Hechenleitner et al. 2020); more derived 2248 2249 than D. matildae (Mannion et al. 2013); within the titanosaurian 'Andesauroidea'; or sister taxon to the Titanosauria (Mannion et al. 2019a).

Over time, new phylogenetic assessments have proposed a more basal position for D. matildae, first falling outside of the derived Saltasauridae and then further outside Lithostrotia. D. matildae has variably been recovered as a derived saltasaurid (Gonzalez Riga et al. 2016; Hocknull et al. 2009; Mannion et al. 2019a; Mannion et al. 2019b; Upchurch et al. 2015); a non-lithostrotian titanosaurian (González Riga et al. 2019) with S. elliottorum as sister taxon (Gonzàlez Riga et al. 2018; Mannion et al. 2017; Mannion et al. 2019a; Mannion et al. 2019b; Poropat et al. 2015b); or close to Yonglinglong (Li et al. 2014).

With the addition of more taxa to these newer phylogenetic analyses, especially adding taxa from Asia, the once derived position of $D$. matildae (along with $S$. elliottorum), relative to $W$. wattsi has eroded. Therefore, with such instability in their relative positions it would be premature to add a further fragmentary taxon to derive another alternative phylogeny. Our new taxon, along with the others from the Winton Formation, is unlikely to provide new

2262 phylogenetically useful data to these large-scale global analyses until the known better-preserved 2263 specimens such as those currently being prepared are available (Hocknull et al. 2019; Poropat et 2264 al. 2019). 
2265 All four taxa possess appendicular elements and for those elements with overlap between at least 2266 two taxa, they allow comparison between each other and to the appendicular synapomorphies 2267 found in Titanosauria (González Riga et al. 2019). The scapulae of D. matildae and W. wattsi 2268 both possess a well-developed ventromedial process of the ventral margin (= Titanosauria) 2269 (Hocknull et al. 2009; Poropat et al. 2015a; Poropat et al. 2016; Poropat et al. 2015b) (Figures 9$227010 \& 28$ A-C), although titanosaurian outgroup taxa, including C. insignis, also possess this 2271 feature (Carballido et al. 2011a; González Riga et al. 2019). The area where this feature would 2272 be found in A. cooperensis and S. elliottorum is missing.

2273 The relative humerus to femur length of $A$. cooperensis, estimated at $79 \%$, is less than $85 \%$ for 2274 D. matildae. However, they are either at or above the limit of this feature being a synapomorphy 2275 of Saltasauridae (i.e. less than $80 \%$ ). Neither $W$. wattsi or S. elliottorum preserve a complete 2276 humerus and femur for comparison.

2277 The deltopectoral crest extends medially across the anterior face of the humerus in both $A$. 2278 cooperensis and D. matildae (= Titanosauria) although it does not extend as far as that of derived 2279 titanosaurians like O. skarzynskii and Sa. loricatus. These features are missing from the 2280 preserved humeri of $W$. watts and S. elliottorum. Based on what is preserved of the humeri in the 2281 four Australian taxa, none of them possess a distally expanded deltopectoral crest or a strong 2282 posterolateral bulge level with the deltopectoral crest ( $\neq$ Saltasauridae). The distal humeral 2283 condyles of $A$. cooperensis and D. matildae are undivided ( $\neq$ Alamosaurus + 'Saltasaurini') and both possess a distal lateral condyle that has a divided anterior surface ( $\neq$ Lithostrotia). The proximal and distal condyles of the humeri of $W$. wattsi and $S$. elliottorum are unknown. The midshaft cross-sectional shape of $W$. wattsi and $S$. elliottorum approximate one another by being anteroposteriorly thick, creating a rounded (ovo-rectangular) outline, whilst in $A$. cooperensis and $D$. matildae, this outline is mediolaterally broad, creating a more oblong outline. The distal end of the radius is bevelled $\sim 20^{\circ}$ proximolaterally relative to the shaft in $D$. matildae (Poropat et al. 2015b) and estimated in $W$. wattsi (Poropat et al. 2015a) although the distal ends in the $W$. wattsi holotype radii are very poorly preserved (= Saltasauridae). The radius is not 2292 bevelled in $S$. elliottorum ( $\neq$ Saltasauridae), and the radius is unknown in $A$. cooperensis. A 2293 prominent olecranon process is present in A. cooperensis and D. matildae (= Lithostrotia), but is 2294 unknown in $S$. elliottorum and not preserved in $W$. wattsi. However, this feature in $W$. wattsi is 2295 likely similar to D. matildae based on shape comparisons of this element (see Figures 18 B \& C 
$2296 \& 28 \mathrm{~L}$ ) and would then place $W$. wattsi within the Lithostrotia. The relative size of metacarpal I 2297 to metacarpal II or III is less than 1.0 in S. elliottorum and D. matildae ( $\neq$ Lithostrotia). This 2298 characteristic is not preserved in W. wattsi and unknown in A. cooperensis.

2299 The anteroposterior length to mediolateral width of the iliac articular surface of the pubis is 2300 greater than 2.0 in both A. cooperensis and D. matildae (= Titanosauria) (Table 8). The pubis is 2301 unknown in $W$. wattsi and the iliac articulation of the pubis is missing from both sides of the 2302 pelvis of S. elliottorum. In D. matildae, A. cooperensis and S. elliottorum, the acetabular margin 2303 of the ischium is strongly concave in lateral view such that the pubic articular surface forms a 2304 proximodorsal projection (= Titanosauria or Lithostrotia). The acetabular rim of the ischium in $2305 W$. wattsi is broken along its entire length, exposing internal cancellous bone (Figure 22). This 2306 indicates the loss of substantial bone around the acetabular rim. Therefore, the morphology of the 2307 acetabular rim cannot be accurately defined, or is questionable. The very similar shape of the 2308 ischium of all four Australian taxa suggests that the acetabular rim of $W$. wattsi could have been concave, changing this feature from a typically non-titanosaurian character state to a character state found in Titanosauria or Lithostrotia (Figure 30).

2311 There is no emargination of the ischium distal to pubic articulation in $A$. cooperensis, $D$. 2312 matildae and S. elliottorum (= Titanosauria). This region of the ischium in W. wattsi is not 2313 preserved, being broken along the pubic articulation and medial region where the contralateral 2314 elements may have met. The ischium curves ventrally at the broken medial margin suggesting a 2315 significant extension of ischium directed medioventrally, similar to that observed in $S$. 2316 elliottorum. Therefore, it is possible that the ischia did meet at a symphysis with no 2317 emargination, thus a feature synapomorphic in Titanosauria. The ratio of dorsoventral width of 2318 the distal end of ischial shaft to minimum shaft dorsoventral width is greater than 1.5 in $A$. 2319 cooperensis, S. elliottorum, D. matildae and estimated to be so in $W$. wattsi ( $\neq$ Titanosauria) 2320 (Tables 8 and 9).

2321 The femur is only known in A. cooperensis and D. matildae. The femur of $A$. cooperensis 2322 possesses a longitudinal ridge on the anterior face of shaft (linea intermuscularis cranialis (= 2323 Alamosaurus + 'Saltasaurini'), but this is absent in D. matildae ( $\neq$ Alamosaurus + 'Saltasaurini'). 2324 The distal condyles are bevelled $10^{\circ}$ dorsomedially with a slightly distally projected fibular 2325 condyle, unlike that of highly derived saltasaurids (González Riga et al. 2019). 
2326 Summarising the above comparative phylogenetic appraisal of the four Australian taxa by using 2327 synapomorphies derived from three independent phylogenetic character assessments (Tables 8 2328 and 9), we find only one character-state of the sixteen, that are found in all four taxa, that is not a 2329 synapomorphy of Titanosauria. Therefore, there is support for the placement of all four Australian taxa within the Titanosauria. In the ischium, the ratio of dorsoventral (anteroposterior) 2331 width of the distal end of the shaft to the minimum shaft dorsoventral (anterior-posterior) width 2332 is greater than 1.5, which is not a synapomorphy of Titanosauria. The ratios for the four 2333 Australian taxa are very similar between A. cooperensis (1.63) and W. wattsi (1.64 est.), and 2334 between D. matildae (1.73) and S. elliottorum (1.74), which reflects the overall similar 2335 morphology of the ischium (Figure 30, M-O). The shared similarities of the ischium, regardless 2336 of overall body-size differences and other appendicular differences, may point to a 2337 synapomorphy uniting all four Australian taxa.

2338 Several other features are shared between the four Australian taxa and are summarised in Table 2339 9. W. wattsi shares with D. matildae a proximal medial tuberosity of the scapular blade (Figure 2340 9). W. wattsi shares with S. elliottorum amphicoelous anterior caudal vertebrae that bear 2341 pneumatic neural arches and zygopophyses with centra possessing dense cancellous bone 2342 (Figures 31-33). These shared features of the ischia, scapulae and caudal vertebrae have not been 2343 observed in combination with other members of the Titanosauria so could be considered 2344 synapomorphies that unite the Australian taxa. In addition, we observe that all of the known 2345 sauropod anterior and middle caudal vertebrae from the Winton Formation, both northern and 2346 southern-central sites are ubiquitously amphicoelous (Figures 29, 31-33). Although most of the 2347 isolated caudal vertebrae are not taxonomically allocated to a known Australian taxon, it is 2348 revealing that they are among the most common of the non-appendicular elements preserved in 2349 the Winton Formation, and yet all of them are amphicoelous. This, although circumstantial, one 2350 could hypothesise that the anterior and middle caudal vertebrae of $D$. matildae and $A$. 2351 cooperensis were likely amphicoelous. Such a hypothesis is supported by the presence of 2352 amphicoelous middle and distal caudal vertebrae found at the referred localities of $A$. 2353 cooperensis (EML010 and EML012) (Figures 29, 31-33) and D. matildae (QML1333 / 2354 AODL127). Of note here is the lack of sauropod proceolous caudal vertebrae from the Winton 2355 Formation. Considering the global distribution of titanosaurian clades by the mid-Cretaceous, 
2356 and the presence of proceolous caudal vertebrae in taxa from most continents, it seems strikingly 2357 at odds with the observed amphicoelous-only caudal vertebrae from Australia.

2358 One feature currently distinguishing the anterior caudal vertebrae of S. elliottorum from $W$. 2359 wattsi is the presence in S. elliottorum of pneumatic fossae (Poropat et al. 2016). These fossae 2360 possess pneumatic pores that lead into the centrum; however, they do not enter a camellate 2361 internal structure, instead, the internal structure of the centrum is dense cancellous bone.

2362 Dorsally, large camellate internal structures are observable in cross-section, occurring within the 2363 neural arch and zygopophyses (Figure 31). The presence in anterior amphicoelous caudal 2364 vertebrae of pneumatic fossae, pores, pneumatic neural arches and zygopophyses, but with a 2365 solid cancellous bone centrum, are symplesiomorphic characteristics of titanosauriformes and 2366 lithostrotian titanosaurians (Mannion et al. 2017; Mannion et al. 2013; Wedel \& Taylor 2013; 2367 Whitlock et al. 2011). This suggests that the Australian taxa have uniquely retained 2368 symplesiomorphic features of the tail but possess derived titanosaurian to saltasaurid features of 2369 the appendicular skeleton. It would seem that all of the Australian taxa did not possess the 2370 derived proceolous caudal vertebrae of saltasaurid titanosaurians (Zurriaguz \& Cerda 2017).

2371 We CT scanned the anterior caudal vertebrae of $W$. wattsi that reveal the presence of pneumatic 2372 camellate chambers in the neural arch and zygopophyses with dense cancellous bone within the 2373 amphicoelous anterior caudal vertebra of this taxon (Figure $32 \& 33$ ). However, there is no clear 2374 indication of external pneumatic pores (Figure 32). Thus pneumaticity of the anterior caudal 2375 neural arch and zygopophyses paired with dense cancellous bone within the centrum is a 2376 characteristic feature now shared between $W$. wattsi and S. elliottorum.

2377 The placement of $W$. wattsi within the Titanosauria is contra previous assessments that found it 2378 to be a non-titanosaurian somphospondylan (Poropat et al. 2015a). However, a more recent 2379 analysis has it occupying a position either within the Titanosauria, as part of the 2380 'Andesauroidea', or as the sister-taxon to the Titanosauria clade (Mannion et al. 2019a). We 2381 recognise the very poor state of preservation in $W$. wattsi which likely contributes to this unstable 2382 phylogenetic position, with less than $50 \%$ of the characters considered here available in the 2383 holotype. However, based on the similarities shared with the other Winton Formation taxa and 2384 our preliminary computational phylogenetic analysis supporting, albeit poorly, a more derived 2385 position of $W$. wattsi with the other Australian taxa (Supplementary Figure 1), we propose that $2386 W$. wattsi should be grouped with the three other Winton Formation taxa, within Titanosauria. 
2387 Refinement of the characters and scoring of the Australian taxa for each of the three separate 2388 phylogenetic assessments (D'Emic 2012; Gonzalez Riga et al. 2016; Mannion et al. 2013) along 2389 with statistical testing of an Australian clade would test this proposal and will be undertaken as 2390 new better preserved specimens come to light.

2391 Recent support for a clade containing D. matildae and S. elliottorum has been advocated 2392 (Poropat et al. 2021; Poropat et al. 2020) with the proposed clade name 'Diamantinasauria'. As 2393 we have demonstrated above, A. cooperensis and $W$. wattsi also show similarities to each other 2394 and with D. matildae and S. elliottorum. All four possess a mosaic of features with some 2395 possibly uniting them all in a single clade. We, therefore, expand a hypothesised Australian clade 2396 to include all four taxa.

2397 Our preliminary computational phylogenetic assessment provides some support for a hypothesis 2398 of a common ancestry for all four Australian taxa (Supplementary Information). Our assessment 2399 of the phylogenetic position of $A$. cooperensis, using the datasets and protocols from two recent analyses (Poropat et al. 2021; Royo-Torres et al. 2020), along with various a priori exclusions of characters and taxa, supports a clade containing at least Australotitan, Diamantinasaurus and Savannasaurus (Supplementary Figure 1. A, C, D, E, G, H, L, M \& N). The position of Wintonotitan was variably resolved as either basal to the 'Australian' clade (Supplementary Figure 1. C, E \& G) or derived within the 'Australian' clade (Supplementary Figure 1. D, H, I, L, $M \& N)$. Some assessments did not resolve the topology of the Australian taxa at all, resulting in large polytomies with no support (Supplementary Figure 1. B, F, J \& K). A priori weighting of characters resolved more clades compared to unweighted analyses; however, it did not impact the overall membership of the Australia clade, or those non-Australian (e.g. Asian or South American) clades or lineages associated with these taxa. Of the fourteen topologies produced from our assessment, only half (seven) resolved the positions of all four Australian taxa. Of 2411 these, four resolved a clade containing all four Australian taxa within Titanosauria, and three did 2412 not. Therefore, the computational phylogenetic assessment does not unequivocally resolve the 2413 positions of all of the Australian taxa, or specifically the position of $W$. wattsi.

2414 Of note in these results is the relative placement of taxa from South America and Asia to those 2415 from Australia (Supplementary Figure 1). 'Diamantinasauria' has recently been proposed to 2416 name a clade that includes two Australian taxa (Diamantinasaurus and Savannasaurus) and one 2417 South American taxon Sarmientosaurus, to the exclusion of Wintonotitan (Poropat et al. 2021). 
2418 The implication of this clade was to conclude that it supports biogeographic interchange between 2419 Australia and South America (Poropat et al. 2021). In their assessment, 'Diamantinasauria' sits 2420 nested between an Asian sister-clade comprised of Dongyangosaurus and Boatianmansaurus, 2421 and a derived Asian clade comprised of Xianshanosaurus and Daxiatitan. Our assessment used 2422 their phylogenetic dataset, but added A. cooperensis and some changes to the character-state 2423 scores for Wintontitan, Savannasaurus and Diamantinasaurus. The resulting topology is not 2424 altered from their assessment, other than to add Australotitan into the proposed

2425 'Diamantinasauria' clade. This would lend support to an Australian-South American clade to the 2426 exclusion of Wintonotitan.

2427 Contrary to this, our resulting strict consensus tree, based on the phylogenetic dataset of Royo2428 Torres et al. (2020) retains a similar topology that includes the Asian taxa of Dongyangosaurus 2429 and Boatianmansaurus within a clade including Diamantinasaurus. This results in an

2430 'Australian-Asian' clade to the exclusion of South American taxa, which is contrary to the 2431 assessment above. Intriguingly, this 'Australian-Asian' clade is nested between the South 2432 American sister taxon, Rinconsaurus, and the closest derived taxon, the South American 2433 Muyelensaurus. This essentially describes the mirror opposite of the result above.

2434 In addition, our resulting strict consensus tree moved Savannasaurus into this 'Australian-Asian' 2435 clade, along with Australotitan and Wintonotitan (Supplementary Figure 1. D, H, L, M, N). No 2436 South American taxa were recovered within this 'Australian-Asian' clade. Similar results were 2437 returned when we used only appendicular characters, or when we excluded taxa younger than 2438 Turonian in age (Supplementary Figure 1. I, J, L, M, N).

2439 In summary, our use of two different datasets, that were initially based from the same original 2440 character sets (Mannion et al. 2013; Mannion et al. 2019b) returned some support for an 2441 Australian clade, comprising either all four or at least three of the four Australian taxa. Our 2442 results retain the non-Australian membership associated with the 'Australian clade' for each of 2443 the assessments, creating two potentially opposing phylogenetic hypotheses: 1) An 'Australian2444 South American' clade that is nested between Asian lineages; and 2) An 'Australian-Asian' 2445 clade nested between South American lineages. The conclusions drawn from these resultant 2446 hypotheses could argue for either faunal interchange between Australia and South America, or 2447 between Australia and Asia, with ancestral and descendant lineages occuring in either South 2448 America, Asia or Australia. 
2449 The caveates of both assessments include poor within-clade and between-clade resolution, and 2450 most importantly, limited statistical support. However, these opposing phylogenetic topologies 2451 could be reconciled if dispersal between all three continents, via Australia, occurred, thus 2452 allowing the opportunity for the presence of related taxa from all three regions occuring in 2453 Australia during the Early to mid-Cretaceous.

2454 Firstly, faunal interchange between South America and Australia, hypothesised to have occurred 2455 via Antarctica, evokes long distance terrestrial dispersal, possibly during a period of mid2456 Cretaceous global warming (Poropat et al. 2016). Faunal interchange between Asia and Australia 2457 evokes long distance oceanic dispersal, which at face value seems unlikely. However, recent 2458 analyses of terrestrial vertebrates demonstrates that long-distance dispersal over oceans is 2459 possible and can occur upwards of 100s to 1000s of kilometers between landmasses (Blom et al. 2460 2019; de Queiroz 2005; Gerlach et al. 2006; Hawlitschek et al. 2017). In addition to these 2461 modern examples of faunal oceanic interchange, dinosaurs, including titanosaurians, have 2462 recently been proposed to have dispersed across oceanic barriers (Longrich et al. 2021).

2463 During the Early to mid-Cretaceous, the significant distance between the Australian continental 2464 landmass and that of Asia seems an unlikely source of faunal interchange. However, recent 2465 geological evidence with tectonic and palaeogeographic modelling has advanced the presence of 2466 a number of intra-oceanic terranes and island arc provinces within the Neo and Meso-Tethys 2467 regions, occuring between Australia and Asia during the Early to mid-Cretaceous. Potential 2468 oceanic 'stepping stones' include the East Java - West Suluwesi and the Sikuleh and Natal 2469 continental fragments, the Sepik Terrane, a proto-Philippine Sea Plate oceanic island arc and the 2470 Incertus and Woyla arcs (Deng et al. 2020; Dimalanta et al. 2020; Hall 2012; Rodrigo et al. 2471 2020; Zahirovic et al. 2016).

2472 We speculate that if such oceanic regions had associated subaerial islands, they might have 2473 provided enough terrain to allow oceanic interchange between Asia and Australia for the largest 2474 terrestrial vertebrates of that time, the titanosaurians. Speculative conclusions, such as those 2475 proposed here, look to reconcile conflicting phylogenetic hypotheses; however, such conflicts in 2476 phylogenetic results more likely reiterate the lack of refined character signals within 2477 titanosaurian phylogenetics. Therefore, until much more refined phylogenies are developed, 2478 biogeographical hypotheses will remain equivocal. 
2480 Body-size and palaeoenvironment of sauropods in the Winton Formation. Regardless of

2481 their phylogenetic relationship, the presence of four recognized sauropod taxa within the Winton

2482 Formation is not unsurprising considering the diversity of sauropod taxa from similar ages and

2483 latitudes (de Jesus Faria et al. 2015). In South America, seven to nine sauropod taxa are known

2484 from the Cenomanian of Argentina, covering a geographical range of approximately 700-1000

$2485 \mathrm{~km}$, similar to that between the northern and southern-central Winton Formation. However,

2486 proposing a framework of explanations for the diversity of the sauropods from the Winton

2487 Formation is still needed.

2488 Firstly, there is a large difference in maximal limb element size between taxa from the northern

2489 and southern-central Winton Formation (Figure $34 \& 35$ ). Secondly, the relative proportions of

2490 these limb elements, as a proxy of body-height, differ when also considering pelvic width, as a

2491 proxy of body-width. Thirdly, each taxon possesses a combination of features of each preserved

2492 limb that seems contrary to what would be expected.

2493 The appendicular elements of the holotype of $A$. cooperensis, in particular the humerus, ulna and

2494 femur, represent the largest appendicular bones so far recovered of any described Australian

2495 dinosaur (Figures 34-36) (Tables 2-7 and 10). In addition, the referred fragmentary femur,

2496 EMF164, represents an even larger individual (Table 10).

2497 An unassigned isolated large sauropod femur (QMF43302 from QML1333) represents the

2498 largest sauropod appendicular element from the northern Winton Formation (Figures 25, J-O, 26

$2499 \& 35)$. This femur is separated into three sections, including a proximal femoral head, a

2500 mediolaterally-crushed and fragmented diaphysis, and a partial distal epiphysis that is missing

2501 the distal condyles. Preserved plant debris cover the broken and missing pieces of the proximal

2502 and distal epiphyses indicating that this specimen underwent considerable transport and abrasion

2503 prior to burial and exposure. The distal condyles were broken off and lost prior to burial, whilst

2504 the proximal head was damaged, which removed 10-20 $\mathrm{mm}$ of cortical bone from around the

2505 proximal articular region of the greater trochanter to the femoral head. QMF43302 measures

$25061505.68 \mathrm{~mm}$ in preserved proximodistal length, and we estimate that with the missing regions

2507 added, this would make a total length of approximately $1600 \mathrm{~mm}$ (Table 7). This is

2508 approximately $250+\mathrm{mm}$ shorter than the reconstructed length of EMF102 and approximately

$2509450+$ mm shorter than the estimated length of EMF164 (Table 10). 
2510 Proximally, the femoral head is proportionately more robust than the femora seen in $A$.

2511 cooperensis, but similar to that seen in D. matildae. The anterior face of the diaphysis is heavily

2512 broken up into mosaic pieces, which obscures the identification of a longitudinal ridge on the

2513 anterior face of the shaft (linea intermuscularis cranialis), which would assist in referring the

2514 femur to $A$. cooperensis or D. matildae. Close inspection of the diaphyseal surface suggests that

2515 there is no sign of a ridge, which would then ally the femur closest to D. matildae, noting that the

2516 femur of $W$. wattsi and S. elliottorum are currently unknown. A partial sauropod skeleton

2517 (AODF836), referred to D. matildae (Poropat et al. 2016), was found $250 \mathrm{~m}$ to the northwest of

2518 QMF43302 (QML1333). This sauropod skeleton does not possess a femur, however, there is no

2519 evidence to demonstrate that these remains are associated with the QMF43302 femur.

2520 When the holotype femur of D. matildae is compared to QMF43302 it shares the straight and

2521 narrow diaphyseal shaft and bulbous proximal head, in contrast to A. cooperensis (Figure $35 \mathrm{H}$,

2522 I, O \& P). However, when isometrically scaled to equal the minimum mediolateral width of $D$.

2523 matildae, the femoral outline of QMF43302 is proportionately taller (Figure 30, Q). Therefore,

2524 although QMF43302 is morphologically most similar to D. matildae in comparison to all of the

2525 southern-central Winton Formation femora described here, it remains morphologically distinct.

2526 When considering the two other possible candidate taxa that QMF43302 could be assigned to, $W$.

2527 wattsi and S. elliottorum, either have preserved femora. $W$. wattsi possesses a proportionately

2528 gracile and long humerus (Figures 15, 30, 35, B) and this may reflect a much larger body-size,

2529 similar to that of the femur. S. elliottorum and D. matildae both have proportionately stocky and

2530 robust humeri than $W$. wattsi. W. wattsi represents the largest named sauropod taxon from the

2531 northern Winton Formation, based on limb element and ischial size. Therefore, it is conceivable

2532 that QMF43302 represents a femur of $W$. wattsi. If true, this assignment would place $W$. wattsi

2533 close to the remains of a specimen referred to D. matildae, albeit not directly associated with its

2534 skeleton at QML1333.

2535 When comparing linear measurements (preserved, reconstructed and estimated) of all of the

2536 appendicular elements for all four Cretaceous Australian taxa, A. cooperensis has the longest

2537 scapula, humerus, ulna, pubis and femur (Table 10). Although the ischium of $A$. cooperensis is

2538 the largest ischium based on preserved length, the ischium of $W$. wattsi holotype is near its size

2539 with a thicker blade along its preserved length. $W$. wattsi is missing the proximal articular end of

2540 the iliac peduncle, acetabular rim, and the mediodistal margin of the ischial symphysis, therefore, 
2541 depending on how much of the ischium is missing, $W$. wattsi could have an ischium of the same 2542 size, if not marginally larger, than A. cooperensis.

2543 The humeri and ulnae of $W$. wattsi are poorly preserved, with all elements missing either both

2544 epiphyses or when preserved, missing most of the articular surfaces. This means that the longest 2545 linear proximodistal length for these elements are underestimates of the length of the bones. 2546 Using the same better-preserved elements in D. matildae as a guide, we were able to align and 2547 scale the 3-D model of D. matildae limb elements to that of $W$. wattsi to provide a prediction of 2548 length. The humerus of $W$. wattsi returned an estimated proximodistal length of $1253 \mathrm{~mm}$ whilst 2549 the ulna was estimated to measure $919 \mathrm{~mm}$. The longest preserved length of ulnae is $897 \mathrm{~mm}$, 2550 some $22 \mathrm{~mm}$ shorter than the estimate; therefore, we suspect about 20-50 mm of length has been 2551 lost of the proximal and distal epiphyses.

2552 We also estimated the length of the humerus from S. elliottorum by isometrically scaling the 2553 complete 3-D model of the humerus of D. matildae to the preserved humerus shape of $S$. 2554 elliottorum, to return an estimated maximum length of $1112 \mathrm{~mm}$. S. elliottorum does not 2555 preserve an ulna or femur so cannot be compared to these appendicular elements.

2556 Considering the sizes of the best comparable elements across the four taxa in relation to 2557 columnar limb elements (i.e. humerus, ulna and femur), A. cooperensis represents overall the 2558 largest taxon, but more specifically the taxon with the longest limbs (Table 10). W. wattsi was 2559 second tallest, whilst D. matildae and S. elliottorum had the shortest limbs and most robust 2560 stature.

2561 When comparing the overall pelvic floor between each taxon, as a proxy of body-width, it is 2562 evident that A. cooperensis had the deepest and widest pelvis in absolute size (Figure 22) (Tables 2563 $5,6 \& 11)$. We cannot reconstruct the pelvis of $W$. wattsi because it is missing the pubes and the medial most portion of the ischial contact. However, the ischium is so close in size and similar in 2565 morphology to both A. cooperensis and D. matildae (Figure 30, M-O) that we would expect the pelvic floor to be proportionately as deep as both of these taxa, and impressively, as large and as wide as that of A. cooperensis. S. elliottorum shows a relatively broader and shallower pelvis 2568 (Figure $22 \& 30$ ). Although this feature looks to be a real and unique feature of S. elliottorum, 2569 there are some areas at, and below, the position of the iliac peduncles of both the pubis and 2570 ischium that may reflect vertical taphonomic compression. If so, this compression would 2571 artificially reduce the pelvic floor depth creating what would seem to be a shallow appearance in 
2572 anterior or posterior views (Figure 22). Large dorsal vertebrae from the skeleton were found 2573 directly above the puboischial complex, and the humerus and ribs also show signs of directional 2574 crushing and distortion. Therefore, taphonomic alteration via trampling is possible thus altering 2575 the pelvic dorsoventral profile.

2576 Each limb segment for the four taxa present unexpected combinations that do not intuitively 2577 correspond with one another, nor can they be easily considered part of a morphocline. $A$.

2578 cooperensis is clearly the largest taxon; however, it both possesses the most lightly built and 2579 gracile scapula, ulna and puboischial complex, but with massive and solidly built humeri and 2580 femora. $W$. wattsi is the second largest taxon with the most solidly built scapulae and ischia, and 2581 most robust ulnae in midshaft cross-section, but the least rotund humeri. D. matildae and $S$. elliottorum both possess equally stocky humeri and D. matildae the stockiest ulnae. However, $S$. 2583 elliottorum possesses a very broad, shallow and lightly built, but completely fused puboischial 2584 complex.

2585 This somewhat contrary mosaic of characteristics for each taxon impedes explanations of 2586 adaptative ecology or as part of a morphocline. Whether or not these features represent 2587 adaptations of body-size, sexual dimorphism, locomotion, habitat (terrestrial versus semi2588 aquatic) and/or feeding strategies are all areas of potential explanation, but are all equally 2589 confounded by a lack of phylogenetic, temporal and environmental resolution. Simplistic 2590 explanations using modern ecological analogies cannot be argued for any of the Winton 2591 Formation sauropod taxa without a detailed understanding of the environmental context in which 2592 each taxon lived, which is severely lacking at present.

2593 The very poor stratigraphic and temporal context of the Australian sauropod type localities as 2594 discussed above means that we cannot easily explain the taxonomic diversity in a temporal 2595 context. Based on our current understanding of the relative stratigraphic positions of the 2596 sauropod taxa within the Winton Formation we propose that D. matildae occurs within $100 \mathrm{~m}$ of 2597 the Winton Formation base, as represented by AODF836, to up to at least $350 \mathrm{~m}$ from the base, 2598 as represented by the type specimen AODF604. Similarly, W. wattsi occurs within the $100 \mathrm{~m}$ of 2599 the Winton Formation base on the tentative identification of a single poorly preserved femur, 2600 QMF43302, up to at least $350 \mathrm{~m}$, as represented by the type specimen, QMF7292. Together, this 2601 suggests that these two taxa co-occurred throughout the basal $350 \mathrm{~m}$ of the northern Winton 2602 Formation. S. elliottorum is only known from the type specimen AODF660 which sits within 100 
$2603 \mathrm{~m}$ of the northern Winton Formation base, whilst $A$. cooperensis is only known from sites that 2604 occur between 270-300 m of the southern-central Winton Formation base. It is therefore unlikely 2605 that all four taxa represent a single chronocline, with some tenuous evidence for three taxa co2606 occurring during the deposition of the basal $100 \mathrm{~m}$ of the northern Winton Formation. However, 2607 there is no definitive evidence demonstrating that any of these taxa were sympatric, with no 2608 single site demonstrably showing more than one taxon in a single bonebed. Therefore, we cannot 2609 definitively place these taxa together with each other at any singular place or time.

2610 The distinctive taphonomic differences observed between sites in the northern and southern2611 central Winton Formation may provide some clues to palaeoenvironmental differences that could 2612 have created enough difference in habitat to select for varying types of megaherbivorous 2613 sauropods. The absence of abundant or diverse aquatic fauna, in particular, freshwater insect 2614 larvae, freshwater bivalves and snails, crustaceans, fish, lungfish and crocodilians along with the 2615 presence of scoured and highly trampled silty-muddy surfaces absent of developed palaeosols, 2616 suggests a highly labile sedimentary and turbid aquatic environment in the southern-central 2617 Winton Formation sites, compared to the northern Winton Formation sites. These observed 2618 differences could be geochronological, but note the caution we discuss above. If 2619 geochronological, the differences could represent a succession of palaeoenvironmental changes 2620 as the basin fills, with the reduction of topographic relief and development of new freshwater 2621 environments with areas likely terraformed by the largest of the sauropod taxa. If the sites are 2622 contemporaneous, then these differences could be due to regional hydroclimatic differences, 2623 perhaps relating to the distance of the southern-central Winton Formation environments from the 2624 topographically higher watershed to the east.

2625 The greater diversity of flora and aquatic fauna in the northern Winton Formation points to a less 2626 turbid and more stable habitat with a greater diversity of vegetation both in terms of taxa and 2627 structure. The proximity of the northern Winton Formation sites to a greater diversity of older 2628 terrestrial and stable terrain provides another source of geographical diversity that would have 2629 likely been a source of biological diversity proximal to the northern Winton Formation but distal 2630 to the southern-central Winton Formation sites (Harrington et al. 2019).

2631 We speculate that a spatiotemporal ecocline developed from east to west, from the eastern basin 2632 periphery and drainage topographic high to the center and topographic low. The basin rapidly 2633 filled with volcanoclastic input from the east and transitioned from low terrestrial vegetation 
2634 productivity (e.g. shallow / coastal marine habitats) to highly productive habitats (e.g. paralic to 2635 fluvial and lacustrine environments). Such labile and frequently disturbed environments were 2636 likely further disturbed by the sauropods themselves, and this was set within a backdrop of 2637 variable or seasonal local climate (Fletcher et al. 2018) and major mid-Cretaceous global 2638 climatic fluctuations (Hay 2011) associated with volcanism (Percival et al. 2020). Of not, a 2639 combination of frequent disturbance with climatic variability and instability has been proposed 2640 as a mechanism that maintained megaherbivore diversity of Quaternary megafauna (Mann et al. 2641 2018).

2642

2643 Body-size of Australotitan cooperensis relative to other giant titanosaurians. It is tempting to 2644 produce an estimate of body mass for $A$. cooperensis based on the preserved and reconstructed 2645 stylopodial circumferences and using formulae previously developed; however, due to the 2646 considerable uncertainty surrounding these formulae for estimating body mass, as discussed 2647 above in the Methods, we will not undertake this estimate. Instead, we can simply use limb-size 2648 alone as a way to compare the size of $A$. cooperensis to other sauropods globally. This is useful 2649 because A. cooperensis represents the first osteological evidence of a very large titanosaurian in 2650 Australia, of comparable size to taxa from other parts of the Gondwanan supercontinent (Otero et 2651 al., 2021).

2652 Humerus and femur lengths, along with humerus and femur circumferences from known taxa 2653 were plotted against the type specimen of $A$. cooperensis (EMF102) to see where this new 2654 Australian taxon falls in regards to the largest sauropods known from femora and humeri (Figure 2655 36). In a comparison of humerus length with circumference (Figure 36, A), A. cooperensis 2656 clusters with Dr. schrani, P. mayorum, Pa. stromeri and No. gonzalezparejasi. In comparison of 2657 femoral length with femoral circumference (Figure 36, B), A. cooperensis clusters with $D r$. 2658 schrani and Brachiosaurus altithorax. In comparison of femoral length with humeral length 2659 (Figure 36, C), A. cooperensis clusters with Futalognkosaurus dukei. Considering the larger 2660 referred femur (EMF164), our estimated femur length of this individual $2146 \mathrm{~mm}$, which would 2661 confirm the limb element size of A. cooperensis close to Dr. schrani and F. dukei, but smaller 2662 than P. mayorum. Body mass estimates for these two titanosaurians vary considerably, from a 2663 minimum estimate for $F$. dukei of $23601 \mathrm{~kg}$ to a maximum estimate for Dr. schrani of $74487 \mathrm{~kg}$ 
2664 (Campione \& Evans 2020). This reflects the uncertainty discussed above and thus demonstrates 2665 the issues relating to body mass estimation in extremely large tetrapods.

2666

2667

2668

2669

2670

2671

2672

2673

2674

2675

2676

2677

2678

2679

2680

2681

2682

2683

2684

2685

2686

2687

2688

2689

2690

2691

2692

2693

2694

\section{Conclusions}

A new dinosaurian fossil field from the southern-central Winton Formation (Eromanga Basin) has yielded a new giant titanosaurian sauropod, Australotitan cooperensis. It represents the largest dinosaur yet known from osteological remains in Australia and confirms the presence of gigantic titanosaurian sauropods in eastern Gondwana during the mid-Cretaceous. The currently described Winton Formation sauropod taxa share with titanosaurians from across the globe a highly fragmentary nature, which creates considerable ambiguity when searching for wellsupported phylogenetic placements for each taxon, or providing useful explanations for morphological and taxonomic diversity, along with inferred palaeobiogeography.

The creation of 3-D surface models from specimens has allowed the development of a coloured schematic as a new method for annotating directly onto the bones where features are not easily distinguished. In addition, the use of a range of 3-D alignment and rendering modes offers better geometric comparison whilst allowing the identification of taphonomic biases. These interpretations of taphonomic alteration and preservation are essential for successive morphological interpretations. Therefore, they need to be captured and communicated in 3-D on the digital models created. This will also allow these interpretations to be tested, re-interpreted, and new versions to be published in subsequent research. We see this method as providing a pathway to share all forms of interpretation undertaken on specimens within the context of a 3-D geometric cybertype of the original.

In a comparative approach, we used previously identified synapomorphic features of the appendicular skeleton and found that all four taxa could be classified as members of the Titanosauria and possibly as basal members of it, or as basal lithostrotians. Focusing on the shared preserved elements for the Winton Formation taxa, we found a mosaic of characteristics that differentiate them from each other and from taxa elsewhere. We also find a mosaic of appendicular features that are shared across titanosaurians of similar size or semicontemporaneous age, indicating that the appendicular skeleton is useful for taxonomic differentiation, but perhaps not as useful in reconciling greater phylogenetic resolution.

PeerJ reviewing PDF | (2020:11:55594:2:1:NEW 28 Mar 2021) 
2695 Other characteristics that are shared between the Winton Formation sauropod taxa; such as the 2696 shared morphology of the ischium in A. cooperensis, D. matildae and W. wattsi; shared 2697 pneumatic anterior caudal vertebrae in S. elliottorum and W. wattsi; and ubiquitous presence of 2698 amphicoelous caudal vertebrae from described and undescribed specimens allude to a shared 2699 common ancestry for all of the Winton Formation taxa. We, therefore, propose a hypothesis of 2700 common ancestry for all four taxa that diversified in Australia during the mid-Cretaceous. Our 2701 preliminary phylogenetic analyses provide some support for this hypothesis by finding resulting 2702 parsimonious hypotheses that include all four taxa within a clade. Such results support a recent 2703 naming of an Australian clade, the 'Diamantinasauria'. However, our assessments find conflict 2704 as to which non-Australian taxa are also shared within 'Diamantinasauria', with separate 2705 analyses supporting either South American or Asian taxa. Therefore, whether Diamantinasauria 2706 represents a stable clade remains to be seen. Considering that the Australian taxa might represent 2707 a single lineage or clade, we further speculate that the Australian clade could represent an 2708 adaptive response to new, rapidly changing environments developing across the Eromanga Basin 2709 during the deposition of the Winton Formation. As the basin filled, it would have transformed 2710 from an eperic epicontinental sea to complex paralic environments, through to vast, labile and 2711 frequently disturbed alluvial and lacustrine habitats. We speculate that such new and rapidly 2712 developing habitats drove the evolution of morphological diversity within the largest herbivores, 2713 the titanosaurians, as new opportunities appeared across the landscape. Alternatively, the taxa 2714 may reflect a complex morphocline or ecocline across variable environments already developed 2715 across the basin during the Cenomanian. We cannot completely rule out the presence of a species 2716 chronocline based on the current stratigraphic or chronological uncertainty of the identified 2717 sauropod taxa so far found. All explanations remain equivocal due to poor local and regional 2718 chronostratigraphic resolution we have demonstrated here. Notably, no Winton Formation 2719 sauropod taxa are verifiably sympatric. Future research should focus on building greater detail of 2720 the local stratigraphic and palaeoenvironmental context, for both previous and new sites, because 2721 until this is achieved, phylogenetic position alone will be of limited interpretative value in the 2722 evolution of Australia's largest terrestrial vertebrates.

2723 2724 2725

\section{Acknowledgements}


2726 We acknowledge and pay respect to the Wangkumura and Boonthamurra People on whose 2727 traditional lands these dinosaurs were discovered. We thank Wangkumura elder, Malcolm 2728 Ebsworth for his assistance and guidance during the fieldwork on Plevna Downs Station. We 2729 would like to acknowledge those who first contributed to this work, both in the field and 2730 laboratory, including, Joanne Wilkinson, Kristen Spring, Elizabeth Cannon, Jo Pegler, Scott 2731 Turner, Alex Cook, Ralph Molnar, Paul Sereno and the Mackenzie family, in particular Sandy 2732 (jnr) Mackenzie who found the first dinosaur bone.

2733 We thank all of the volunteers and supporters of the Queensland Museum and Eromanga Natural 2734 History Museum who have made significant contributions in the field and laboratory: Jim 2735 Macmillan, Maxine Macmillan, Stephen Tully, Annabel Tully, Tom Meakin, Janine Meakin, 2736 Scott Pegler, Denise O’Boyle, Jill Corrigan, June Gunn, Doug Miller, June Richardson, Joan 2737 Rasmussen, Angelica Wilson, Maria Zammitt, Graham Wilson, Clare Steele, Phil Wharton, 2738 Ursula Wharton, Jacki Erickson, Corey Richards, Laurie Beirne, Liz Towns, Pam Towns, Keith 2739 McGlashin, Pat Turner, Geoff Turner, Nan Mackenzie, Sandy (snr) Mackenzie, Jonathan Cramb, 2740 Susan Rigby, Noel Cannon, Wendy Groves, Kimberley Smith, Tanya Hudson, Louise 2741 McGowan, the Skinner family, and the Eromanga \& Quilpie Communities. We thank Nikki 2742 Newman and Queensland X-Ray for CT scanning the specimens described here. We thank 2743 Kristen Spring (QM), Trish Sloan and David Elliott (AAOD) for access to specimens for 2744 comparative purposes. SAH thanks Adamm Yates for his assistance with Winton Formation 2745 fossils from the Northern Territory. We thank Ralph Molnar, E. Martin Hechenleitner and a third 2746 anonymous reviewer for their useful insights that have subsequently improved this work. 2747

2748 Funding Statement - Field work, preparation and digital capture and processing was supported 2749 by Eromanga Natural History Museum, Outback Gondwana Foundation, Santos, Eromanga 2750 Earth Moving, Bill Pegler, Eromanga Contracting, IOR and Eagle Gallery, Queensland Museum, 2751 Queensland Museum Foundation, Project DIG and ARC Linkage Grant LP100100339. 
2760

2761

2762

2763

2764

2765

2766

2767

2768

2769

2770

2771

2772

2773

2774

2775

2776

2777

2778

2779

2780

2781

2782

2783

2784

2785

2786

2787

2788

2789

2790

2791

2792

2793

2794

2795

2796

2797

2798

2799

2800

2801

2802

2803

Allen CM, and Campbell IH. 2012. Identification and elimination of a matrix-induced systematic error in LA-ICP-MS 206Pb/238U dating of zircon. Chemical Geology 332-333:157-165. 10.1016/j.chemgeo.2012.09.038

Almond CS. 1983. Stratigraphic Drilling Report - GSQ Eromanga 1. Queensland Government Mining Journal 84:358-368.

Andersen T, Elburg MA, and Magwaza BNJE-SR. 2019. Sources of bias in detrital zircon geochronology: Discordance, concealed lead loss and common lead correction. 197:102899.

Balfe PE. 1978. Stratigraphic Drilling Report - Manuka 1. Queensland Government Mining Journal 70:258-269.

Bates KT, Falkingham PL, Macaulay S, Brassey C, and Maidment SC. 2015. Downsizing a giant: re-evaluating Dreadnoughtus body mass. Biol Lett 11:20150215. 10.1098/rsbl.2015.0215

Bates KT, Falkingham PL, Rarity F, Hodgetts D, Purslow A, and Manning PL. 2010. Application of high-resolution laser scanning and photogrammetric techniques to data acquisition, analysis and interpretation in palaeontology. Int Arch Photogramm Remote Sens Spat Inf Sci 38.

Bates KT, Manning PL, Hodgetts D, and Sellers WI. 2009. Estimating mass properties of dinosaurs using laser imaging and 3D computer modelling. PLoS One 4:e4532. 10.1371/journal.pone.0004532

Bates KT, Mannion PD, Falkingham PL, Brusatte SL, Hutchinson JR, Otero A, Sellers WI, Sullivan C, Stevens KA, and Allen V. 2016. Temporal and phylogenetic evolution of the sauropod dinosaur body plan. $R$ Soc Open Sci 3:150636. 10.1098/rsos.150636

Behrensmeyer AK. 1978. Taphonomic and ecologic information from bone weathering. Paleobiology 4:150-162.

Bell PR, Brougham T, Herne MC, Frauenfelder T, and Smith ET. 2019a. Fostoria dhimbangunmal, gen. et sp. nov., a new iguanodontian (Dinosauria, Ornithopoda) from the mid-Cretaceous of Lightning Ridge, New South Wales, Australia. Journal of Vertebrate Paleontology:e1564757.

Bell PR, Fanti F, Hart LJ, Milan LA, Craven SJ, Brougham T, and Smith E. 2019b. Revised geology, age, and vertebrate diversity of the dinosaur-bearing Griman Creek Formation (Cenomanian), Lightning Ridge, New South Wales, Australia. Palaeogeography, Palaeoclimatology, Palaeoecology 514:655-671.

Bell PR, Herne MC, Brougham T, and Smith ET. 2018. Ornithopod diversity in the Griman Creek Formation (Cenomanian), New South Wales, Australia. PeerJ 6:e6008.

Benson RB, Campione NE, Carrano MT, Mannion PD, Sullivan C, Upchurch P, and Evans DC. 2014. Rates of dinosaur body mass evolution indicate 170 million years of sustained ecological innovation on the avian stem lineage. PLoS Biol 12:e1001853. 10.1371/journal.pbio.1001853

Berrell RW, Alvarado-Ortega J, Yabumoto Y, and Salisbury SW. 2014. The first record of the ichthyodectiform fish Cladocyclus from eastern Gondwana: a new species from the Lower Cretaceous of Queensland, Australia. Acta Palaeontologica Polonica 59:903-920.

Bitelli G, Rinaudo F, Gonzalez-Aguilera D, and Grussenmeyer P. 2020. Data Acquisition and Processing in Cultural Heritage: ISPRS International Journal of Geo-Information.

Peer) reviewing PDF | (2020:11:55594:2:1:NEW 28 Mar 2021) 
2804

2805

2806

2807

2808

2809

2810

2811

2812

2813

2814

2815

2816

2817

2818

2819

2820

2821

2822

2823

2824

2825

2826

2827

2828

2829

2830

2831

2832

2833

2834

2835

2836

2837

2838

2839

2840

2841

2842

2843

2844

2845

2846

2847

2848

2849
Blom MPK, Matzke NJ, Bragg JG, Arida E, Austin CC, Backlin AR, Carretero MA, Fisher RN, Glaw F, Hathaway SA, Iskandar DT, McGuire JA, Karin BR, Reilly SB, Rittmeyer EN, Rocha S, Sanchez M, Stubbs AL, Vences M, and Moritz C. 2019. Habitat preference modulates trans-oceanic dispersal in a terrestrial vertebrate. Proc Biol Sci 286:20182575. 10.1098/rspb.2018.2575

Bonaparte J. 1996. Cretaceous tetrapods of Argentina. Münch Geowis Abhand 30:73-130.

Bonnan MF. 2004. Morphometric analysis of humerus and femur shape in Morrison sauropods: implications for functional morphology and paleobiology. Paleobiology 30:444-470.

Bonnan MF. 2007. Linear and geometric morphometric analysis of long bone scaling patterns in Jurassic neosauropod dinosaurs: their functional and paleobiological implications. Anat Rec (Hoboken) 290:1089-1111. 10.1002/ar.20578

Boothby P. 1989. DIO Navalla 1 Well Completion Report. Delhi Petroleum Pty Ltd. Report CR 20109. Brisbane, Queensland: Department of Natural Resources and Mines Queensland

Borsuk-Bialynicka M. 1977. A new camarasaurid sauropod Opisthocoelicaudia skarzynskii gen. n., sp. n. from the Upper Cretaceous of Mongolia. Palaeontologia Polonica 37:5-64.

Brecko J, and Mathys A. 2020. Handbook of best practice and standards for 2D+ and 3D imaging of natural history collections. European Journal of Taxonomy 623:1-115. https://doi.org/10.5852/ejt.2020.623

Britt BB, Eberth DA, Scheetz RD, Greenhalgh BW, and Stadtman KL. 2009. Taphonomy of debris-flow hosted dinosaur bonebeds at Dalton Wells, Utah (Lower Cretaceous, Cedar Mountain Formation, USA). Palaeogeography, Palaeoclimatology, Palaeoecology 280:1-22. 10.1016/j.palaeo.2009.06.004

Bryan SE, Cook A, Allen CM, Siegel C, Purdy D, Greentree J, and Uysal T. 2012. Early-mid Cretaceous tectonic evolution of eastern Gondwana: from silicic LIP magmatism to continental rupture. Episodes 35:142-152.

Callieri M, Ranzuglia G, Dellepiane M, Cignoni P, and Scopigno R. 2012. Meshlab as a complete open tool for the integration of photos and colour with high-resolution 3D geometry data. Comput Appl Quant Methods Archaeol:406-416.

Calvo JO, González-Riga BJ, and Porfiri JD. 2007a. A New Titanosaur Sauropod From The Late Cretaceous Of Neuquén, Patagonia, Argentina. Arquivos do Museu Nacional, Rio de Janeiro 65:485-504.

Calvo JO, and González Riga BJ. 2003. Rinconsaurus caudamirus gen. et sp. nov., a new titanosaurid (Dinosauria, Sauropoda) from the Late Cretaceous of Patagonia, Argentina. Revista geológica de Chile 30:333-353.

Calvo JO, Porfiri JD, Riga BJG, and Kellner AWA. 2007b. Anatomy of Futalognkosaurus dukei Calvo, Porfiri, González Riga \& Kellner, 2007 (Dinosauria, Titanosauridae) From The Neuquén Group (Late Cretaceous), Patagonia, Argentina. Arquivos do Museu Nacional, Rio de Janeiro 65:511-526.

Campione NE, and Evans DC. 2012. A universal scaling relationship between body mass and proximal limb bone dimensions in quadrupedal terrestrial tetrapods. BMC Biol 10:60. doi:10.1186/1741-7007-10-60

Campione NE, and Evans DC. 2020. The accuracy and precision of body mass estimation in non-avian dinosaurs. Biol Rev Camb Philos Soc 95:1759-1797. 10.1111/brv.12638

Carballido JL, Pol D, Cerda I, and Salgado L. 2011a. The osteology of Chubutisaurus insignis del Corro, 1975 (Dinosauria: Neosauropoda) from the 'middle'Cretaceous of central Patagonia, Argentina. Journal of Vertebrate Paleontology 31:93-110.

Peer) reviewing PDF | (2020:11:55594:2:1:NEW 28 Mar 2021) 
2850

2851

2852

2853

2854

2855

2856

2857

2858

2859

2860

2861

2862

2863

2864

2865

2866

2867

2868

2869

2870

2871

2872

2873

2874

2875

2876

2877

2878

2879

2880

2881

2882

2883

2884

2885

2886

2887

2888

2889

2890

2891

2892

2893

2894

2895

Carballido JL, Pol D, Otero A, Cerda IA, Salgado L, Garrido AC, Ramezani J, Cuneo NR, and Krause JM. 2017. A new giant titanosaur sheds light on body mass evolution among sauropod dinosaurs. Proc Biol Sci 284. 10.1098/rspb.2017.1219

Carballido JL, Rauhut OWM, Pol D, and Salgado L. 2011b. Osteology and phylogenetic relationships of Tehuelchesaurus benitezii (Dinosauria, Sauropoda) from the Upper Jurassic of Patagonia. Zoological Journal of the Linnean Society 163:605-662. 10.1111/j.1096-3642.2011.00723.x

Cignoni P, Callieri M, Corsini M, Dellepiane M, Ganovelli F, and Ranzuglia G. 2008. Meshlab: an open-source mesh processing tool. Eurographics Italian chapter conference. p 129136.

Cignoni P, Montani C, Rocchini C, Scopigno R, and Tarini M. 1999. Preserving attribute values on simplified meshes by resampling detail textures. The Visual Computer 15:519-539.

Cignoni P, Rocchini C, and Scopigno R. 1998. Metro: measuring error on simplified surfaces. Computer graphics forum: Wiley Online Library. p 167-174.

Cook A. 2005. First record of fossil freshwater gastropods within the Winton Formation. Memoirs of the Queensland Museum 51:406.

Cook AG, and Jell JS. 2013. Paleogene and Neogene. In: Jell PA, ed. Geology of Queensland. Brisbane, Queensland: Geological Survey of Queensland., 577-652.

Cook AG, McKellar JL, and Draper JJ. 2013. Post-orogenic Mesozoic basins and magmatism. In: Jell PA, ed. Geology of Queensland. Brisbane, Queensland: Geological Survey of Queensland, 515-576.

Coote SM. 1987. GSQ Blackall 2 - Preliminary Lithological and Composite Log. In: Queensland GSo, editor. Brisbane: Queensland Government.

Coutts DS, Matthews WA, and Hubbard SM. 2019. Assessment of widely used methods to derive depositional ages from detrital zircon populations. Geoscience Frontiers. 10.1016/j.gsf.2018.11.002

Curry Rogers K. 2009. The postcranial osteology of Rapetosaurus krausei (Sauropoda: Titanosauria) from the Late Cretaceous of Madagascar. Journal of Vertebrate Paleontology 29:1046-1086. 10.1671/039.029.0432

D'Emic MD. 2012. The early evolution of titanosauriform sauropod dinosaurs. Zoological Journal of the Linnean Society 166:624-671. 10.1111/j.1096-3642.2012.00853.x

D'Emic MD, Wilson JA, and Williamson TE. 2011. A sauropod dinosaur pes from the latest Cretaceous of North America and the validity of Alamosaurus sanjuanensis (Sauropoda, Titanosauria). Journal of Vertebrate Paleontology 31:1072-1079. $10.1080 / 02724634.2011 .595856$

Day RW, Whitaker WG, Murray CG, Wilson IH, and Grimes KG. 1983. Queensland Geology. A companion volume to the 1:2 500000 scale geological map (1975). Geological Survey of Queensland Publication 383.

de Jesus Faria CC, Riga BG, dos Anjos Candeiro CR, da Silva Marinho T, David LO, Simbras FM, Castanho RB, Muniz FP, and Gomes da Costa Pereira PVL. 2015. Cretaceous sauropod diversity and taxonomic succession in South America. Journal of South American Earth Sciences 61:154-163. 10.1016/j.jsames.2014.11.008

de Queiroz A. 2005. The resurrection of oceanic dispersal in historical biogeography. Trends Ecol Evol 20:68-73. 10.1016/j.tree.2004.11.006

Delhi Petroleum PL. 1966. Delhi-Santos Mt Howitt 1 Well Report. In: Queensland GSo, editor. Brisbane: Queensland Government.

Peer) reviewing PDF | (2020:11:55594:2:1:NEW 28 Mar 2021) 
2896

2897

2898

2899

2900

2901

2902

2903

2904

2905

2906

2907

2908

2909

2910

2911

2912

2913

2914

2915

2916

2917

2918

2919

2920

2921

2922

2923

2924

2925

2926

2927

2928

2929

2930

2931

2932

2933

2934

2935

2936

2937

2938

2939

2940
Delhi Petroleum PL. 1991. 1990 Oxley Seismic Survey ATP 259 Queensland Final Report. Delhi Petroleum Pty Ltd. Report CR 23106 Brisbane, Queensland: Department of Natural Resources and Mines Queensland.

Deng J, Yang X, Zartman RE, Qi H, Zhang L, Liu H, Zhang Z-f, Mastoi AS, Berador AEG, and Sun W. 2020. Early cretaceous transformation from Pacific to Neo-Tethys subduction in the SW Pacific Ocean: Constraints from Pb-Sr-Nd-Hf isotopes of the Philippine arc. Geochimica et Cosmochimica Acta 285:21-40. 10.1016/j.gca.2020.06.024

Dettmann ME, Clifford HT, and Peters M. 2009. Lovellea wintonensis gen. et sp. nov.- Early Cretaceous (late Albian), anatomically preserved, angiospermous flowers and fruits from the Winton Formation, western Queensland, Australia. Cretaceous Research 30:339-355. 10.1016/j.cretres.2008.07.015

Díaz VD. 2013. Revisión del dinosaurio saurópodo lirainosaurus astibiae (titanosauria) del cretácico superior de la península ibérica: comparación con otros titanosaurios del suroeste de europa. Hipótesis filogenéti. Universidad del País Vasco-Euskal Herriko Unibertsitatea.

Díaz VD, Suberbiola XP, and Sanz JL. 2013. Appendicular skeleton and dermal armour of the Late Cretaceous titanosaur Lirainosaurus astibiae (Dinosauria: Sauropoda) from Spain. Palaeontologia Electronica 16:1-18.

Dimalanta CB, Faustino-Eslava DV, Gabo-Ratio JAS, Marquez EJ, Padrones JT, Payot BD, Queaño KL, Ramos NT, and Yumul GP. 2020. Characterization of the proto-Philippine Sea Plate: Evidence from the emplaced oceanic lithospheric fragments along eastern Philippines. Geoscience Frontiers 11:3-21. 10.1016/j.gsf.2019.01.005

Draper JJ. 2002. Geology of the Cooper and Eromanga basins, Queensland: Department of Natural Resources and Mines.

Elliott D. 2004. In the name of Science. Australian Age of Dinosaurs:33-41.

Elliott D, and Cook A. 2004. A Bug's Life. Australian Age of Dinosaurs:13.

Espurt N, Callot JP, Totterdell J, Struckmeyer H, and Vially R. 2009. Interactions between continental breakup dynamics and large-scale delta system evolution: Insights from the Cretaceous Ceduna delta system, Bight Basin, Southern Australian margin. Tectonics 28.

Exoma Energy PL. 2013. Wardoo 1 Well Completion Report. In: Queensland GSo, editor. Brisbane: Queensland Government.

Exon NF, and Senior BR. 1976. The Cretaceous of the Eromanga and Surat Basins. BMR Journal of Australian Geology and Geophysics 1:33-50.

Faggotter S, Salisbury S, and Yabumoto Y. 2007. A new possible haleocomorph fish from the mid-Cretaceous (Albian-Cenomanian) Winton Formation of Isisford, central-western Queensland, Australia. 11th Conference on Australian Vertebrate Evolution, Palaeontology and Systematics, 2007: Geological Society of Australia. p 55-55.

Falkingham PL. 2012. Acquisition of high resolution three-dimensional models using free, opensource, photogrammetric software. Palaeontologia Electronica 15:15.

Filippi LS, García RA, and Garrido AC. 2011. A new titanosaur sauropod dinosaur from the Upper Cretaceous of North Patagonia, Argentina. Acta Palaeontologica Polonica 56:505520. 10.4202/app.2010.0019

Finlayson B. 1984. 1983-4 Gray Seismic Survey ATP 259 Queensland Final Report. Delhi Petroleum Pty Ltd. Report CR 15494. Brisbane, Queensland: Department of Natural Resources and Mines Queensland.

Peer) reviewing PDF | (2020:11:55594:2:1:NEW 28 Mar 2021) 
2941 Fletcher TL, Moss PT, and Salisbury SW. 2018. The palaeoenvironment of the Upper

2942

2943

2944

2945

2946

2947

2948

2949

2950

2951

2952

2953

2954

2955

2956

2957

2958

2959

2960

2961

2962

2963

2964

2965

2966

2967

2968

2969

2970

2971

2972

2973

2974

2975

2976

2977

2978

2979

2980

2981

2982

2983

2984

2985
Cretaceous (Cenomanian-Turonian) portion of the Winton Formation, Queensland, Australia. PeerJ 6:e5513. 10.7717/peerj.5513

Fletcher TL, and Salisbury SW. 2014. Probable oribatid mite (Acari: Oribatida) tunnels and faecal pellets in silicified conifer wood from the Upper Cretaceous (CenomanianTuronian) portion of the Winton Formation, central-western Queensland, Australia. Alcheringa: An Australasian Journal of Palaeontology 38:541-545.

Flynn MJ. 1985. 1984 Brahe Seismic Survey ATP 259 Queensland Final Report. Delhi Petroleum Pty Ltd. Report CR 16024 Brisbane, Queensland: Department of Natural Resources and Mines Queensland.

Forbes BG. 1966. The geology of the Marree 1:250 000 map area. South Australia Geological Survey, Report of Investigations 28.

Gallina PA, and Apesteguía S. 2015. Postcranial anatomy of Bonitasaura salgadoi (Sauropoda, Titanosauria) from the Late Cretaceous of Patagonia. Journal of Vertebrate Paleontology 35:e924957. 10.1080/02724634.2014.924957

Garrad D, and Russel T. 2014. Petroleum Geology and Prospectivity of ATP 927 CooperEromanga Basin, SW Queensland including the Interpretation of 2014 Reprocessed 2D Seismic Data. Real Energy Queensland Pty Ltd. Report CR 88747. Brisbane, Queensland: Department of Natural Resources and Mines Queensland.

Gauld T. 1981. DIO Wareena 1 Well Completion Report. Delhi Petroleum Pty Ltd. CR 9549. Brisbane, Queensland: Department of Natural Resources and Mines Queensland.

Gerlach J, Muir C, and Richmond MD. 2006. The first substantiated case of trans-oceanic tortoise dispersal. Journal of Natural History 40:2403-2408. 10.1080/00222930601058290

Gilmore CW. 1946. Reptilian fauna of the North Horn Formation of central Utah: US Government Printing Office.

Girardeau-Montaut D. 2016. CloudCompare. EDF R\&D Telecom ParisTech.

Goloboff PA, Farris JS, and Nixon KC. 2008. TNT, a free program for phylogenetic analysis. Cladistics 24:774-786. https://doi.org/10.1111/j.1096-0031.2008.00217.x

Gomani EM. 2005. Sauropod Dinosaurs from the Early Cretaceous of Malawi, Africa. Palaeontologia Electronica 8:1-37.

González Riga BJ, and Astini RA. 2007. Preservation of large titanosaur sauropods in overbank fluvial facies: A case study in the Cretaceous of Argentina. Journal of South American Earth Sciences 23:290-303. 10.1016/j.jsames.2007.02.005

González Riga BJ, and David LO. 2014. A new titanosaur (Dinosauria, Sauropoda) from the Upper Cretaceous (Cerro Lisandro Formation) of Mendoza Province, Argentina. Ameghiniana 51:3-25. 10.5710/amegh.26.12.1013.1889

Gonzalez Riga BJ, Lamanna MC, Ortiz David LD, Calvo JO, and Coria JP. 2016. A gigantic new dinosaur from Argentina and the evolution of the sauropod hind foot. Sci Rep 6:19165. 10.1038/srep19165

González Riga BJ, Lamanna MC, Otero A, David LDO, Kellner AWA, and Ibiricu LM. 2019. An overview of the appendicular skeletal anatomy of South American titanosaurian sauropods, with definition of a newly recognized clade. An Acad Bras Cienc 91.

Gonzàlez Riga BJ, Mannion PD, Poropat SF, Ortiz David LD, and Coria JP. 2018. Osteology of the Late Cretaceous Argentinean sauropod dinosaur Mendozasaurus neguyelap:

Peer] reviewing PDF | (2020:11:55594:2:1:NEW 28 Mar 2021) 
2986

2987

2988

2989

2990

2991

2992

2993

2994

2995

2996

2997

2998

2999

3000

3001

3002

3003

3004

3005

3006

3007

3008

3009

3010

3011

3012

3013

3014

3015

3016

3017

3018

3019

3020

3021

3022

3023

3024

3025

3026

3027

3028

3029

3030

implications for basal titanosaur relationships. Zoological Journal of the Linnean Society 184:136-181. 10.1093/zoolinnean/zlx103

Gorscak E, and O'Connor PM. 2019. A new African Titanosaurian Sauropod Dinosaur from the middle Cretaceous Galula Formation (Mtuka Member), Rukwa Rift Basin, Southwestern Tanzania. PLoS One 14:e0211412.

Grant CD, and Blackmore AV. 1991. Self mulching behavior in clay soils-Its definition and measurement. Soil Research 29:155-173.

Gray ARG, McKillop M, and McKellar JL. 2002. Eromanga Basin Stratigraphy. . In: Draper JJ, ed. Geology of the Cooper and Eromanga Basins, Queensland. Brisbane, Queensland: Queensland Department of Natural Resources and Mines., 55.

Greentree J. 2011. Palaeoenvironmental setting of dinosaur trackways in the context of the closing stages of Eromanga Basin evolution Honours Honours. Queensland University of Technology.

Hailu Y, Qiang J, Lamanna MC, Jinglu L, and Yinxian L. 2004. A titanosaurian sauropod dinosaur with opisthocoelous caudal vertebrae from the early Late Cretaceous of Liaoning Province, China. Acta Geologica Sinica 78:907-911.

Hall LS, Hill, A., Troup, A., Korsch, R., Radke, B., Nicoll, R. S., Palu, T., Wang, L. \& Stacey, A. 2015. Cooper Basin Architecture and Lithofacies: Regional Hydrocarbon Prospectivity of the Cooper Basin, Part 1. Canberra: Geoscience Australia.

Hall R. 2012. Late Jurassic-Cenozoic reconstructions of the Indonesian region and the Indian Ocean. Tectonophysics 570-571:1-41. 10.1016/j.tecto.2012.04.021

Harrington L, Zahirovic S, Salles T, Braz C, and Müller RD. 2019. Tectonic, geodynamic and surface process driving forces of Australia's paleogeography since the Jurassic. In: Keep M, and Moss SJ, editors. The Sedimentary Basins of Western Australia V: Proceedings of the Petroleum Exploration Society of Australia Symposium. Perth, WA. p 29.

Harris JD. 2007. The appendicular skeleton of Suuwassea emilieae (Sauropoda: Flagellicaudata) from the Upper Jurassic Morrison Formation of Montana (USA). Geobios 40:501-522. 10.1016/j.geobios.2006.02.002

Hawlitschek O, Ramirez Garrido S, and Glaw F. 2017. How marine currents influenced the widespread natural overseas dispersal of reptiles in the Western Indian Ocean region. Journal of Biogeography 44:1435-1440.

Hay WW. 2011. Can humans force a return to a 'Cretaceous' climate? Sedimentary Geology 235:5-26. 10.1016/j.sedgeo.2010.04.015

Hechenleitner EM, Leuzinger L, Martinelli AG, Rocher S, Fiorelli LE, Taborda JR, and Salgado L. 2020. Two Late Cretaceous sauropods reveal titanosaurian dispersal across South America. Communications Biology 3:1-13.

Helby R, Morgan RP, and Partridge AD. 1987. A palynological zonation of the Australian Mesozoic. Association of Australasian Palaeontologists Memoir 4:1-94.

Herne MC, Nair JP, Evans AR, and Tait AM. 2019. New small-bodied ornithopods (Dinosauria, Neornithischia) from the Early Cretaceous Wonthaggi Formation (Strzelecki Group) of the Australian-Antarctic rift system, with revision of Qantassaurus intrepidus Rich and Vickers-Rich, 1999. Journal of Paleontology 93:543-584.

Herne MC, Tait AM, Weisbecker V, Hall M, Nair JP, Cleeland M, and Salisbury SW. 2018. A new small-bodied ornithopod (Dinosauria, Ornithischia) from a deep, high-energy Early Cretaceous river of the Australian-Antarctic rift system. PeerJ 5:e4113. 
3031

3032

3033

3034

3035

3036

3037

3038

3039

3040

3041

3042

3043

3044

3045

3046

3047

3048

3049

3050

3051

3052

3053

3054

3055

3056

3057

3058

3059

3060

3061

3062

3063

3064

3065

3066

3067

3068

3069

3070

3071

3072

3073

3074

Hocknull S. 1997. Cretaceous freshwater bivalves from Queensland. Memoirs of the Queensland Museum 42:223-226.

Hocknull S. 2000. Mesozoic freshwater and estuarine bivalves from Australia. Memoirs of the Queensland Museum 45:405-426.

Hocknull S. 2005. Poor Wally. Australian Age of Dinosaurs Museum of Natural History 3:66-83. Hocknull S, and Cook A. 2008. Hypsilophodontid (Dinosauria: Ornithischia) from latest Albian, Winton Formation, central Queensland. Memoirs of the Queensland Museum 52:212.

Hocknull SA, Lewis R, Arnold LJ, Pietsch T, Joannes-Boyau R, Price GJ, Moss P, Wood R, Dosseto A, and Louys J. 2020. Extinction of eastern Sahul megafauna coincides with sustained environmental deterioration. Nat Commun 11:1-14.

Hocknull SA, White MA, Tischler TR, Cook AG, Calleja ND, Sloan T, and Elliott DA. 2009. New Mid-Cretaceous (Latest Albian) Dinosaurs from Winton, Queensland, Australia (New Australian Dinosaurs). PLoS One 4:e6190. 10.1371/journal.pone.0006190

Hocknull SA, Wilkinson M, Lawrence RA, Newman N, and R. M. 2019. On the shoulders of titans: Introducing new Cretaceous dinosaur fossil fields from Southwest Queensland, Australia, and demonstrating the utility of scanning (surface and CT) in taphonomic and ichnofossil interpretation. Society of Vertebrate Paleontology. Brisbane: Journal of Vertebrate Paleontology, Program and Abstracts. p 119.

Hocknull SA, Zhao J-X, Feng Y-X, and Webb GE. 2007. Responses of Quaternary rainforest vertebrates to climate change in Australia. Earth and Planetary Science Letters 264:317331. 10.1016/j.eps1.2007.10.004

Hoffman KL, and Brain TJ. 1991. Stratigraphic Drilling Report - GSQ McKinlay 1. In: Queensland GSo, editor. Brisbane: Queensland Government.

Hoffmann KL. 1989. The influence of pre-Jurassic tectonic regimes on the structural development of the southern Eromanga Basin, Queensland. Proceedings of the Cooper and Eromanga Basins Conference: Petroleum Exploration Society of Australia. p 315.

Hollands CB, Nanson GC, Jones BG, Bristow CS, Price DM, and Pietsch TJ. 2006. Aeolianfluvial interaction: evidence for Late Quaternary channel change and wind-rift linear dune formation in the northwestern Simpson Desert, Australia. Quaternary Science Reviews 25:142-162. 10.1016/j.quascirev.2005.02.007

Horstwood MSA, Košler J, Gehrels G, Jackson SE, McLean NM, Paton C, Pearson NJ, Sircombe K, Sylvester P, Vermeesch P, Bowring JF, Condon DJ, and Schoene B. 2016. Community-Derived Standards for LA-ICP-MS U-(Th-)Pb Geochronology - Uncertainty Propagation, Age Interpretation and Data Reporting. Geostandards and Geoanalytical Research 40:311-332. 10.1111/j.1751-908X.2016.00379.x

Idnurm M, and Senoir BR. 1978. Palaeomagnetic ages of Late Cretaceous and Tertiary weathered profiles in the Eromanga Basin, Queensland. Palaeogeography, Palaeoclimatology, Palaeoecology 24:263-277. https://doi.org/10.1016/00310182(78)90010-X

Ingram JA. 1971. Eromanga, Qld Geological Map Sheet SG/54-12 1:250 000 Geological SeriesExplanatory Notes. Bureau of Mineral Resources Geology and Geophysics 1.

Jell PA. 2004. Fossil insects of Australia. Memoirs of the Queensland Museum 50:1-124.

Johnstone S, Schwartz T, and Holm-Denoma C. 2019. A Stratigraphic Approach to Inferring Depositional Ages From Detrital Geochronology Data. Front. Earth Sci 7:57.

Peer) reviewing PDF | (2020:11:55594:2:1:NEW 28 Mar 2021) 
3075

3076

3077

3078

3079

3080

3081

3082

3083

3084

3085

3086

3087

3088

3089

3090

3091

3092

3093

3094

3095

3096

3097

3098

3099

3100

3101

3102

3103

3104

3105

3106

3107

3108

3109

3110

3111

3112

3113

3114

3115

3116

3117

3118

3119

Juárez Valieri RD, and Calvo JO. 2011. Revision of MUCPv 204, a Senonian basal titanosaur from Northern Patagonia. . Paleontología y dinosarios desde América Latina. Mendoza: Editorial de la Universidad Nacional de Cuyo, Mendoza, 143-152.

Junchang L, Azuma Y, Rongjun C, Wenjie Z, and Xingsheng J. 2008. A new titanosauriform sauropod from the early Late Cretaceous of Dongyang, Zhejiang Province. Acta Geologica Sinica-English Edition 82:225-235.

Junchang L, Li X, Xingliao Z, Weiyong H, Yanhua W, Songhai J, and Qiang J. 2007. A new gigantic sauropod dinosaur with the deepest known body cavity from the Cretaceous of Asia. Acta Geologica Sinica-English Edition 81:167-176.

Kazhdan M, and Hoppe H. 2013. Screened poisson surface reconstruction. ACM Transactions on Graphics 32:1-13.

Keany M, Holford S, and Bunch M. 2016. Constraining Late Cretaceous exhumation in the Eromanga Basin using sonic velocity data. The APPEA Journal 56:101-126. https://doi.org/10.1071/AJ15009

Kemp A. 1991. Australian Mesozoic and Cainozoic lungfish. In: Vickers-Rich P, Monaghan JM, Baird RF, and Rich TH, eds. Vertebrate palaeontology of Australasia. Melbourne, Victoria: Monash University, 465-496.

Kemp A. 1997. Four species of Metaceratodus (Osteichthyes: Dipnoi, Family Ceratodontidae) from Australian Mesozoic and Cenozoic deposits. Journal of Vertebrate Paleontology 17:26-33.

Kilbourne BM, and Makovicky PJ. 2010. Limb bone allometry during postnatal ontogeny in non-avian dinosaurs. J Anat 217:135-152.

King S, and Mee B. 2004. The seismic stratigraphy and petroleum potential of the Late Cretaceous Ceduna Delta, Ceduna Sub-basin, Great Australian Bight. PESA Eastern Australasian Basins Symposium II. Adelaide, 19- 22 September, 2004: Petroleum Exploration Society of Australia (PESA).

Klötzli U, Klötzli E, Günes Z, and Kosler J. 2009. Accuracy of laser ablation U-Pb zircon dating: Results from a test using five different reference zircons. Geostandards and Geoanalytical Research 33:5-15.

Košler J, Sláma J, Belousova E, Corfu F, Gehrels GE, Gerdes A, Horstwood MS, Sircombe KN, Sylvester PJ, and Tiepolo M. 2013. U-Pb detrital zircon analysis-Results of an inter-laboratory comparison. Geostandards and Geoanalytical Research 37:243-259.

Kreutzer LA. 1988. Megafaunal butchering at Lubbock Lake, Texas: a taphonomic reanalysis. Quaternary Research 30:221-231.

Krieg GW, Callen RA, Gravestock DI, and Gatehouse CG. 1990. Geology. In: Tyler MJ, Twidale CR, Davies M, and Wells CB, eds. Natural History of the Northern Deserts. Adelaid, South Australia: Royal Society of South Australia Occassional Publications, 126.

Lacovara KJ, Lamanna MC, Ibiricu LM, Poole JC, Schroeter ER, Ullmann PV, Voegele KK, Boles ZM, Carter AM, Fowler EK, Egerton VM, Moyer AE, Coughenour CL, Schein JP, Harris JD, Martinez RD, and Novas FE. 2014. A gigantic, exceptionally complete titanosaurian sauropod dinosaur from southern Patagonia, Argentina. Sci Rep 4:6196. 10.1038/srep06196

Lautenschlager S. 2016. Reconstructing the past: methods and techniques for the digital restoration of fossils. $R$ Soc Open Sci 3:160342. 10.1098/rsos. 160342

Peer] reviewing PDF | (2020:11:55594:2:1:NEW 28 Mar 2021) 
3120

3121

3122

3123

3124

3125

3126

3127

3128

3129

3130

3131

3132

3133

3134

3135

3136

3137

3138

3139

3140

3141

3142

3143

3144

3145

3146

3147

3148

3149

3150

3151

3152

3153

3154

3155

3156

3157

3158

3159

3160

3161

3162

3163

3164

Lawrence MG. 1998. SSL Wareena 4 Well Completion Report. Santos Ltd. ReportCR 30831. Brisbane, Queensland: Department of Natural Resources and Mines Queensland.

Le Cabec A, and Toussaint M. 2017. Impacts of curatorial and research practices on the preservation of fossil hominid remains. J Anthropol Sci 95:7-34. 10.4436/JASS.95002

Le Loeuff J. 2005. Osteology of Ampelosaurus atacis (Titanosauria) from southern France. Thunder-lizards The sauropodomorph dinosaurs, 115-137.

Leahey LG, Molnar RE, Carpenter K, Witmer LM, and Salisbury SW. 2015. Cranial osteology of the ankylosaurian dinosaur formerly known as Minmi sp.(Ornithischia: Thyreophora) from the Lower Cretaceous Allaru Mudstone of Richmond, Queensland, Australia. PeerJ 3:e1475.

Leahey LG, and Salisbury SW. 2013. First evidence of ankylosaurian dinosaurs (Ornithischia: Thyreophora) from the mid-Cretaceous (late Albian-Cenomanian) Winton Formation of Queensland, Australia. Alcheringa: An Australasian Journal of Palaeontology 37:249257. 10.1080/03115518.2013.743703

Lehman TM, and Coulson AB. 2002. A juvenile specimen of the sauropod dinosaur Alamosaurus sanjuanensis from the Upper Cretaceous of Big Bend National Park, Texas. Journal of Paleontology 76:156-172.

Li LG, Li DQ, You HL, and Dodson P. 2014. A new titanosaurian sauropod from the Hekou Group (Lower Cretaceous) of the Lanzhou-Minhe Basin, Gansu Province, China. PLoS One 9:e85979. 10.1371/journal.pone.0085979

Lloyd J, Collins AS, Payne JL, Glorie S, Holford S, and Reid AJ. 2016. Tracking the Cretaceous transcontinental Ceduna River through Australia: The hafnium isotope record of detrital zircons from offshore southern Australia. Geoscience Frontiers 7:237-244.

https://doi.org/10.1016/j.gsf.2015.06.001

Longman HA. 1927. The giant dinosaur: Rhoetosaurus brownei. Memoirs of the Queensland Museum 9:1-18.

Longrich NR, Suberbiola XP, Pyron RA, and Jalil N-E. 2021. The first duckbill dinosaur (Hadrosauridae: Lambeosaurinae) from Africa and the role of oceanic dispersal in dinosaur biogeography. Cretaceous Research 120. 10.1016/j.cretres.2020.104678

Lowman R. 2010. SSL Wareena 5 Well Completion Report. Santos Ltd. Report CR 62290. Brisbane, Queensland: Department of Natural Resources and Mines Queensland.

Lü J, Xu L, Jia S, Zhang X, Zhang J, Yang L, You H, and Ji Q. 2009. A new gigantic sauropod dinosaur from the Cretaceous of Ruyang, Henan, China. Geological Bulletin of China 28:1-10.

Ludbrook N. 1985. Trigonioididae (Mollusca: Bivalvia) from the Cretaceous of Lake Eyre North, South Australia. Trans R Soc South Aust 109:77-82.

Lyman RL. 1994. Accumulation and dispersal of vertebrate remains. In: Lyman RL, ed. Vertebrate Taphonomy. Cambridge: Cambridge University Press, 161-222.

Maddison WP, and Maddison DR. 2019. Mesquite: a modular system for evolutionary analysis. Version 3.61 ed.

Mann DH, Groves P, Gaglioti BV, and Shapiro BA. 2018. Climate-driven ecological stability as a globally shared cause of Late Quaternary megafaunal extinctions: the Plaids and Stripes Hypothesis. Biol Rev Camb Philos Soc. 10.1111/brv.12456

Mannion PD, Allain R, and Moine O. 2017. The earliest known titanosauriform sauropod dinosaur and the evolution of Brachiosauridae. PeerJ 5:e3217. 10.7717/peerj.3217 
3165

3166

3167

3168

3169

3170

3171

3172

3173

3174

3175

3176

3177

3178

3179

3180

3181

3182

3183

3184

3185

3186

3187

3188

3189

3190

3191

3192

3193

3194

3195

3196

3197

3198

3199

3200

3201

3202

3203

3204

3205

3206

3207

3208

3209

3210

Mannion PD, and Calvo JO. 2011. Anatomy of the basal titanosaur (Dinosauria, Sauropoda) Andesaurus delgadoi from the mid-Cretaceous (Albian-early Cenomanian) Río Limay Formation, Neuquén Province, Argentina: implications for titanosaur systematics. Zoological Journal of the Linnean Society:no-no. 10.1111/j.1096-3642.2011.00699.x Mannion PD, and Otero A. 2012. A reappraisal of the Late Cretaceous Argentinean sauropod dinosaur Argyrosaurus superbus, with a description of a new titanosaur genus. Journal of Vertebrate Paleontology 32:614-638. 10.1080/02724634.2012.660898

Mannion PD, Upchurch P, Barnes RN, and Mateus O. 2013. Osteology of the Late Jurassic Portuguese sauropod dinosaur Lusotitan atalaiensis (Macronaria) and the evolutionary history of basal titanosauriforms. Zoological Journal of the Linnean Society 168:98-206. 10.1111/zoj.12029

Mannion PD, Upchurch P, Jin X, and Zheng W. 2019a. New information on the Cretaceous sauropod dinosaurs of Zhejiang Province, China: impact on Laurasian titanosauriform phylogeny and biogeography. R Soc Open Sci 6:191057. 10.1098/rsos.191057

Mannion PD, Upchurch P, Schwarz D, and Wings O. 2019b. Taxonomic affinities of the putative titanosaurs from the Late Jurassic Tendaguru Formation of Tanzania: phylogenetic and biogeographic implications for eusauropod dinosaur evolution. Zoological Journal of the Linnean Society.

Maroulis JC, Nanson GC, Price DM, and Pietsch T. 2007. Aeolian-fluvial interaction and climate change: source-bordering dune development over the past $100 \mathrm{ka}$ on Cooper Creek, central Australia. Quaternary Science Reviews 26:386-404.

Martínez RD, Giménez O, Rodríguez J, Luna M, and Lamanna MC. 2004. An articulated specimen of the basal titanosaurian (Dinosauria: Sauropoda) Epachthosaurus sciuttoi from the early Late Cretaceous Bajo Barreal formation of Chubut Province, Argentina. Journal of Vertebrate Paleontology 24:107-120. 10.1671/9.1

Martinez RD, Lamanna MC, Novas FE, Ridgely RC, Casal GA, Martinez JE, Vita JR, and Witmer LM. 2016. A Basal Lithostrotian Titanosaur (Dinosauria: Sauropoda) with a Complete Skull: Implications for the Evolution and Paleobiology of Titanosauria. PLoS One 11:e0151661. 10.1371/journal.pone.0151661

Mateus O, Jacobs LL, Schulp AS, Polcyn MJ, Tavares TS, Neto AB, Morais ML, and Antunes MT. 2011. Angolatitan adamastor, a new sauropod dinosaur and the first record from Angola. Anais da Academia Brasileira de Ciências (Annals of the Brazilian Academy of Sciences) 83:221-233.

Mateus O, Mannion PD, and Upchurch P. 2014. Zby atlanticus, a New Turiasaurian Sauropod (Dinosauria, Eusauropoda) from the Late Jurassic of Portugal. Journal of Vertebrate Paleontology 34:618-634. 10.1080/02724634.2013.822875

Mond A. 1974. Simpson Desert North, Northern Territory: 1:250,000 Geological Series Explanatory Notes. Record SG5304. . Geoscience Australia, Canberra.

Monteil E. 2006. Australian Mesozoic and Cenozoic Palynology Zonations - update to the 2004 Geologic Time Scale. In: Australia G, editor. Canberra, Australia: Geosciences Australia.

Moore PS, and Pitt GM. 1985. Cretaceous subsurface of the southwestern Eromanga Basin: a review. In: Lindsay JM, ed. Stratigraphy, Palaeontology, Malacology - papers in honour of Dr Nell Ludbrook. Adelaide, South Australia: South Australia Department of Mines and Energy, 269-286.

Moore PS, Pitt GM, and Dettmann ME. 1986. The Early Cretaceous Coorikiana Sandstone and Toolebuc Formation: their recognition and stratigraphic relationship in the south-western

Peer) reviewing PDF | (2020:11:55594:2:1:NEW 28 Mar 2021) 
3211

3212

3213

3214

3215

3216

3217

3218

3219

3220

3221

3222

3223

3224

3225

3226

3227

3228

3229

3230

3231

3232

3233

3234

3235

3236

3237

3238

3239

3240

3241

3242

3243

3244

3245

3246

3247

3248

3249

3250

3251

3252

3253

3254

3255
Eromanga Basin. . In: Gravestock DI, Moore PS, and Pitt GM, eds. Contributions to the geology and hydrocarbon potential of the Eromanga Basin. Canberra, ACT: Geological Society of Australia Special Publication 97-114.

Musser AM, Luo Z-X, Martinelli AG, Lamanna MC, Weisbecker V, Wroe S, and Salisbury SW. 2009. First Australian non-mammalian cynodont: new evidence for the unusual nature of Australia's Cretaceous vertebrate faunas. In: Travuillon KJ, Worthy TH, Hand SJ, and Creaser P, editors. 12th Conference on Australian Vertebrate Evolution, Palaeontology and Systematics. Sydney, New South Wales: Geological Society of Australia. p 47.

Navarrete C, Casal G, and Martínez R. 2011. Drusilasaura deseadensis gen. et sp. nov., un nuevo titanosaurio (Dinosauria-Sauropoda), de la Formación Bajo Barreal, Cretácico Superior del norte de Santa Cruz, Argentina. Revista Brasileira de Paleontologia 14:114.

Otero A. 2010. The Appendicular Skeleton of Neuquensaurus, a Late Cretaceous Saltasaurine Sauropod from Patagonia, Argentina. Acta Palaeontologica Polonica 55:399-426. 10.4202/app.2009.0099

Otero A. 2018. Forelimb musculature and osteological correlates in sauropodomorpha (Dinosauria, Saurischia). PLoS One 13:e0198988.

Otero A, Carballido JL, and Moreno AP. 2020a. The appendicular osteology of Patagotitan mayorum (Dinosauria, Sauropoda). Journal of Vertebrate Paleontology 40:e1793158.

Otero A, Moreno AP, Falkingham PL, Cassini G, Ruella A, Militello M, and Toledo N. 2020 b. Three-dimensional image surface acquisition in vertebrate paleontology: a review of principal techniques. Publicación Electrónica de la Asociación Paleontológica Argentina 20 1-14. http://dx.doi.org/10.5710/PEAPA.04.04.2020.310

Otero A, Carballido JL, Salgado L, Canudo JI, Garrido AC. 2021. Report of a giant titanosaur sauropod from the Upper Cretaceous of Neuquén Province, Argentina. Cretaceous Research, 122, 104754. https://doi.org/10.1016/j.cretres.2021.104754.

Pangaea Resources PL. 2013. Well completion report well, abandonment report QLD_ATP_1041P_Minion_9. In: Queensland GSo, editor. Brisbane: Queensland Government.

Páramo A, Mocho P, and Ortega F. 2020. Three-dimensional analysis of the titanosaurian limb skeleton: implications for systematic analysis. Journal of Iberian Geology 46:369-402. $10.1007 / \mathrm{s} 41513-020-00139-8$

Paul G. 2019. Determining the largest known land animal: A critical comparison of differing methods for restoring the volume and mass of extinct animals. Annals of Carnegie Museum 85:335-358.

Pentland AH, Poropat SF, Tischler TR, Sloan T, Elliott RA, Elliott HA, Elliott JA, and Elliott DA. 2019. Ferrodraco lentoni gen. et sp. nov., a new ornithocheirid pterosaur from the Winton Formation (Cenomanian-lower Turonian) of Queensland, Australia. Scientific Reports (Nature Publisher Group) 9:1-13.

Percival LME, Helmond NAGM, Selby D, Goderis S, and Claeys P. 2020. Complex Interactions Between Large Igneous Province Emplacement and Global-Temperature Changes During the Cenomanian-Turonian Oceanic Anoxic Event (OAE 2). Paleoceanography and Paleoclimatology 35. 10.1029/2020pa004016

Pietroni N, Tarini M, and Cignoni P. 2009. Almost isometric mesh parameterization through abstract domains. IEEE Transactions on Visualization Computer Graphics 16:621-635.

Peer] reviewing PDF | (2020:11:55594:2:1:NEW 28 Mar 2021) 
3256

3257

3258

3259

3260

3261

3262

3263

3264

3265

3266

3267

3268

3269

3270

3271

3272

3273

3274

3275

3276

3277

3278

3279

3280

3281

3282

3283

3284

3285

3286

3287

3288

3289

3290

3291

3292

3293

3294

3295

3296

3297

3298

3299

3300

3301

Poropat SF, Kundrát M, Mannion PD, Upchurch P, Tischler TR, and Elliott DA. 2021. Second specimen of the Late Cretaceous Australian sauropod dinosaur Diamantinasaurus matildae provides new anatomical information on the skull and neck of early titanosaurs. Zoological Journal of the Linnean Society. 10.1093/zoolinnean/zlaa173

Poropat SF, Mannion PD, Upchurch P, and Elliott DA. 2019. New sauropod dinosaur discoveries in the lower upper Cretaceous Winton Formation (Cenomanian- Lower Turonian) of Queensland, Australia: implications for titanosaurian evolution. Society of Vertebrate Palaeontology. Brisbane, Australia: Journal of Vertebrate Paleontology Program and Abstracts. p 171.

Poropat SF, Mannion PD, Upchurch P, Hocknull SA, Kear BP, and Elliott DA. 2015a. Reassessment of the non-titanosaurian somphospondylan Wintonotitan wattsi (Dinosauria: Sauropoda: Titanosauriformes) from the mid-Cretaceous Winton Formation, Queensland, Australia. Papers in Palaeontology 1:59-106. 10.1002/spp2.1004

Poropat SF, Mannion PD, Upchurch P, Hocknull SA, Kear BP, Kundrat M, Tischler TR, Sloan T, Sinapius GH, Elliott JA, and Elliott DA. 2016. New Australian sauropods shed light on Cretaceous dinosaur palaeobiogeography. Sci Rep 6:34467. 10.1038/srep34467

Poropat SF, Mannion PD, Upchurch P, Tischler TR, Sloan T, Sinapius GH, Elliott JA, and Elliott DA. 2020. Osteology of the Wide-Hipped Titanosaurian Sauropod Dinosaur Savannasaurus Elliottorum from the Upper Cretaceous Winton Formation of Queensland, Australia. Journal of Vertebrate Paleontology:e1786836.

Poropat SF, Nair JP, Syme CE, Mannion PD, Upchurch P, Hocknull SA, Cook AG, Tischler TR, and Holland T. 2017. Reappraisal of Austrosaurus mckillopi Longman, 1933 from the Allaru Mudstone of Queensland, Australia's first named Cretaceous sauropod dinosaur. Alcheringa: An Australasian Journal of Palaeontology:1-38. 10.1080/03115518.2017.1334826

Poropat SF, Upchurch P, Mannion PD, Hocknull SA, Kear BP, Sloan T, Sinapius GH, and Elliott DA. 2015b. Revision of the sauropod dinosaur Diamantinasaurus matildae Hocknull et al. 2009 from the mid-Cretaceous of Australia: implications for Gondwanan titanosauriform dispersal. Gondwana Research 27:995-1033.

Ransley T, and Smerdon B. 2012. Hydrostratigraphy, hydrogeology and system conceptualisation of the Great Artesian Basin. In: CSIRO, editor. A technical report to the Australian Government from the CSIRO Great Artesian Basin Water Resource Assessment. Canberra, Australia: CSIRO Water for a Healthy Country Flagship Australia.

Raymond O, Liu S, Gallagher R, Zhang W, and Highet L. 2012. Surface Geology of Australia 1: 1 million scale dataset, 2012 edition. . In: Australia G, editor. Canberra, Australia: Geoscience Australia. p 20.

Robinson S. 1988. DIO Wareena 2 Well Completion Report. Delhi Petroleum Pty Ltd. Report CR 19911. Brisbane, Queensland: Department of Natural Resources and Mines Queensland.

Rodgers J, Wehr F, and Hunt J. 1991. Tertiary uplift estimation from velocity data in the Eromanga Basin. Exploration Geophysics 22:321-324.

Rodrigo JD, Gabo-Ratio JAS, Queaño KL, Fernando AGS, Silva LP, Yonezu K, and Zhang Y. 2020. Geochemistry of the Late Cretaceous Pandan Formation in Cebu Island, Central Philippines: Sediment contributions from the Australian plate margin during the Mesozoic. The Depositional Record 6:309-330. 10.1002/dep2.103

Peer) reviewing PDF | (2020:11:55594:2:1:NEW 28 Mar 2021) 
3302 Royo-Torres R, Cobos A, and Alcala L. 2006. A giant European dinosaur and a new sauropod

3303

3304

3305

3306

3307

3308

3309

3310

3311

3312

3313

3314

3315

3316

3317

3318

3319

3320

3321

3322

3323

3324

3325

3326

3327

3328

3329

3330

3331

3332

3333

3334

3335

3336

3337

3338

3339

3340

3341

3342

3343

3344

3345

clade. Science 314:1925-1927. 10.1126/science.1132885

Royo-Torres R, Cobos A, Mocho P, and Alcalá L. 2020. Origin and evolution of turiasaur dinosaurs set by means of a new 'rosetta' specimen from Spain. Zoological Journal of the Linnean Society 191:201-227. 10.1093/zoolinnean/zlaa091 \%J Zoological Journal of the Linnean Society

Salisbury S. 2003. On the shoulders of a giant. Australian Age of Dinosaurs:12-19.

Salisbury SW. 2005. A new vertebrate assemblage from the mid-Cretaceous (AlbianCenomanian) Winton Formation, central-western Queensland. In: Reed L, Bourne D, Megirian D, Prideaux G, Young G, and Wright A, editors. Proceedings of Conference of Vertebrate Evolution, Systematics and Palaeontology. Adelaide, South Australia: Alcheringa. p 465.

Salisbury SW, Herne MC, Lamanna MC, Nair JP, Syme C, and Witmer LM. 2019. An exceptionally preserved small-bodied ornithopod dinosaur from the Lower Cretaceous (Upper Albian) Winton Formation of Isisford, central-western Queensland, Australia, and the diversification of Gondwanan ornithopods. Society of Vertebrate Paleontology. Brisbane: Journal of Vertebrate Paleontology Program and Abstracts. p 185.

Salisbury SW, Molnar RE, Frey E, and Willis PM. 2006. The origin of modern crocodyliforms: new evidence from the Cretaceous of Australia. Proceedings of the Royal Society B: Biological Sciences 273:2439-2448.

Salisbury SW, Romilio A, Herne MC, Tucker RT, and Nair JP. 2016. The Dinosaurian Ichnofauna of the Lower Cretaceous (Valanginian-Barremian) Broome Sandstone of the Walmadany Area (James Price Point), Dampier Peninsula, Western Australia. Journal of Vertebrate Paleontology 36:1-152. 10.1080/02724634.2016.1269539

Santos VF, Moratalla JJ, and Royo-Torres R. 2009. New Sauropod Trackways from the Middle Jurassic of Portugal. Acta Palaeontologica Polonica 54:409-422. 10.4202/app.2008.0049

Sauermilch I, Whittaker JM, Bijl PK, Totterdell JM, and Jokat W. 2019. Tectonic, Oceanographic, and Climatic Controls on the Cretaceous-Cenozoic Sedimentary Record of the Australian-Antarctic Basin. Journal of Geophysical Research: Solid Earth 124:7699-7724. 10.1029/2018jb016683

Scanlon JD, and Hocknull SA. 2008. A dolichosaurid lizard from the latest Albian (midCretaceous) Winton Formation, Queensland, Australia. Transactions of the Kansas Academy of Science (Fort Hays Studies Special Issue-Proceedings of the Second Mosasaur Meeting). p 131-136.

Seedsman KR. 1998. 1997 SQ 97 Seismic Survey ATP 259 Queensland Interpretation Report. Santos Ltd. Report CR 31073. Brisbane, Queensland: Department of Natural Resources and Mines Queensland.

Senior B, and Mabbutt J. 1979. A proposed method of defining deeply weathered rock units based on regional geological mapping in southwest Queensland. Journal of the Geological Society of Australia 26:237-254.

Senior BR. 1970. Barrolka, Qld Geological Map Sheet SG/54-11 1:250 000 Geological SeriesExplanatory Notes. Bureau of Mineral Resources Geology and Geophysics 1.

Senior D. 1968. Durham Downs, Qld Geological Map Sheet SG/54-15 1:250 000 Geological Series-Explanatory Notes. Bureau of Mineral Resources Geology and Geophysics 1.

Peer) reviewing PDF | (2020:11:55594:2:1:NEW 28 Mar 2021) 
3346

3347

3348

3349

3350

3351

3352

3353

3354

3355

3356

3357

3358

3359

3360

3361

3362

3363

3364

3365

3366

3367

3368

3369

3370

3371

3372

3373

3374

3375

3376

3377

3378

3379

3380

3381

3382

3383

3384

3385

3386

3387

3388

3389

3390

3391

Sharman GR, and Malkowski MA. 2020. Needles in a haystack: Detrital zircon U Pb ages and the maximum depositional age of modern global sediment. Earth-Science Reviews 203. 10.1016/j.earscirev.2020.103109

Silva J, Marinho TS, Martinelli AG, and Langer MC. 2019. Osteology and systematics of Uberabatitan ribeiroi (Dinosauria; Sauropoda): a Late Cretaceous titanosaur from Minas Gerais, Brazil. Zootaxa 4577:zootaxa 45774573 4571. 10.11646/zootaxa.4577.3.1

Simón E, Salgado L, and Calvo JO. 2017. A New Titanosaur Sauropod from the Upper Cretaceous of Patagonia, Neuquén Province, Argentina. Ameghiniana 55:1-29. 10.5710/AMGH.01.08.2017.3051

Smith JB, Lamanna MC, Lacovara KJ, Dodson P, Smith JR, Poole JC, Giegengack R, and Attia Y. 2001. A giant sauropod dinosaur from an Upper Cretaceous mangrove deposit in Egypt. Science (New York, NY) 292:1704-1706.

Stromer R. 1932. Ergebnisse der Forschungsreisen Prof. E. Stromers in den Wüsten Ägyptens. II. Wirbeltierreste der Baharîje-Stufe (unterstes Cenoman). 11. Sauropoda. Abhandlungen der Bayerischen Akademie der Wissenschaften, Mathematisch-Naturwissenschaftliche Abteilung 10:1-21.

Swofford DL. 2003. PAUP*. Phylogenetic Analysis Using Parsimony (*and Other Methods), Version 4. 4 ed: Sinauer Associates, Sunderland, Massachusetts.

Thulborn RA, and Wade M. 1984. Dinosaur trackways in the Winton Formation (midCretaceous) of Queensland. Memoirs of the Queensland Museum 21:413-517.

Totterdell JM, and Krassay AA. 2003. Sequence stratigraphic correlation of onshore and offshore Bight Basin successions. In: Australia G, editor. Canberra: Australian Government.

Tschopp E, and Upchurch P. 2019. The challenges and potential utility of phenotypic specimenlevel phylogeny based on maximum parsimony. Journal of Earth and Environmental Science Transactions of the Royal Society of Edinburgh 109:301-323.

Tucker RT, Roberts EM, Darlington V, and Salisbury SW. 2017. Investigating the stratigraphy and palaeoenvironments for a suite of newly discovered mid-Cretaceous vertebrate fossillocalities in the Winton Formation, Queensland, Australia. Sedimentary Geology 358:210-229. 10.1016/j.sedgeo.2017.05.004

Tucker RT, Roberts EM, Henderson RA, and Kemp AI. 2016. Large igneous province or longlived magmatic arc along the eastern margin of Australia during the Cretaceous? Insights from the sedimentary record. Bulletin 128:1461-1480.

Tucker RT, Roberts EM, Hu Y, Kemp AI, and Salisbury SW. 2013. Detrital zircon age constraints for the Winton Formation, Queensland: contextualizing Australia's Late Cretaceous dinosaur faunas. Gondwana Research 24:767-779.

Turner M. 1997. SSL Wareena 3 Well Completion Report. Santos Ltd. Report CR 30488. Brisbane, Queensland: Department of Natural Resources and Mines Queensland.

Tykoski RS, and Fiorillo AR. 2016. An articulated cervical series of Alamosaurus sanjuanensis Gilmore, 1922 (Dinosauria, Sauropoda) from Texas: new perspective on the relationships of North America's last giant sauropod. Journal of Systematic Palaeontology 15:339-364. 10.1080/14772019.2016.1183150

Ullmann PV, and Lacovara KJ. 2016. Appendicular osteology of Dreadnoughtus schrani, a giant titanosaurian (Sauropoda, Titanosauria) from the Upper Cretaceous of Patagonia, Argentina. Journal of Vertebrate Paleontology 36:e1225303. 10.1080/02724634.2016.1225303

Peer) reviewing PDF | (2020:11:55594:2:1:NEW 28 Mar 2021) 
3392

3393

3394

3395

3396

3397

3398

3399

3400

3401

3402

3403

3404

3405

3406

3407

3408

3409

3410

3411

3412

3413

3414

3415

3416

3417

3418

3419

3420

3421

3422

3423

3424

3425

3426

3427

3428

3429

3430

3431

3432

3433

3434

3435

Upchurch P. 1998. The phylogenetic relationships of sauropod dinosaurs. Zoological Journal of the Linnean Society 124:43-103.

Upchurch P, Mannion PD, and Taylor MP. 2015. The anatomy and phylogenetic relationships of "Pelorosaurus" becklesii (Neosauropoda, Macronaria) from the Early Cretaceous of England. PLoS One 10:e0125819. 10.1371/journal.pone.0125819

Vanderstaay AGB. 2000. Soils of Western Queensland, Technical notes Western Queensland best practice guidelines. . In: Roads. QGDoM, editor. Brisbane, Queensland: Queensland Government.

Vergne R, Pacanowski R, Barla P, Granier X, and Schlick C. 2010. Radiance scaling for versatile surface enhancement. Proceedings of the 2010 ACM SIGGRAPH symposium on Interactive 3D Graphics and Games. p 143-150.

Vidal D, and Díez Díaz V. 2017. Reconstructing hypothetical sauropod tails by means of 3D digitization: Lirainosaurus astibiae as case study. Journal of Iberian Geology 43:293-305. 10.1007/s41513-017-0022-6

Vila B, Galobart À, Canudo J, Le Loeuff J, Dinarès-Turell J, Riera V, Oms O, Tortosa T, and Gaete R. 2012. The diversity of sauropod dinosaurs and their first taxonomic succession from the latest Cretaceous of southwestern Europe: clues to demise and extinction. Palaeogeography, Palaeoclimatology, Palaeoecology 350:19-38.

Voorhies MR. 1969. Taphonomy and population dynamics of an early Pliocene vertebrate fauna, Knox County, Nebraska: University of Wyoming Laramie.

Watson PJ. 1973. Lovelle Downs 1, Well Completion Report (Hematite Petroleum Ltd.). In: Queensland GSo, editor. Brisbane: Queensland Government.

Wedel MJ, and Taylor MP. 2013. Caudal pneumaticity and pneumatic hiatuses in the sauropod dinosaurs Giraffatitan and Apatosaurus. PLoS One 8:e78213.

White MA, Bell PR, Poropat SF, Pentland AH, Rigby SL, Cook AG, Sloan T, and Elliott DA. 2020. New theropod remains and implications for megaraptorid diversity in the Winton Formation (lower Upper Cretaceous), Queensland, Australia. 7:191462. doi:10.1098/rsos. 191462

Whitlock JA, D'Emic MD, and Wilson JA. 2011. Cretaceous diplodocids in Asia? Re-evaluating the phylogenetic affinities of a fragmentary specimen. J Palaeontology 54:351-364.

Wilford J, Searle R, Thomas M, Pagendam D, and Grundy M. 2016. A regolith depth map of the Australian continent. Geoderma 266:1-13.

Wilkinson M, Hocknull SA, and Mackenzie R. 2019. What is and can be known about the Winton Formation? Understanding the geology of the Winton Formation and integrating newly discovered fossil fields from south-west Queensland, Australia. . Society of Vertebrate Paleontology. Brisbane, Queensland: Journal of Vertebrate Paleontology Program and Abstracts. p 219.

Wu W-H, Dong Z-M, Sun Y-W, Li C-T, and Li T. 2006. A New Sauropod Dinosaur from the Cretaceous of Jiutai, Jilin, China. Global Geology 25:6-9.

You H, Li D, Zhou L, and Ji Q. 2006. Huanghetitan liujiaxiaensis, a new sauropod dinosaur from the Lower Cretaceous Hekou Group of Lanzhou Basin, Gansu Province, China. Geological Review 52:668-674.

You H, Li D, Zhou L, and Ji Q. 2008. Daxiatitan binglingi: a giant sauropod dinosaur from the Early Cretaceous of China. Gansu Geology 17:1-10.

Peer) reviewing PDF | (2020:11:55594:2:1:NEW 28 Mar 2021) 
3436 Zahirovic S, Matthews KJ, Flament N, Müller RD, Hill KC, Seton M, and Gurnis M. 2016.

3437

3438

3439

3440

3441

3442

3443

3444

3445

3446

3447
Tectonic evolution and deep mantle structure of the eastern Tethys since the latest

Jurassic. Earth-Science Reviews 162:293-337. 10.1016/j.earscirev.2016.09.005

Zurriaguz VL, and Cerda IA. 2017. Caudal pneumaticity in derived titanosaurs (Dinosauria:

Sauropoda). Cretaceous Research 73:14-24. 10.1016/j.cretres.2017.01.001 


\section{Table $\mathbf{1}$ (on next page)}

Table 1. Cenomanian - ?Turonian fauna from the Winton Formation.

Superscript numbers refer to citations: ${ }^{1}$ (Cook 2005) , ${ }^{2}$ (Hocknull 1997) , ${ }^{3}$ (Hocknull 2000), ${ }^{4}$ Hocknull pers. obs. $(2002,2009,2019),{ }^{5}$ (Ludbrook 1985) , ${ }^{6}$ (Fletcher \& Salisbury 2014) , ${ }^{7}$ (Jell 2004),${ }^{8}$ (Elliott \& Cook 2004),${ }^{9}$ (Salisbury 2003),${ }^{10}$ (Kemp 1991),${ }^{11}$ (Kemp 1997),${ }^{12}$ (Berrell et al. 2014),${ }^{13}$ (Faggotter et al. 2007),${ }^{14}$ (Mond 1974),${ }^{15}$ (Salisbury 2005),${ }^{16}$ (Scanlon \& Hocknull 2008) , ${ }^{17}$ (Salisbury et al. 2006) , ${ }^{18}$ (Pentland et al. 2019) , ${ }^{19}$ (Hocknull et al. 2009) , ${ }^{20}$ (Poropat et al. 2016) , ${ }^{21}$ (Hocknull et al. 2019) , ${ }^{22}$ (Poropat et al. 2019) , ${ }^{23}$ (Elliott 2004) , ${ }^{24}$ (White et al. 2020) , ${ }^{25}$ (Thulborn \& Wade 1984),${ }^{26}$ (Hocknull \& Cook 2008) , ${ }^{27}$ (Salisbury et al. 2019) , ${ }^{28}$ (Leahey \& Salisbury 2013),${ }^{29}$ (Musser et al. 2009) . 
1 Table 1. Cenomanian - ?Turonian fauna from the Winton Formation. Superscript numbers

2 refer to citations: ${ }^{1}$ (Cook 2005), ${ }^{2}$ (Hocknull 1997), ${ }^{3}$ (Hocknull 2000), ${ }^{4}$ Hocknull pers. obs. (2002,

3 2009, 2019), ${ }^{5}$ (Ludbrook 1985), ${ }^{6}\left(\right.$ Fletcher \& Salisbury 2014), ${ }^{7}(J e l l ~ 2004),{ }^{8}($ Elliott \& Cook

4 2004), ${ }^{9}$ (Salisbury 2003), ${ }^{10}$ (Kemp 1991), ${ }^{11}$ (Kemp 1997), ${ }^{12}$ (Berrell et al. 2014), ${ }^{13}$ (Faggotter et

5 al. 2007), ${ }^{14}$ (Mond 1974), ${ }^{15}$ (Salisbury 2005), ${ }^{16}$ (Scanlon \& Hocknull 2008), ${ }^{17}$ (Salisbury et al.

6 2006), ${ }^{18}$ (Pentland et al. 2019), ${ }^{19}$ (Hocknull et al. 2009), ${ }^{20}$ (Poropat et al. 2016), ${ }^{21}$ (Hocknull et

7 al. 2019), ${ }^{22}$ (Poropat et al. 2019), ${ }^{23}$ (Elliott 2004), ${ }^{24}$ (White et al. 2020), ${ }^{25}$ (Thulborn \& Wade

8 1984), ${ }^{26}$ (Hocknull \& Cook 2008), ${ }^{27}$ (Salisbury et al. 2019), ${ }^{28}$ (Leahey \& Salisbury 2013),

$9{ }^{29}$ (Musser et al. 2009).

10

\begin{tabular}{|c|c|c|c|c|c|}
\hline & $\begin{array}{l}\text { Northern Winton } \\
\text { Formation } \\
\text { (Winton, QLD) }\end{array}$ & $\begin{array}{l}\text { Eastern Winton } \\
\text { Formation } \\
\text { (Isisford, QLD) }\end{array}$ & $\begin{array}{l}\text { Southern Winton } \\
\text { Formation } \\
\text { (Eromanga- } \\
\text { Quilpie, QLD) } \\
\end{array}$ & $\begin{array}{l}\text { Western Winton } \\
\text { Formation } \\
\text { (Northern } \\
\text { Territory) } \\
\end{array}$ & $\begin{array}{l}\text { South-western } \\
\text { Winton Formation } \\
\text { (South Australia) }\end{array}$ \\
\hline $\begin{array}{l}\text { Freshwater } \\
\text { Gastropods }\end{array}$ & Melanoides sp. indet. ${ }^{1}$ & & & & \\
\hline $\begin{array}{l}\text { Freshwater } \\
\text { Bivalves }\end{array}$ & $\begin{array}{l}\text { Hyridella } \\
\text { (Protohyridella) } \\
\text { goodiwindiensis }{ }^{2,3} \\
\text { Hyridella (Hyridella) } \\
\text { macmichaeli } 2,3 \\
\text { Megalovirgus } \\
\text { wintonensis } 2,3 \\
\text { new genus et sp. }{ }^{4} \\
\end{array}$ & & $\begin{array}{l}\text { Hyridella } \\
\text { (Hyridella) } \\
\text { macmichaeli }^{4,21}\end{array}$ & & Pledgia eyrensis ${ }^{5}$ \\
\hline Insects & $\begin{array}{l}\text { ?orbatid mite } \\
\text { Odonata }^{7}, 8 \\
\text { Mecoptera }^{7,8} \\
\text { Coleoptera }^{9}\end{array}$ & & & & \\
\hline Fish & $\begin{array}{l}\text { Teleostii }^{4} \\
\text { Metaceratodus } \\
\text { wollastoni }^{10,11} \\
\text { Metaceratodus } \\
\text { ellioti }^{10,11} \\
\text { shark }^{4}\end{array}$ & $\begin{array}{l}\text { Cladocyclus } \\
\text { geddesi }^{12} \\
\text { ?haleocomorph }^{13}\end{array}$ & & $\begin{array}{l}\text { Metaceratodus } \\
\text { wollastoni }^{4,10,11}\end{array}$ & $\begin{array}{l}\text { Metaceratodus } \\
\text { wollastoni }^{10,11} \\
\text { Metaceratodus } \\
\text { ellioti }^{10,11} \\
\text { shark }^{14}\end{array}$ \\
\hline Plesiosaur & Plesiosaur ${ }^{15}$ & & & & \\
\hline Squamates & cf. Coniasaurus ${ }^{16}$ & & & & \\
\hline Turtles & Chelidae $^{15,19}$ & & Chelidae $^{4,21}$ & & \\
\hline Crocodiles & Crocodilia indet. ${ }^{15,19}$ & Isisfordia duncani $^{17}$ & & & \\
\hline Pterosaurs & Ferodraco lentoni $^{18}$ & & & & \\
\hline Sauropods & $\begin{array}{l}\text { Diamantinasaurus } \\
\text { matildae }^{19,20} \\
\text { Savannasaurus }^{20} \\
\text { elliottorum }^{20}\end{array}$ & & $\begin{array}{l}\text { Australotitan } \\
\text { cooperensis (here) } \\
\text { sauropod trample }^{21}\end{array}$ & & \\
\hline
\end{tabular}




\begin{tabular}{|c|c|c|c|c|}
\hline & $\begin{array}{l}\text { Wintonotitan } \text { wattsi }^{19} \\
\text { sauropod tracks }\end{array}$ & & & \\
\hline Theropods & $\begin{array}{l}\text { Australovenator } \\
\text { wintonensis }^{19} \\
\text { Theropodan indet. }^{23} \\
\text { Megaraptoran } \\
\text { Theropod tracks } \\
\text { Th }\end{array}$ & & Theropod tracks ${ }^{21}$ & \\
\hline Ornithopods & $\begin{array}{l}\text { Ornithopod indet. } \\
\text { Ornithopod tracks }\end{array}$ & new $^{27}$ & Ornithopod tracks ${ }^{21}$ & \\
\hline Ankylosaurs & Thyreophora indet. ${ }^{28}$ & & & \\
\hline Cynodont & ?cynodont $^{29}$ & & & \\
\hline Dinosauria & & & & $\begin{array}{l}\text { Indeterminate } \\
\text { bone }^{4}\end{array}$ \\
\hline
\end{tabular}


Table 2 (on next page)

Scapula measurements of Winton Formation sauropods.

All measurements in $\mathrm{mm}$. 
1 Table 2. Scapula measurements of Winton Formation sauropods.

\begin{tabular}{|c|c|c|}
\hline & Preserved & Reconstructed \\
\hline \multicolumn{3}{|l|}{ EMF102 Australotitan cooperensis } \\
\hline Maximum proximodistal length & $1220.5+$ & 2182.98 \\
\hline Maximum acromial plate dorsoventral height (c) & $498.94+$ & \\
\hline Minimum scapular blade dorsoventral height (a) & 264.89 (at base) & 264.89 \\
\hline Maximum scapular blade dorsoventral height & $313.36+$ & \\
\hline Maximum proximodistal scapular blade length & $911.12+$ & \\
\hline Maximum mediolateral scapular blade thickness (b) & 65.86 & 65.86 \\
\hline (b)/(a) - relative thickness of blade & 0.25 & 0.25 \\
\hline $\begin{array}{l}\text { (a) / (c) - relative acromion plate to minimum } \\
\text { scapular blade height }\end{array}$ & & 0.48 \\
\hline \multicolumn{3}{|l|}{ AODF603 Diamantinasaurus matildae } \\
\hline Maximum proximodistal length $(\mathrm{d})$ & 1485.48 & \\
\hline Maximum acromial plate dorsoventral height & $354.46+$ & \\
\hline Minimum scapular blade dorsoventral height (a) & 283.15 (mid-blade) & \\
\hline Maximum scapular blade dorsoventral height & $\begin{array}{l}407.37+(\text { distal } \\
\text { expansion })\end{array}$ & \\
\hline Maximum proximodistal scapular blade length (c) & 876.94 & \\
\hline Maximum mediolateral scapular blade thickness (b) & 59.13 & \\
\hline (b)/(a) - relative thickness of blade & 0.21 & \\
\hline \multicolumn{3}{|l|}{ QMF7292 Wintonotitan wattsi } \\
\hline Maximum proximodistal length & $1088.48+$ & \\
\hline Maximum acromial plate dorsoventral height (c) & 563.14 & \\
\hline Minimum scapular blade dorsoventral height (a) & 235.34 (at mid-blade) & \\
\hline Maximum scapular blade dorsoventral height & $\begin{array}{l}287.53+(\text { distal } \\
\text { expansion })\end{array}$ & \\
\hline Maximum proximodistal scapular blade length & $652.19+$ & \\
\hline Maximum mediolateral scapular blade thickness (b) & 77.42 & \\
\hline (b)/(a) - relative thickness of blade & 0.33 & \\
\hline $\begin{array}{l}\text { (a) / (c) - relative acromion plate to minimum } \\
\text { scapular blade height }\end{array}$ & 0.42 & \\
\hline
\end{tabular}

2 Footnotes. All measurements in $\mathrm{mm} .+=$ full length not preserved. 
Table 3(on next page)

Humerus measurements of Winton Formation sauropods.

All measurements in $\mathrm{mm}$. 
1 Table 3. Humerus measurements of Winton Formation sauropods.

\begin{tabular}{|l|l|l|l|}
\hline & $\begin{array}{l}\text { Left } \\
\text { (Preserved) }\end{array}$ & $\begin{array}{l}\text { Right } \\
\text { (Preserved) }\end{array}$ & Model \\
\hline EMF102 Australotitan cooperensis & & & \\
\hline Maximum proximodistal length (d) & $1394.87+$ & 1494.73 & 1500.25 \\
\hline Maximum medial, proximodistal length & & 1479.75 & 1448.58 \\
\hline Maximum lateral, proximodistal length & $1329.61+$ & 1390.54 & 1433.06 \\
\hline $\begin{array}{l}\text { Maximum mediolateral width of proximal } \\
\text { epiphysis }\end{array}$ & & $<723.26$ & 667.95 \\
\hline $\begin{array}{l}\text { Maximum anteroposterior length of proximal } \\
\text { epiphysis }\end{array}$ & & $79.42+$ & 114.23 \\
\hline $\begin{array}{l}\text { Maximum mediolateral width across distal } \\
\text { condyles }\end{array}$ & $<561.87$ & $514.83+$ & 516.78 \\
\hline $\begin{array}{l}\text { Maximum anteroposterior length of distal medial } \\
\text { condyle }\end{array}$ & $118.92+$ & 186.25 & 173.11 \\
\hline $\begin{array}{l}\text { Maximum anteroposterior length of distal centro- } \\
\text { condyle }\end{array}$ & $126.46+$ & $187.27+$ & 204.31 \\
\hline $\begin{array}{l}\text { Maximum anteroposterior length of distal lateral } \\
\text { condyle }\end{array}$ & $99.44+$ & $158.15+$ & 172.02 \\
\hline Maximum midshaft mediolateral width (a) & & 333.34 & 335.81 \\
\hline Minimum midshaft anteroposterior length (b) & & 101.80 & 101.67 \\
\hline Minimum mediolateral width (c) & & 292.8 & 1621.54 \\
\hline Proximal epiphysis circumference & & $1564.36+$ & 1041.69 \\
\hline $\begin{array}{l}\text { Midshaft circumference (incl. base of } \\
\text { deltopectoral crest (dpc)) }\end{array}$ & & $1021.55+$ & 759 \\
\hline Minimum diaphyseal circumference & 1105.9 & $961.84+$ & 1131.86 \\
\hline Distal condyles circumference & 1049.68 & 1056.55 & 1105.53 \\
\hline (b)/(a) - midshaft length to width & 487.66 & $392.75+$ & 510.27 \\
\hline (c)/(d) & 1238.31 & $1351.50+$ & 1368.78 \\
\hline AODF603 Diamantinasaurus matildae & 0.30 & 0.30 \\
\hline Maximum proximodistal length (d) & 0.19 & 119.75 \\
\hline Maximum medial, proximodistal length & & 119.75 & 448.37 \\
\hline Maximum lateral, proximodistal length & $403.44+$ \\
\hline $\begin{array}{l}\text { Maximum mediolateral width of proximal } \\
\text { epiphysis }\end{array}$ & & $1056.34+$ & \\
\hline $\begin{array}{l}\text { Maximum anteroposterior length of proximal } \\
\text { epiphysis }\end{array}$ & & & $1154.56+$ \\
\hline $\begin{array}{l}\text { Maximum mediolateral width across distal } \\
\text { condyles }\end{array}$ & & & \\
\hline
\end{tabular}




\begin{tabular}{|c|c|c|c|}
\hline $\begin{array}{l}\text { Maximum anteroposterior length of distal medial } \\
\text { condyle }\end{array}$ & & 208.16 & 208.16 \\
\hline $\begin{array}{l}\text { Maximum anteroposterior length of distal lateral } \\
\text { condyle }\end{array}$ & & 195.19 & 195.19 \\
\hline Maximum midshaft mediolateral width (a) & 229.38 & 230.38 & 230.38 \\
\hline Minimum midshaft anteroposterior length (b) & & 81.4 & 81.4 \\
\hline Minimum mediolateral width (c) & & & 234.11 \\
\hline Proximal epiphysis circumference & $\overline{735.29+}$ & $1047.71+$ & 1338.46 \\
\hline Midshaft circumference (incl. base of dpc) & $331.62+$ & 580.83 & 580.83 \\
\hline Minimum diaphyseal circumference & & & 559.26 \\
\hline Distal condyles circumference & $627.37+$ & 1099.51 & 1128.89 \\
\hline (b)/(a) - midshaft length to width & & 0.35 & 0.35 \\
\hline$(\mathrm{c}) /(\mathrm{d})$ & & & 0.20 \\
\hline \multicolumn{4}{|l|}{ QMF7292 Wintonotitan wattsi } \\
\hline Maximum proximodistal length (d) & $787.55+$ & $617.05+$ & $924.45+$ \\
\hline Maximum medial, proximodistal length & $\mathrm{n} / \mathrm{a}$ & $575.09+$ & $785.63+$ \\
\hline Maximum lateral, proximodistal length & $726.01+$ & & $878.31+$ \\
\hline $\begin{array}{l}\text { Maximum mediolateral width of proximal } \\
\text { epiphysis }\end{array}$ & $333.58+$ & & $333.58+$ \\
\hline $\begin{array}{l}\text { Maximum anteroposterior length of proximal } \\
\text { epiphysis }\end{array}$ & $71.7+$ & & $71.7+$ \\
\hline Maximum midshaft mediolateral width (a) & $183.49+$ & $100.14+$ & 241.15 \\
\hline Minimum midshaft anteroposterior length (b) & 115.72 & $94.71+$ & 115.72 \\
\hline Minimum mediolateral width (c) & & & 248.81 \\
\hline Midshaft circumference (incl. base of dpc) & $447.16+$ & $187.92+$ & 674.30 \\
\hline Minimum diaphyseal circumference & & & 583.48 \\
\hline (b)/(a) - midshaft length to width & & & 0.48 \\
\hline \multicolumn{4}{|l|}{ AODF660 Savannasaurus elliottorum } \\
\hline Maximum proximodistal length $(\mathrm{d})$ & $577.34+$ & $1020.78+$ & 1112 est. \\
\hline Maximum medial, proximodistal length & & $864.07+$ & $864.07+$ \\
\hline Maximum lateral, proximodistal length & & $878.6^{+}$ & $878.6+$ \\
\hline $\begin{array}{l}\text { Maximum mediolateral width of proximal } \\
\text { epiphysis }\end{array}$ & & $300.73+$ & $300.73+$ \\
\hline Maximum midshaft mediolateral width (a) & $232.6+$ & 243.55 & 243.55 \\
\hline Minimum midshaft anteroposterior length (b) & 136.77 & $<171.97$ & 136.77 \\
\hline Minimum mediolateral width (c) & & & 223.30 \\
\hline Midshaft circumference (incl. base of dpc) & $666.49+$ & $<727.66$ & 713.04 \\
\hline Minimum diaphyseal circumference & & & 601.54 \\
\hline (b)/(a) - midshaft length to width & & & 0.56 \\
\hline
\end{tabular}


2 Footnotes. All measurements in $\mathrm{mm} .+=$ full length not preserved, est. $=$ estimated, $<=$ less 3 than.

4 
Table 4 (on next page)

Ulna measurements of Winton Formation sauropods.

All measurements in $\mathrm{mm}$. 
1 Table 4. Ulna measurements of Winton Formation sauropods.

\begin{tabular}{|l|l|l|}
\hline & Preserved & Reconstructed \\
\hline EMF102 Australotitan cooperensis & & \\
\hline Maximum proximodistal length & $1043.90+$ & 1056.35 \\
\hline Olecranon - anteromedial process length & $501.34+$ & 518.46 \\
\hline Olecranon - anterolateral process length & 298.85 & 298.85 \\
\hline Maximum distal condylar width & $225.05+$ & 241.67 \\
\hline Minimum distal condylar width & $122.65+$ & 134.72 \\
\hline Angle formed (amp-oc-alp) & $48^{\circ}$ & $48^{\circ}$ \\
\hline Angle formed (oc-alp-amp) & $102^{\circ}$ & $102^{\circ}$ \\
\hline Angle formed (alp-amp-oc) & $29^{\circ}$ & $29^{\circ}$ \\
\hline AODF603 Diamantinasaurus matildae & & \\
\hline Maximum proximodistal length & 727.83 & \\
\hline Olecranon - anteromedial process length & 359.09 & \\
\hline Olecranon - anterolateral process length & 321.98 & \\
\hline Maximum distal condylar width & 204.37 & \\
\hline Minimum distal condylar width & 157.53 & \\
\hline Angle formed (amp-oc-alp) & $51^{\circ}$ & \\
\hline Angle formed (oc-alp-amp) & $71^{\circ}$ & \\
\hline Angle formed (alp-amp-oc) & $57^{\circ}$ & \\
\hline QMF7292 Wintonotitan wattsi & & \\
\hline Maximum proximodistal length & $897.39+$ & \\
\hline Olecranon - anterolateral process length & $326.42+$ & \\
\hline Foototes Al & \\
\hline
\end{tabular}

2 Footnotes. All measurements in $\mathrm{mm} .+=$ full length not preserved, ${ }^{\circ}$ degree of angle. 
Table 5 (on next page)

Pubes measurements of Winton Formation sauropods.

All measurements in $\mathrm{mm}$. 
1 Table 5. Pubes measurements of Winton Formation sauropods.

\begin{tabular}{|l|l|l|l|}
\hline & Preserved & Preserved & Reconstructed \\
\hline EMF102 Australotitan cooperensis & Left & Right & \\
\hline Maximum pubis length & 1262.77 & $1206.7+$ & \\
\hline Maximum proximolateral to distolateral length (b) & 1118.73 & $1035.18+$ & \\
\hline Maximum length of ischial peduncle & 628.22 & $615.27+$ & \\
\hline Maximum anteroposterior acetabular length & 389.58 & n/a & \\
\hline Maximum mediolateral mid-blade distance (a) & 514.98 & $405.26+$ & \\
\hline Maximum mediolateral distal-blade length & 513.46 & $492.96+$ & \\
\hline Maximum anteroposterior iliac peduncle length (c) & 414.21 & & \\
\hline Maximum mediolateral iliac peduncle width (d) & 158.51 & & \\
\hline Maximum obturator foramen length & 113.87 & 112.41 & \\
\hline Maximum obturator foramen width & 86.43 & 73.28 & \\
\hline Distance between anterior margin of iliac peduncles & & & 1564.32 \\
\hline (a)/(b) & 0.46 & & \\
\hline (c)/(d) & 2.61 & & \\
\hline AODF603 Diamantinasaurus matildae & & & \\
\hline Maximum pubis length & 1056.28 & 1082.88 & \\
\hline Maximum proximolateral to distolateral length (b) & 942.25 & 957.12 & \\
\hline Maximum length of ischial peduncle & 413.24 & $379.21+$ & \\
\hline Maximum anteroposterior acetabular length & 441.29 & 348.15 & \\
\hline Maximum mediolateral mid-blade distance (a) & 386.65 & 370.9 & \\
\hline Maximum mediolateral distal-blade length & 305.24 & 357.74 & \\
\hline Maximum anteroposterior iliac peduncle length (c) & 297.65 & 280.55 & \\
\hline Maximum mediolateral iliac peduncle width (d) & 113.20 & 99.86 & \\
\hline Maximum obturator foramen length & 71.92 & 80.76 & \\
\hline Maximum obturator foramen width & 57.45 & 60.55 & \\
\hline Distance between anterior margin of iliac peduncles & & & 1219.42 \\
\hline (a)/(b) & 0.41 & 0.39 & \\
\hline (c)/(d) & 2.63 & 2.81 & \\
\hline AODF660 Savannasaurus elliottorum & & & \\
\hline Maximum pubis length & $894.13+$ & 997.18 & \\
\hline Maximum proximolateral to distolateral length (b) & $651.8+$ & 802.88 & \\
\hline Maximum length of ischial peduncle & $458.9+$ & $366.82+$ & \\
\hline Maximum anteroposterior acetabular length & & 209.65 & \\
\hline Maximum mediolateral mid-blade distance (a) & 415.58 & 420.97 & \\
\hline Maximum mediolateral distal-blade length & 409.5 & 407.46 & \\
\hline Maximum obturator foramen length & & 98.02 & \\
\hline
\end{tabular}




\begin{tabular}{|l|l|l|l|}
\hline Maximum obturator foramen width & & 52.75 & \\
\hline Distance between anterior margin of iliac peduncles & & & $1083.71+$ \\
\hline (a)/(b) & & 0.52 & \\
\hline
\end{tabular}

2 Footnotes. All measurements in $\mathrm{mm} .+=$ full length not preserved. 
Table 6(on next page)

Ischia measurements of Winton Formation sauropods.

All measurements in $\mathrm{mm}$. 
1 Table 6. Ischia measurements of Winton Formation sauropods.

\begin{tabular}{|l|l|l|l|}
\hline & Preserved & Preserved & Reconstructed \\
\hline EMF102 Australotitan cooperensis & Left & Right & \\
\hline Maximum ischial length & 901.23 & $879.87+$ & \\
\hline Maximum proximolateral to distomedial length & 644.46 & $577.35+$ & \\
\hline Maximum length of pubic peduncle & 600.37 & 614.43 & \\
\hline Maximum anteroposterior acetabular length (a) & 213.94 & & \\
\hline Maximum anteroposterior mid-blade length (b) & 274.97 & $250.05+$ & \\
\hline $\begin{array}{l}\text { Maximum dorsoventral (anteroposterior) distal-shaft } \\
\text { width (c) }\end{array}$ & 423.05 & & \\
\hline $\begin{array}{l}\text { Minimum dorsoventral (anteroposterior) ischial blade } \\
\text { width (d) }\end{array}$ & 259.15 & & \\
\hline Maximum anteroposterior iliac peduncle length & 227.81 & & \\
\hline Maximum mediolateral iliac peduncle width & 117.49 & & 1171.71 \\
\hline Distance between iliac peduncles (mirrored) & & & \\
\hline $\begin{array}{l}\text { Posterior-most medial projection to posterior-most } \\
\text { point on iliac peduncle }\end{array}$ & 602.5 & & \\
\hline $\begin{array}{l}\text { Posterior-most medial projection to anterior-most } \\
\text { pubic peduncle }\end{array}$ & 425.6 & 381.12 & \\
\hline (a)/(b) & 0.78 & 220.23 & \\
\hline (c)/(d) & 1.63 & 176.69 & \\
\hline AODF603 Diamantinasaurus matildae & & 56.63 & \\
\hline Maximum ischial length & & $366.73+$ & \\
\hline Maximum proximolateral to distomedial length & & 182.93 & \\
\hline Maximum length of pubic peduncle & & & \\
\hline Maximum anteroposterior acetabular length (a) & & & \\
\hline Maximum anteroposterior mid-blade length (b) & & & \\
\hline $\begin{array}{l}\text { Maximum dorsoventral (anteroposterior) distal-shaft } \\
\text { width (c) }\end{array}$ & & & \\
\hline $\begin{array}{l}\text { Minimum dorsoventral (anteroposterior) ischial blade } \\
\text { width (d) }\end{array}$ & & & \\
\hline Maximum anteroposterior iliac peduncle length & & & \\
\hline Maximum mediolateral iliac peduncle width & & & \\
\hline Distance between iliac peduncles & & & \\
\hline $\begin{array}{l}\text { Posterior-most medial projection to posterior-most } \\
\text { point on iliac peduncle }\end{array}$ & & & \\
\hline $\begin{array}{l}\text { Posterior-most medial projection to anterior-most } \\
\text { pubic peduncle }\end{array}$ & & & \\
\hline
\end{tabular}




\begin{tabular}{|c|c|c|c|}
\hline (a)/(b) & & 0.88 & \\
\hline$(\mathrm{c}) /(\mathrm{d})$ & & 1.73 & \\
\hline \multicolumn{4}{|l|}{ QMF7292 Wintonotitan wattsi } \\
\hline Maximum ischial length & $776.9+$ & & \\
\hline Maximum proximolateral to distomedial length & $643.5+$ & & \\
\hline Maximum length of pubic peduncle & $337.6+$ & & \\
\hline Maximum anteroposterior acetabular length (a) & 271.3 & & \\
\hline Maximum anteroposterior mid-blade length (b) & 276.6 & & \\
\hline $\begin{array}{l}\text { Maximum dorsoventral (anteroposterior) distal-shaft } \\
\text { width (c) }\end{array}$ & $\begin{array}{l}274.1+(420 \\
\text { est. })\end{array}$ & & \\
\hline $\begin{array}{l}\text { Minimum dorsoventral (anteroposterior) ischial blade } \\
\text { width (d) }\end{array}$ & 255.23 & & \\
\hline Distance between iliac peduncles & & & 1065 est. \\
\hline $\begin{array}{l}\text { Posterior-most medial projection to posterior-most } \\
\text { point on iliac peduncle }\end{array}$ & 616.92 & & \\
\hline $\begin{array}{l}\text { Posterior-most medial projection to anterior-most } \\
\text { pubic peduncle }\end{array}$ & 413.69 & & \\
\hline (a)/(b) & 0.98 & & \\
\hline (c)/(d) & 1.64 est. & & \\
\hline \multicolumn{4}{|l|}{ AODF660 Savannasaurus elliottorum } \\
\hline Maximum ischial length & $578.28+$ & 656.08 & \\
\hline Maximum proximolateral to distomedial length & $546.49+$ & 601.44 & \\
\hline Maximum length of pubic peduncle & $449.59+$ & $375.46+$ & \\
\hline Maximum anteroposterior acetabular length (a) & & 198.89 & \\
\hline Maximum anteroposterior mid-blade length (b) & 235.67 & 227.67 & \\
\hline $\begin{array}{l}\text { Maximum dorsoventral (anteroposterior) distal-shaft } \\
\text { width (c) }\end{array}$ & 415.22 & 403.22 & \\
\hline $\begin{array}{l}\text { Minimum dorsoventral (anteroposterior) ischial blade } \\
\text { width (d) }\end{array}$ & 238.32 & 233.5 & \\
\hline Maximum anteroposterior iliac peduncle length & & 189.59 & \\
\hline Maximum mediolateral iliac peduncle width & & 82.11 & \\
\hline Distance between iliac peduncles & & & $\begin{array}{l}1045.87+ \\
1078 \text { est. }\end{array}$ \\
\hline $\begin{array}{l}\text { Posterior-most medial projection to posterior-most } \\
\text { point on iliac peduncle }\end{array}$ & 611.7 & & \\
\hline $\begin{array}{l}\text { Posterior-most medial projection to anterior-most } \\
\text { pubic peduncle }\end{array}$ & 392.47 & & \\
\hline$(a) /(b)$ & & 0.87 & \\
\hline$(\mathrm{c}) /(\mathrm{d})$ & 1.74 & 1.73 & \\
\hline
\end{tabular}


2 Footnotes. All measurements in $\mathrm{mm} .+=$ full length not preserved, est. $=$ estimated.

3

4

5

6 
Table 7 (on next page)

Femur measurements of Winton Formation sauropods.

All measurements in $\mathrm{mm}$. 
1 Table 7. Femur measurements of Winton Formation sauropods.

\begin{tabular}{|c|c|c|c|}
\hline & Preserved & $\begin{array}{l}\text { Estimate } 1 \\
\text { reconstruction }\end{array}$ & $\begin{array}{l}\text { Estimate 2 } \\
\text { EMF105 }\end{array}$ \\
\hline \multicolumn{4}{|l|}{ EMF102 Australotitan cooperensis (holotype) } \\
\hline Maximum proximodistal length (b) & & 1886.02 & 1888.32 \\
\hline Maximum medial, proximodistal length & $\begin{array}{l}1587.76+ \\
\text { (right) }\end{array}$ & 1854.44 & 1791.32 \\
\hline Maximum lateral, proximodistal length & $\begin{array}{l}1582.46+ \\
\text { (right) }\end{array}$ & 1833.52 & 1795.69 \\
\hline $\begin{array}{l}\text { Maximum mediolateral width of proximal } \\
\text { epiphysis }\end{array}$ & $525.53+$ (left) & 626.93 & 611.85 \\
\hline $\begin{array}{l}\text { Maximum anteroposterior length of proximal } \\
\text { epiphysis }\end{array}$ & $161.9+($ left $)$ & 213.16 & 276.88 \\
\hline $\begin{array}{l}\text { Maximum mediolateral width across distal } \\
\text { condyles }\end{array}$ & 584.79 & 588.76 & 611.23 \\
\hline $\begin{array}{l}\text { Maximum anteroposterior length of distal medial } \\
\text { condyle }\end{array}$ & $357.72+$ & 363.64 & 375.12 \\
\hline $\begin{array}{l}\text { Maximum anteroposterior length of distal lateral } \\
\text { condyle }\end{array}$ & $316.29+$ & 324.63 & $332.69+$ \\
\hline Maximum midshaft mediolateral width (a) & $<466.03$ & 460.09 & 409.63 \\
\hline Minimum midshaft anteroposterior width & $166.21+$ & 189.56 & 167.69 \\
\hline Proximal epiphysis circumference & $1148.61+$ & 1389.47 & 1427.78 \\
\hline Midshaft circumference & $992.70+$ & 1095.46 & 1018.37 \\
\hline Minimum diaphyseal circumference & 932.8 & 932.8 & 915.9 \\
\hline Distal condyles circumference & $1772.86+$ & 1937.46 & $1757.5+$ \\
\hline$(\mathrm{a}) /(\mathrm{b})$ & & 0.24 & 0.21 \\
\hline \multicolumn{4}{|l|}{ EMF105 Australotitan cooperensis (referred) } \\
\hline Maximum proximodistal length (b) & 1412.32 & 1412.32 & \\
\hline Maximum medial, proximodistal length & 1310.42 & 1310.42 & \\
\hline Maximum lateral, proximodistal length & 1379.44 & 1379.44 & \\
\hline $\begin{array}{l}\text { Maximum mediolateral width of proximal } \\
\text { epiphysis }\end{array}$ & 469.77 & 469.77 & \\
\hline $\begin{array}{l}\text { Maximum anteroposterior length of proximal } \\
\text { epiphysis }\end{array}$ & $219.82+$ & 232.41 & \\
\hline $\begin{array}{l}\text { Maximum mediolateral width across distal } \\
\text { condyles }\end{array}$ & 470.88 & 470.88 & \\
\hline $\begin{array}{l}\text { Maximum anteroposterior length of distal medial } \\
\text { condyle }\end{array}$ & $279.32+$ & 320.49 & \\
\hline $\begin{array}{l}\text { Maximum anteroposterior length of distal lateral } \\
\text { condyle }\end{array}$ & $251.04+$ & 296.94 & \\
\hline
\end{tabular}




\begin{tabular}{|l|l|l|l|}
\hline Maximum midshaft mediolateral width (a) & 298.99 & 298.99 & \\
\hline Minimum midshaft anteroposterior width & 143.16 & 143.16 & \\
\hline Proximal epiphysis circumference & $1123.53+$ & 1134.25 & \\
\hline Midshaft circumference & 733.74 & 733.74 & \\
\hline Minimum diaphyseal circumference & 717.91 & 717.91 & \\
\hline Distal condyles circumference & $1273.13+$ & 1443.93 & \\
\hline (a)/(b) & 0.21 & & \\
\hline AODF604 Diamantinasaurus matildae & & & \\
\hline Maximum proximodistal length (b) & 1357.87 & & \\
\hline Maximum medial, proximodistal length & 1297.88 & & \\
\hline Maximum lateral, proximodistal length & 1336.72 & & \\
\hline $\begin{array}{l}\text { Maximum mediolateral width of proximal } \\
\text { epiphysis }\end{array}$ & 412.5 & & \\
\hline $\begin{array}{l}\text { Maximum anteroposterior length of proximal } \\
\text { epiphysis }\end{array}$ & 187.42 & & \\
\hline $\begin{array}{l}\text { Maximum mediolateral width across distal } \\
\text { condyles }\end{array}$ & 488.57 & & \\
\hline $\begin{array}{l}\text { Maximum anteroposterior length of distal medial } \\
\text { condyle }\end{array}$ & 255.32 & & \\
\hline $\begin{array}{l}\text { Maximum anteroposterior length of distal lateral } \\
\text { condyle }\end{array}$ & 235.43 & & \\
\hline Maximum midshaft mediolateral width (a) & 274.21 & & \\
\hline Minimum midshaft anteroposterior width & 104.54 & & \\
\hline Proximal epiphysis circumference & 902.19 & & \\
\hline Midshaft circumference & 661.92 & & \\
\hline Distal condyles circumference & 1366.26 & & \\
\hline (a)/(b) & 0.20 & & \\
\hline QMF43302 ?Wintontitan wattsi & 1505.68 & & \\
\hline Maximum proximodistal length (b) & $1430.59+$ & & \\
\hline Maximum medial, proximodistal length & $388.78+$ & & \\
\hline Maximum lateral, proximodistal length & $188.98+$ & & \\
\hline $\begin{array}{l}\text { Maximum mediolateral width of proximal } \\
\text { epiphysis }\end{array}$ & 436.86 & & \\
\hline $\begin{array}{l}\text { Maximum anteroposterior length of proximal } \\
\text { epiphysis }\end{array}$ & $202.89+$ & & \\
\hline $\begin{array}{l}\text { Maximum mediolateral width across distal } \\
\text { condyles }\end{array}$ & & & \\
\hline $\begin{array}{l}\text { Maximum anteroposterior length of distal medial } \\
\text { condyle }\end{array}$ & & & \\
\hline
\end{tabular}




\begin{tabular}{|l|l|l|l|}
\hline $\begin{array}{l}\text { Maximum anteroposterior length of distal lateral } \\
\text { condyle }\end{array}$ & $161.68+$ & & \\
\hline
\end{tabular}

2 Footnotes. All measurements in $\mathrm{mm} .+=$ full length not preserved, $<=$ less than

3

4

5 


\section{Table 8 (on next page)}

Synapomorphies of Titanosauria in Australian Taxa.

Synapomorphies of Titanosauria from (González Riga et al. 2019) 


\section{Table 8. Synapomorphies of Titanosauria in Australian Taxa.}

2

\begin{tabular}{|c|c|c|c|c|c|}
\hline Synapomorphy & Clade & $\begin{array}{l}\text { Australotitan } \\
\text { cooperensis }\end{array}$ & $\begin{array}{l}\text { Diamantinasaurus } \\
\text { matildae }\end{array}$ & $\begin{array}{l}\text { Wintonotitan } \\
\text { wattsi }\end{array}$ & $\begin{array}{l}\text { Savannasaurus } \\
\text { elliottorum }\end{array}$ \\
\hline \multicolumn{6}{|l|}{ Scapula } \\
\hline $\begin{array}{l}\text { Scapula, ventral } \\
\text { margin with well- } \\
\text { developed } \\
\text { ventromedial } \\
\text { process }\end{array}$ & Titanosauria & $?$ & 田 & 队 & $?$ \\
\hline \multicolumn{6}{|l|}{ Humerus } \\
\hline $\begin{array}{l}\text { humerus length } \\
\text { less than } 80 \% \\
\text { femur length }\end{array}$ & Saltasauridae & ß $(\sim 79 \%)$ & 咉 $(85 \%)$ & $?$ & $?$ \\
\hline $\begin{array}{l}\text { deltopectoral crest } \\
\text { extends medially } \\
\text { across anterior face }\end{array}$ & Titanosauria & $\begin{array}{l}\text { 厄 - less than } \\
\text { Saltasaurus / } \\
\text { Opithsocoelicaudia }\end{array}$ & $\begin{array}{l}\text { Po - less than } \\
\text { Saltasaurus / } \\
\text { Opithsocoelicaudia }\end{array}$ & $?$ & $?$ \\
\hline $\begin{array}{l}\text { deltopectoral crest } \\
\text { strongly expanded } \\
\text { distally }\end{array}$ & Saltasauridae & per & per & per & pe \\
\hline $\begin{array}{l}\text { strong } \\
\text { posterolateral } \\
\text { bulge around level } \\
\text { of deltopectoral } \\
\text { crest }\end{array}$ & Saltasauridae & $?$ & pe & per & pe \\
\hline $\begin{array}{l}\text { radial and ulnar } \\
\text { condyles divided } \\
\text { distally }\end{array}$ & $\begin{array}{l}\text { Alamosaurus } \\
+ \\
\text { 'Saltasaurini' }\end{array}$ & 色 & per & $?$ & $?$ \\
\hline $\begin{array}{l}\text { Anterior surface of } \\
\text { distal lateral } \\
\text { condyle of } \\
\text { humerus undivided }\end{array}$ & Lithostrotia & pe & per & $?$ & $?$ \\
\hline \multicolumn{6}{|l|}{ Radius } \\
\hline $\begin{array}{l}\text { radius distal end } \\
\text { beveled } \sim 20^{\circ} \\
\text { proximolaterally } \\
\text { relative to shaft }\end{array}$ & Saltasauridae & $?$ & 层 & $\begin{array}{l}\text { ß - poorly } \\
\text { preserved }\end{array}$ & pe \\
\hline \multicolumn{6}{|l|}{ Ulna } \\
\hline Prominent & Lithostrotia & 队2 & B & ß? & $?$ \\
\hline
\end{tabular}




\begin{tabular}{|c|c|c|c|c|c|}
\hline $\begin{array}{l}\text { olecranon process, } \\
\text { projecting well } \\
\text { above proximal } \\
\text { articulation }\end{array}$ & & & & & \\
\hline \multicolumn{6}{|l|}{ Manus } \\
\hline $\begin{array}{l}\text { Metacarpal } \\
\text { I:metacarpal II/III } \\
\text { proximodistal } \\
\text { length ratio } \geq 1.0\end{array}$ & Lithostrotia & $?$ & per & $?$ & 角 \\
\hline \multicolumn{6}{|l|}{ Pubis } \\
\hline $\begin{array}{l}\text { Anteroposterior to } \\
\text { mediolateral width } \\
\text { ratio of iliac } \\
\text { articular surface of } \\
\text { pubis } \geq 2.0\end{array}$ & Titanosauria & 网 & 厄 & $?$ & $?$ \\
\hline \multicolumn{6}{|l|}{ Ischium } \\
\hline $\begin{array}{l}\text { Acetabular margin } \\
\text { of ischium strongly } \\
\text { concave in lateral } \\
\text { view such that } \\
\text { pubic articular } \\
\text { surface forms } \\
\text { proximodorsal } \\
\text { projection }\end{array}$ & $\begin{array}{l}\text { Titanosauria } \\
\text { or } \\
\text { Lithostrotia }\end{array}$ & 队2 & 厄 & ß? & $\beta$ \\
\hline $\begin{array}{l}\text { No emargination of } \\
\text { ischium distal to } \\
\text { pubic articulation }\end{array}$ & Titanosauria & 网 & 死 & 厄? & 四 \\
\hline $\begin{array}{l}\text { Ratio of } \\
\text { dorsoventral width } \\
\text { of distal end of } \\
\text { ischial shaft: } \\
\text { minimum shaft } \\
\text { dorsoventral width } \\
<1.5\end{array}$ & Titanosauria & 的 (1.63) & 娟(1.73) & pe $(\sim 1.64)$ & 的 (1.74) \\
\hline \multicolumn{6}{|l|}{ Femur } \\
\hline $\begin{array}{l}\text { Femur with } \\
\text { longitudinal ridge } \\
\text { on } \\
\text { anterior face of } \\
\text { shaft }\end{array}$ & $\begin{array}{l}\text { Alamosaurus } \\
+ \\
\text { 'Saltasaurini' }\end{array}$ & 队2 & 层 & $?$ & $?$ \\
\hline
\end{tabular}




\begin{tabular}{|c|c|c|c|c|c|}
\hline $\begin{array}{l}\text { Femoral distal } \\
\text { condyles beveled } \\
10^{\circ} \text { dorsomedially } \\
\text { relative to shaft }\end{array}$ & Saltasauridae & $\begin{array}{l}\text { B - less than } \\
\text { Saltasaurus / } \\
\text { Bonatitan }\end{array}$ & $\begin{array}{l}\text { B - less than } \\
\text { Saltasaurus / } \\
\text { Bonatitan }\end{array}$ & $?$ & $?$ \\
\hline $\begin{array}{l}\text { \% of known } \\
\text { characters }\end{array}$ & & $75 \%$ & $100 \%$ & $31-50 \%$ & $43 \%$ \\
\hline \multicolumn{6}{|l|}{ Shared Characters } \\
\hline Not Titanosauria & & 1 & 1 & 1 & 1 \\
\hline $\begin{array}{l}\text { Within } \\
\text { Titanosauria }\end{array}$ & & 8 & 9 & $\begin{array}{l}2+3 \\
\text { possible }\end{array}$ & 2 \\
\hline $\begin{array}{l}\text { Within Lithostrotia } \\
\text { or Saltasaurini } \\
\text { /Saltasauridae }\end{array}$ & & 5 & 5 & $\begin{array}{l}1+2 \\
\text { possible }\end{array}$ & 1 \\
\hline $\begin{array}{l}\text { Not within } \\
\text { Lithostrotia or } \\
\text { Saltasaurini / } \\
\text { Saltasauridae }\end{array}$ & & 4 & 8 & 3 & 5 \\
\hline
\end{tabular}

3 Footnotes. Synapomorphies of Titanosauria from (González Riga et al. 2019)

4

5 


\section{Table 9 (on next page)}

Shared features between two or more Australian species.

*assumed present due to ubiquitous presence within the Winton Formation (See Discussion). 
1 Table 9. Shared features between two or more Australian species.

2

\begin{tabular}{|c|c|c|c|c|}
\hline Characteristic & Australotitan & Diamantinasaurus & Wintontitan & Savannasaurus \\
\hline \multicolumn{5}{|l|}{ Scapula } \\
\hline $\begin{array}{l}\text { Medial } \\
\text { tuberosity on } \\
\text { the proximal } \\
\text { scapular blade }\end{array}$ & per & $\beta$ & $\beta$ & $?$ \\
\hline $\begin{array}{l}\text { Proximoventral } \\
\text { process }\end{array}$ & $?$ & $\beta$ & $\beta$ & $?$ \\
\hline \multicolumn{5}{|l|}{ Humerus } \\
\hline $\begin{array}{l}\text { Midshaft cross- } \\
\text { sectional shape }\end{array}$ & $\begin{array}{l}\text { Mediolaterally } \\
\text { broad, } \\
\text { anteroposteriorly } \\
\text { narrow }\end{array}$ & $\begin{array}{l}\text { Mediolaterally } \\
\text { broad, } \\
\text { anteroposteriorly } \\
\text { narrow }\end{array}$ & $\begin{array}{l}\text { Mediolateral } \\
\text { breadth similar } \\
\text { to } \\
\text { anteroposterior } \\
\text { length }\end{array}$ & $\begin{array}{l}\text { Mediolateral } \\
\text { breadth similar } \\
\text { to } \\
\text { anteroposterior } \\
\text { length }\end{array}$ \\
\hline \multicolumn{5}{|l|}{ Pubis } \\
\hline $\begin{array}{l}\text { Dorsoventral } \\
\text { thickness along } \\
\text { pubic blade. }\end{array}$ & Thin & Thick & $?$ & Thin \\
\hline \multicolumn{5}{|l|}{ Ischium } \\
\hline $\begin{array}{l}\text { Distal ischial } \\
\text { blade ventrally } \\
\text { curved, dorsal } \\
\text { margin } \\
\text { posteriorly } \\
\text { facing. }\end{array}$ & $\beta$ & per & ?巴 & $\beta$ \\
\hline \multicolumn{5}{|l|}{$\begin{array}{l}\text { Anterior Caudal } \\
\text { Vertebrae }\end{array}$} \\
\hline Amphicoelous & 凤* & ß* & 四 & 四 \\
\hline $\begin{array}{l}\text { Pneumatic } \\
\text { neural arch and } \\
\text { zygopophyses }\end{array}$ & $?$ & $?$ & $\beta$ & $\beta$ \\
\hline $\begin{array}{l}\text { Centrum } \\
\text { cancellous }\end{array}$ & 目* & ß* & $\beta$ & 四 \\
\hline
\end{tabular}

3 Footnote: *assumed present due to ubiquitous presence within the Winton Formation (See

4 Discussion). 


\section{Table $\mathbf{1 0}$ (on next page)}

Maximum appendicular bone lengths for Australian sauropod taxa.

${ }^{1}$ (Longman 1927) . Abbreviations; pres $=$ as preserved, est $=$ estimated, recon $=$ as reconstructed. 
1 Table 10. Maximum appendicular bone lengths for Cretaceous Australian sauropod taxa.

\begin{tabular}{|l|l|l|l|l|}
\hline Taxon & Specimen & Humerus & Ulna & Femur \\
\hline $\begin{array}{l}\text { Diamantinasaurus } \\
\text { matildae }\end{array}$ & AODF603 & $1122 \mathrm{~mm}^{\text {pres }}$ & $728 \mathrm{~mm}^{\text {pres }}$ & $1358 \mathrm{~mm}^{\text {pres }}$ \\
\hline Wintonotitan wattsi & QMF7292 & $\begin{array}{l}924 \mathrm{~mm}^{\text {recon pres }} \\
1253 \mathrm{~mm}^{\text {recon est }}\end{array}$ & $\begin{array}{l}897 \mathrm{~mm}^{\text {recon pres }} \\
919 \mathrm{~mm}^{\text {recon est }}\end{array}$ & \\
\hline $\begin{array}{l}\text { Wintonotitan wattsi? } \\
\begin{array}{l}\text { Savannasaurus } \\
\text { elliottorum }\end{array}\end{array}$ QMF43302 & & & $1505 \mathrm{~mm}^{\text {pres }}$ \\
\hline $\begin{array}{l}\text { Australotitan } \\
\text { cooperensis }\end{array}$ & EODF660 & $1020 \mathrm{~mm}^{\text {recon pres }}$ & & $1600 \mathrm{~mm}^{\text {est }}$ \\
\hline $\begin{array}{l}\text { Australotitan } \\
\text { cooperensis (referred) }\end{array}$ & EMF164 & $1112^{\text {recon est }}$ & & \\
\hline
\end{tabular}

2 Footnote: ${ }^{1}$ (Longman 1927). Abbreviations; pres $=$ as preserved, est $=$ estimated, recon $=$ as

3 reconstructed. 


\section{Figure 1}

Vertebrate fossil sites of the Winton Formation (Eromanga Basin).

Geographical map data from ( http://pid.geoscience.gov.au/dataset/ga/61754 ) used under CC-BY 4.0 AU. Geological datasets, including the distribution and interpretation of the Quaternary, Winton and Mackunda Formations and their associated and interpreted structures were combined using QGIS 3.14.1 software ( http://agis.org ) with data retrieved for; Northern Territory from STRIKE ( http://strike.nt.gov.au/wss.html ) under CC-BY 4.0; South Australia from SARIG (http:/map.sarig.sa.gov.au) under CC-BY 3.0 AU; Queensland from QGlobe ( http://aldglobe.information.qld.gov.au ) under CC-BY 4.0; New South Wales and overall Eromanga Basin structure retrieved from (Raymond et al. 2012) ( http://ga.gov.au ) used under CC-BY 3.0 AU. Great Artesian (Australian) (Ransley \& Smerdon 2012) . 


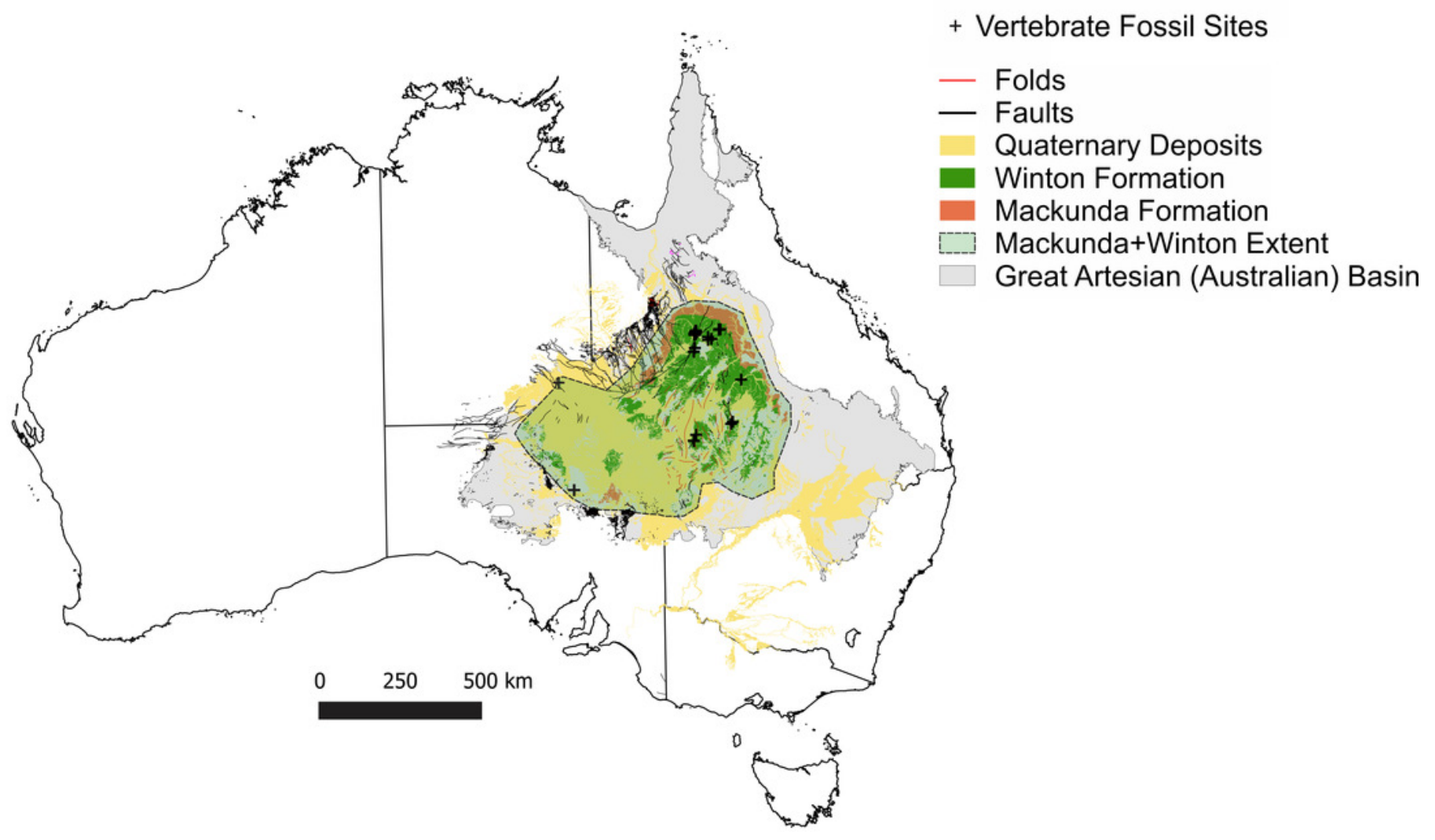




\section{Figure 2}

Distribution of vertebrate fossil sites within the Winton Formation with regionally mapped geology and geological structures relating to the fossil sites described here.

(A) The Winton Formation is here divided into five provinces of known vertebrate fossil sites, including a northern (Winton-Opalton region), central-eastern (Isisford), southern-central (Eromanga-Quilpie region), south-western (Kati Thunda / Lake Eyre) and western (MungaThirri / Simpson Desert). South-eastern semi-contemporaneous Griman Creek Formation (Lightning Ridge). Sauropod Type Localities, 1. QML313 (Wintonotitan wattsi); 2. AODL085 (Diamantinasaurus matildae), 3. AODL082 (Savannasaurus elliottorum) and 4. EML010 (Australotitan cooperensis gen. et sp. nov.). (B) New vertebrate fossil sites of the southerncentral Winton Formation described here including the type locality for $A$. cooperensis gen. et sp. nov. (EML011). Cross-sectional line (NW-SE) shown in Figure 4, A. Seismic line (83-NJZ) cross-sectional interpretation shown in Figure 4, B. Geographical map data from ( http://pid.geoscience.gov.au/dataset/ga/61754 ) used under CC-BY 4.0 AU. Geological datasets, including the distribution and interpretation of the Quaternary, Alluvium, Sand Dunes, Glendower, Winton and Mackunda Formations and their associated and interpreted structures were combined using QGIS 3.14.1 software ( http://qgis.org ) with data retrieved for; Northern Territory from STRIKE ( http://strike.nt.gov.au/wss.html ) under CC-BY 4.0; South Australia from SARIG (http:/map.sarig.sa.gov.au) under CC-BY 3.0 AU; Queensland from QGlobe ( http://qldglobe.information.qld.gov.au ) under CC-BY 4.0; New South Wales and overall Eromanga Basin structure retrieved from (Raymond et al. 2012) ( http://ga.gov.au ) used under CC-BY 3.0 AU. Great Artesian (Australian) Basin (Ransley \& Smerdon 2012) . Detailed southern-central geological structures, bores, wells and seismic data retrieved from Qglobe ( http://laldglobe.information.qld.gov.au ) under CC-BY 4.0. 

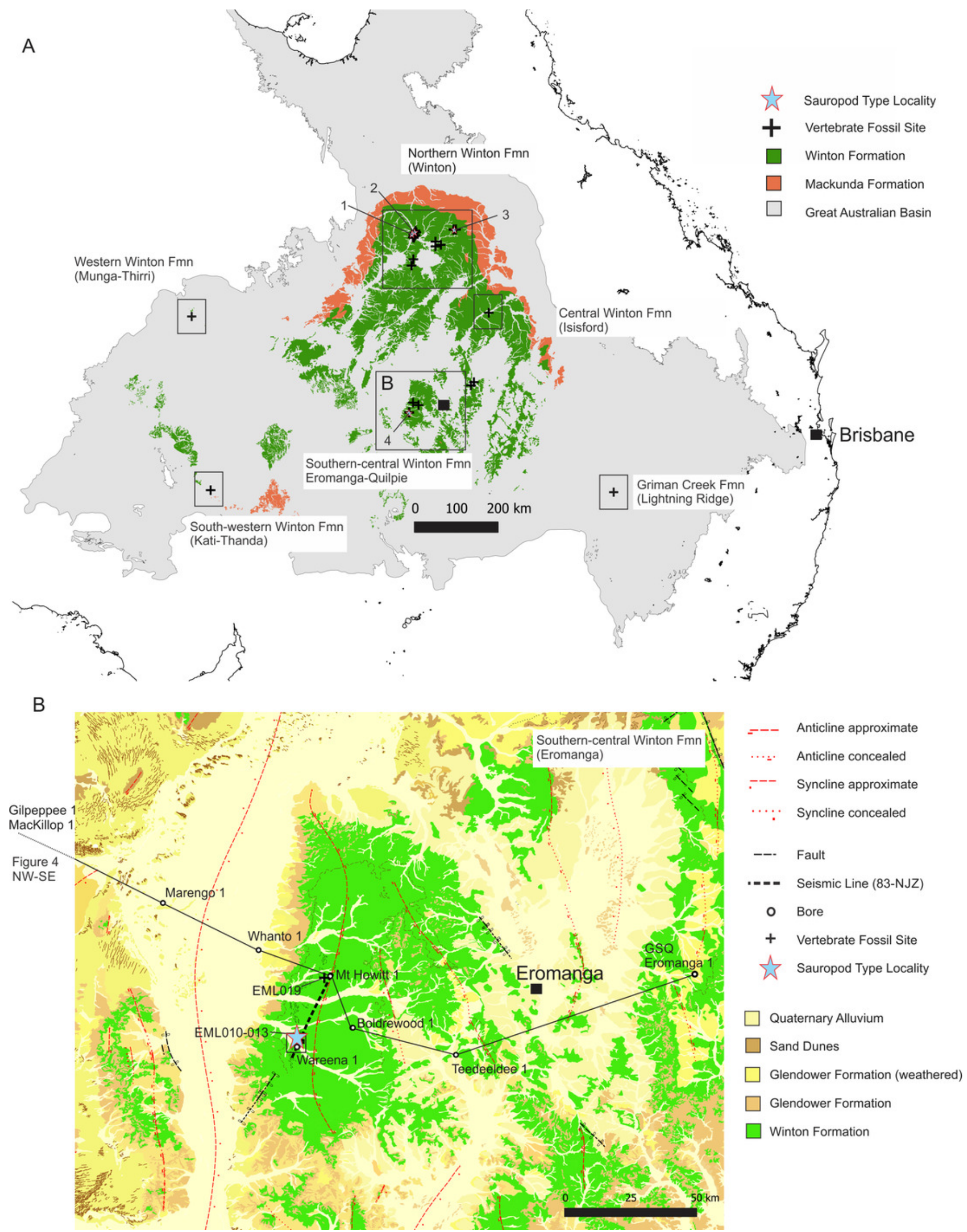


\section{Figure 3}

Distribution of weathering depths of regolith and soil depth, relative to the Winton Formation.

(A) Regolith depth illustrates the significantly deep weathering throughout central and southern Eromanga Basin, which has significantly influenced the Winton Formation in terms of geochemical alteration and post-diagenetic alterations at vertebrate fossil localities. (B) Soil depth illustrates relatively deep soil profiles associated with vertebrate fossils sites from the Winton Formation, reflecting the impact of soil forming processes on available outcrop and vertebrate fossil preservation and exposure. Geographical map data from ( http://pid.geoscience.gov.au/dataset/ga/61754 ) used under CC-BY 4.0 AU. Soil Depth dataset retrieved from CSIRO Soil and Landscape Grid National Soil Attribute Maps ( https://data.csiro.au/dap/ ) under CC-BY 4.0. Regolith Depth dataset (Wilford et al. 2016) retrieved from CSIRO Soil and Landscape Grid National Soil Attribute Maps ( https://data.csiro.au/dap/ ) under CC-BY 4.0. Outline of Winton and Mackunda formations retrieved for; Northern Territory from STRIKE ( http://strike.nt.gov.au/wss.html ) under CC-BY 4.0; South Australia from SARIG (http:/map.sarig.sa.gov.au) under CC-BY 3.0 AU; Queensland from QGlobe ( http://qldglobe.information.gld.gov.au ) under CC-BY 4.0; New South Wales and overall Eromanga Basin structure retrieved from (Raymond et al. 2012) ( http://ga.gov.au ) used under CC-BY 3.0 AU. Great Artesian (Australian) Basin (Ransley \& Smerdon 2012) . 
A

Regolith Depth

$0-1 \mathrm{~m}$
$1-2 \mathrm{~m}$
$2-3 \mathrm{~m}$
$3-10 \mathrm{~m}$
$10-20 \mathrm{~m}$
$20-30 \mathrm{~m}$
$30-40 \mathrm{~m}$
$>40 \mathrm{~m}$

B

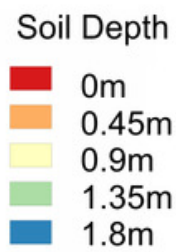

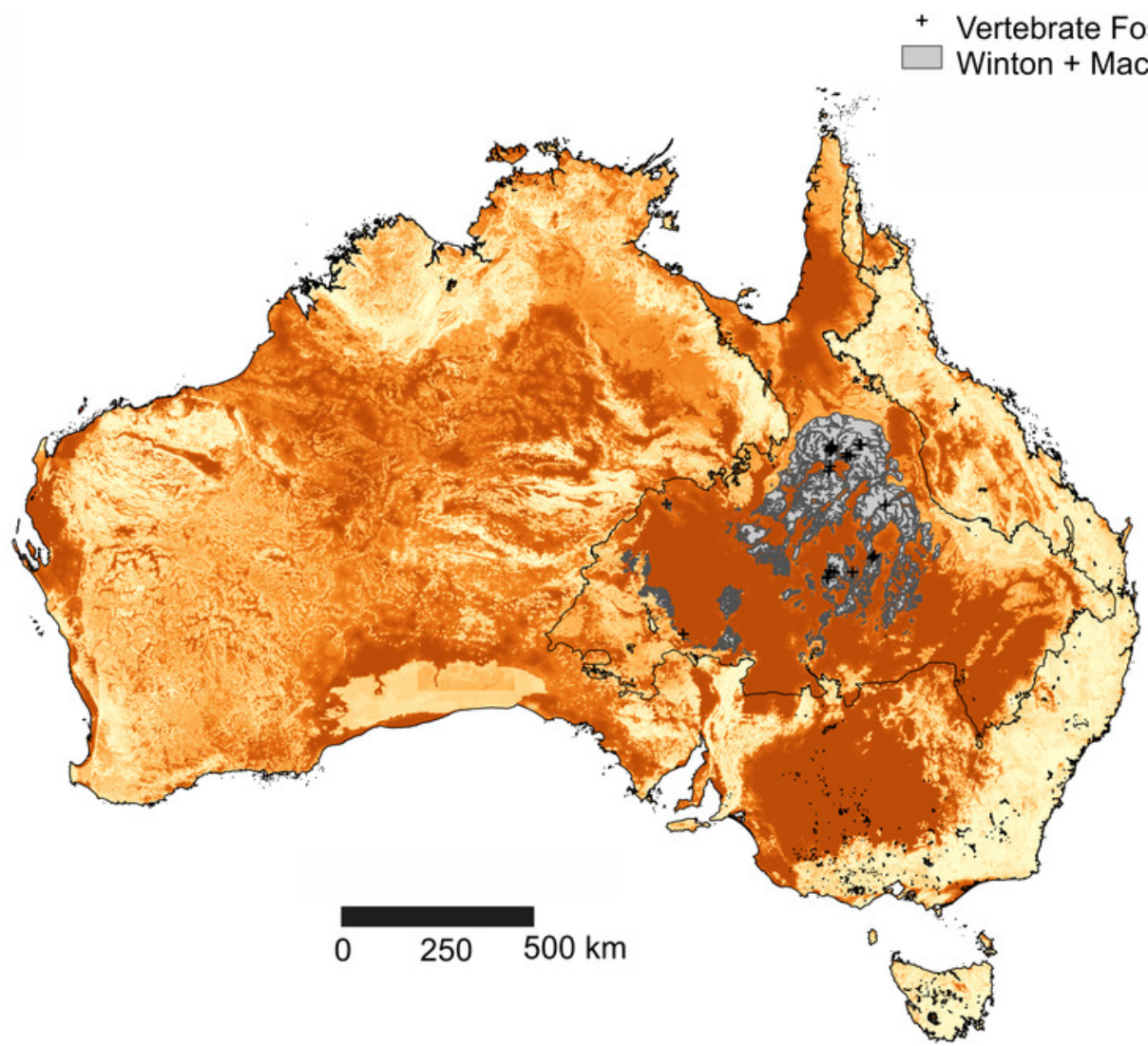

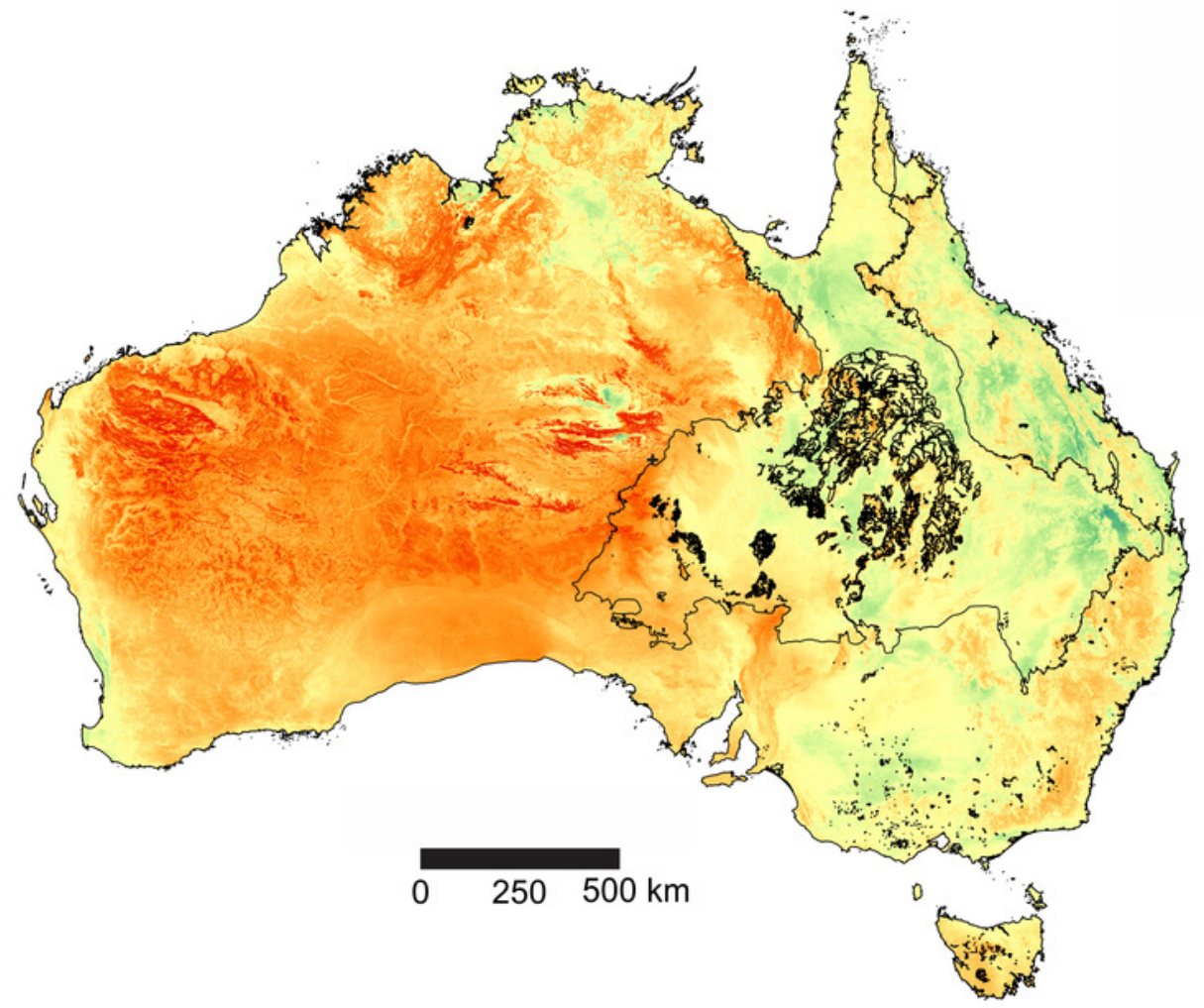




\section{Figure 4}

Interpretations of Winton Formation thickness associated with the vertebrate fossil sites described here, including the type locality for Australotitan cooperensis gen. et sp. nov.

(A) Cross-sectional thickness of the Cenozoic/Quaternary deposits overlying the Winton Formation. Cross-section adapted from Figure 11d of (Hall 2015) under CC-BY 4.0. Mt. Howitt 1 well, which occurs close to the northern-most Plevna Downs vertebrate fossil sites (e.g.

EML019), provides an approximate estimation of $300 \mathrm{~m}$ of Winton Formation thickness. However, the thickness of the preserved Winton Formation rapidly increases away from the crest of the anticline on the eastern and western flanks of the Mt. Howitt Anticline. (B) Seismic Line 83-NJZ data has been reinterpreted by Santos Pty Ltd for this research project and includes the interpreted base of the Winton Formation by M.W. The base of the Winton Formation interpreted in Wareena 1 from petro-physical data is 270-300 metres. Interpretation of seismic line 83-NJZ indicates the dinosaur sites EML 010-013 are at a similar structural level to Wareena 1 , near the crest of the anticline. Therefore, the type locality for A. cooperensis gen. et sp. nov. is interpreted to be $270-\mathrm{m}$ from the base of the Winton Formation (see text for additional justification). Seismic Line data available CC-BY 4.0 from Qglobe and GSQ Open Data Portal ( http://qldglobe.information.qld.gov.au and http://geoscience.data.qld.gov.au/seismic/ss095410 ). 


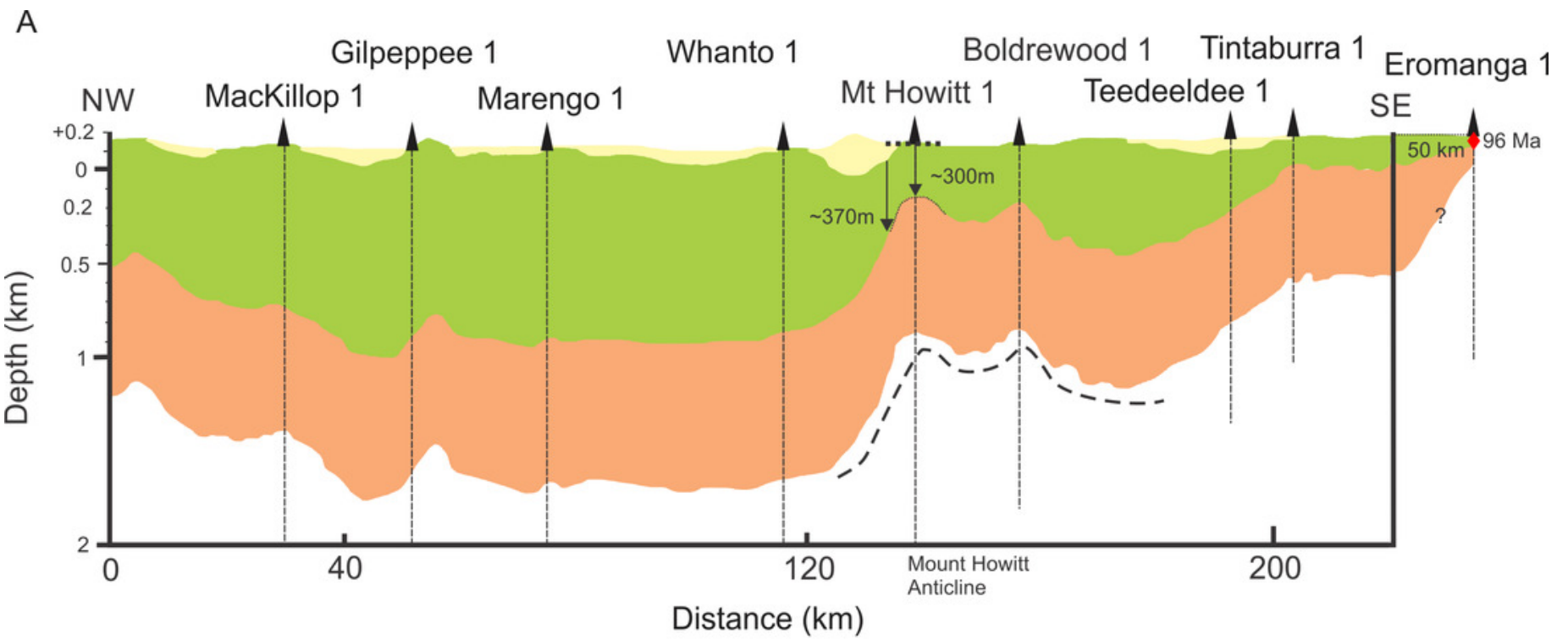

$\square \quad$ Cenozoic / Quaternary Alluvium
$\square \quad$ Winton Formation
$\square \quad$ Mackunda / Allaru / Toolebuc Formations

...... Estimated E-W spread of vertebrate fossil sites relative to anticline

B

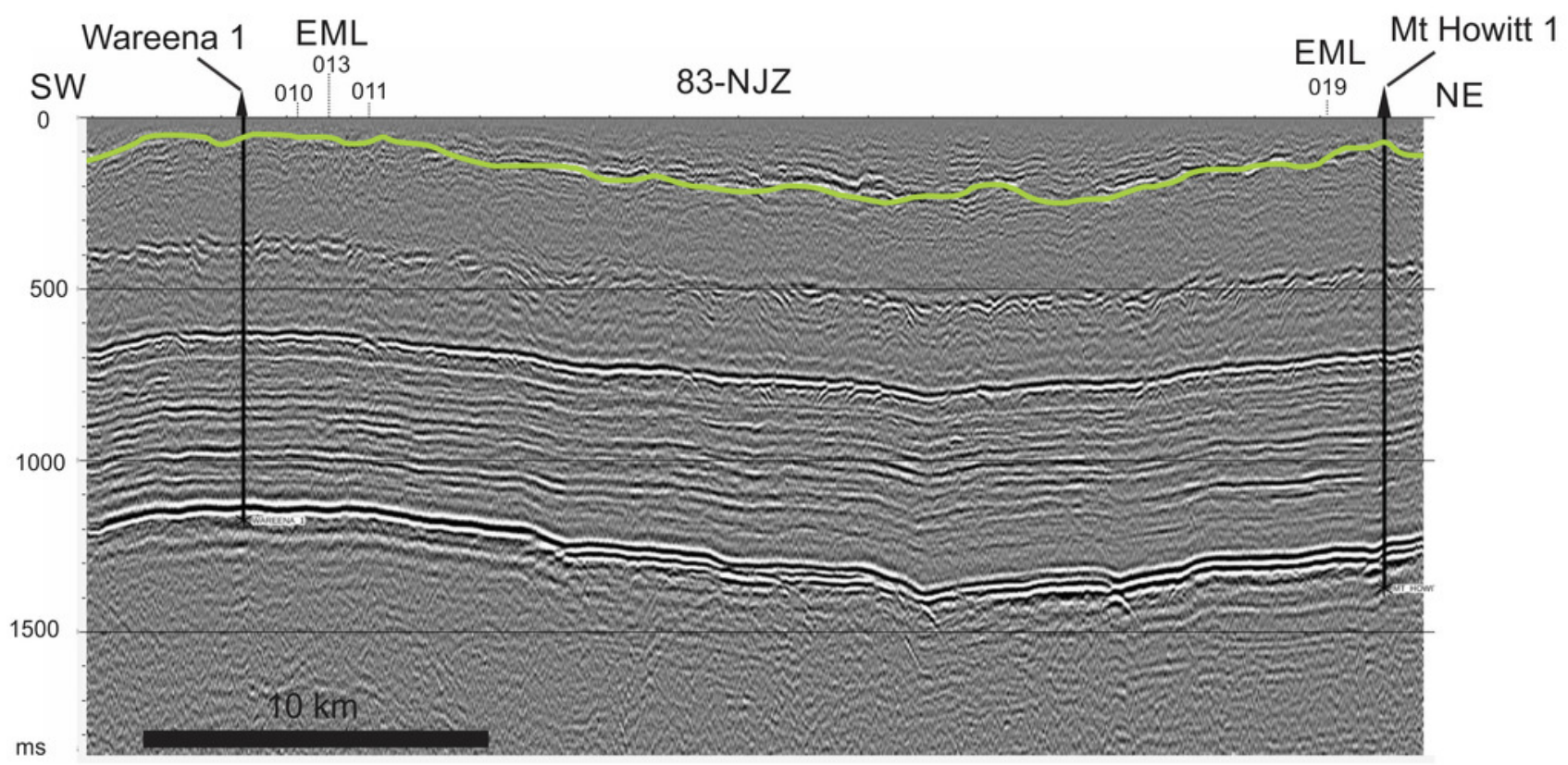

Interpreted base of Winton Formation 


\section{Figure 5}

Winton Formation Thickness and Age.

(A) Chronostratigraphic scheme showing the palynostratigraphic zones and lithostratigraphic units discussed in the text. (B) Mackunda and Winton Formation outcrop distribution map showing dominant structural elements associated with sauropod type localities, position of stratigraphic cores and petroleum wells used to estimate the thickness of Winton Formation at the four sauropod type localities, 1: Wintonotitan wattsi type locality QML313, 2: Diamantinasaurus matildae / Australovenator wintonensis type locality AODL085, 3: Savannasaurus elliottorum type locality AODL082, 4: Diamantinasaurus matildae (referred) and QMF43302 discussed here from QML1333. (C) Close up of the northern Winton Formation sauropod type localities associated with stratigraphic cores, petroleum wells, geological structures (faults and anticlines). Dashed lines A-A' and B-B' indicate cross-sections provided in D. (D) Two generalised cross-sections of the Winton Formation, west (A-A') and east (B-B') of the Cork Fault, showing the relative position of the sauropod type localities in relation to the estimated base of the Winton Formation. Red diamonds indicate the core depth of zircon samples with the age in millions of years (Ma) provided for the youngest graphical detrital zircon age peak (YPP) (Bryan et al. 2012; Tucker et al. 2016) . Abbreviations: CA, Canaway Anticline; CF, Cork Fault; CNF, Canaway Fault; CS, Cooper Syncline; EA, Eyriewald Anticline; F, unnamed Fault; HA, Mt. Howitt Anticline; WS, Wetherby Structure. Geographical map data from ( http://pid.geoscience.gov.au/dataset/ga/61754 ) used under CC-BY 4.0 AU. Winton and Mackunda formations retrieved for South Australia from SARIG (http:/map.sarig.sa.gov.au) under CC-BY 3.0 AU; Queensland from QGlobe ( http://qldglobe.information.qld.gov.au ) under CC-BY 4.0; New South Wales from (Raymond et al. 2012) ( http://ga.gov.au ) used under CC-BY 3.0 AU. Stratigraphic and petroleum wells, water bores and geological structures retrieved from Qglobe ( http://qldglobe.information.qld.gov.au ) under CC-BY 4.0. 


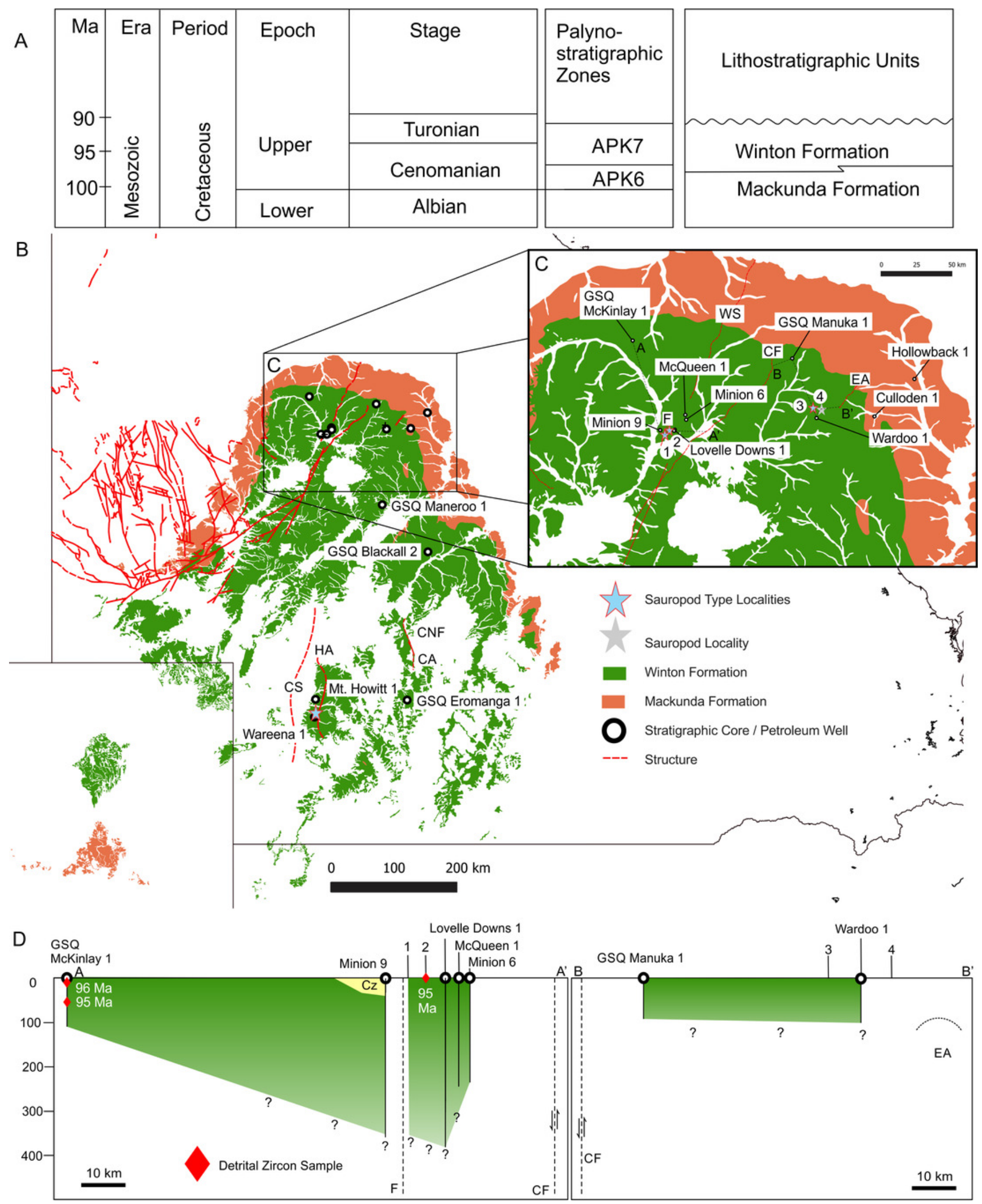




\section{Figure 6}

Preservational examples of leaves, wood debris, bone debris, trampled sediments and articulated remains from southern Plevna Downs sites (EML011, 012 and 013).

(A-F) Leaves preserved indicate a dominance of conifers (Pinophyta) and ferns (Pterophyta). (A) EMF177, conifer twig with leaves. (B) EMF175, ?Bennettitalean leaf. (C) EMF176, conifer twig with poorly preserved leaves. (D) EMF174, Pterophyte leaf (?Cladophlebis sp.). (E) EMF172, Pterophyte leaf (?Sphenopteris sp.). (F) EMF173, conifer leaf 'mat'. (G\&H) Woody (wd) debris impressions in layers showing preferred orientation within thick sections of cemented siltstone. (I) Bone (bn) and woody debris in cross-section with bone occurring at the base of the woody debris beds (arrow indicating upward direction). Underside of bone either corroded or eroded off creating a scoured (sc) underside (EML013). (J) Massive ichnological features showing trampled and cemented (cem) siltstone horizon, sediment deformation buldges (def) and partial sauropod foot imprints (tr) (EMLO11) (Scale Bar = 1m). (K) Articulated sauropod skeleton from EML012 preserved within a siltstone concretion, including the torso and tail. Identifiable elements include ribs (rib), dorsal vertebrate (dor), pelvic elements (pel) and caudal vertebrae (cdl). Scale Bars $=10 \mathrm{~mm}(\mathrm{~A}-\mathrm{F}), 50 \mathrm{~mm}(\mathrm{G}-\mathrm{I}), 100$ $\mathrm{cm}(\mathrm{\&} \& \mathrm{~K})$. 


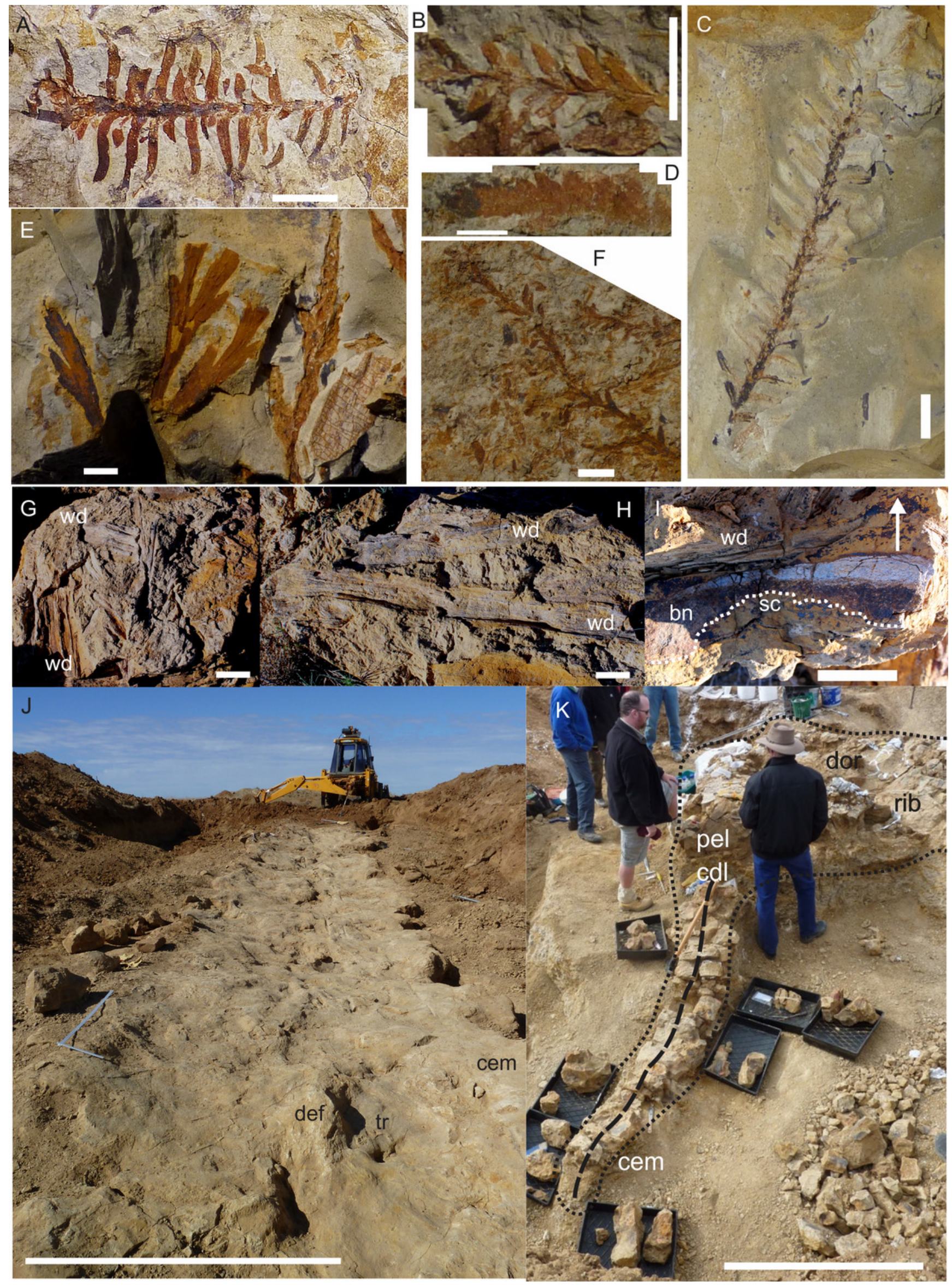




\section{Figure 7}

EML011, type locality of Australotitan cooperensis gen. et sp. nov. site sedimentology and taphonomy.

(A) Site overview showing excavation pit, distant weathered geochemically weathered Glendower (Gl) and more proximal weathered Winton (Wf) and Quaternary alluvial (Qa) deposits. (B) Semi-articulated pubes and ischia from A. cooperensis gen. et sp. nov. with mediodorsal surfaces of each pubis facing upwards with the dislocated ischia in close articular approximation (arrows indicate d, distal; p, proximal; rd, right dorsal and Id, left dorsal). (C) In situ ovo-lobate deformation (def) of pubis. (D) Cross-section (a-b) of sediment beneath pelvis showing downwardly deformed laminations (lam) of the siltstone (sIt) above E. (E) a lower surface-scoured sandstone (ss) layer. (F) Associated humerus (hum), ulna (uln) and scapula (sca) of $A$. cooperensis gen. et sp. nov. within the shallow stratigraphy of the site, including the surface vertosol (blacksoil, bs) that transitions into underlying Winton Formation siltstone (slt) with the bonebed (bb). A thin sandstone (ss) layer occurs below the siltstone and bonebed. Scale bars $=10 \mathrm{~cm}(\mathrm{C}-\mathrm{E})$ and $100 \mathrm{~cm}(\mathrm{~B} \& \mathrm{~F})$. 


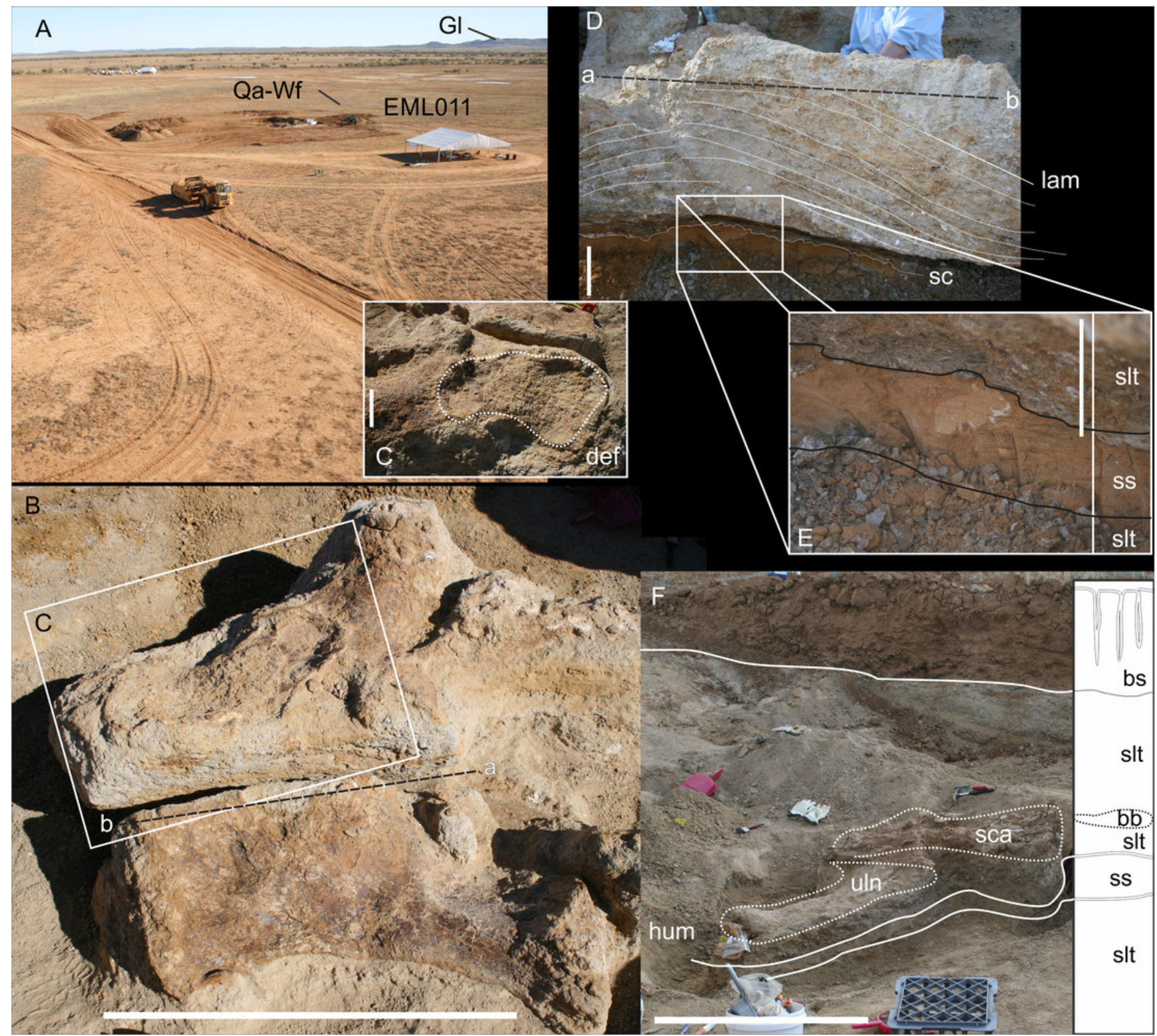




\section{Figure 8}

Examples of sauropod bone preservation and taphonomic alteration, including coloured reference scheme for 3-D models.

(A-F) \& (H\&I). A. cooperensis gen. et sp. nov. (EMF102), right femur showing vertical displacement via a localized downward force acting upon the bone to deform the shaft. (A) 3-

D model showing the upward-facing in situ surface. (B) 3-D model in medial view showing the relative downward deformation that has occurred to the bone from horizontal orientation. (C) 3-D model in distomedial view showing a triangular-shaped depressed deformation of the femoral shaft, likely from a manual I claw. $(D, E, \& F)$ The large ovo-lobate deformation structure impacting the proximal shaft of the femur and connected to C. (G) Sauropod manus footprint adapted from Figure 6, p 11 (Santos et al. 2009) (CC-BY-4.0) for comparison with crush outline provided in I. (H) Depth of deformation of the depressed (surface) cortical bone. (I) Edge-detected 3-D model outline with interpreted outline of depression and indicating sauropod manus-like shape. (J \& K). EMF102, right ulna showing deformation of the distal shaft in J and the digitally retrodeformed shaft in K. (L-O) The right humerus illustrating the outward collapse of the deltopectoral crest (that occurred during excavation) $(M \& N)$ and the digitally retrodeformed deltopectoral crest $(L \& N)$. (P) Coloured reference scheme for 3-D models illustrating preservational, taphonomic and 3-D model observations. Abbreviations: brk, broken or missing connecting surfaces; col, collapsed deltopectoral crest; cor, corroded surface; def, deformation; los, bone loss; mat, obscuring matrix; mod, poor model alignment/surface; mos, mosaic-fractured cortical bone surface; pla, plaster/infill; sur, surface/cortical bone missing; undef, undeformed. Scale bars $=20 \mathrm{~cm}$. 


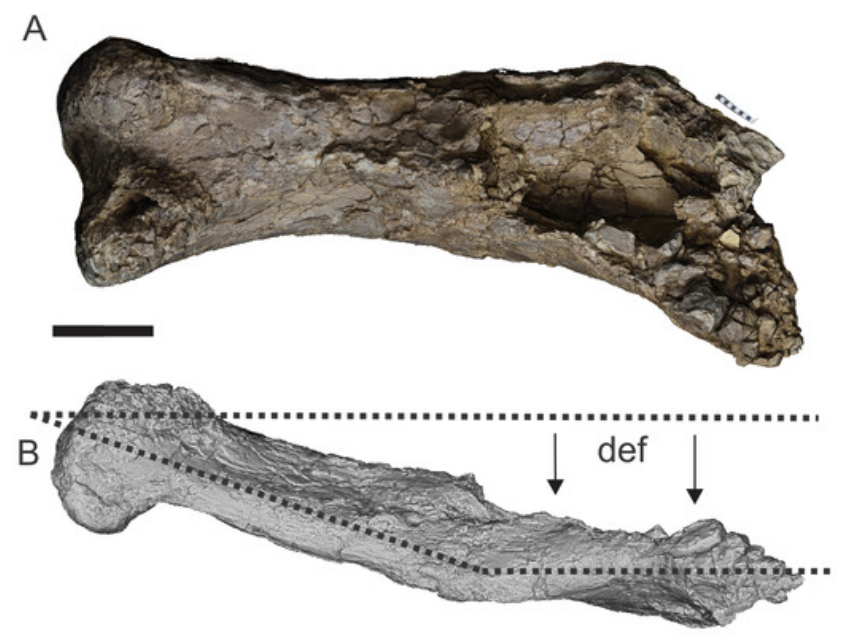

C
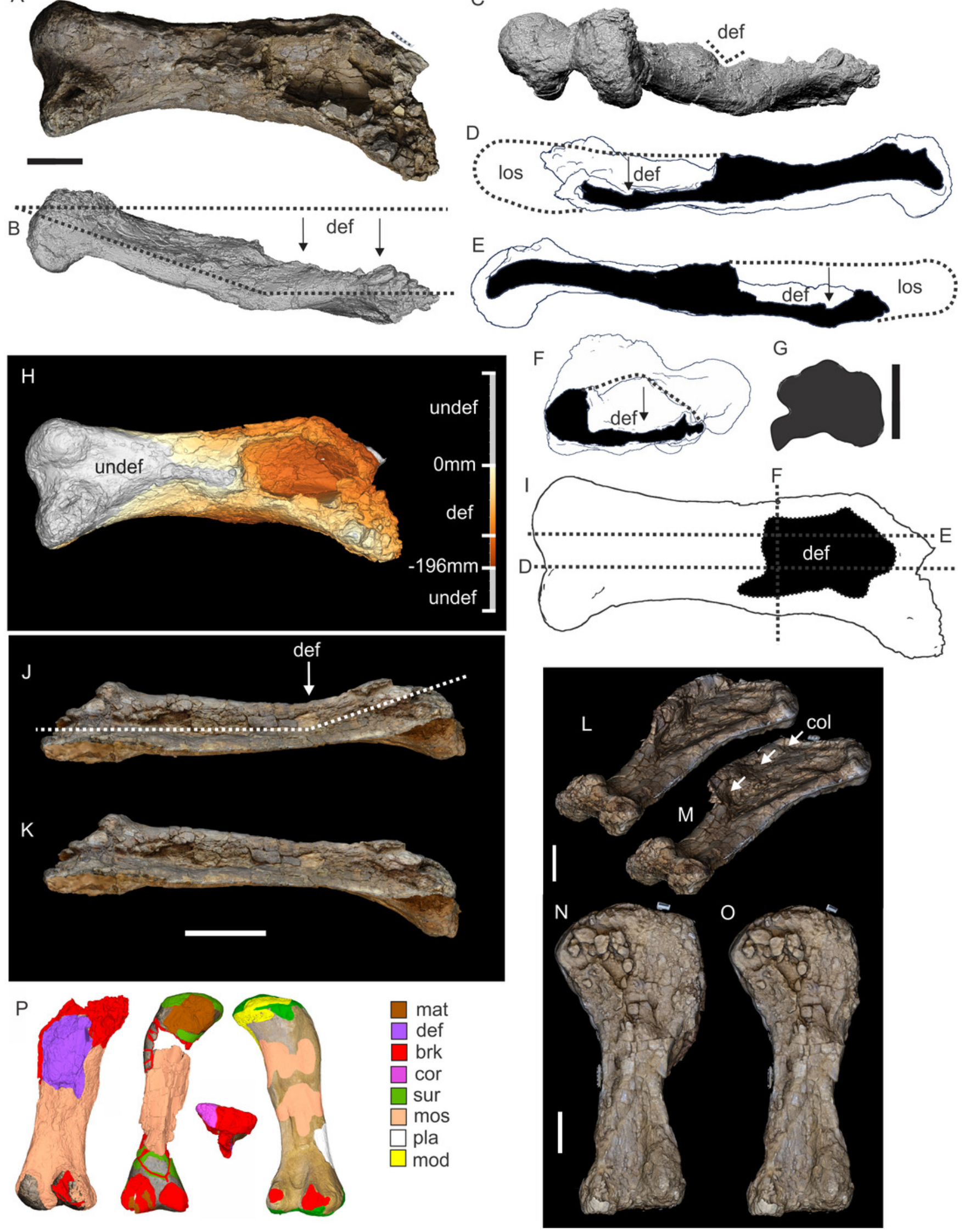

Peerj reviewing PDF | (2020:11:55594:2:1:NEW 28 Mar 2021) 


\section{Figure 9}

Scapulae of Australotitan cooperensis gen. et sp. nov. (EMF102), Wintonotitan wattsi (QMF7292) and Diamantinasaurus matildae (AODF603).

Each element is rendered using four methods from top to bottom, natural; ambient occlusion with radiance scaling; coloured schematic (see Figure 8); and orthogonal outline edge detection. $(A \& B)$ 3-D model of $A$. cooperensis gen. et sp. nov. left scapula in lateral (A) medial (B) views. (C\&D) 3-D model of W. wattsi left scapula in lateral (C) and medial (D) views. (E \& F) 3-D model of $D$. matildae right scapula (mirrored) in lateral (E) and medial (F) views. (G-I) Proximoventral views showing mid scapular blade cross-sectional profile in $A$. cooperensis gen. et sp. nov. $(\mathrm{G}), W$. wattsi $(\mathrm{H})$ and mirrored in $D$. matildae (I). Arrows indicate direction ( $d$, dorsal; di, distal; p, proximal; $v$, ventral). Feature abbreviations: $c r$, central ridge of scapular blade; $\mathrm{mt}$, medial tuberosity; pvp, proximoventral process; vr, ventral ridge of scapular blade. Scale bar $=20 \mathrm{~cm}$. 
A
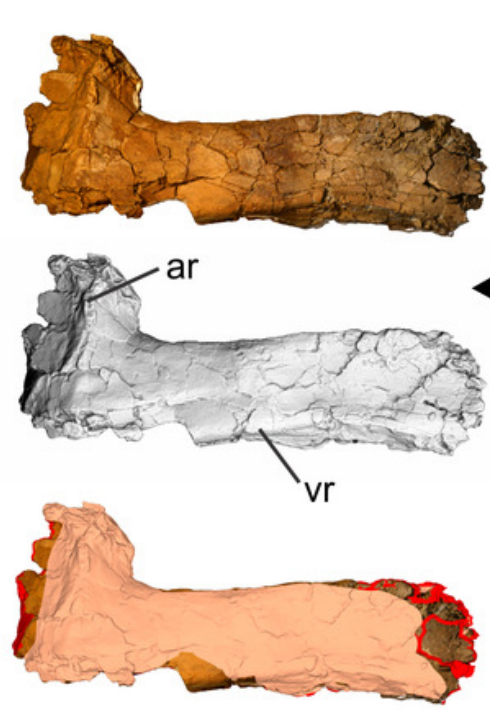

$a_{v}^{d} d d D^{a r}$

C
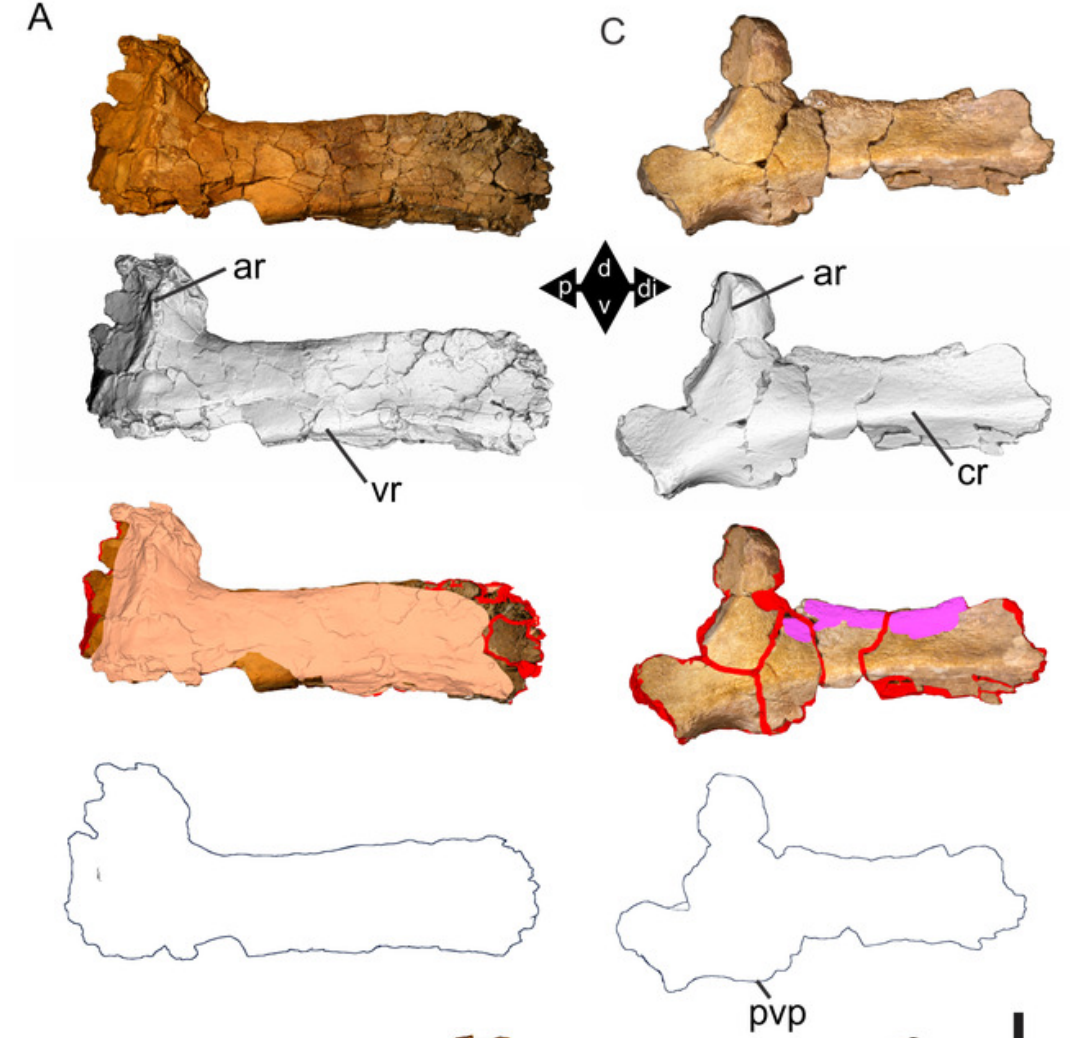

B
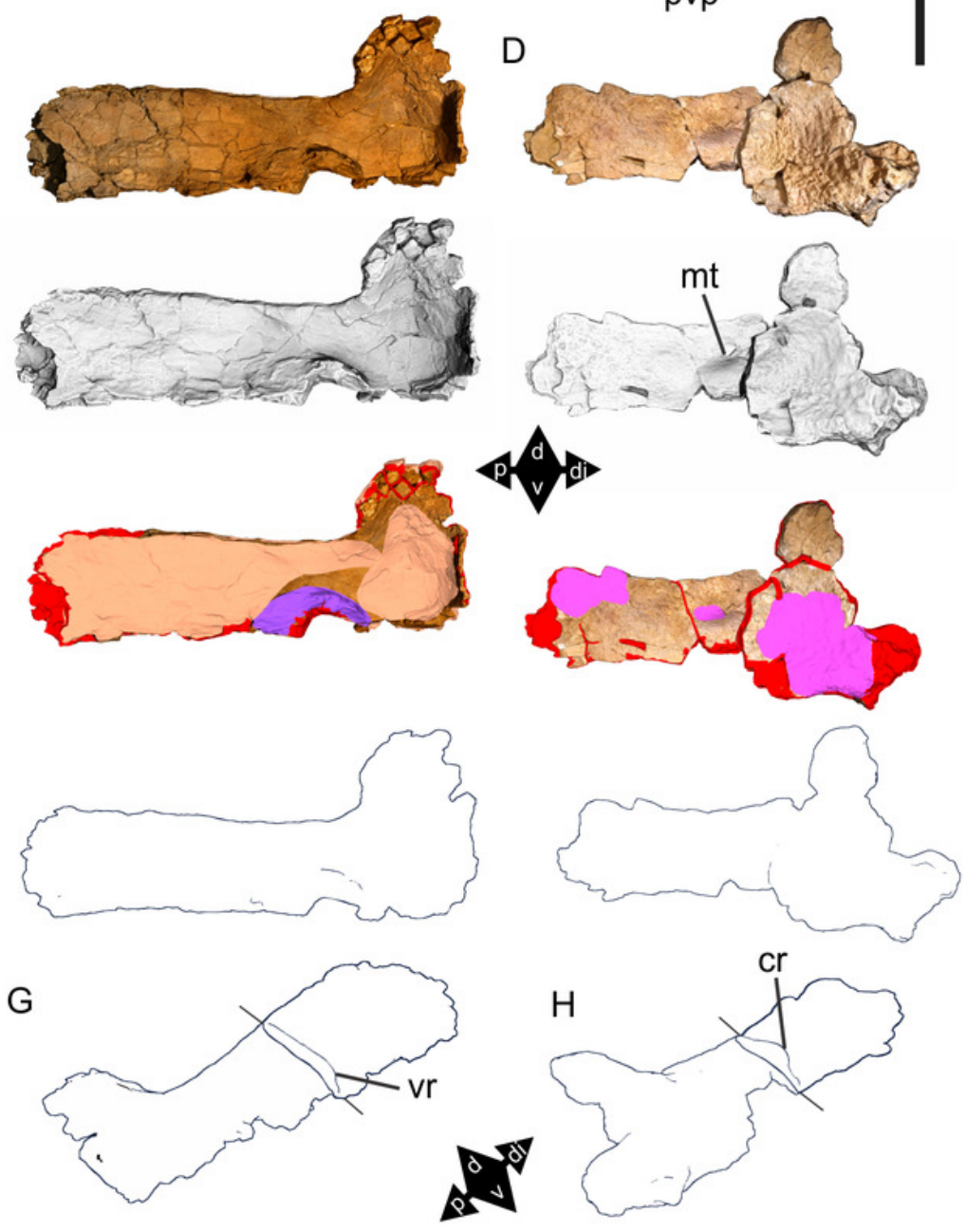

E
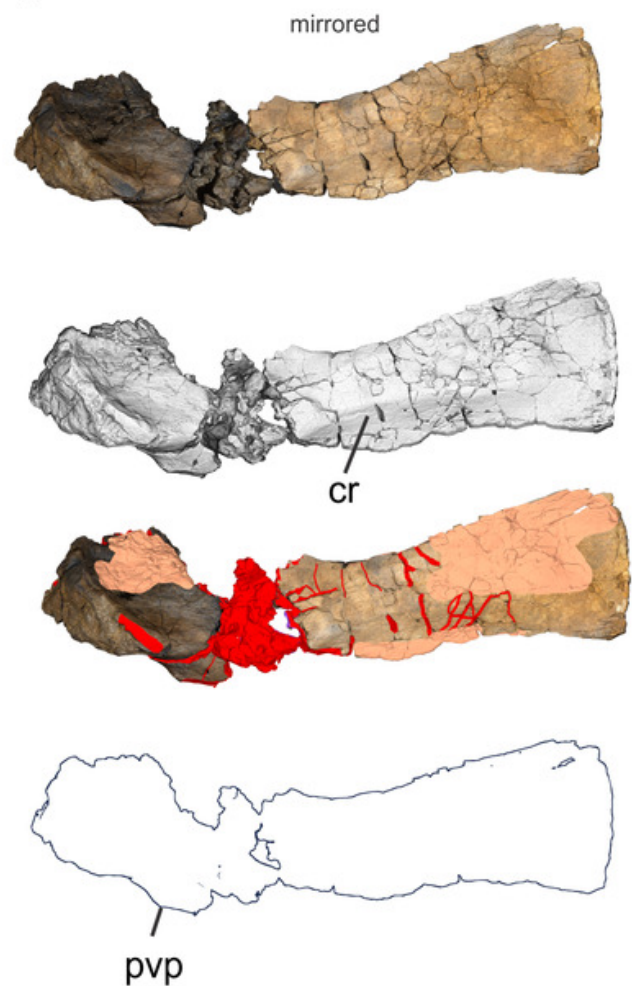

F
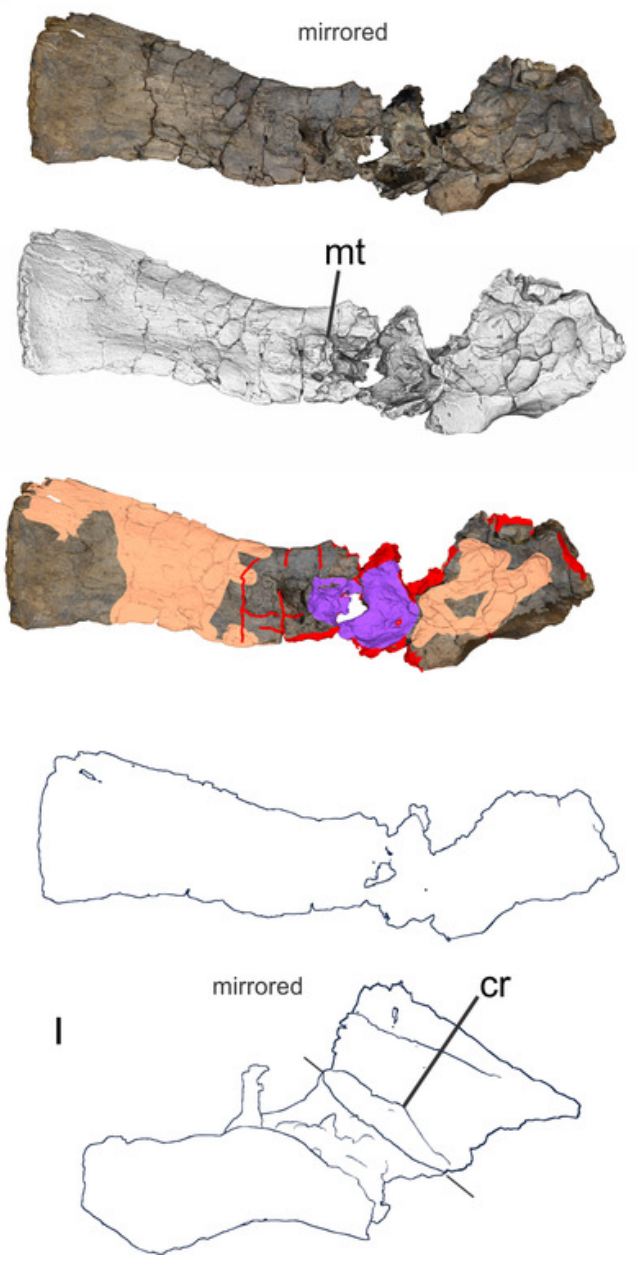

Peer) reviewing PDF | (2020:11:55594:2:1:NEW 28 Mar 2021) 


\section{Figure 10}

Scapulae of Australotitan cooperensis gen. et sp. nov. (EMF102), Diamantinasaurus matildae (AODF603) and Wintonotitan wattsi (QMF7292) and showing relative crosssectional profile across the scapular blade.

(A) A. cooperensis gen. et sp. nov. preserved scapula aligned within the reconstructed scapula. Aligned models rendered using transparency tool and orthogonal outline edge detection. (B) D. matildae (mirrored right 3-D model). (C) W. wattsi. Dashed vertical lines indicate position of cross-section. Dotted lines indicate estimation of missing scapular blade.

All three scapulae are isometrically scaled to the minimum scapular blade dorsoventral height. Arrows indicate direction ( $d$, dorsal; di, distal; p, proximal; v, ventral). Feature abbreviations as per Figure 9. 

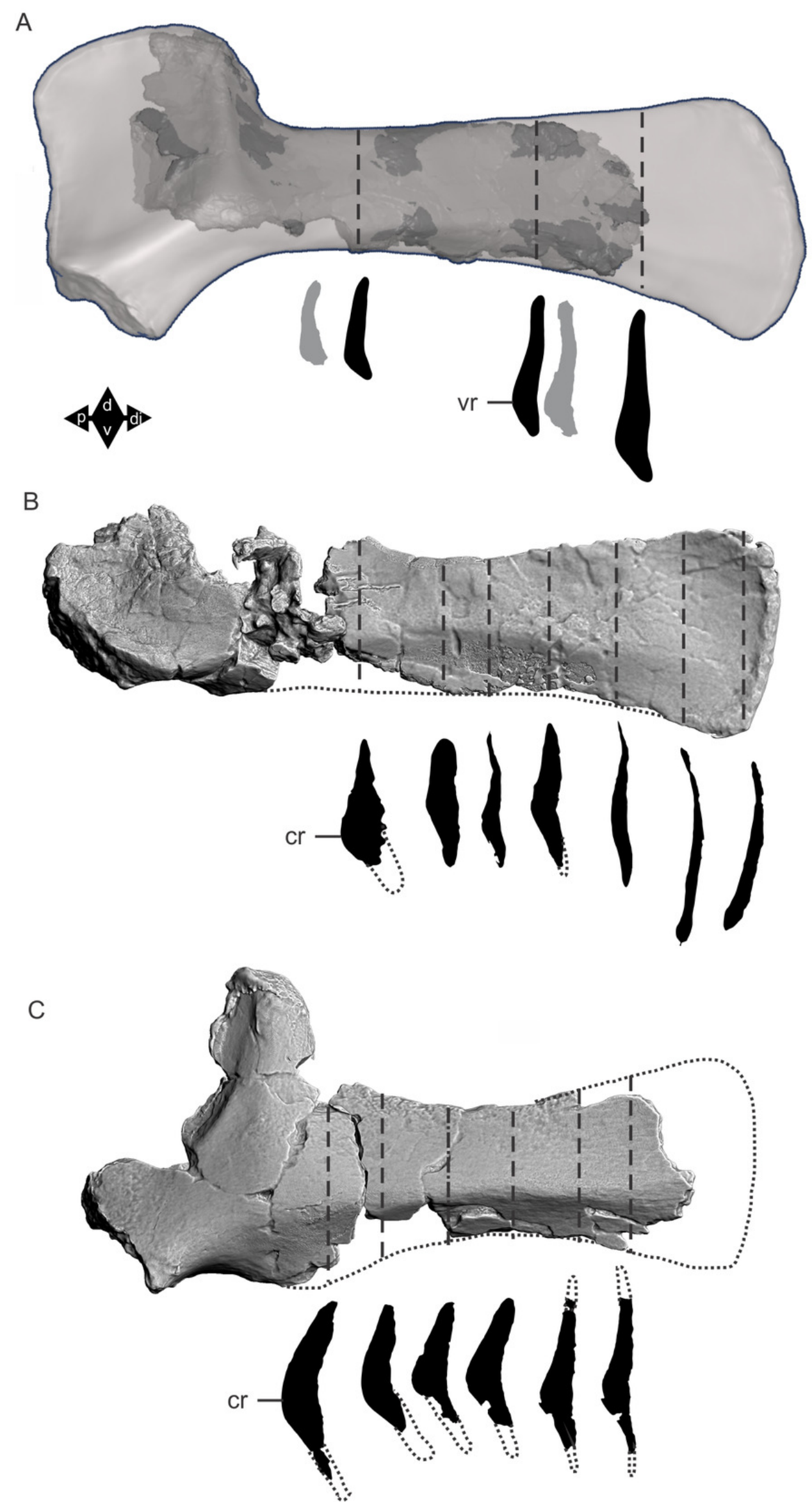


\section{Figure 11}

Humeri of Australotitan cooperensis gen. et sp. nov. (EMF102).

$(A \& B)$ Left partial humerus in anterior (A) and posterior (B) views. (C-S). Right humerus in anterior $(C \& D)$, posterior $(E \& F)$, distal $(G)$ and oblique anterodistal $(H-S)$ views. $C, F$ and $H$ are retrodeformed. 3-D image rendering methods used included, natural, (A (left), B (right), $C, D$ (middle), E (middle), F, G (middle), $H \& R$; ambient occlusion with radiance scaling, $A$ (middle), B (middle), D (left), E (right), G (left) \& I and coloured schematic (see Figure 8), A (right), B (left), D (right), E (left), G (right) \& S. Arrows indicate direction (a, anterior; $p$, posterior). Feature abbreviations: af, anconeal fossa; cbr, coracobrachialis scar; dpc, deltopectoral crest; dpcb, deltopectoral crest base; hd, humeral head; rc, radial condyle; uc, ulnar condyle. Scale bars $=20 \mathrm{~cm}$. 

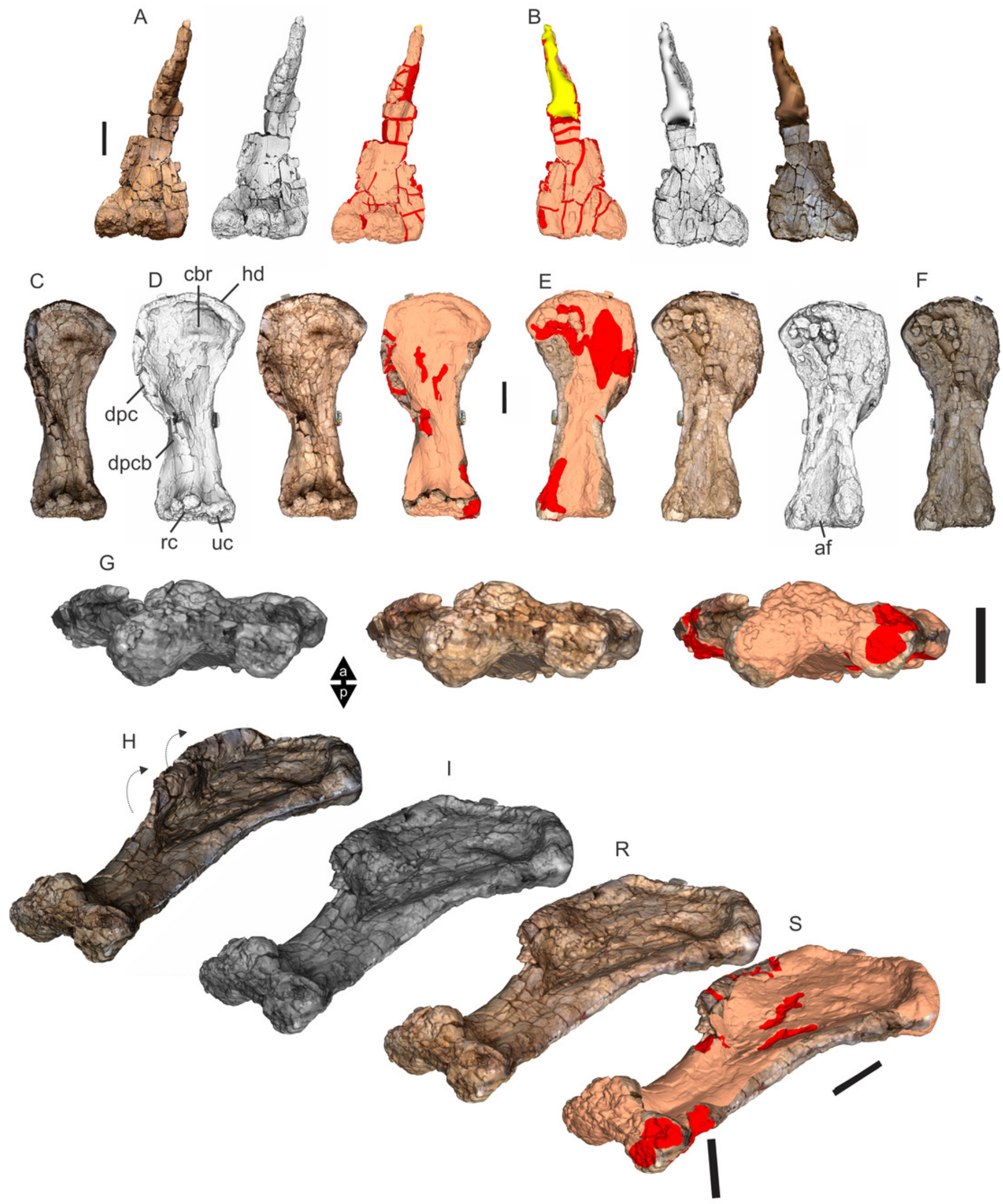


\section{Figure 12}

Humeri of Diamantinasaurus matildae (AODF603).

$(A \& B)$ Left humerus in proximal $(A)$ and anterior (B) views. (C-F) Right humerus in proximal (C), anterior (D), posterior (E) and distal (F) views. (G-L) Reconstructed left humerus using the left and right (mirrored) humeri in medial $(\mathrm{G})$, posterior $(\mathrm{H})$, anterior (I), lateral (J), proximal (K) and distal (L) views. 3-D image rendering methods used included, natural, (A-D (left), E \& F (right)); ambient occlusion with radiance scaling, A-F (middle); coloured schematic (see Figure 8), A-D (right), E-F (left) and orthogonal outline edge detection (G-L). Arrows indicate direction ( $a$, anterior; p, posterior). Feature abbreviations: af, anconeal fossa; $\mathrm{dpc}$, deltopectoral crest; dpcb, deltopectoral crest base; hd, humeral head; rc, radial condyle; uc, ulnar condyle. Scale bars $=20 \mathrm{~cm}$. 


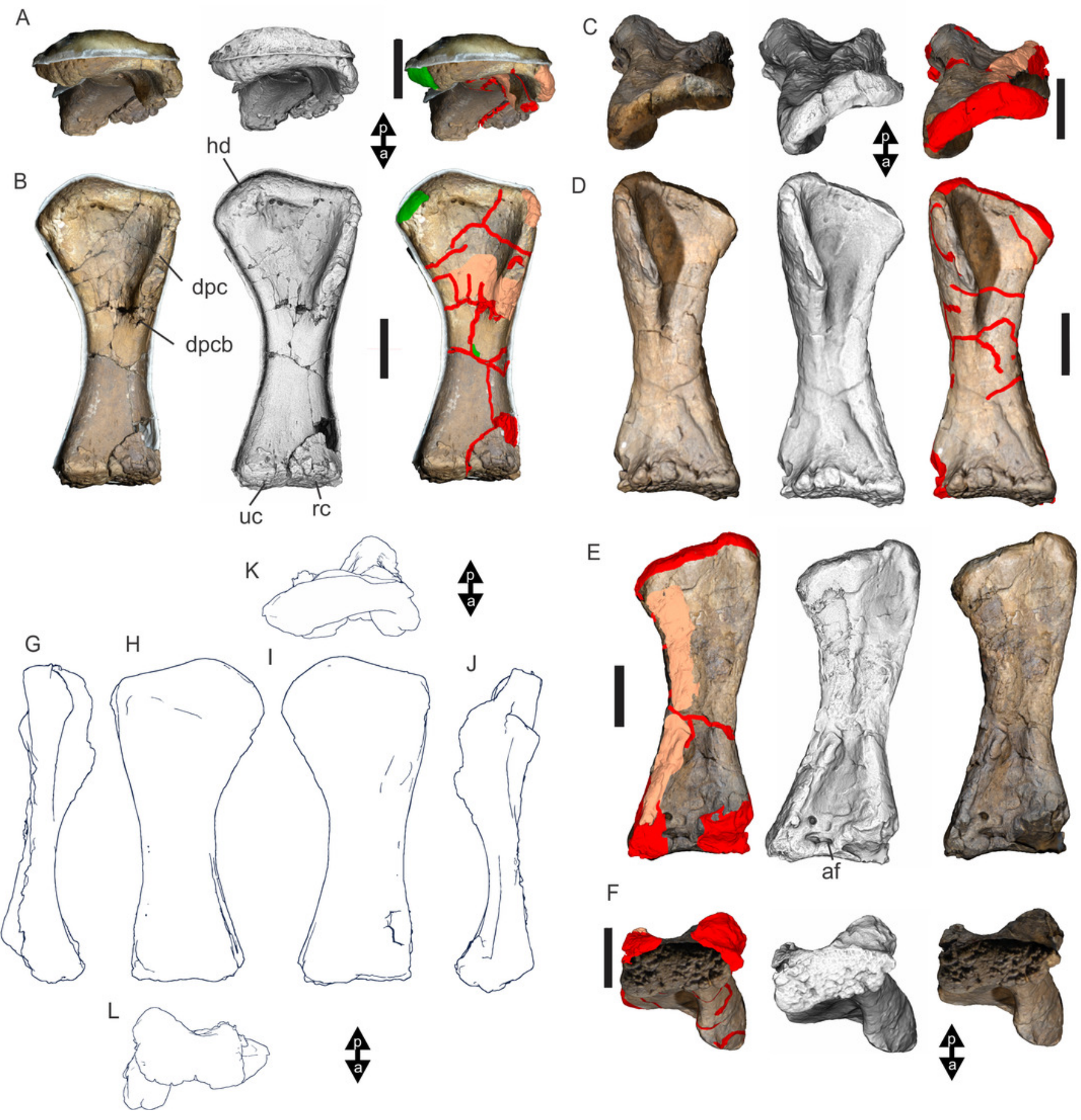




\section{Figure 13}

Humeri of Wintonotitan wattsi (QMF7292).

$(A \& B)$ Partial right humerus in posterior (A) and anterior (B) views. (C\&D). Partial left humerus in anterior (C) and posterior (D) views. (E-J) Reconstructed right humerus using partial left (mirrored) and right humeri in medial $(E)$, posterior $(F)$, anterior $(G)$, lateral $(H)$, proximal (I) and distal (J) views. 3-D image rendering methods used included, natural, A \& C (right), B \& D (left); ambient occlusion with radiance scaling, A-D (middle); coloured schematic (see Figure 8), $A \& C$ (left), B \& D (right); orthogonal outline edge detection (E-J). Arrows indicate direction ( $a$, anterior; $p$, posterior). Feature abbreviations: $d p c b$, deltopectoral crest base. Scale bars $=20 \mathrm{~cm}$. 

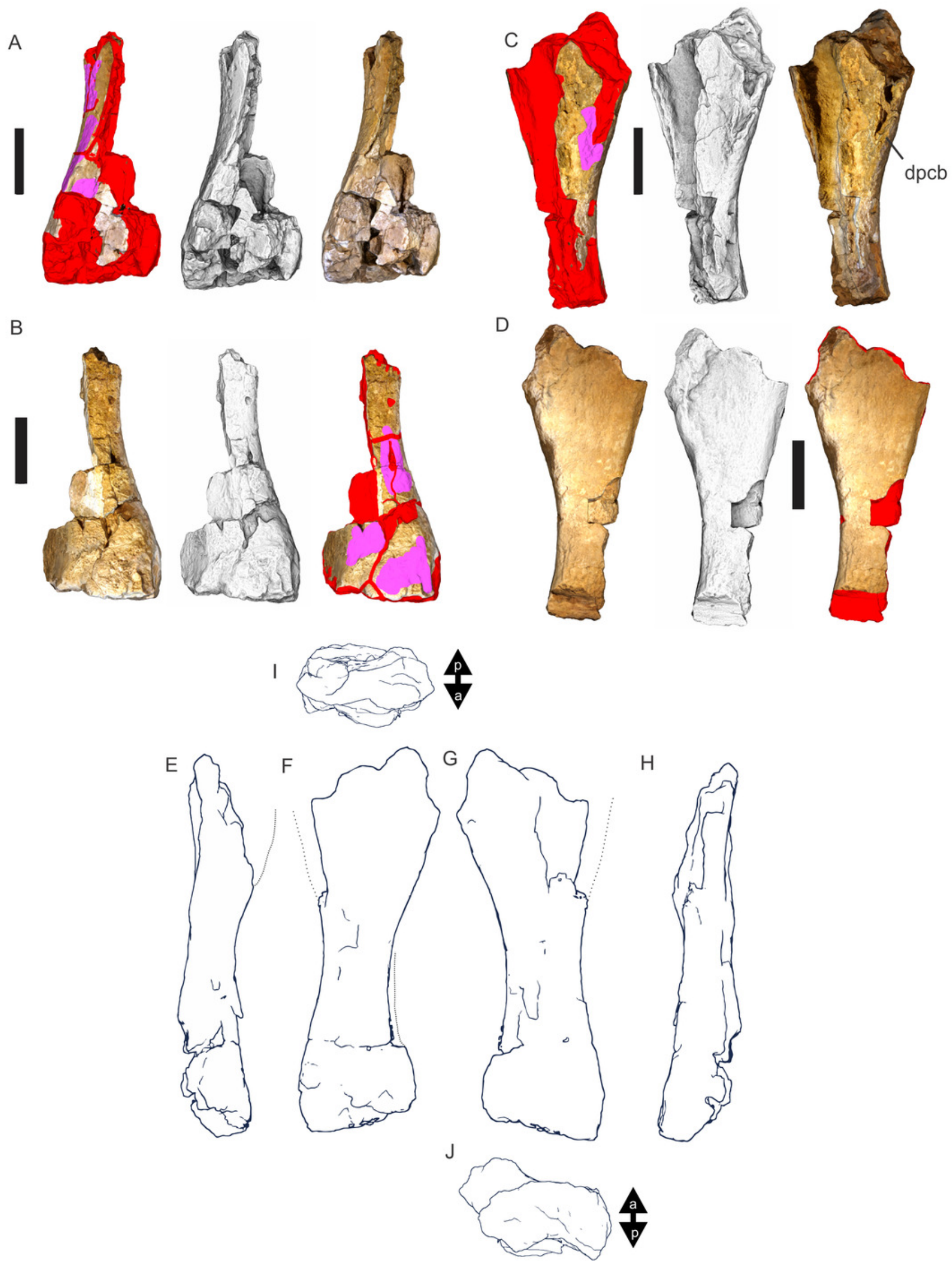


\section{Figure 14}

Humeri of Savannasaurus elliottorum (AODF660).

$(A \& B)$ Left partial humerus in anterior $(A)$ and posterior (B) views. (C \& D) Right partial humerus in anterior (C) and posterior (D) views. (E-J) Reconstructed right humerus using partial left (mirrored) and right humeri in medial $(E)$, posterior $(F)$, anterior $(G)$, lateral $(H)$, proximal (I) and distal (J) views. 3-D image rendering methods used included, natural, A \& C (left), B \& D (right); ambient occlusion with radiance scaling, A-D (middle); coloured schematic (see Figure 8), A \& C (right), B \& D (left); orthogonal outline edge detection (E-J). Arrows indicate direction ( $a$, anterior; $p$, posterior). Feature abbreviations: $d p c b$, deltopectoral crest base. Scale bars $=20 \mathrm{~cm}$. 
A
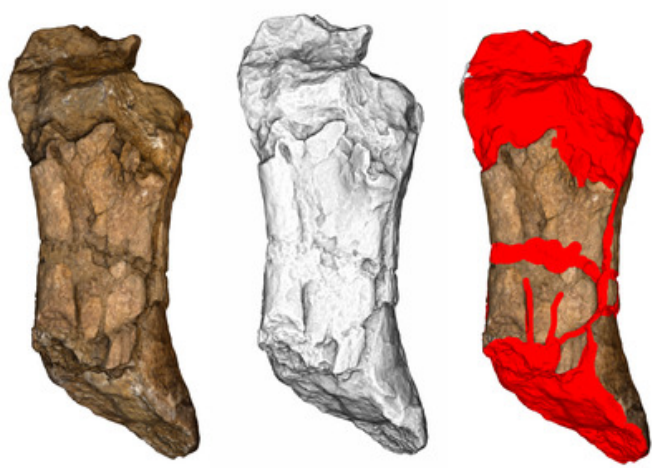

B
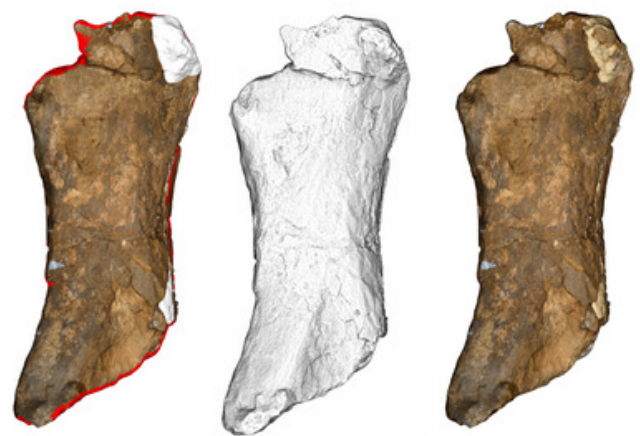
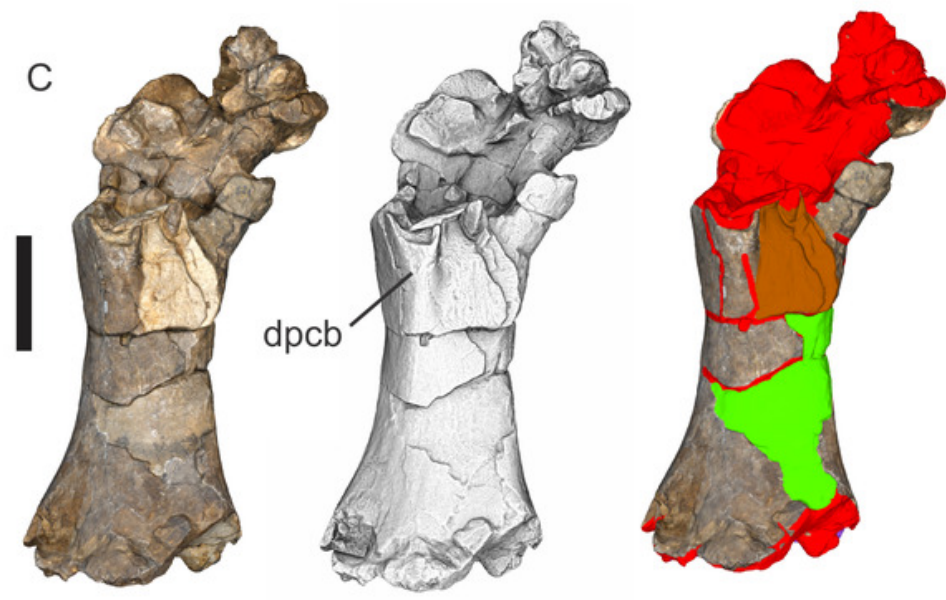

D
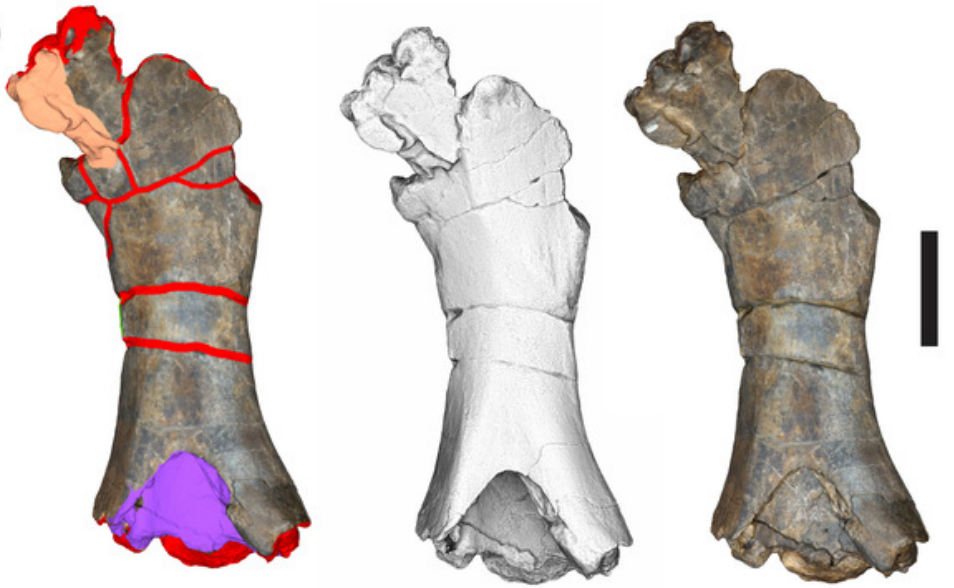

I
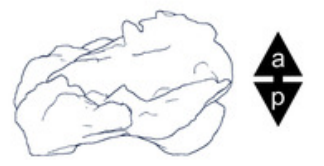

E
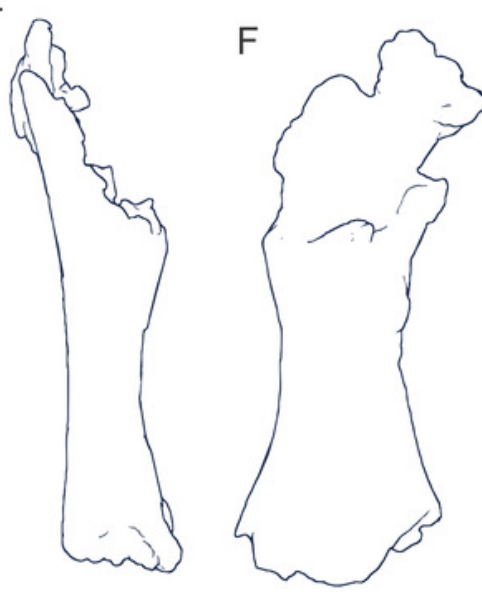

G
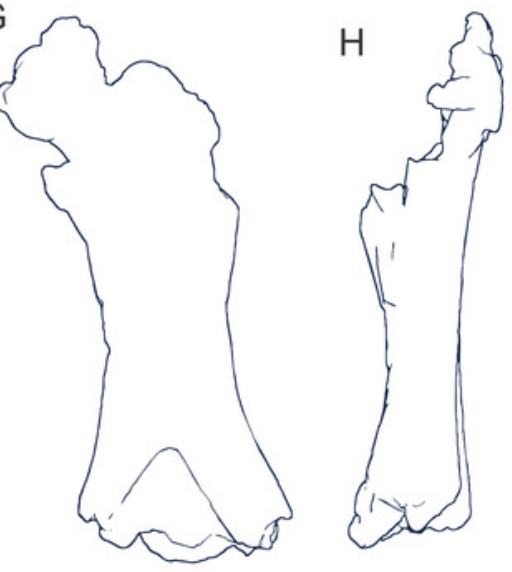

$\mathrm{J}$

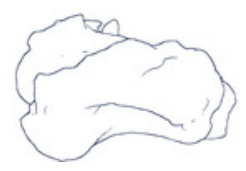

a 


\section{Figure 15}

Comparisons of Winton Formation sauropod humeri.

(A-F) Australotitan cooperensis gen. et sp. nov. (EMF102) right humerus in medial (A), anterior (B), posterior (C), lateral (D), proximal (E) and distal (F) views. (G-L) D. matildae (AODF602), reconstructed as right humerus, in medial $(G)$, anterior $(H)$, posterior $(I)$, lateral (J), proximal (K) and distal (L) views. (M-R) W. wattsi (QMF7292) reconstructed as right humerus, in medial $(\mathrm{M})$, anterior $(\mathrm{N})$, posterior $(\mathrm{O})$, lateral $(\mathrm{P})$, proximal $(\mathrm{Q})$ and distal $(\mathrm{R})$ views. S-X. S. elliottorum (AODF660), reconstructed as right humerus, in medial (S), anterior $(\mathrm{T})$, posterior $(\mathrm{U})$, lateral $(\mathrm{V})$, proximal $(\mathrm{W})$ and distal $(\mathrm{X})$ views. $\mathrm{Y}-\mathrm{AB}$. Reconstructed right humeri of $A$. cooperensis gen. et sp. nov. $(\mathrm{Y}), W$. wattsi $(\mathrm{Z}), D$. matildae (AA) and $S$. elliottorum (AB) scaled to minimum mediolateral width of the midshaft. Dotted lines estimating missing portions and shape of humerus. All 3-D models rendered using orthogonal outline edge detection. Arrows indicate direction ( $a$, anterior; $p$, posterior). Scale bars $=20$ $\mathrm{cm}$. 

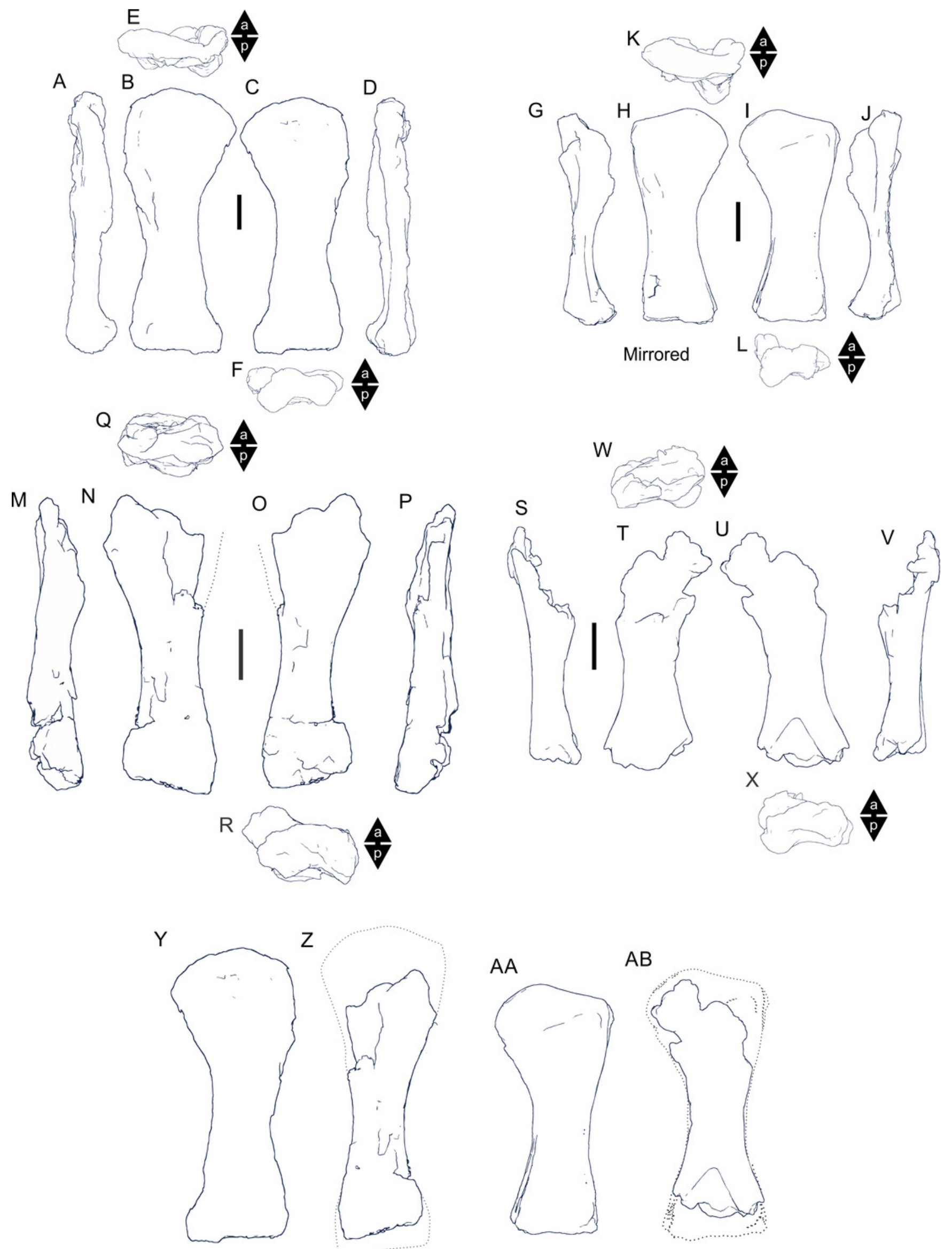

AB 


\section{Figure 16}

Comparisons of Winton Formation sauropod humeri in cross-section, scaled to minimum mediolateral midshaft width.

(A) Australotitan cooperensis gen. et sp. nov. (B) Diamantinasaurus matildae. (C)

Savannasaurus elliottorum. (D) Wintonotitan wattsi. Dotted line represents estimated extent of bone. Arrows indicate direction ( $a$, anterior; I, lateral; $m$, medial; p, posterior). Feature abbreviations: af, anconeal fossa; cbr, coracobrachialis scar; dpc, deltopectoral crest; dpcb, deltopectoral crest base; hd, humeral head; rc, radial condyle; uc, ulnar condyle. 
A
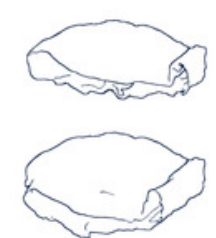

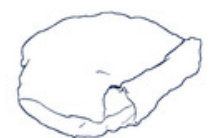
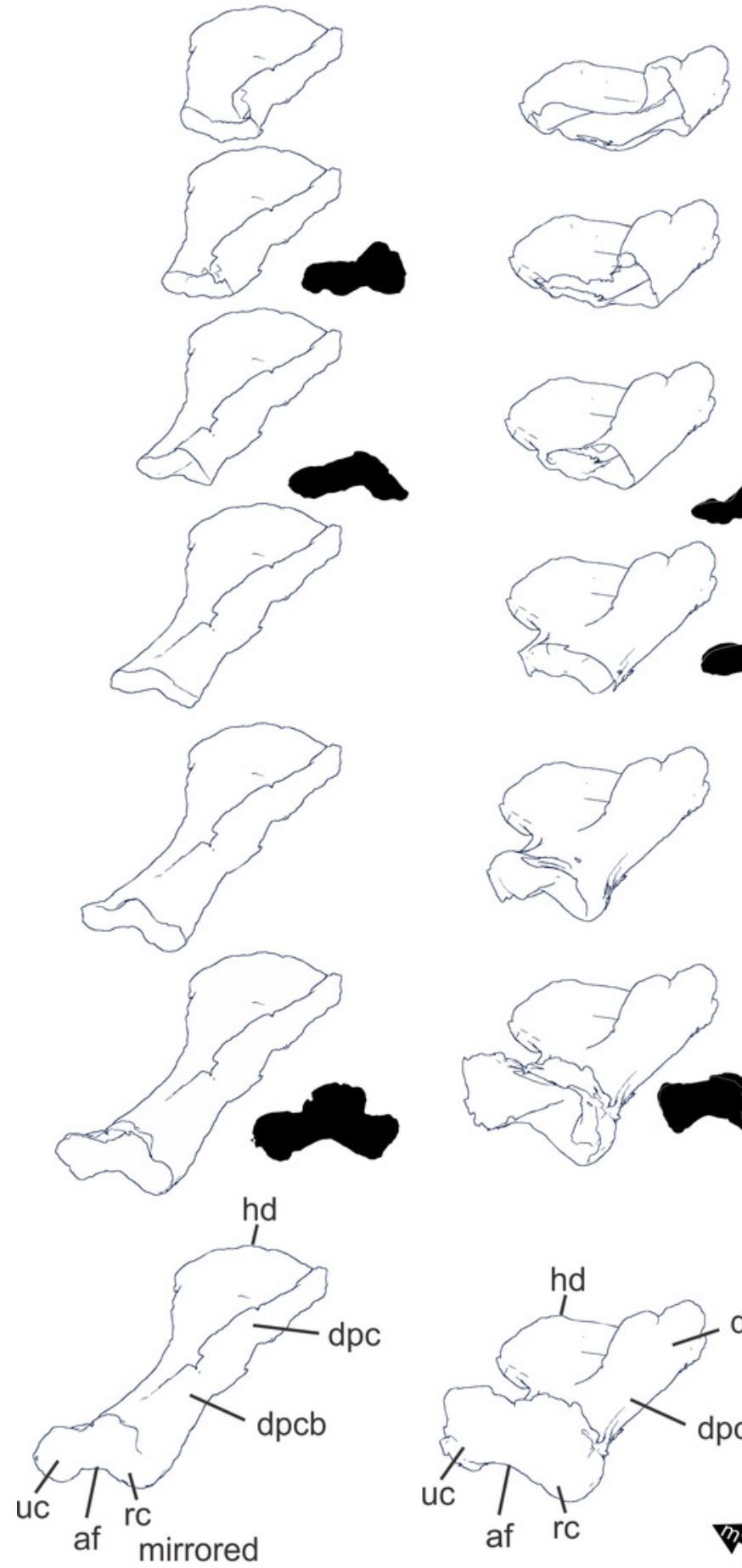

B
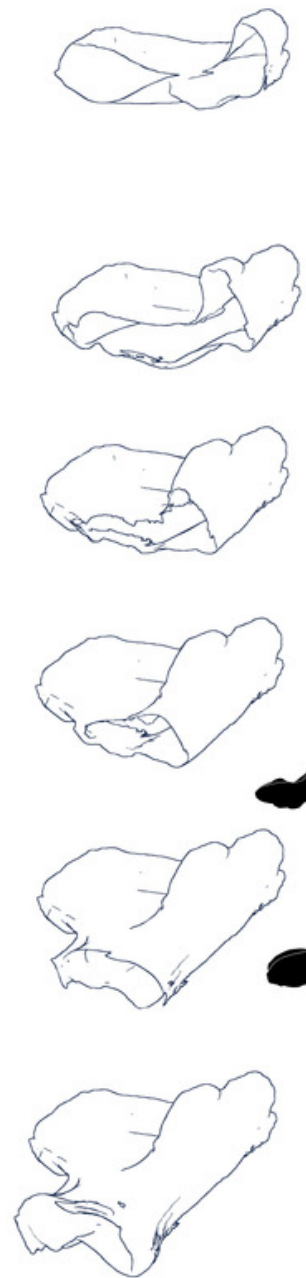
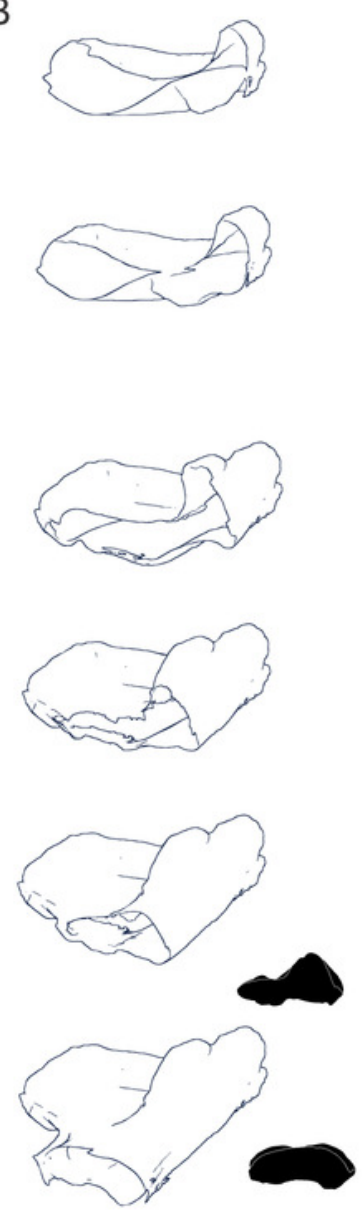

C
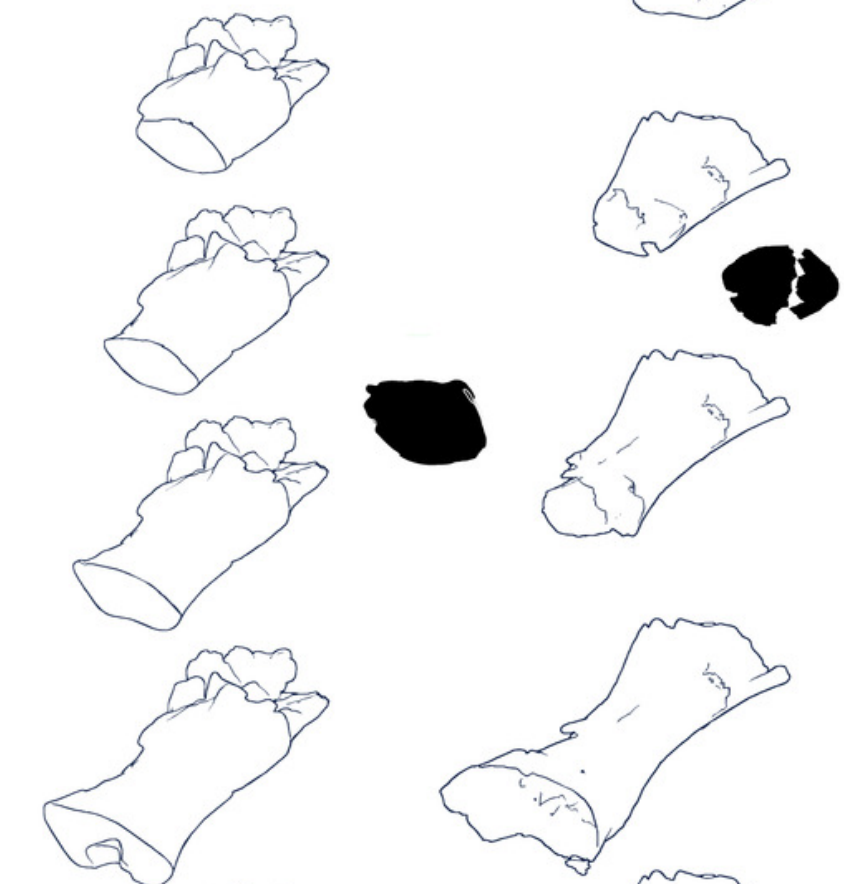

$\checkmark$
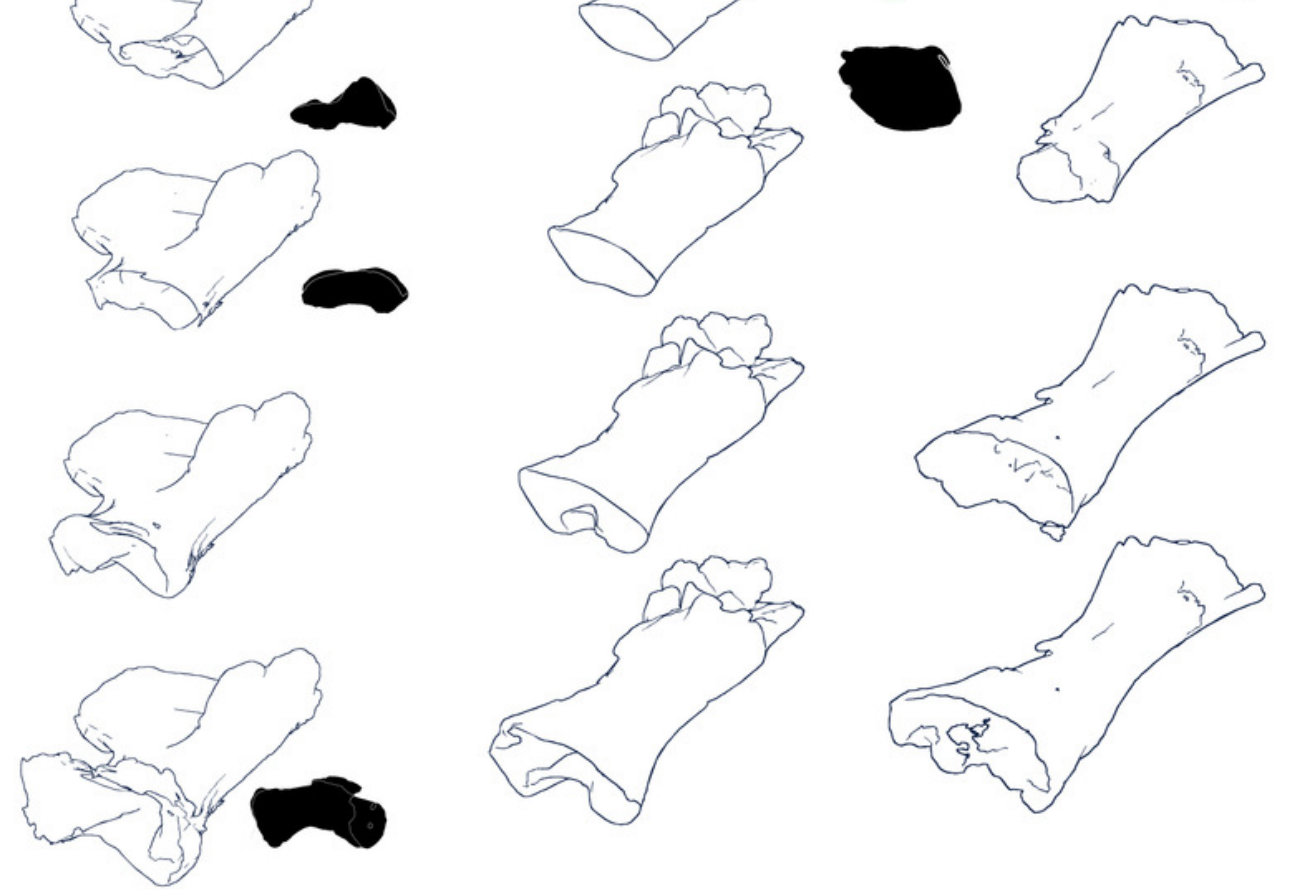

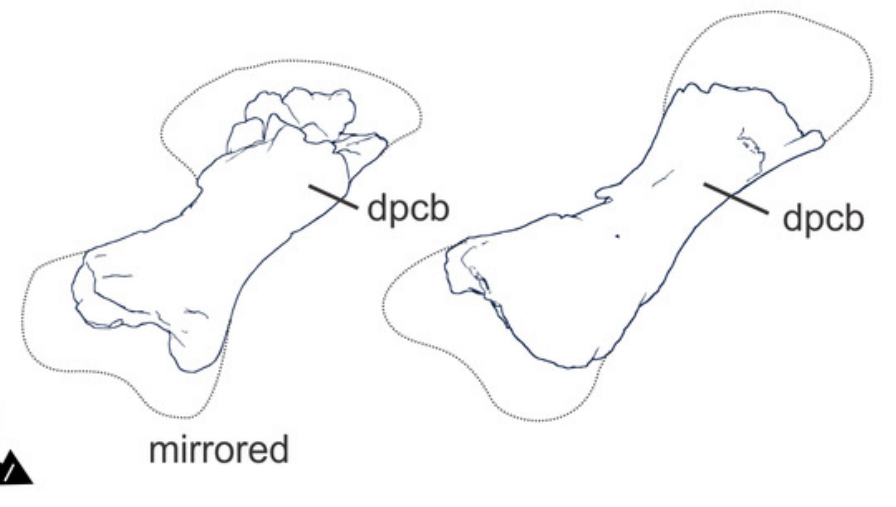




\section{Figure 17}

Ulnae of Australotitan cooperensis gen. et sp. nov. (EMF102), Diamantinasaurus matildae (AODF603) and Wintonotitan wattsi (QMF7292).

(A-D) A. cooperensis gen. et sp. nov. ulna in proximal (A), anterolateral (B), medial (C) and distal (D) views. $(\mathrm{E}-\mathrm{H})$ D. matildae ulna in proximal $(\mathrm{E})$, anteromedial $(\mathrm{F})$, lateral $(\mathrm{G})$ and distal (H) views. (I-P) W. wattsi ulnae in proximal (I \& M), anterolateral (J), anteromedial (N), medial $(K)$, lateral $(O)$ and distal ( $L \& P$ ) views. 3-D image rendering methods used included, natural, A, B, E, F, I, J, M \& N (left), C, D, G, H, K, L, O, P (right); ambient occlusion with radiance scaling, A-P (middle); coloured schematic (see Figure 8), A, B, E, F, I, J, M, N (right), C, D, G, $\mathrm{H}, \mathrm{K}, \mathrm{L}, \mathrm{O}, \mathrm{P}$ (left). Arrows indicate direction (a, anterior; I, lateral; $\mathrm{m}$, medial; p, posterior). Feature abbreviations: alp, anterolateral process; amp, anteromedial process; ior, interosseous ridge of radial fossa; oc, olecranon process; if, radial fossa; uac, distal ulnar accessory process. Scale bars $=20 \mathrm{~cm}$. 


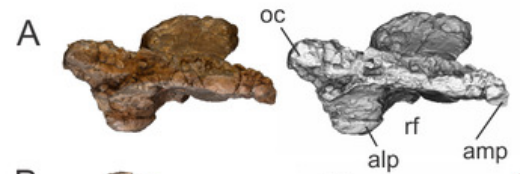

B

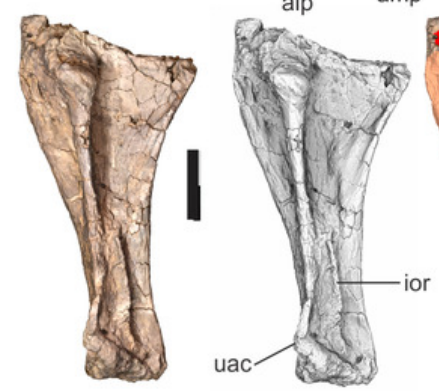

C

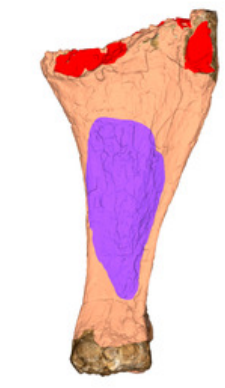

Condery
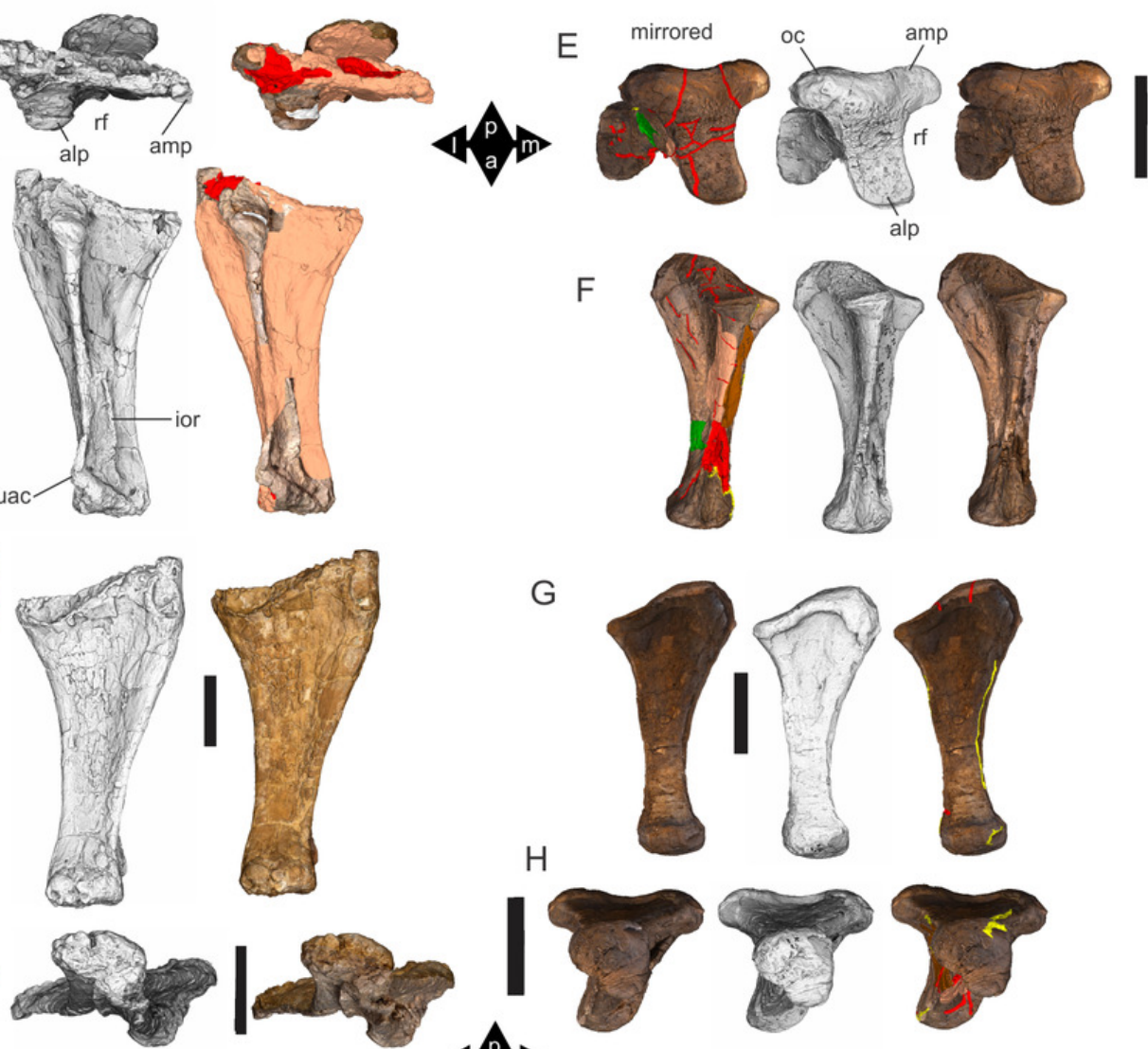

G
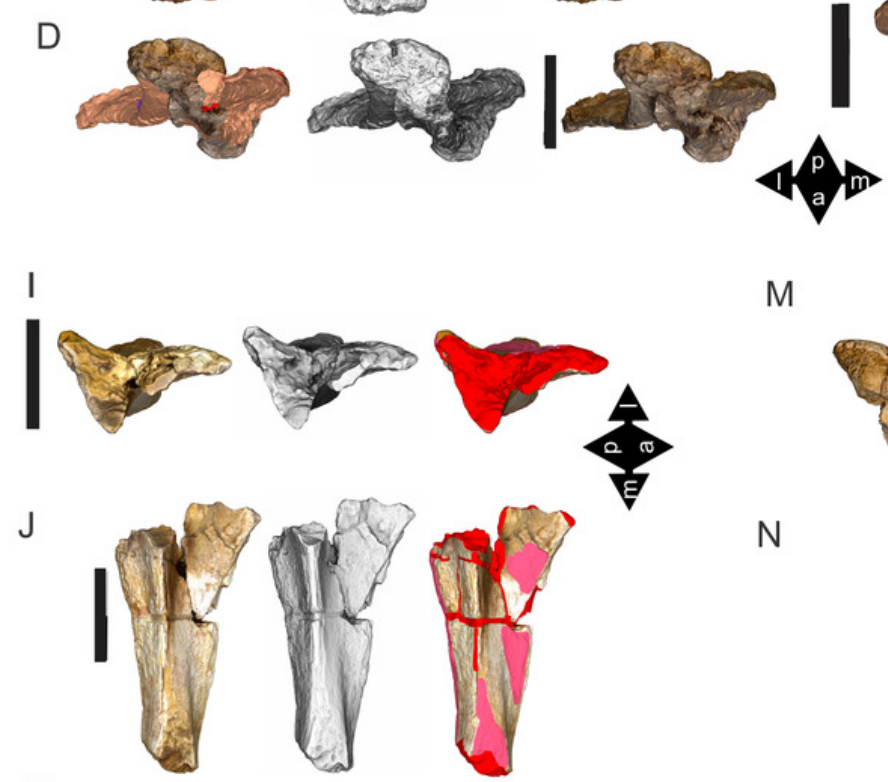

K

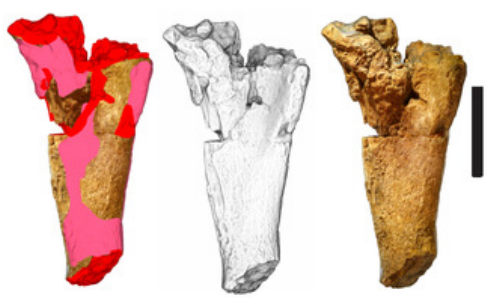

म.
M

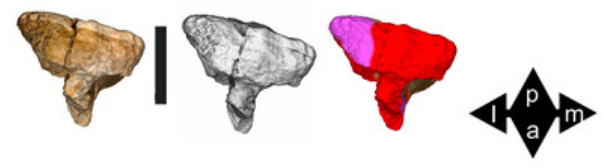

$\mathrm{N}$
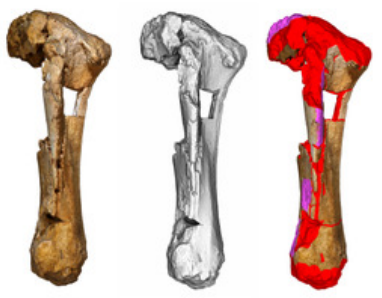

$\mathrm{O}$
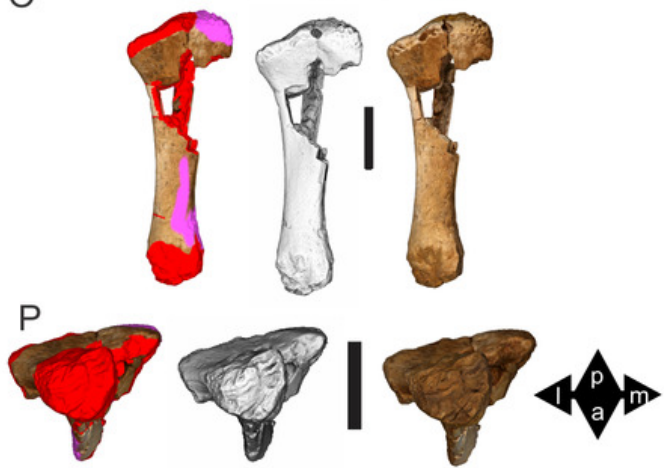


\section{Figure 18}

Comparisons of Winton Formation sauropod ulnae in cross-section, scaled to minimum midshaft width.

(A) Australotitan cooperensis gen. et sp. nov. (B) Diamantinasaurus matildae. (C)

Savannasaurus elliottorum. (D) Wintonotitan wattsi (reconstructed from both preserved ulnae). Abbreviations as in Figure 16. Dashed line indicates position of cross-section. Dotted line indicates estimation of missing bone. Arrows indicate direction ( $a$, anterior; $p$, posterior). Feature abbreviations: alp, anterolateral process; amp, anteromedial process; ior, interosseous ridge of radial fossa; oc, olecranon process; rf, radial fossa.

A

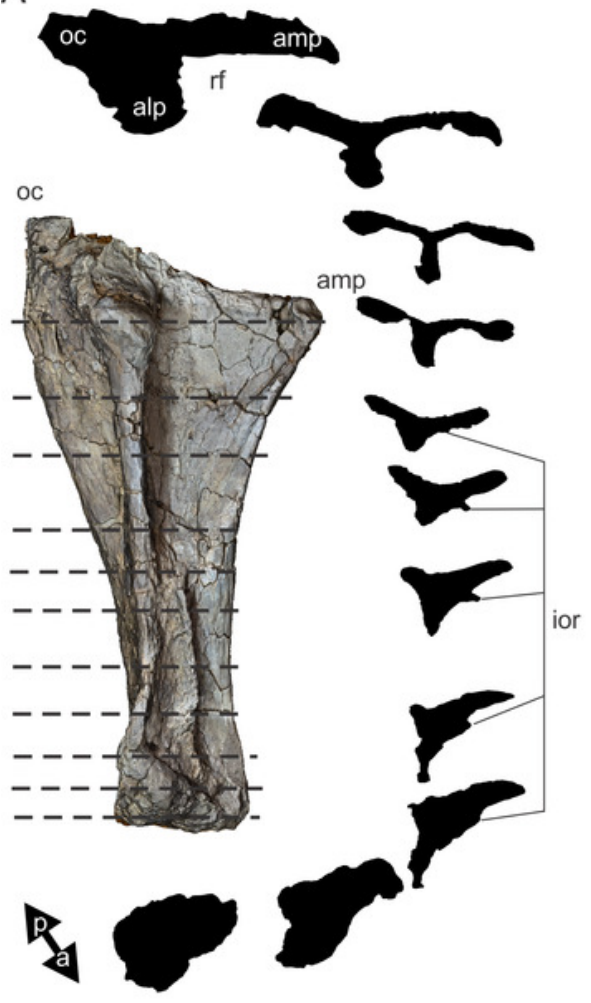

B

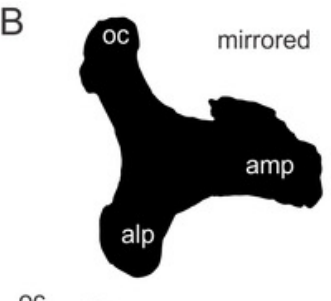

OC

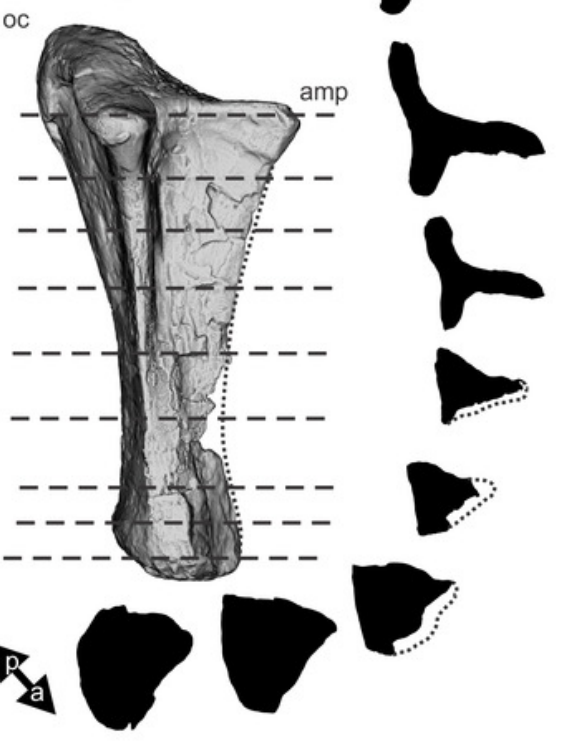

C
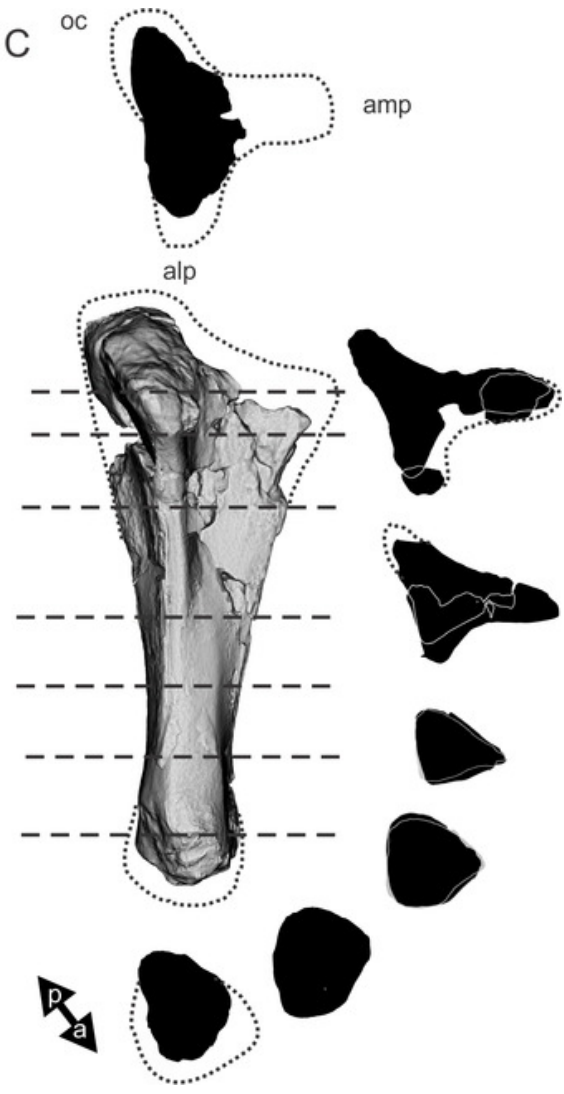


\section{Figure 19}

Comparisons of Winton Formation sauropod ulnae in preserved right ulna outline, scaled to minimum midshaft width.

(A-E) Australotitan cooperensis gen. et sp. nov. in lateral (A), anterolateral (B), anteromedial (C), medial (D) and posterior (E). (F-J) D. matildae in lateral (F), anterolateral (G), anteromedial $(\mathrm{H})$, medial $(\mathrm{I})$ and posterior $(\mathrm{J})$. (K-O) W. wattsi (reconstruction) in lateral (K), anterolateral (L), anteromedial (M), medial (N) and posterior (O). 3-D images rendered using orthogonal outline edge detection. 


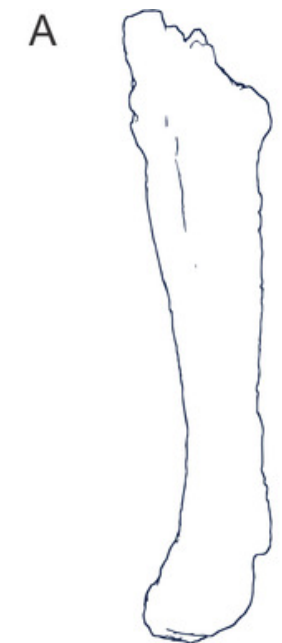

B

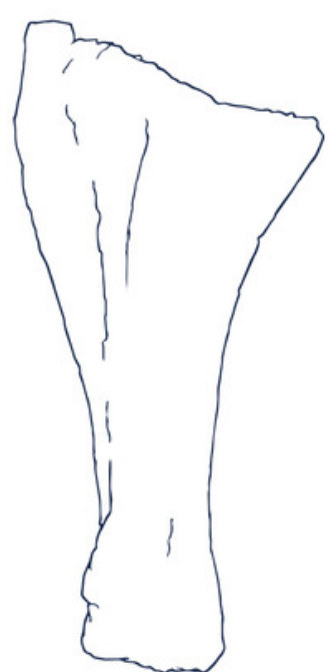

F
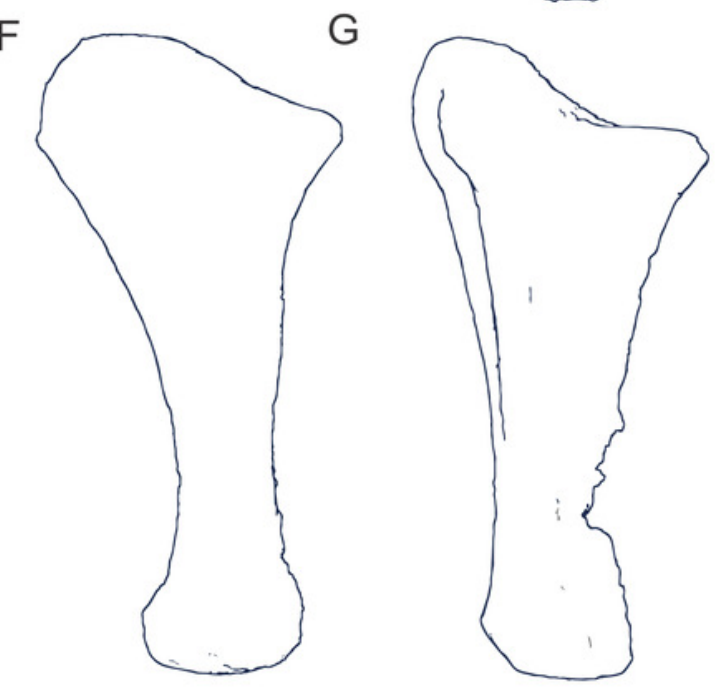

K

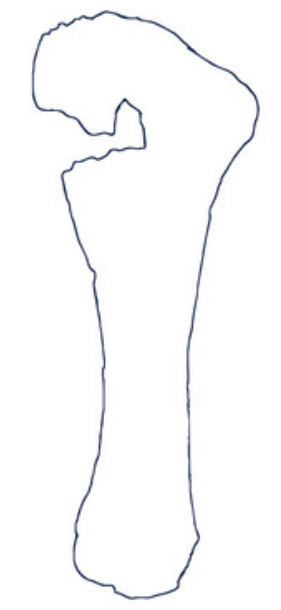

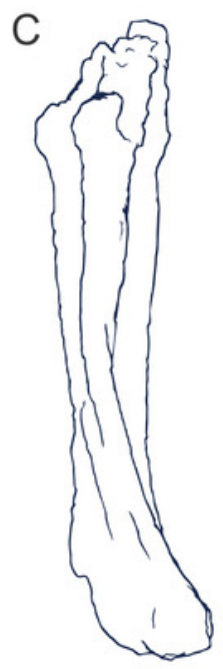

$\mathrm{H}$

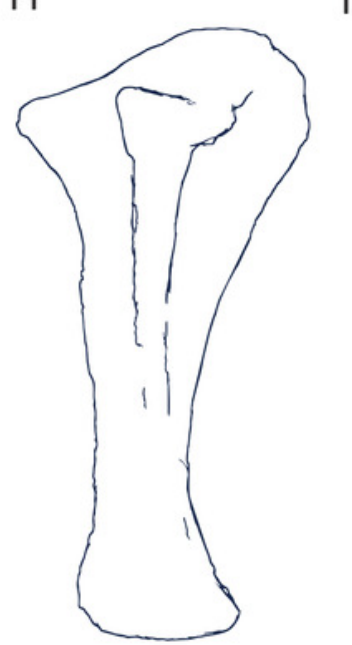

M
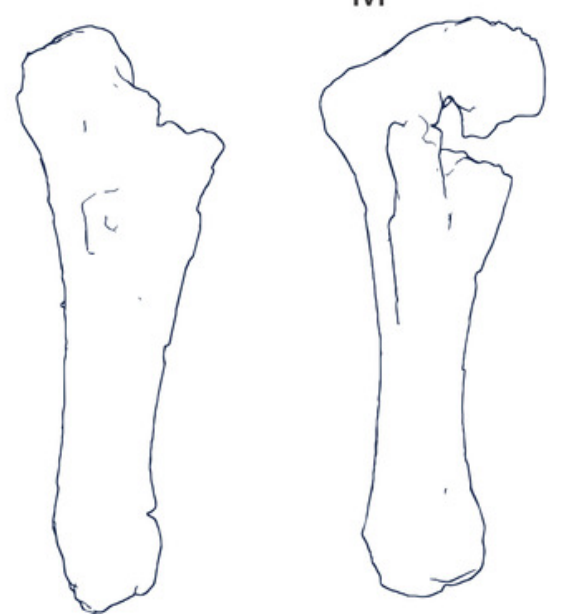
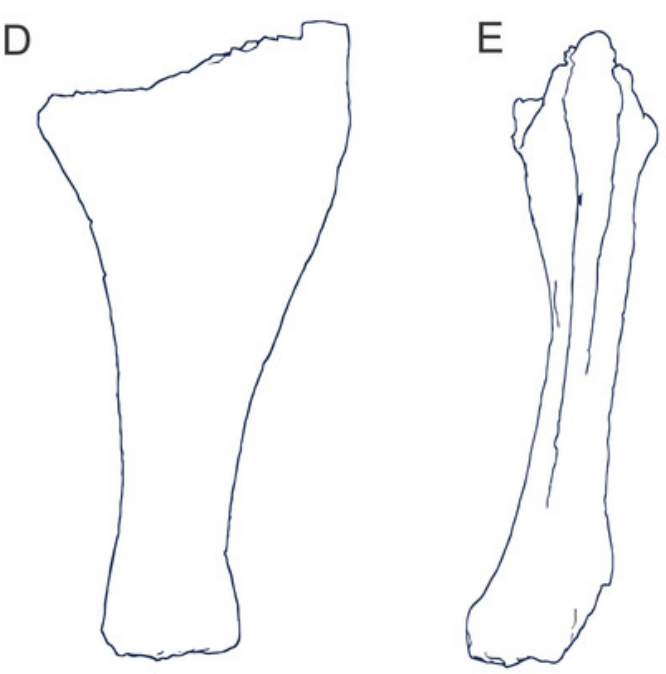

J
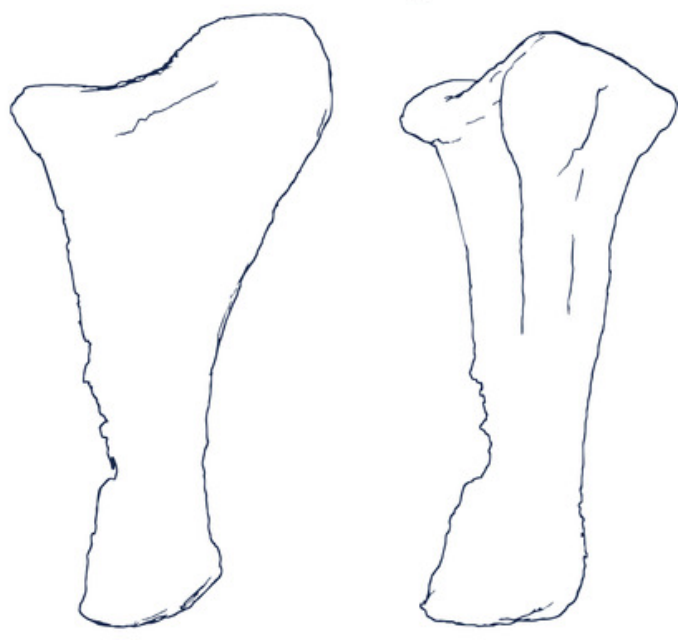

N

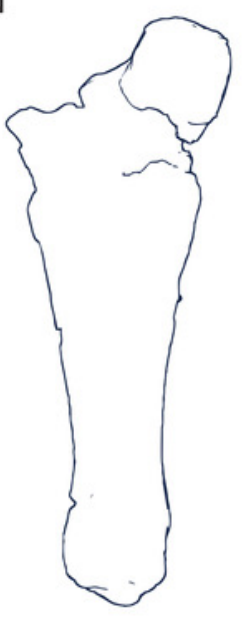

O

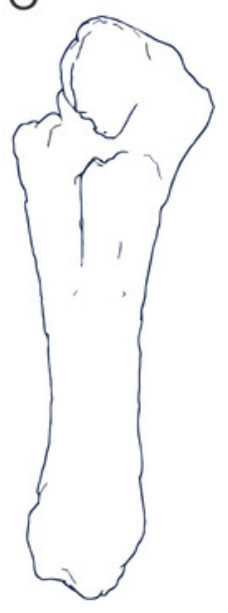




\section{Figure 20}

Pubes and ischia of Australotitan cooperensis gen. et sp. nov. (EMF102).

$(A \& B)$ Right pubis and ischium in ventrolateral $(A)$ and dorsomedial $(B)$ views. $(C \& D)$ Left pubis and ischium in ventrolateral (C) and dorsomedial (D) views). (E) Preserved left pubis and ischium in lateral view, red dotted line indicating region of deformation. (F) Retrodeformed and digitally restored right pubis and ischium. 3-D image rendering methods used included, natural, A \& D (right), B \& C (left); ambient occlusion with radiance scaling, A$\mathrm{D}$ (middle); coloured schematic (see Figure 8), $A \& D$ (left), $B \& C$ (right); vertex and texture uncoloured ( $E \& F$ ). Arrows indicate direction (d, dorsal; dl, dorsolateral; v, ventral; vm, ventromedial). Feature abbreviations: ilped; iliac peduncle; isc, ischium; isped, ischial peduncle; of, obturator foramen; pub, pubis. Scale bars $=20 \mathrm{~cm}$. 

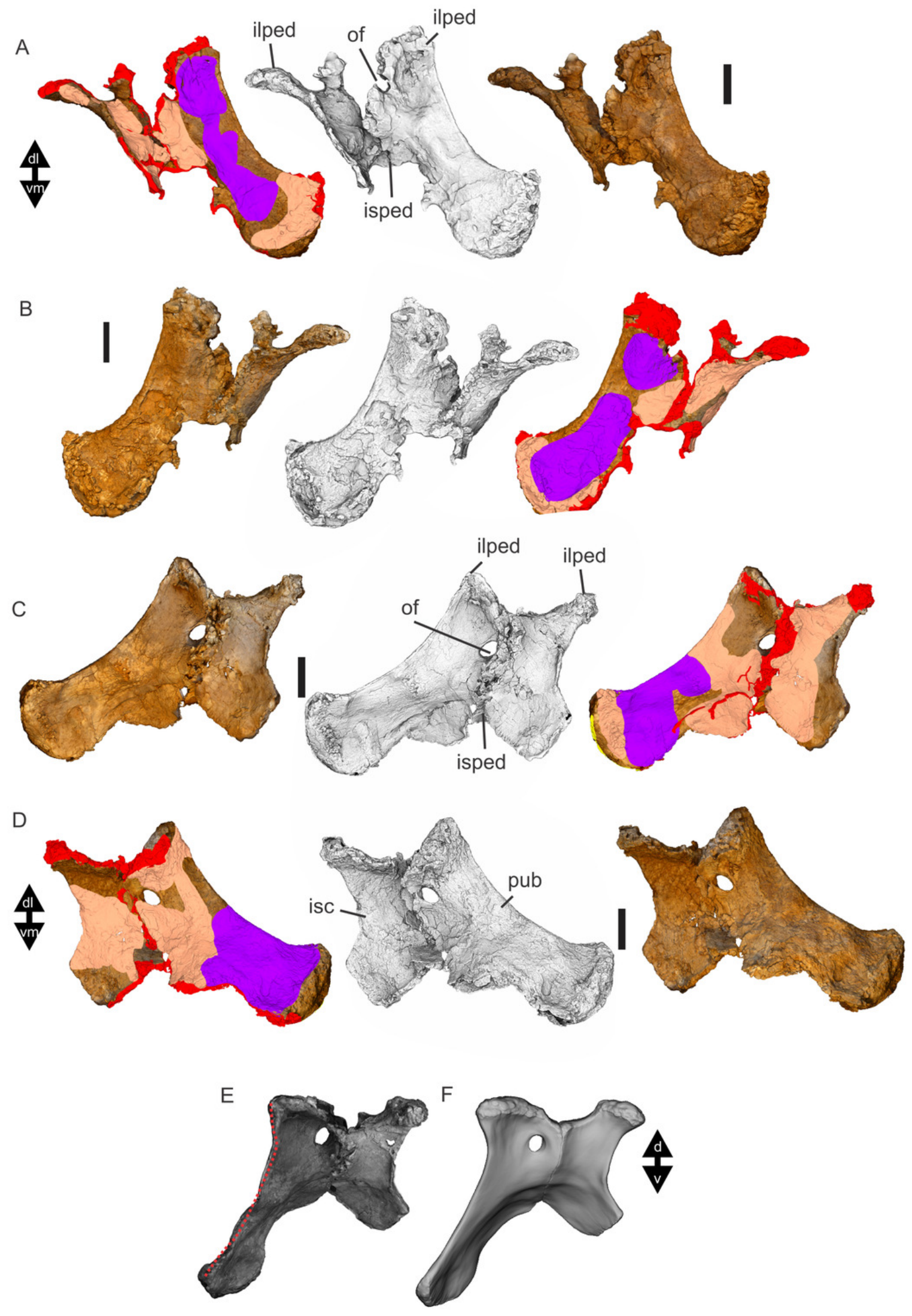


\section{Figure 21}

Pubes and ischia of Australotitan cooperensis gen. et sp. nov. (EMF102) continued.

(A) In-field 3-D model of pubes and ischia at EML011. (B \& C) After preparation, 3-D model of pubes and ischia reoriented to connect at pubic and ischial symphyses pre-displacement in dorsal (B) and anterior (C) views. ( $\& \& E$ ) Mirror of left pubis and ischium (least distorted) to reconstruct overall pelvic floor shape in anterior (D) and dorsal (E) views. Red dotted line indicates estimated extent of pubic and ischial blade contralateral bone with central diamond-shaped gap. (F-H) Digitally restored pubes and ischia in dorsal (F), anterior (G) and posterior $(\mathrm{H})$ views. 3-D image rendering methods used included, natural, A-E and vertex and texture uncoloured in $\mathrm{F}-\mathrm{H}$. Arrows indicate direction ( $\mathrm{a}$, anterior; $\mathrm{p}$, posterior). Scale bars $=$ $20 \mathrm{~cm}$. 

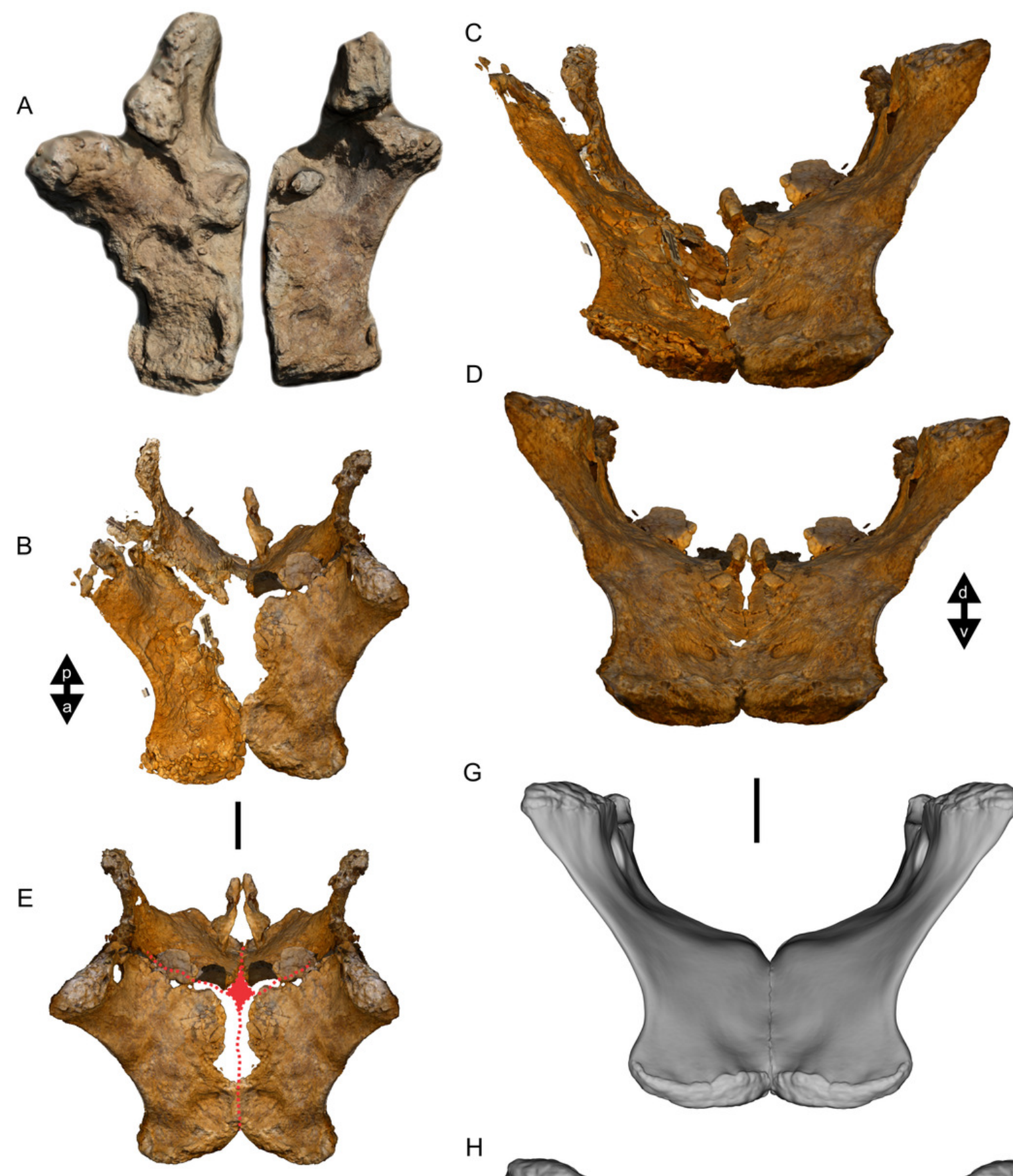

G

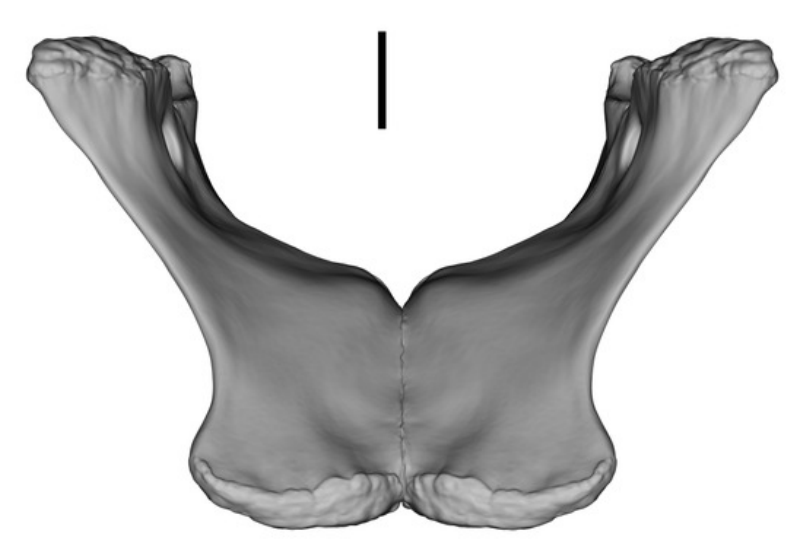

F

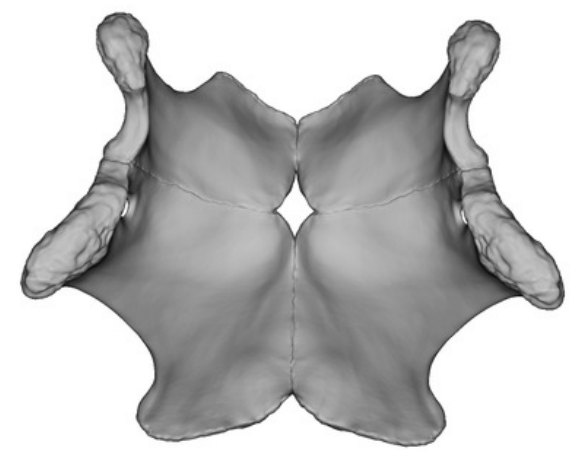

H

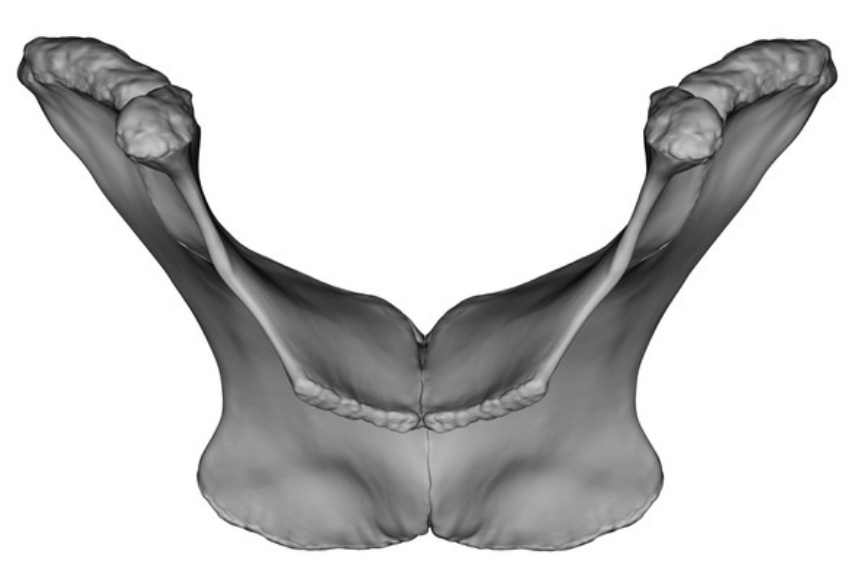




\section{Figure 22}

Comparisons of Winton Formation sauropod pubes and ischia in dorsal, lateral, anterior and posterior views.

(A) \& (E) W. wattsi, (B, F, I \& L) D. matildae, (C, G, J \& M), A. cooperensis gen. et sp. nov. and $(D, H, K \& N) S$. elliottorum. 3-D image rendering methods used included, ambient occlusion with radiance scaling, A-H (top); orthogonal outline edge detection, A-D (bottom) and I-N. Dashed line with grey fill indicates estimated ventral pelvic cavity from acetabular opening to pubo-ischial commissure. Arrows indicate direction ( $a$, anterior; p, posterior). Feature abbreviations: ilped; iliac peduncle. Scale bars $=20 \mathrm{~cm}$. 


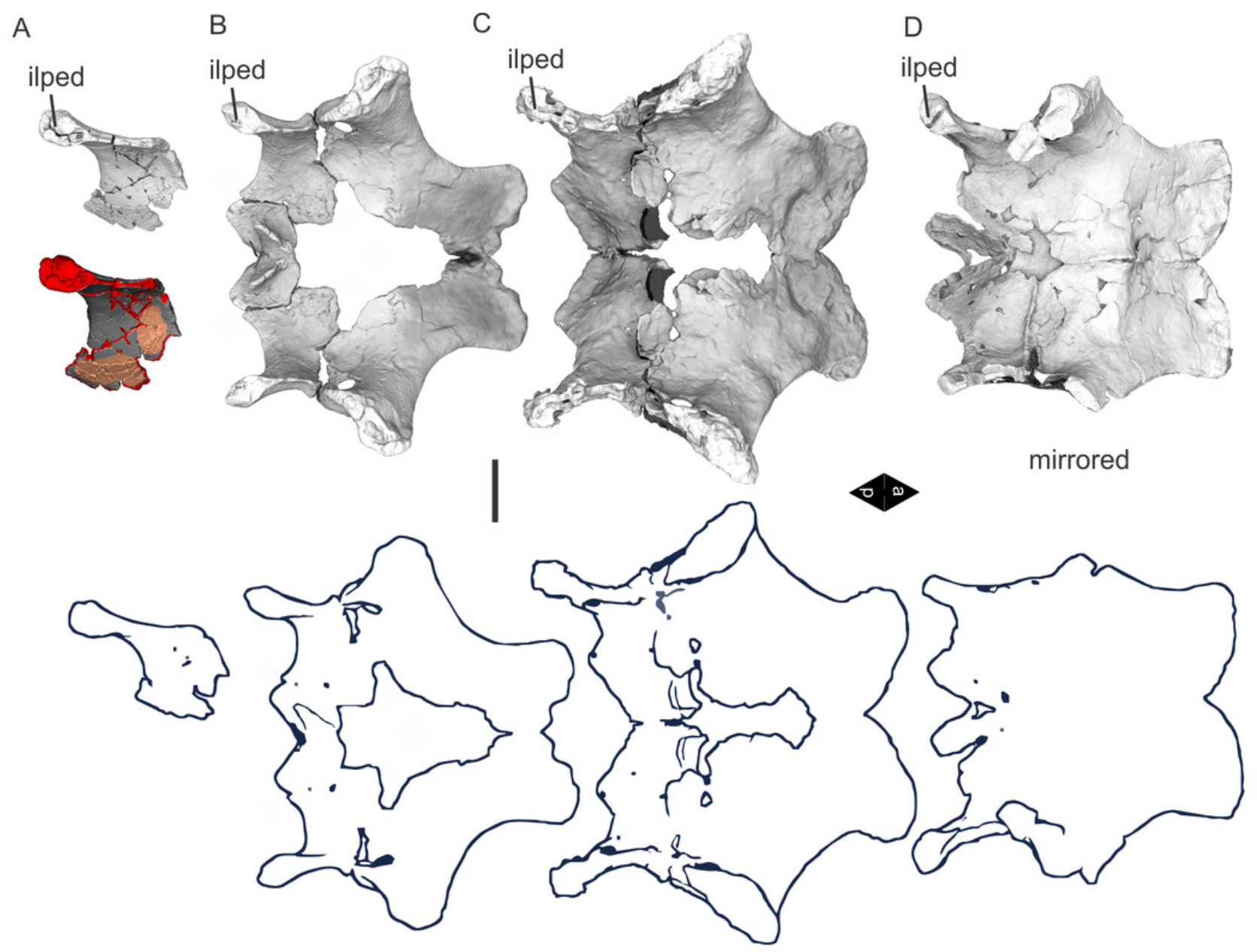

E

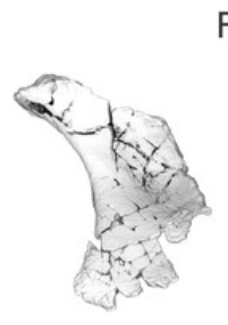

F

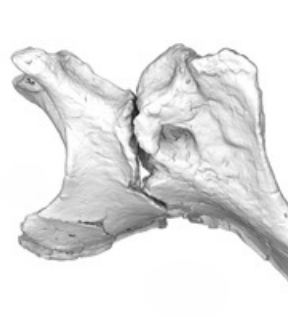

G
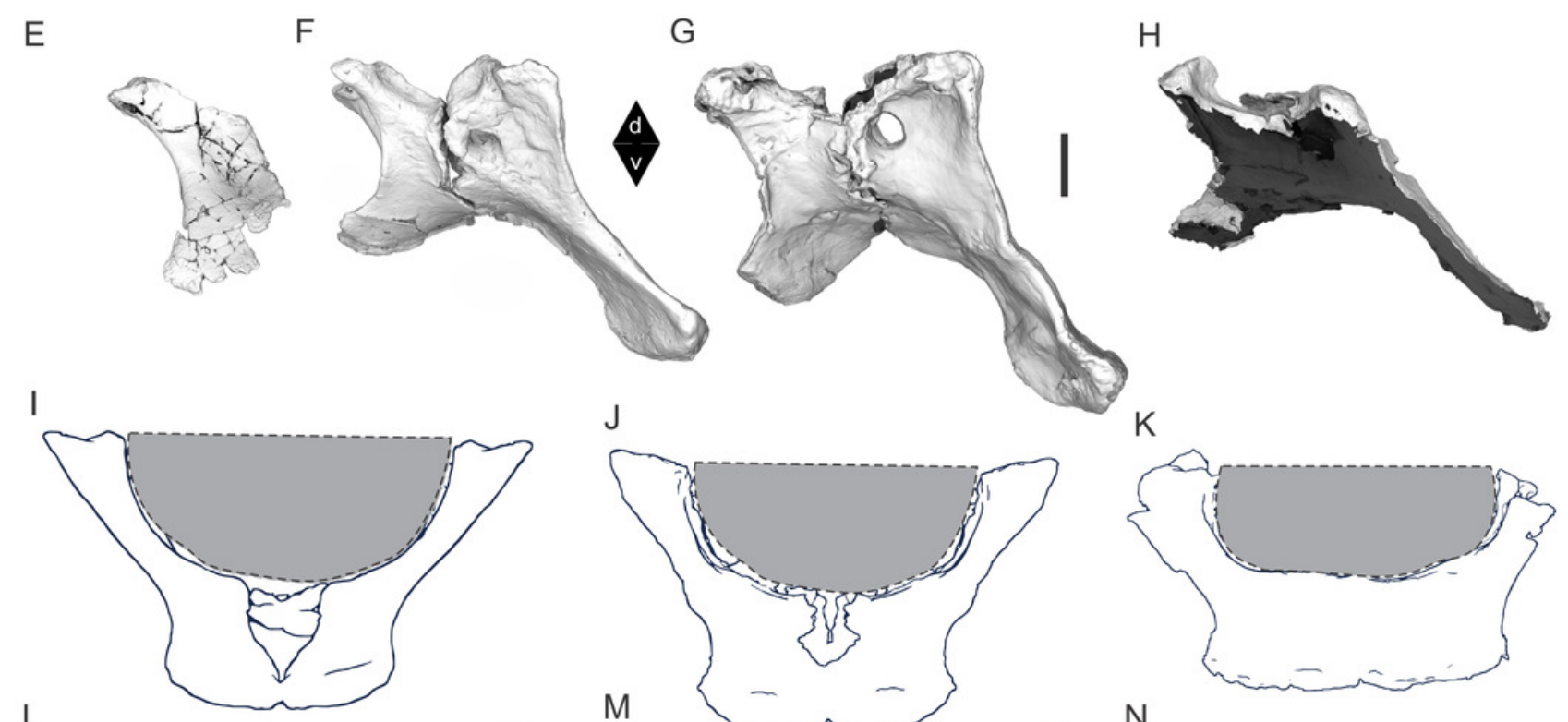

L

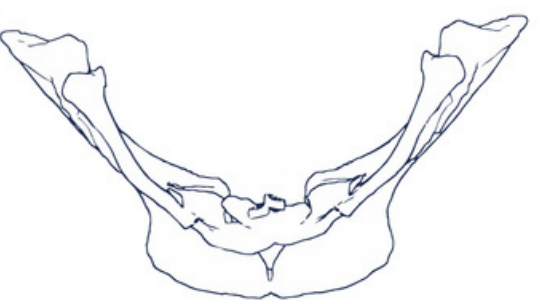

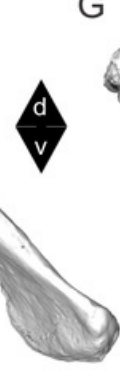
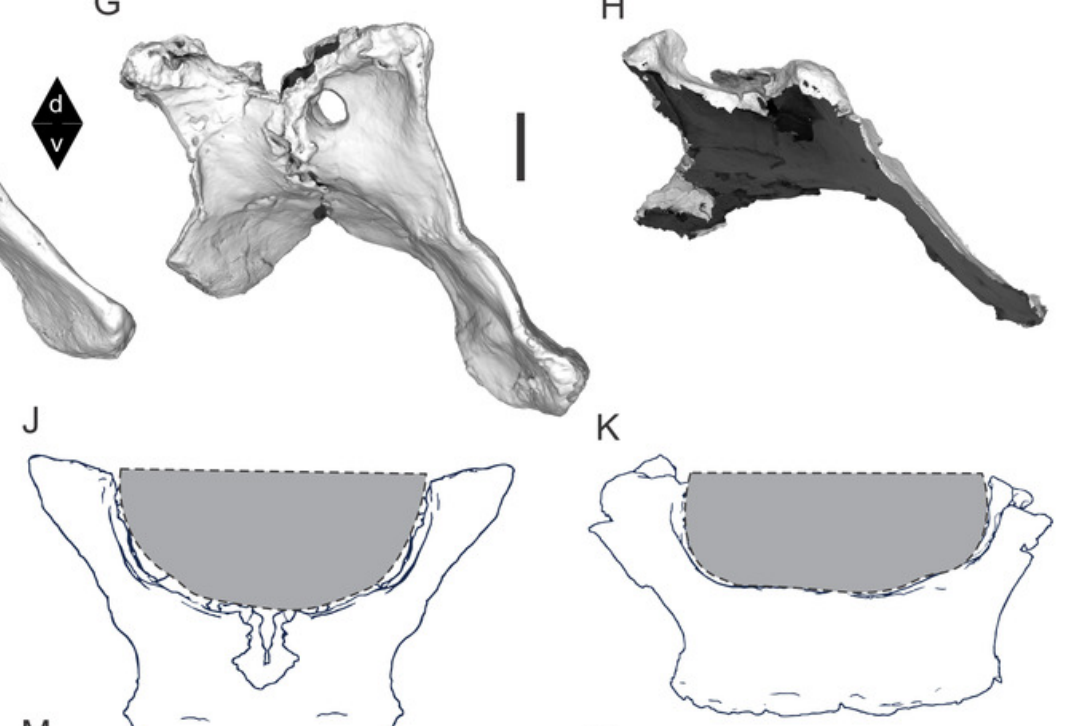

N
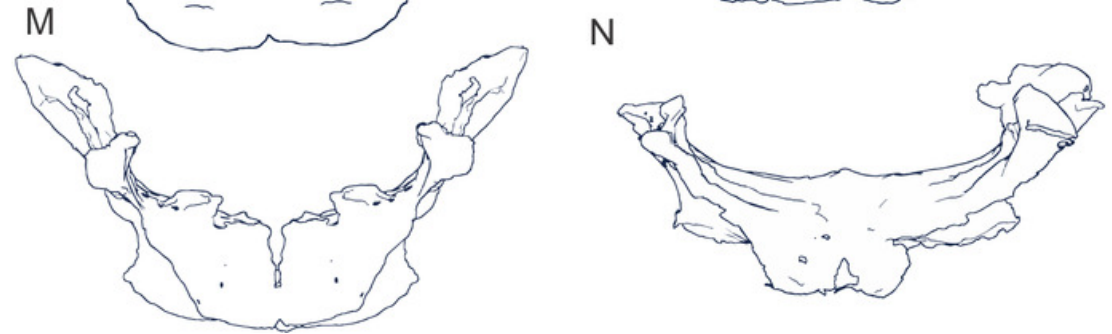


\section{Figure 23}

Femora of Australotitan cooperensis gen. et sp. nov. (EMF102) and referred specimen (EMF105).

(A-C) EMF102, left proximal femur head in proximal (A), posterior (B) and anterior (C) views.

(D-G) EMF102, right near complete femur in proximal (D), posterior (E), anterior (F) and distal (G) views. (H-K) EMF105, right femur in proximal (H), posterior (I), anterior (J) and distal (K) views. 3-D image rendering methods used included, natural, B, D, F, I, K (left), A, C, E, G, H, J (right); ambient occlusion with radiance scaling, A-K (middle); coloured schematic (see Figure 8), B, D, F, I, K (right), A, C, E, G, H, J (left). Arrows indicate direction (a, anterior; I, lateral, m, medial, p, posterior). Feature abbreviations: fic, fibular condyle; ft, forth trochanter; gtr, greater trochanter; hd, femoral head; lb, lateral bulge; lec, lateral epicondyle; lic, linea intermuscularis cranialis. Scale bars $=20 \mathrm{~cm}$. 

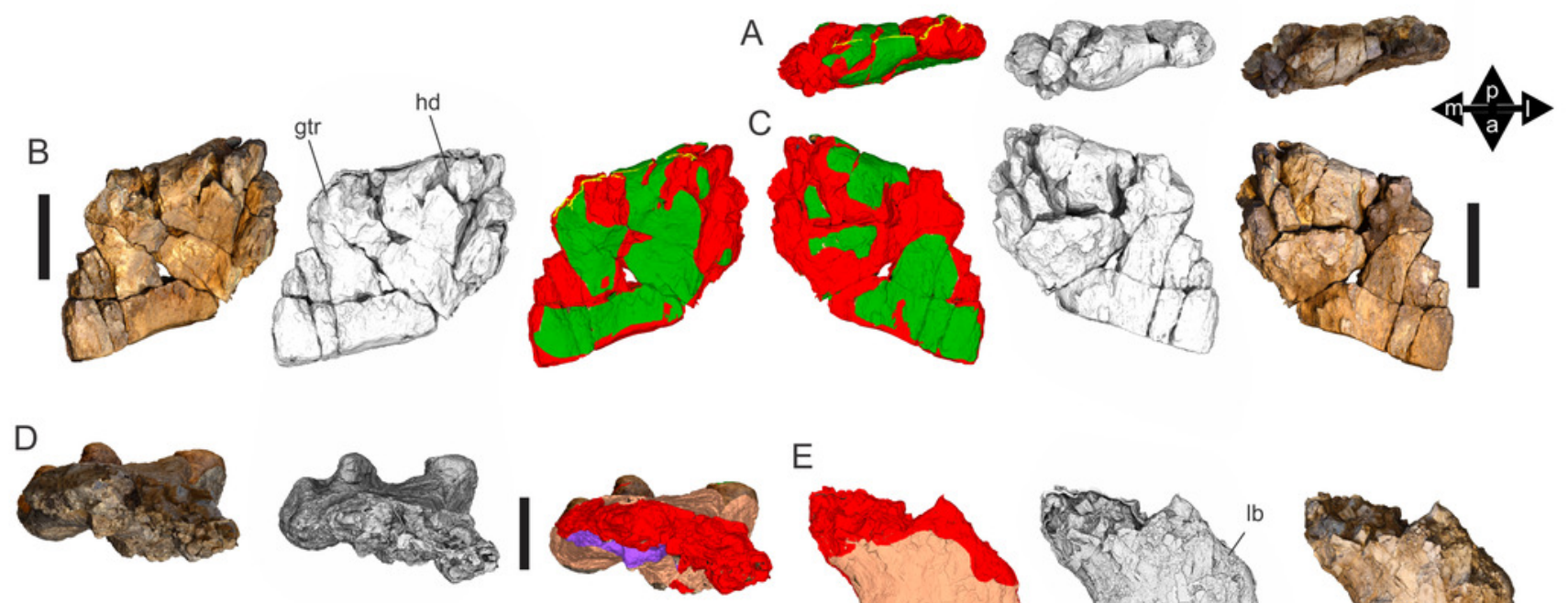

E
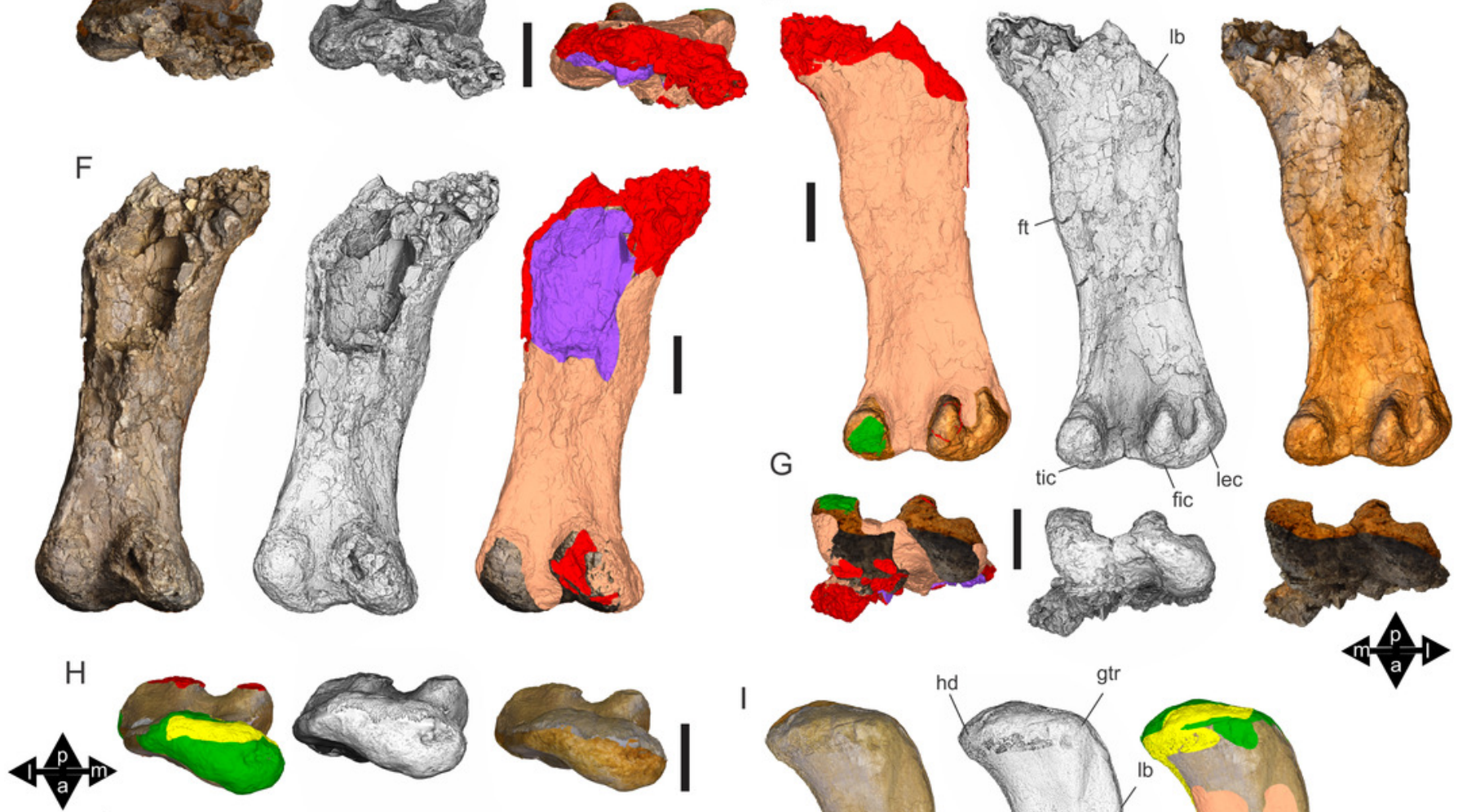

G
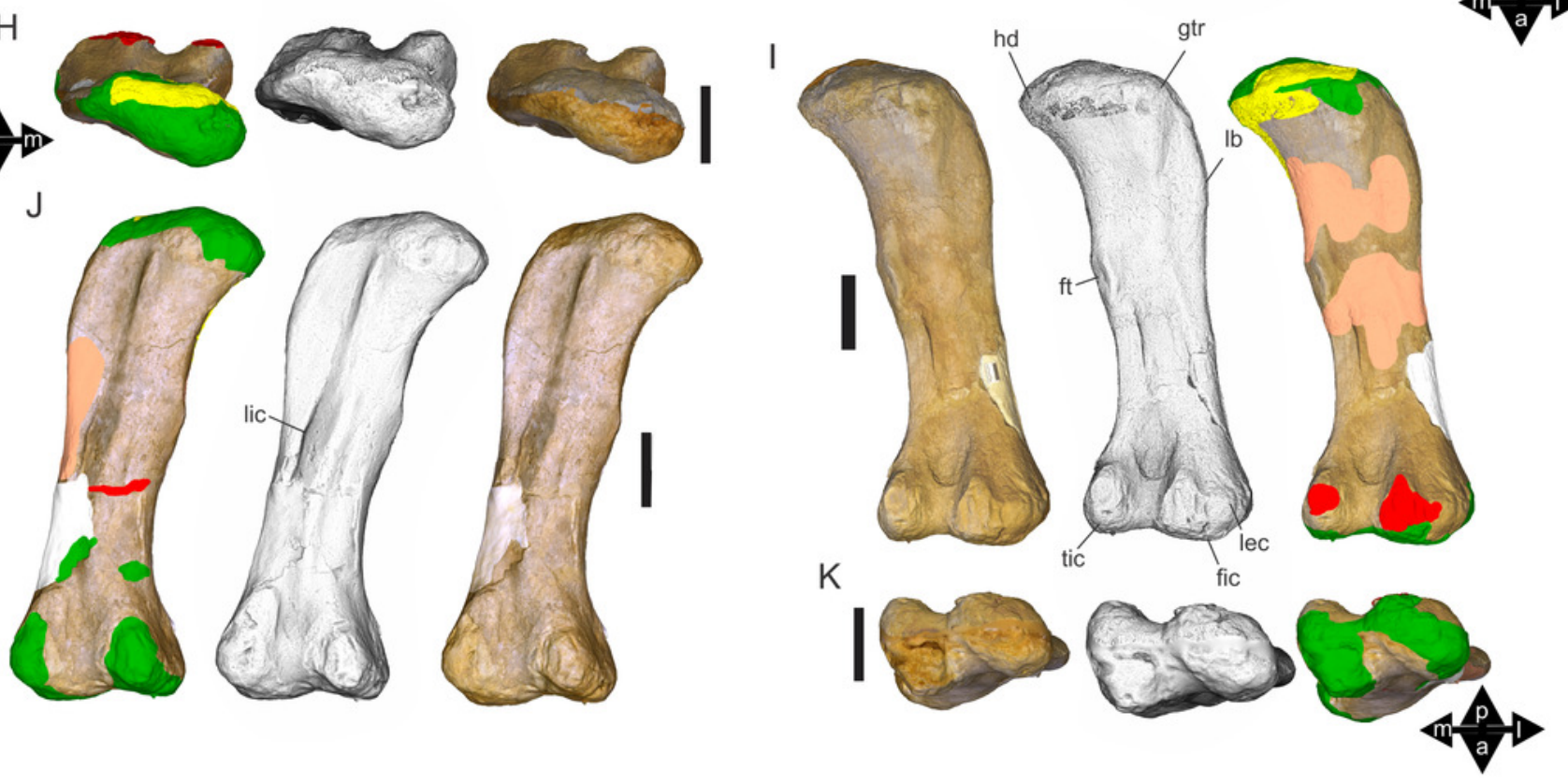


\section{Figure 24}

Femoral orthogonal outlines of Australotitan cooperensis gen. et sp. nov. (EMF102) as preserved and reconstructed, and referred femur (EMF105).

(A-E) EMF102 as preserved in medial (A), anterior (B), posterior (C), oblique lateral (D) and lateral (E). (F-J). Reconstructed femur using left and right specimens in medial $(F)$, anterior $(\mathrm{G})$, posterior $(\mathrm{H})$, lateral $(\mathrm{I})$ and distal (J). (K-O) EMF105 as preserved in medial (K), anterior

$(\mathrm{L})$, posterior $(\mathrm{M})$, lateral $(\mathrm{N})$ and distal $(\mathrm{O})$. All images scaled to equal minimum mediolateral midshaft width. 3-D image rendering methods used orthogonal outline edge detection. Arrows indicate direction ( $a$, anterior; l, lateral; $\mathrm{m}$, medial; $\mathrm{p}$, posterior). Scale bars $=20 \mathrm{~cm}$. 

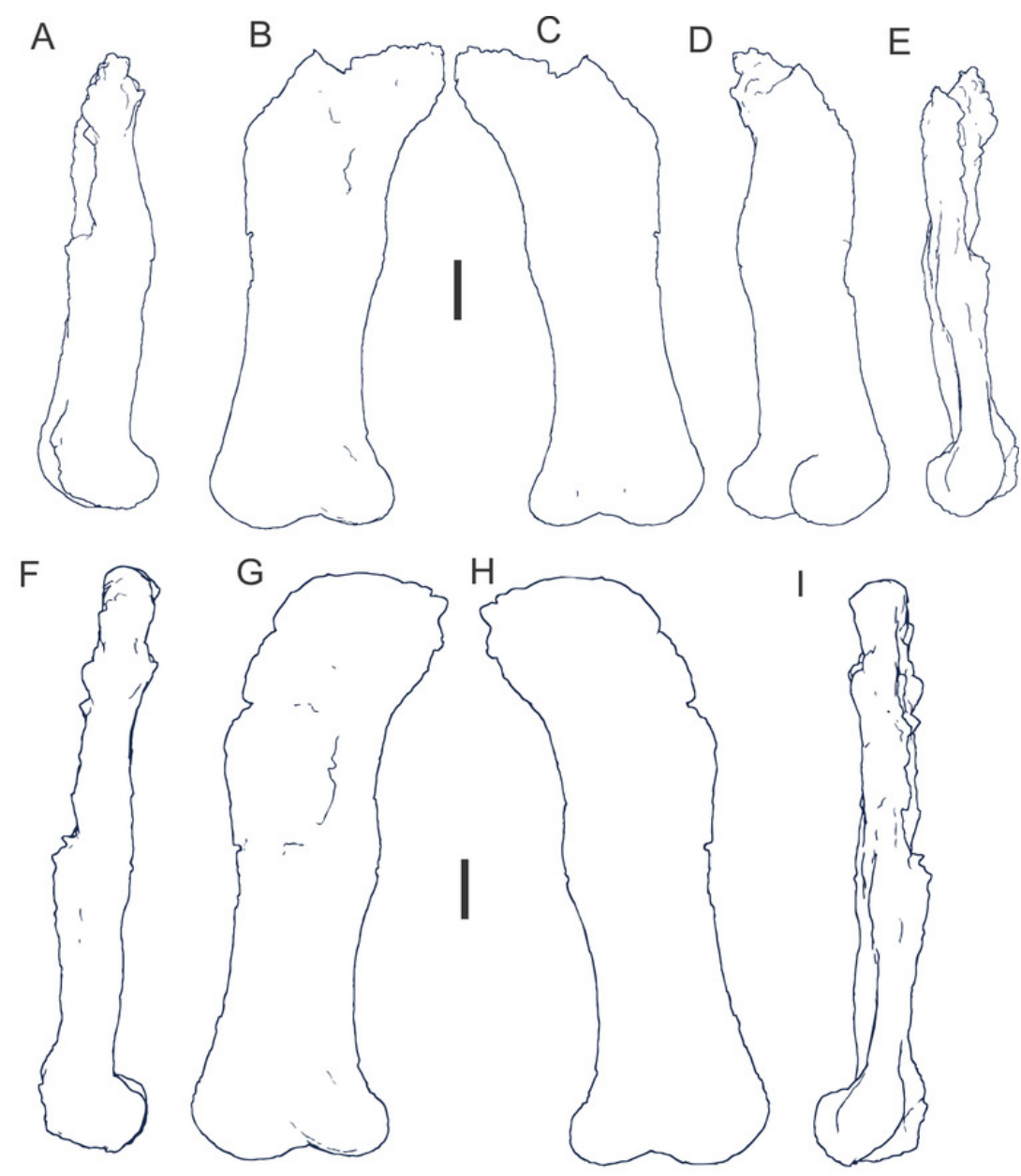

I
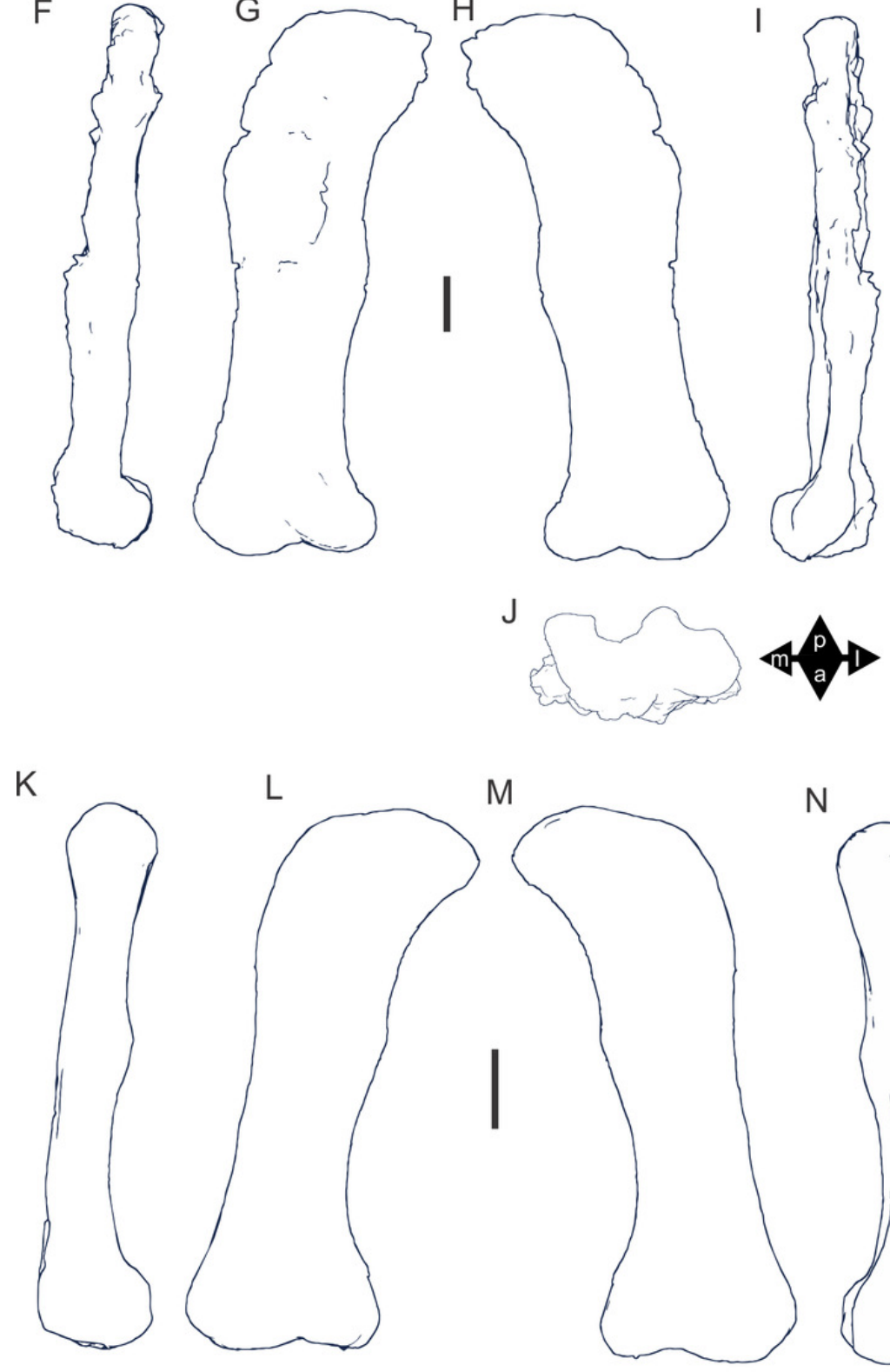

$\mathrm{N}$
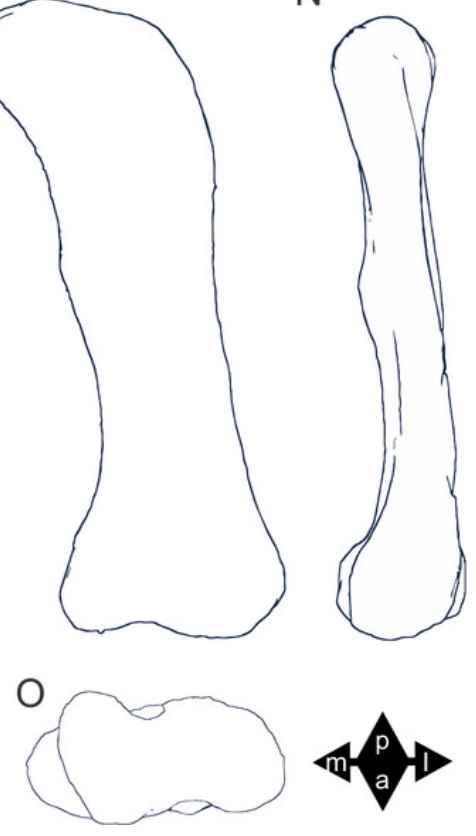


\section{Figure 25}

Northern Winton Formation femora, including the femur of Diamantinasaurus matildae holotype (AODF603).

(A-C) AODF603 right femur in proximal (A), posterior (B) and distal (C) views. Anterior face of femur within fiberglass cradle and not available to this study. (D-F) QMF3390 distal right femur in anterior (D), posterior (E) and distal (F) views. (G-I) QMF7291 distal right femur in anterior (G), posterior (H) and distal (I) views. (J-O) QMF43302 partial right femur in anterior $(J)$, posterior $(K)$, oblique medial $(L)$, lateral $(M \& N)$ and medial $(O)$ views. Posterior face of femur within fiberglass cradle and not available to this study. 3-D image rendering methods used included, natural, A, B, C, E, F, G, J, (left), D, H, I, K (right), L \& M; ambient occlusion with radiance scaling A-K (middle), N\& O; coloured schematic (see Figure 8), A, B, C, E, F, G, J, (right), D, H, I, K (left). Arrows indicate direction (a, anterior; p, posterior). Feature abbreviations: fic, fibular condyle; ft, forth trochanter; gtr, greater trochanter; hd, femoral head; Ib, lateral bulge; lec, lateral epicondyle. Scale bars $=20 \mathrm{~cm}$. 


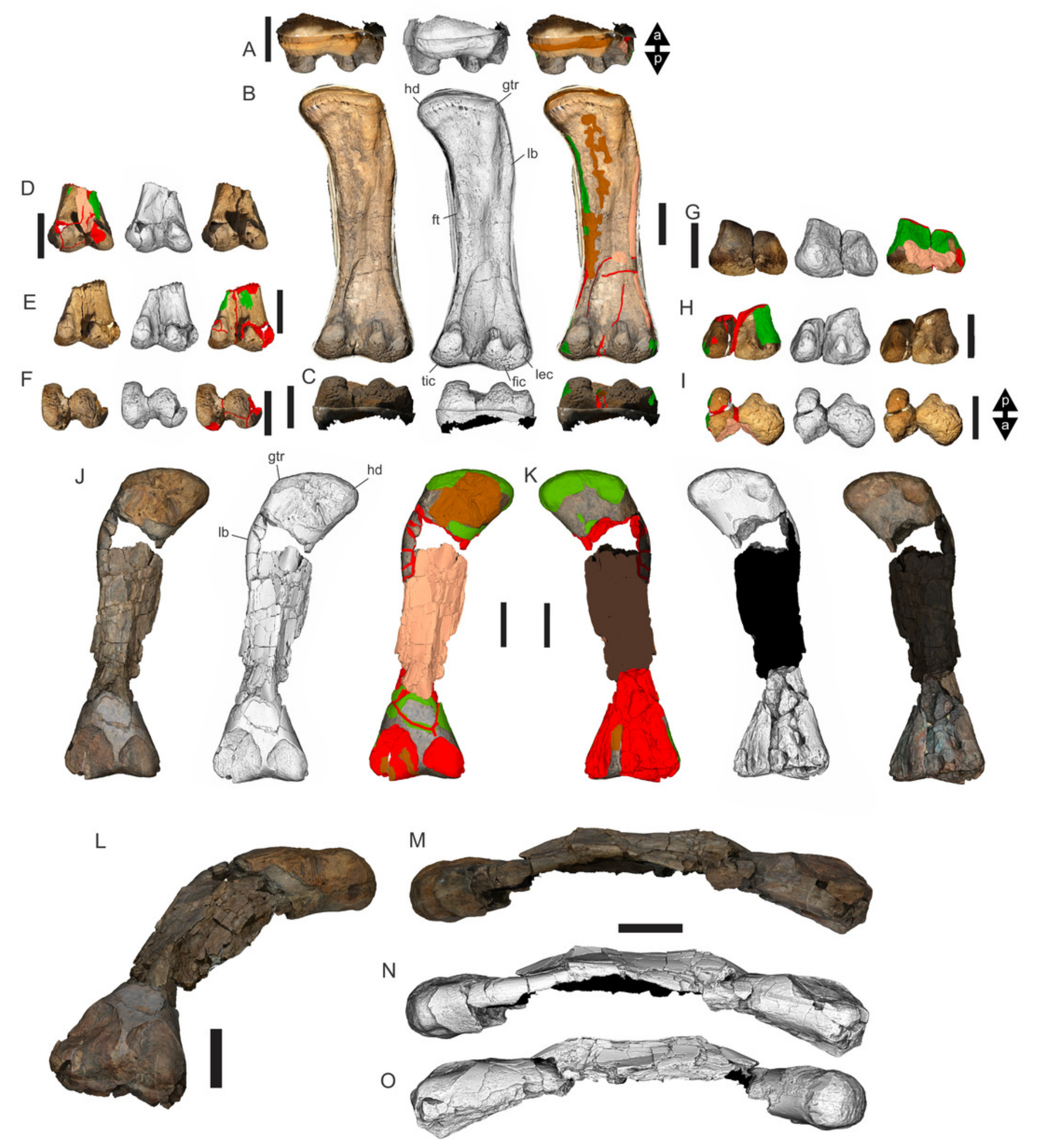


Figure 26

Northern Winton Formation femora in orthogonal outlines, including the femur of Diamantinasaurus matildae holotype (AODF603).

(A-C) AODF603 right femur in proximal (A), posterior (B) and distal (C) views. (D-G) QMF43302 partial right femur in medial (D), anterior (E), posterior (F) and lateral (G) views. (H-L) QMF3390 distal right femur in medial $(\mathrm{H})$, anterior $(\mathrm{I})$, distal $(\mathrm{J})$, lateral $(\mathrm{K})$ and posterior (L). (M-Q) QMF7291 distal right femur in medial (M), anterior (N), distal (O), lateral (P) and posterior (Q). Arrows indicate direction (a, anterior; $p$, posterior). Scale bars $=20 \mathrm{~cm}$.

A

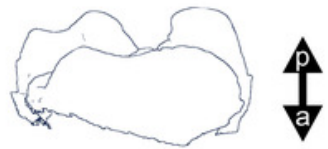

B

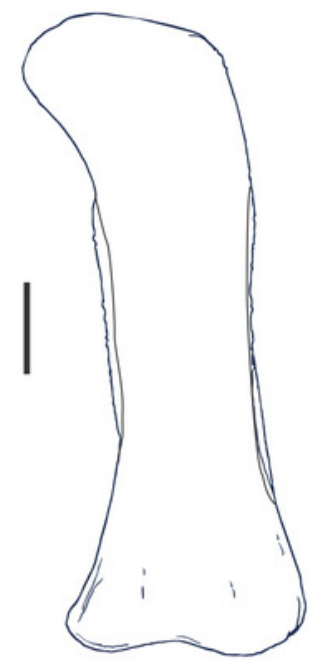

C

昘

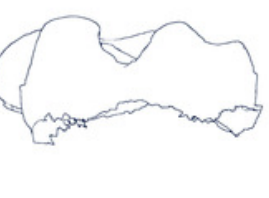

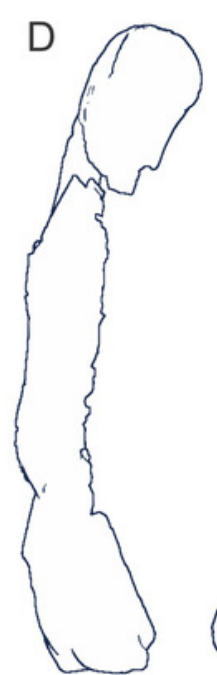
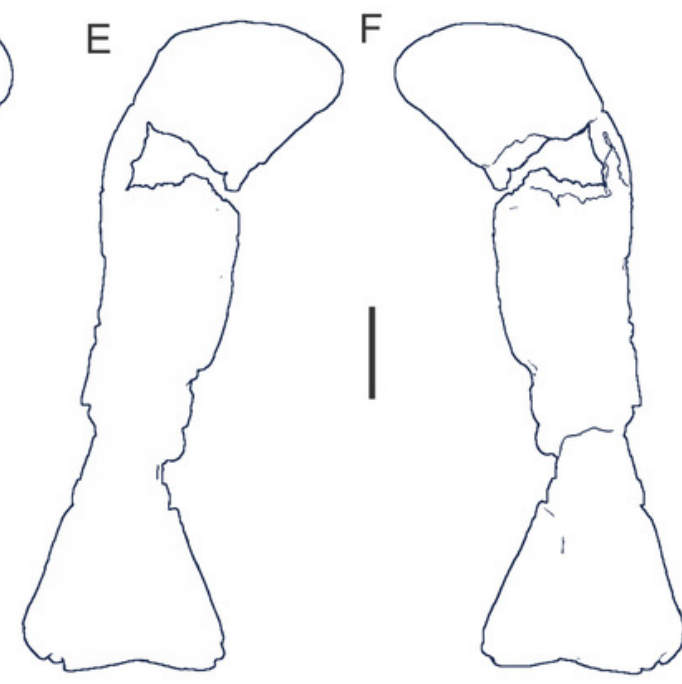

G
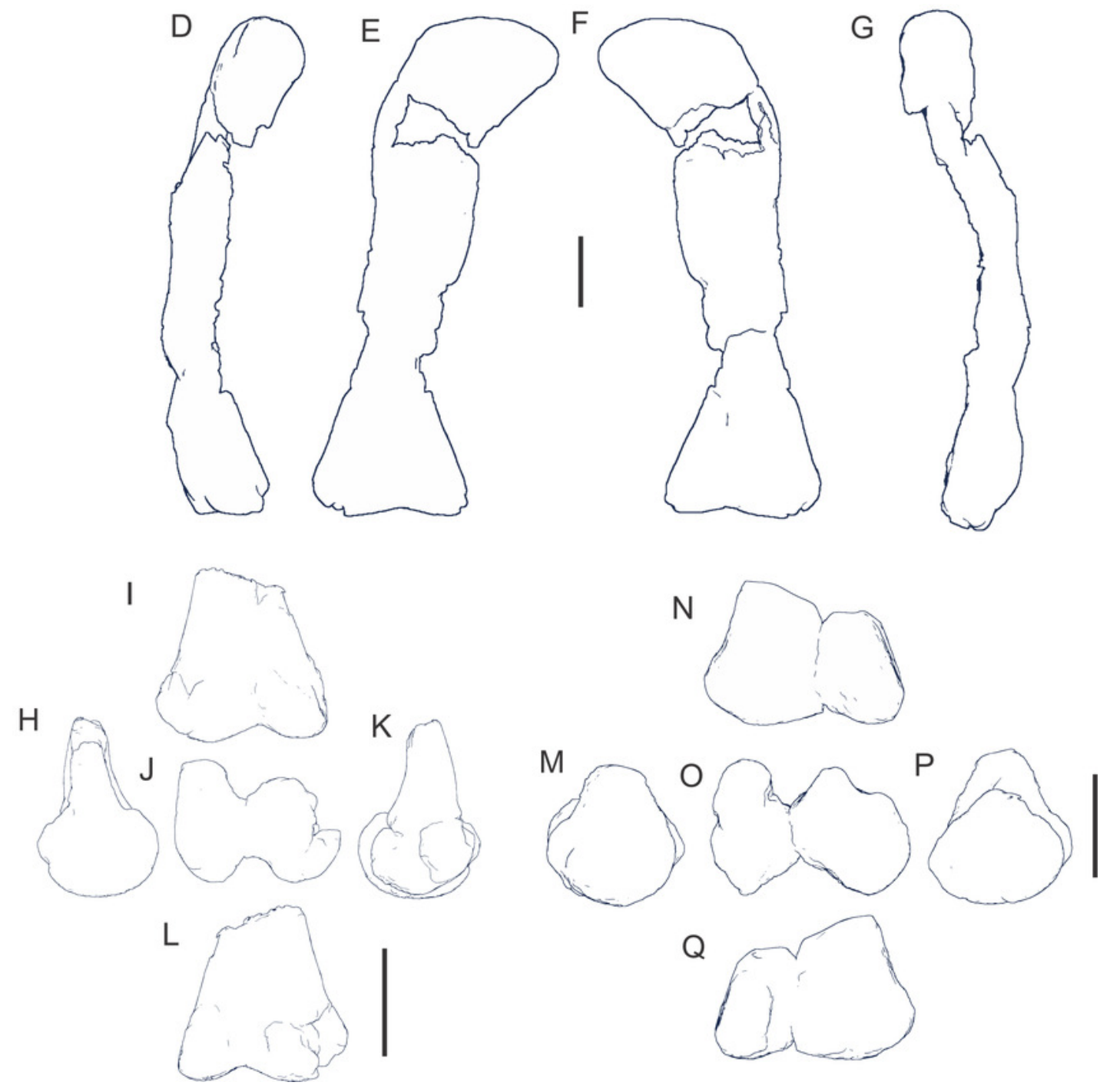


\section{Figure 27}

EMF165, a distal humerus referred to Australotitan cooperensis gen. et sp. nov.

(A) Anterior view. (B) Posterior view. (C) Distal view. 3-D image rendering methods used included, natural, A \& C (left), B (right); ambient occlusion with radiance scaling A-C (middle); coloured schematic (see Figure 8) A \& C (right), B (left). Arrows indicate direction ( $a$, anterior; I, lateral; $\mathrm{m}$, medial; $\mathrm{p}$, posterior). Scale bars $=20 \mathrm{~cm}$. 
A

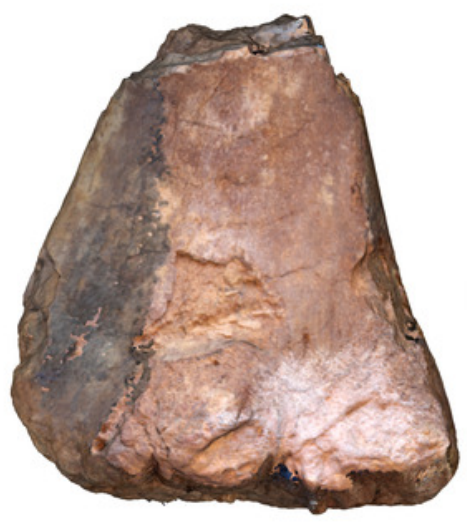

B

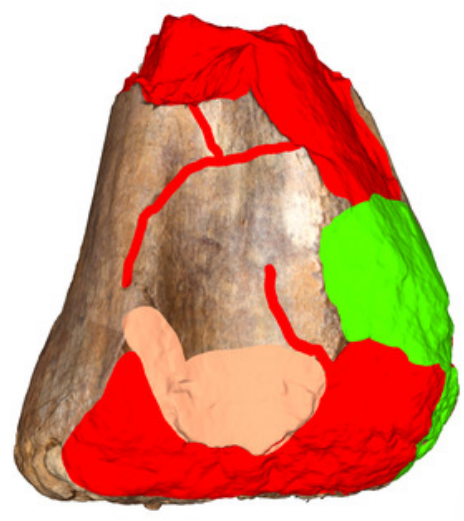

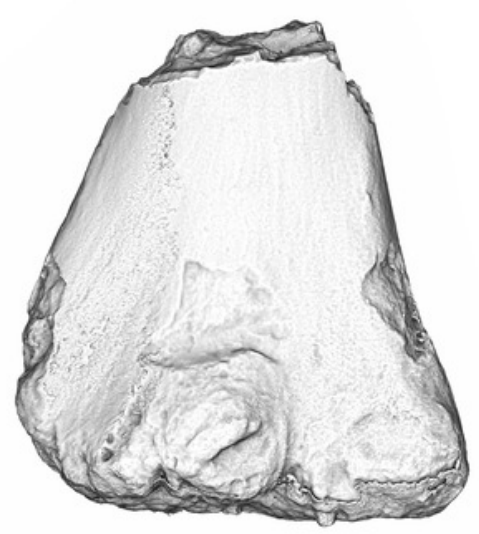
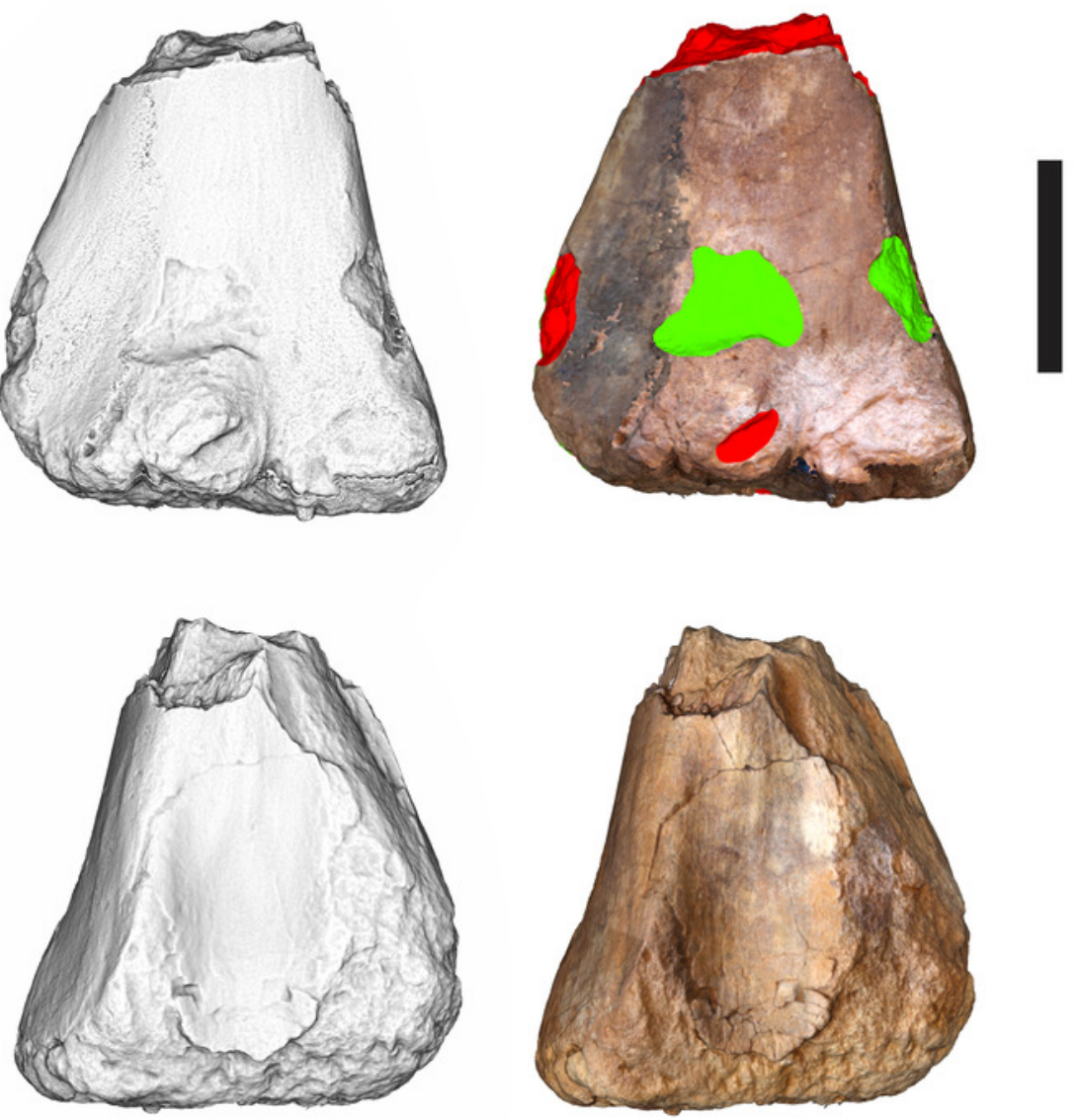

C
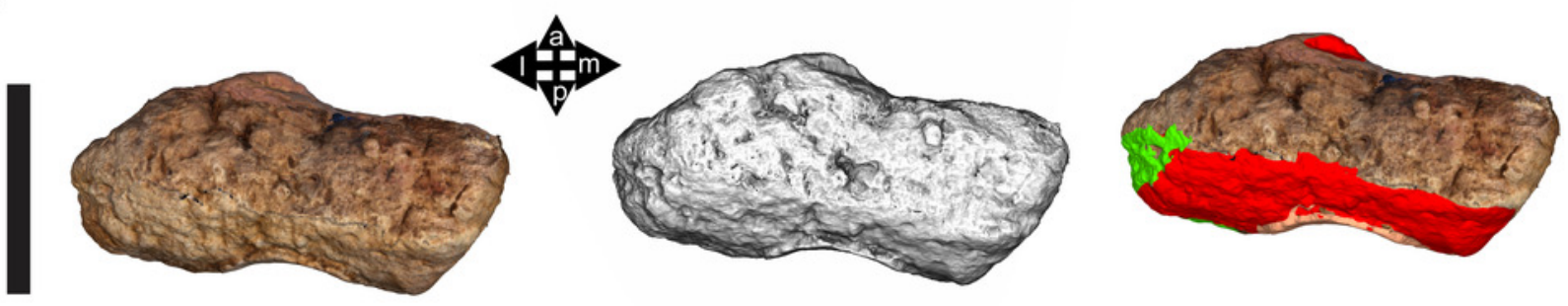


\section{Figure 28}

EMF100 (EML01), a small partial ulna with similar morphological features to Australotitan cooperensis gen. et sp. nov.

(A \&B) Ulna in mediolateral (A) and medial (B) views. (C-J) Comparisons between EMF100 (D) with $A$. cooperensis gen. et sp. nov. $(C \& \mathrm{~J})$, W. wattsi $(\mathrm{E} \& \mathrm{H})$ and $D$. matildae $(\mathrm{F} \& \mathrm{~J})$, scaled to minimum midshaft width. Mediolateral shape (top left), medial shape (top right), proximal shape (middle left), distal shape (middle right), midshaft cross-sectional shape (bottom left, cross-section position indicated by dotted line in top) and distal margin outline (bottom right). 3-D image rendering methods used included, natural, A (left), B (right); ambient occlusion with radiance scaling $A \& B$ (middle), C-J top and middle row; coloured schematic (see Figure 8) A (right), B (left); and orthogonal outline edge detect (bottom row). Scale bars $=20 \mathrm{~cm}$. 

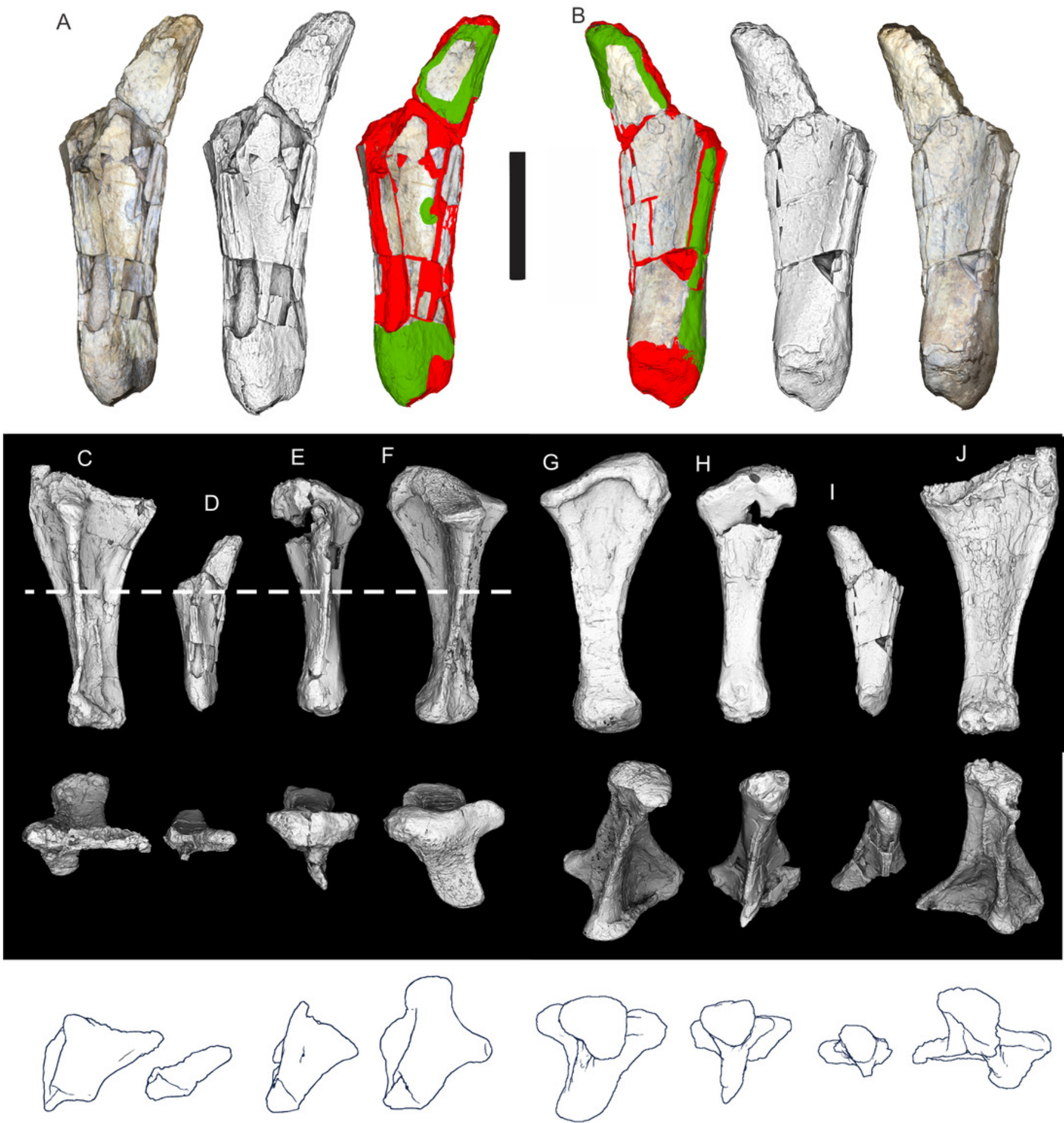


\section{Figure 29}

Sauropod caudal vertebrae from southern-central Winton Formation sites compared to Wintonotitan wattsi (QMF7292).

(A) EMF109, series of articulated distal caudal vertebrae as part of an articulated skeleton (see Figure 7K), right lateral view. (B) QMF7292, Wintonotitan wattsi holotype distal caudal vertebral series, right lateral view. (C) Closeup of the most complete distal caudal in the series for W. wattsi, in oblique craniolateral view. (D) QMF7292, W. wattsi holotype middle caudal vertebra, in oblique cranioventral view. (E) EMF109 (EML012) middle caudal vertebra, in oblique cranioventral view. (F) EMF171 (EML028) middle caudal vertebra, in oblique cranioventral view. (G\&H) Partial proximal distal caudal, EMF106, from EML010 in anterior $(\mathrm{G})$ and lateral $(\mathrm{H})$ views. Abbreviations: ns, neural spine; post, postzygopophysis; pre, prezygopophysis. Scale bars $=10 \mathrm{~cm}$. 


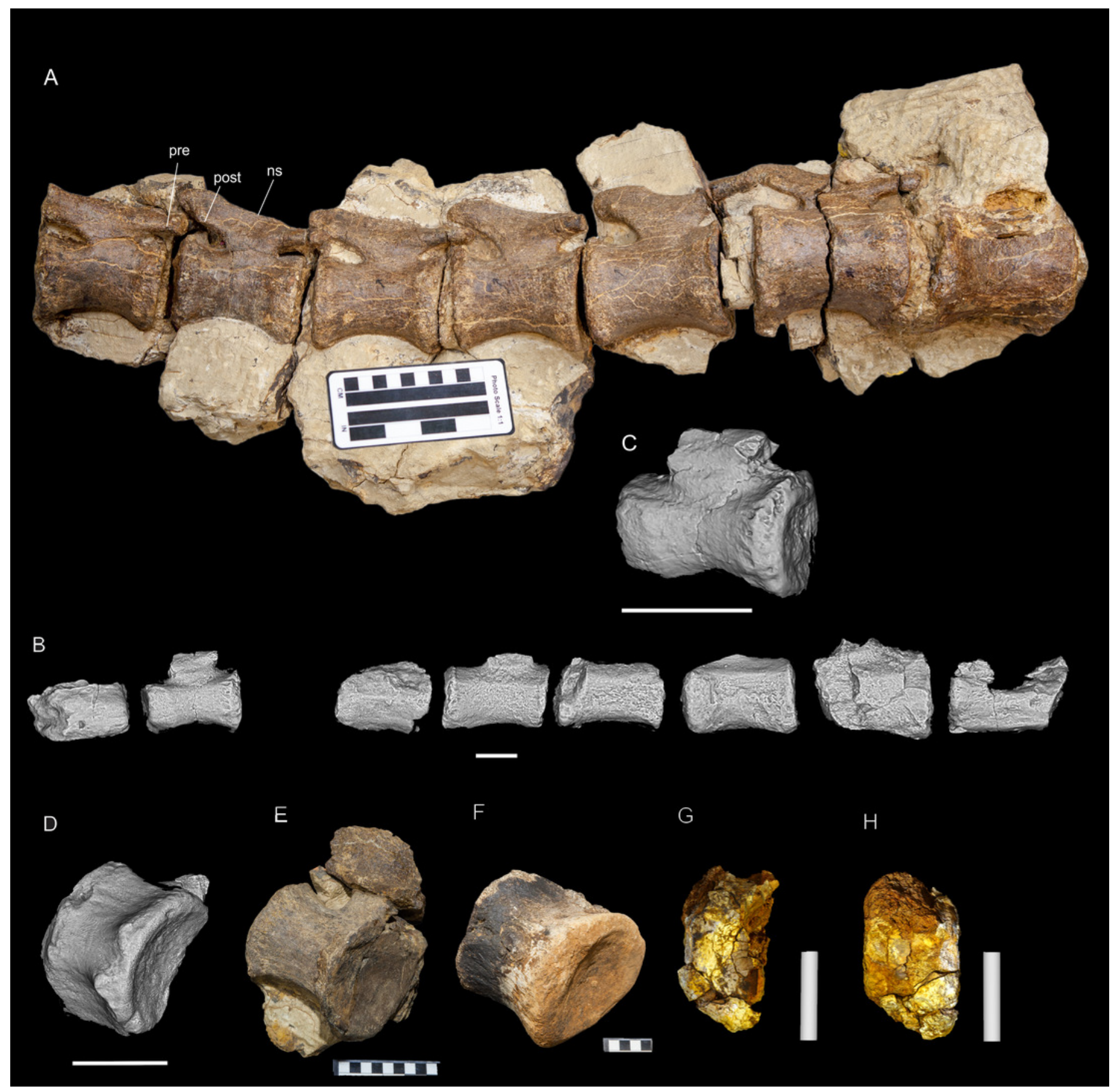




\section{Figure 30}

Comparative Meshlab ' $x$-ray' renders of isometrically aligned skeletal elements shared between Australotitan cooperensis gen. et sp. nov. and other Winton Formation sauropods.

(A-C) Comparison of preserved scapulae in lateral view. (A) A. cooperensis aligned to $D$. matildae. (B) A. cooperensis gen. et sp. nov. aligned to W. wattsi. (C) W. wattsi aligned to $D$. matildae. (D-I) Comparison of preserved humeri in anterior view. (D) A. cooperensis gen. et sp. nov. aligned to D. matildae. (E) A. cooperensis gen. et sp. nov. aligned to $S$. elliottorum. (F) A. cooperensis gen. et sp. nov. aligned to W. wattsi. (G) W. wattsi aligned to $S$. elliottorum. (H) D. matildae aligned to S. elliottorum. (I) D. matildae aligned to W. wattsi. (J-L) Comparison of preserved ulnae in mediolateral view. (J) A. cooperensis gen. et sp. nov. aligned to $D$. matildae. (K) A. cooperensis gen. et sp. nov. aligned to W. wattsi. (L) D. matildae aligned to W. wattsi. (M-O) Comparison of preserved ischium. (M) A. cooperensis gen. et sp. nov. aligned to W. wattsi. (N) D. matildae aligned to W. wattsi. (O) S. elliottorum aligned to W. wattsi. (P-S) Comparison of preserved femora in posterior view. (P) QMF43302 aligned to EMF105. (Q) QMF43302 aligned to D. matildae. (R) EMF105 aligned to D. matildae. (S) Reconstructed femur of $A$. cooperensis gen. et sp. nov. (EMF102) aligned to referred femur EMF105. 


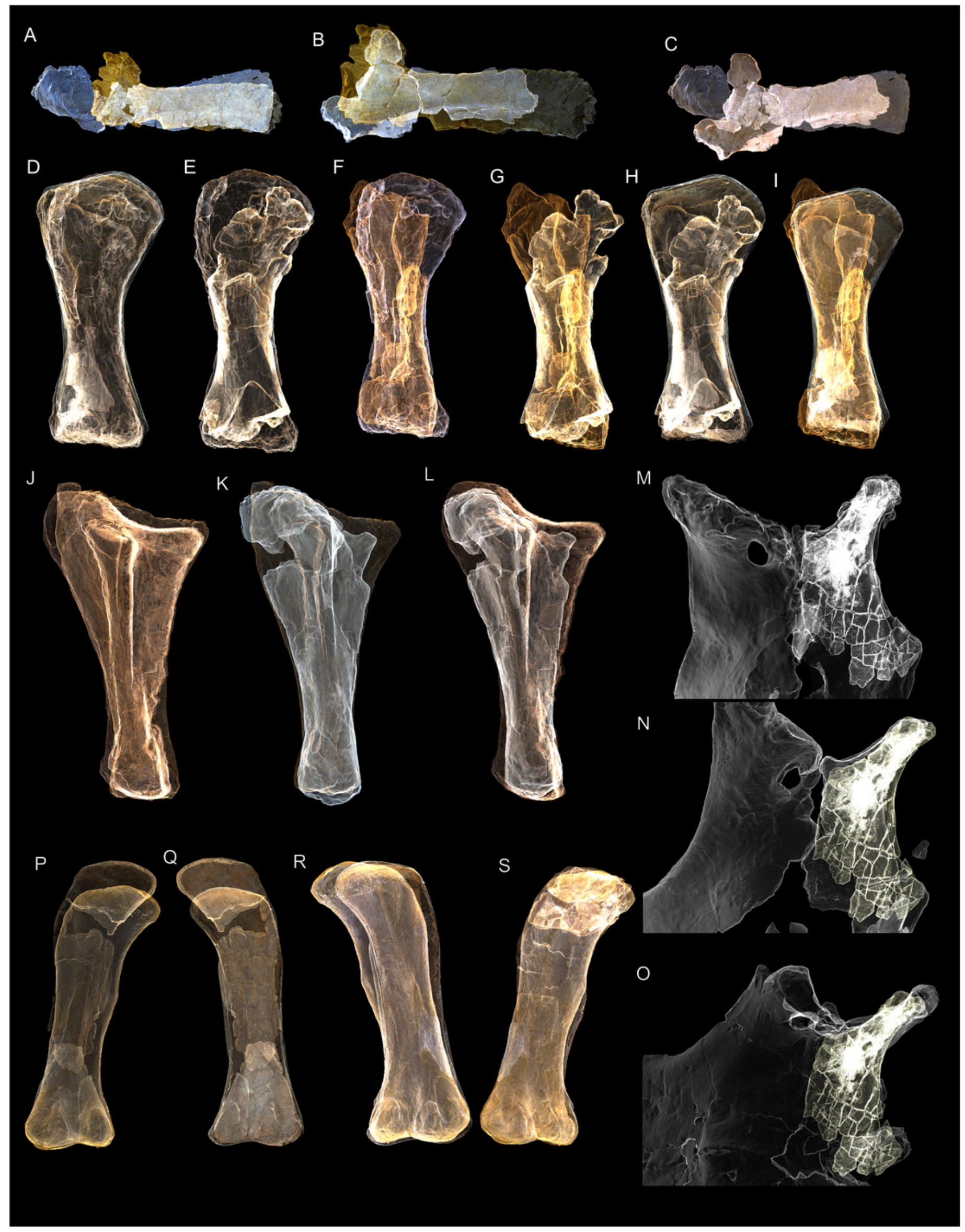




\section{Figure 31}

Anterior caudal vertebra from Savannasaurus elliottorum holotype (QMF7292).

(A) Right lateral view. (B) left lateral view. (C) Cranial view. (D) Caudal view. (E) Right lateral view. (F) Left lateral view. (G) Anterior view. (H) Posterior view. (I-K) Anterior caudal vertebra of $S$. elliottorum (I \& J) compared to W. wattsi $(K)$ isometrically scaled to minimum central cranial-caudal length. All in left lateral orthogonal outline view. 3-D image rendering methods used included, natural; A, D, F, G (right), B, C, E, H (left); ambient occlusion with radiance scaling, A-H (middle); coloured schematic (see Figure 8), A, D, F, G (left) \& B, C, E, H (right); Orthogonal outline edge detect, A-D (far left), F-H (far right) \& I-K. Abbreviations: pne; pneumatic cavities; post, postzygopophysis; pre, prezygopophysis; ns, neural spine; tp, transverse process. Scale bars $=20 \mathrm{~cm}$. 

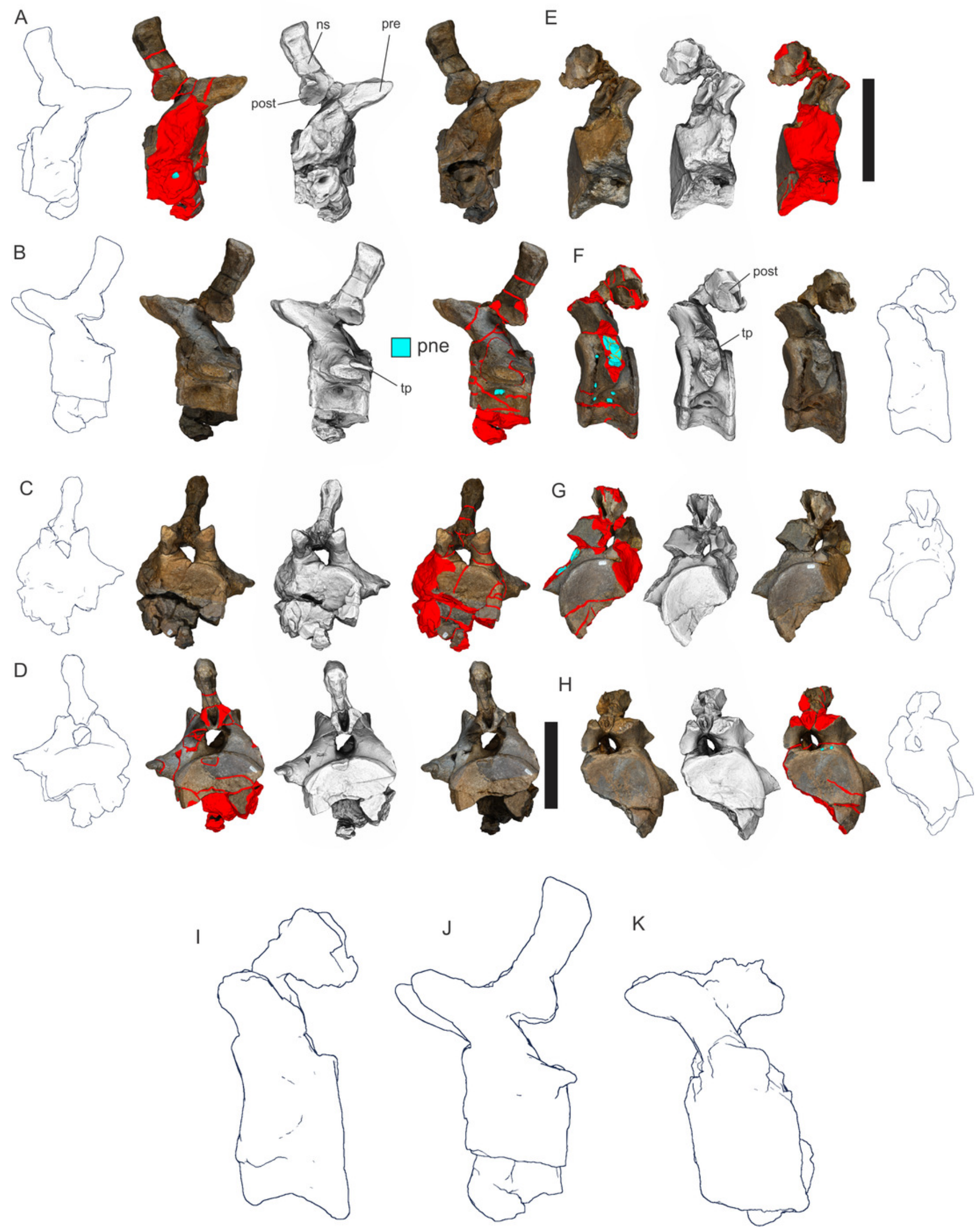

K

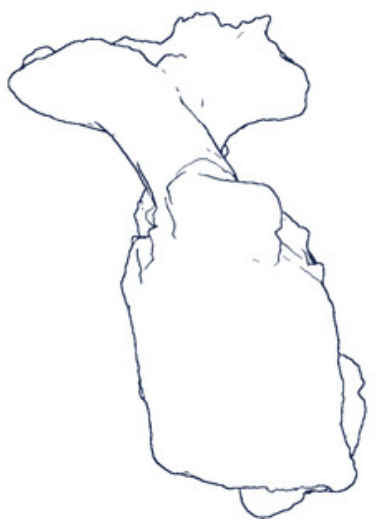




\section{Figure 32}

Anterior caudal vertebra from Wintonotitan wattsi holotype (QMF7292).

(A) Cranial view. (B) Caudal view. (C) Left lateral view. (D) Right lateral view. 3-D image rendering methods used included, ambient occlusion with radiance scaling $A \& D$ (left), $B \& C$ (right); coloured schematic (see Figure 8) A \& D (right), B \& C (left). Abbreviations: pne; pneumatic cavities; post, postzygopophysis; pre, prezygopophysis. Scale bars $=20 \mathrm{~cm}$.

A

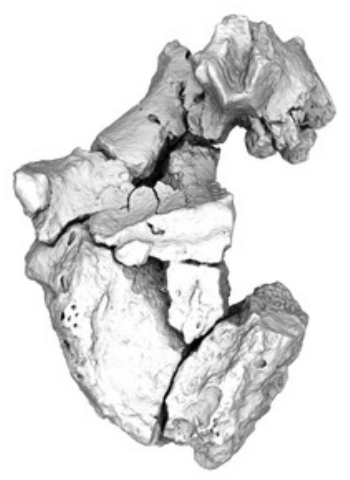

C

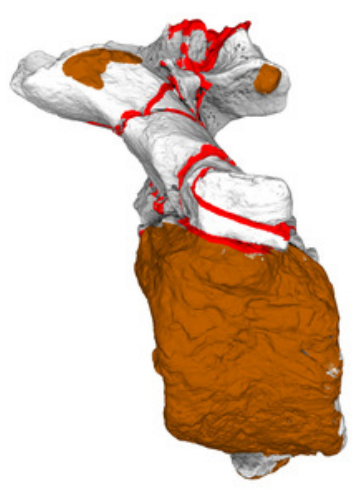

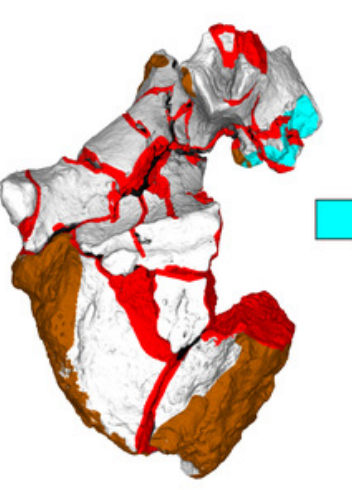

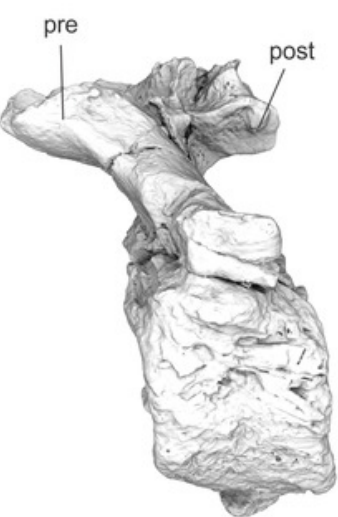

B

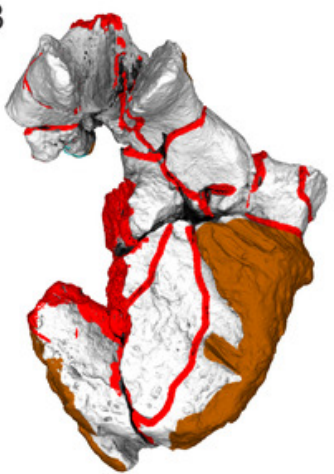

$\mathrm{D}$

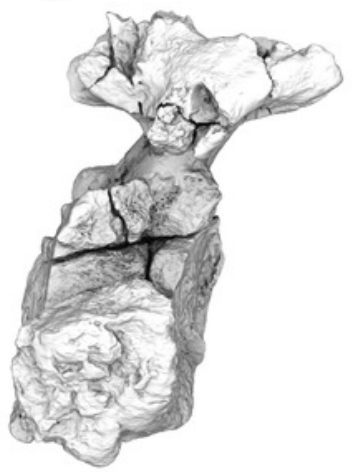

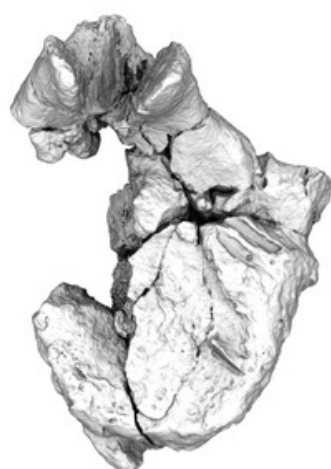
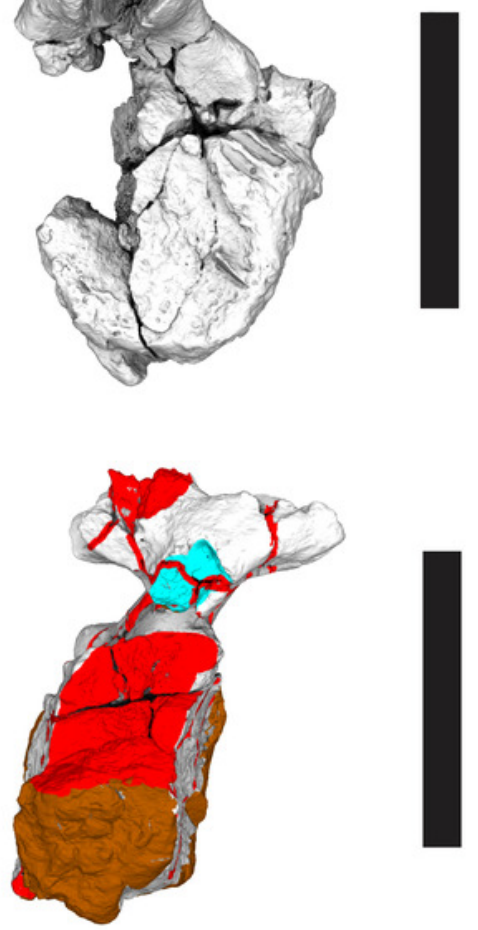


\section{Figure 33}

Anterior caudal vertebra from Wintonotitan wattsi holotype (QMF7292) showing pneumatic cavities within the neural arch.

(A) A series of absorption contrast CT scan images taken from dorsal view through the prezygopophyses, neural arch and centrum. Revealing the internal cavities of the zygopophyses and neural arch that have been infilled with a dense material (iron-oxide pseudomorph of pyrite). (B) A series of maximum intensity CT scan images taken from dorsal view through the prezygopophyses, through the neural arch and into the centrum. (C\&D) Coloured volume renders of the anterior caudal vertebra, clipped longitudinally through the vertebra at the position of the left prezygopophysis (C) and right prezygopophysis (D) to reveal the internal pneumatic cavities that have been partially infilled with iron-oxide pseudomorph of pyrite. Abbreviations: pne; pneumatic cavities, pyr; dense material infill (pseudomorph of pyrite). Scale bars $=5 \mathrm{~cm}(A \& B) ; 10 \mathrm{~cm}(C \& D)$. 


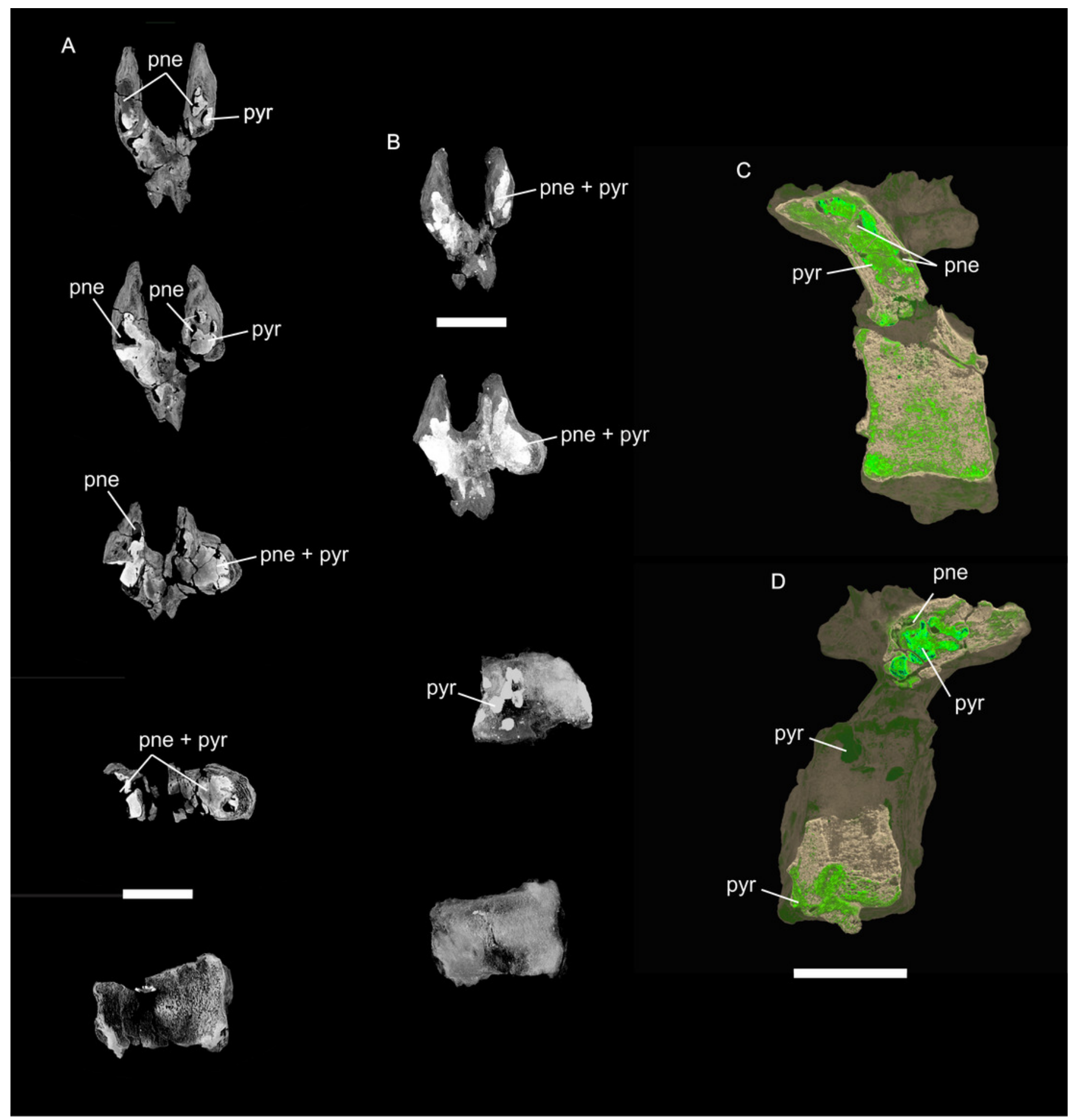




\section{Figure 34}

3-D digital model restorations of the appendicular elements of Australotitan cooperensis gen. et sp. nov. holotype EMF102.

$(A \& B)$ Scapula in lateral $(A)$ and medial views (B). (C\&D) Humerus in anterior (C) and posterior (D) views. E-G. Ulna in anterolateral $(E)$, posterior $(F)$ and anteromedial $(G)$ views. $H$ $\& \mathrm{I}$. Pubes and ischia in dorsal $(\mathrm{H})$ and lateral (I) views. $\mathrm{J} \& \mathrm{~K}$. Femur in posterior (J) and anterior (K) views. 3-D image rendering method was $\mathrm{x}$-ray overlay of aligned 3-D models in orthogonal view. 


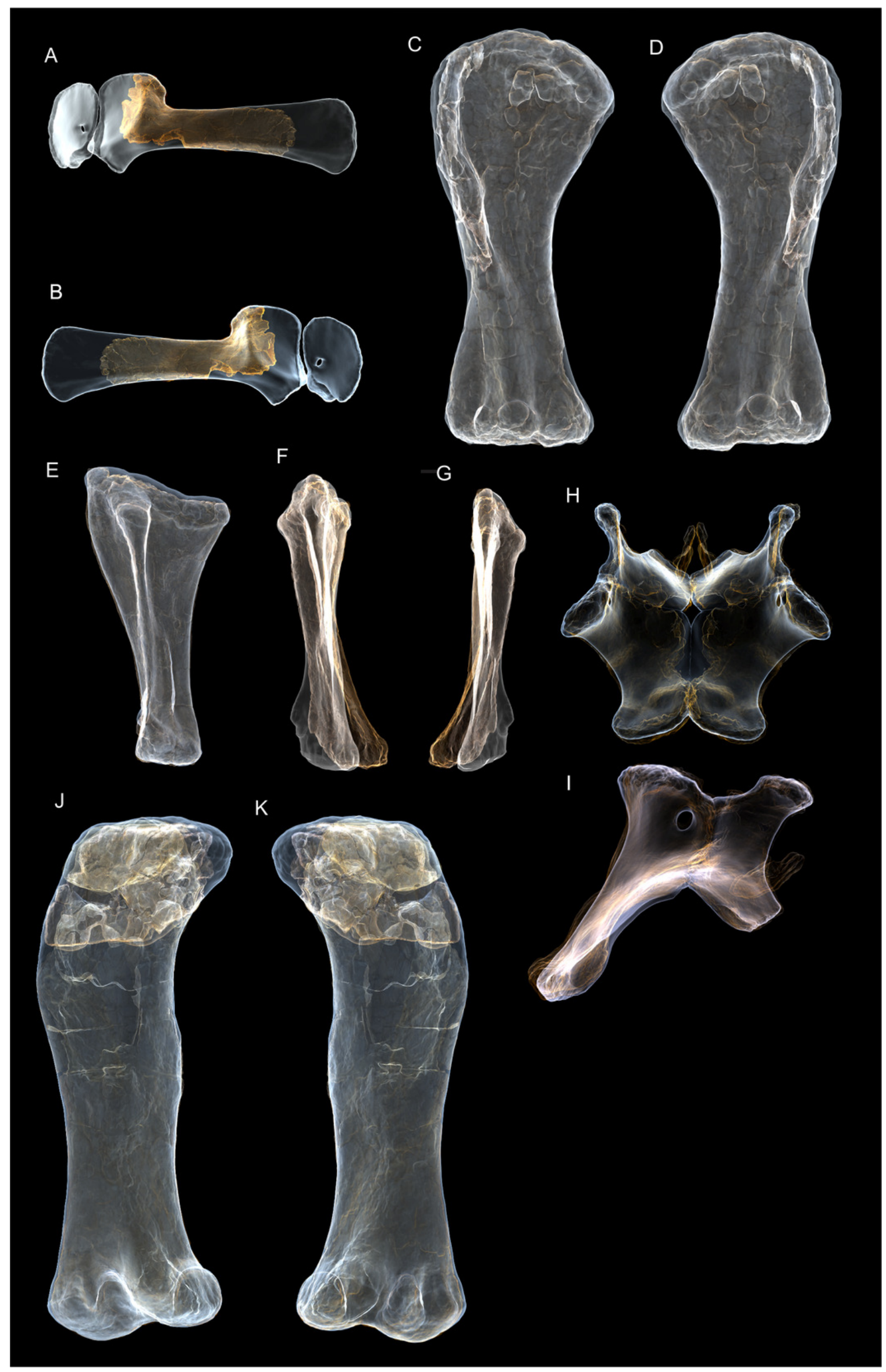

Peerj reviewing PDF | (2020:11:55594:2:1:NEW 28 Mar 2021) 


\section{Figure 35}

Comparison of preserved size, estimated size, and shape in Winton Formation sauropod humeri, ulnae and femora (rendered as right elements).

(A-D) Humeri in anterior view; (A) A. cooperensis gen. et sp. nov. (B) W. wattsi, (C) D.

matildae and (D) S. elliottorum. (E \& F) Ulnae in anterolateral view; (E) A. cooperensis gen. et sp. nov.; (F) D. matildae, (G) W. wattsi (reconstruction). (H-K) Femora in anterior view; (H) D. matildae, (I) ?W. wattsi (QMF43302), (J) A. cooperensis gen. et sp. nov. (EMF105), (K) A. cooperensis gen. et sp. nov. (reconstructed, EMF102). (L-P) Femora in posterior view; (L) A. cooperensis gen. et sp. nov. (EMF164) femoral pieces set within a reconstructed outline model (transparent) (M) A. cooperensis gen. et sp. nov. (reconstruction, EMF102), (N) A. cooperensis gen. et sp. nov. (EMF105), (O) ?W. wattsi (QMF43302) and (P) D. matildae. Top rows are all natural vertex colour renders and bottom row are all orthogonal edge detected outlines. Dotted lines indicate estimated missing regions for incomplete specimens. Scale bar $=20 \mathrm{~cm}$. 

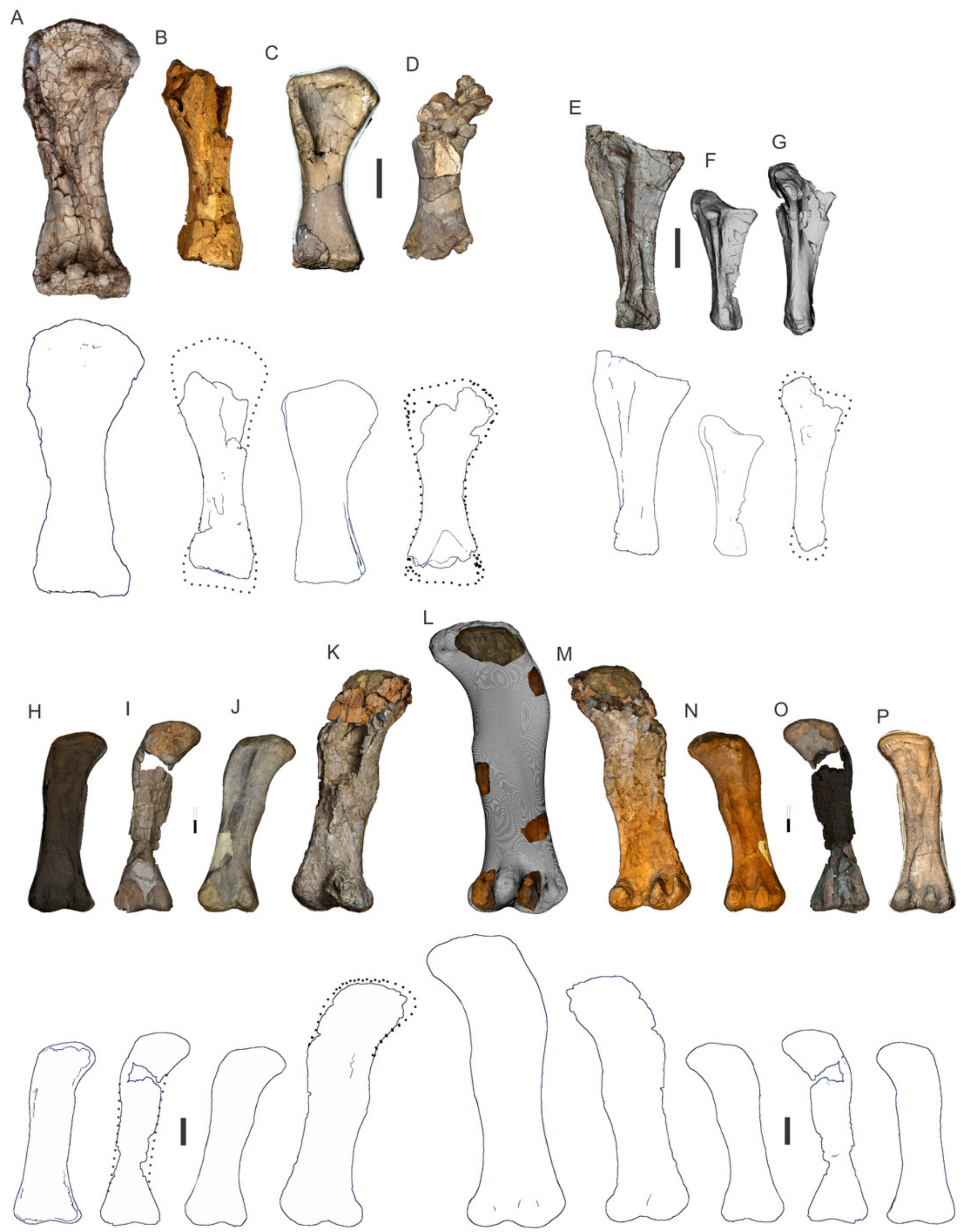


\section{Figure 36}

Scatterplots of stylopodial measurements ( $\mathrm{mm})$.

(A) Humerus length ( $\mathrm{HL}$ ) plotted against humerus circumference $(\mathrm{HC})$. (B) Femoral length (FL) plotted against femoral circumference (FC). (C) Femoral length (FL) plotted against humeral length (HL). Red stars indicate positions of holotype specimens of $D$. matildae (Dm) and Australotitan cooperensis gen. et sp. nov. (Ac), with the grey star representing the estimated position for $A$. cooperensis gen. et sp. nov. referred femur EMF164. Abbreviations of sauropod taxa: Ah, Argentinosaurus huiculensis; Ai, Atlasaurus imelakei; As, Alamosaurus sanjuanensis; Ay, Argyrosaurus superbus; Aw, Antarctosaurus wichmannianus; $\mathrm{Ba}$, Brachiosaurs altithorax; Ci, Chubutisaurus insignis; Ds, Dreadnoughtus schrani; El, Elaltitan lilloi; Fd, Futalognkosaurus dukei; Gb, Giraffatitan brancai; La, Lourinhasaurus alenquerensis; LI, Ligabuesaurus leanzai; Ng, Notocolossus gonzalezparejasi; Ps, Paralititan stromeri; Pm, Patagotitan mayorum; Tb, Tehuelchesaurus benitezii; Te, Traukutitan eocaudata. Measurement data from (Benson et al. 2014) 

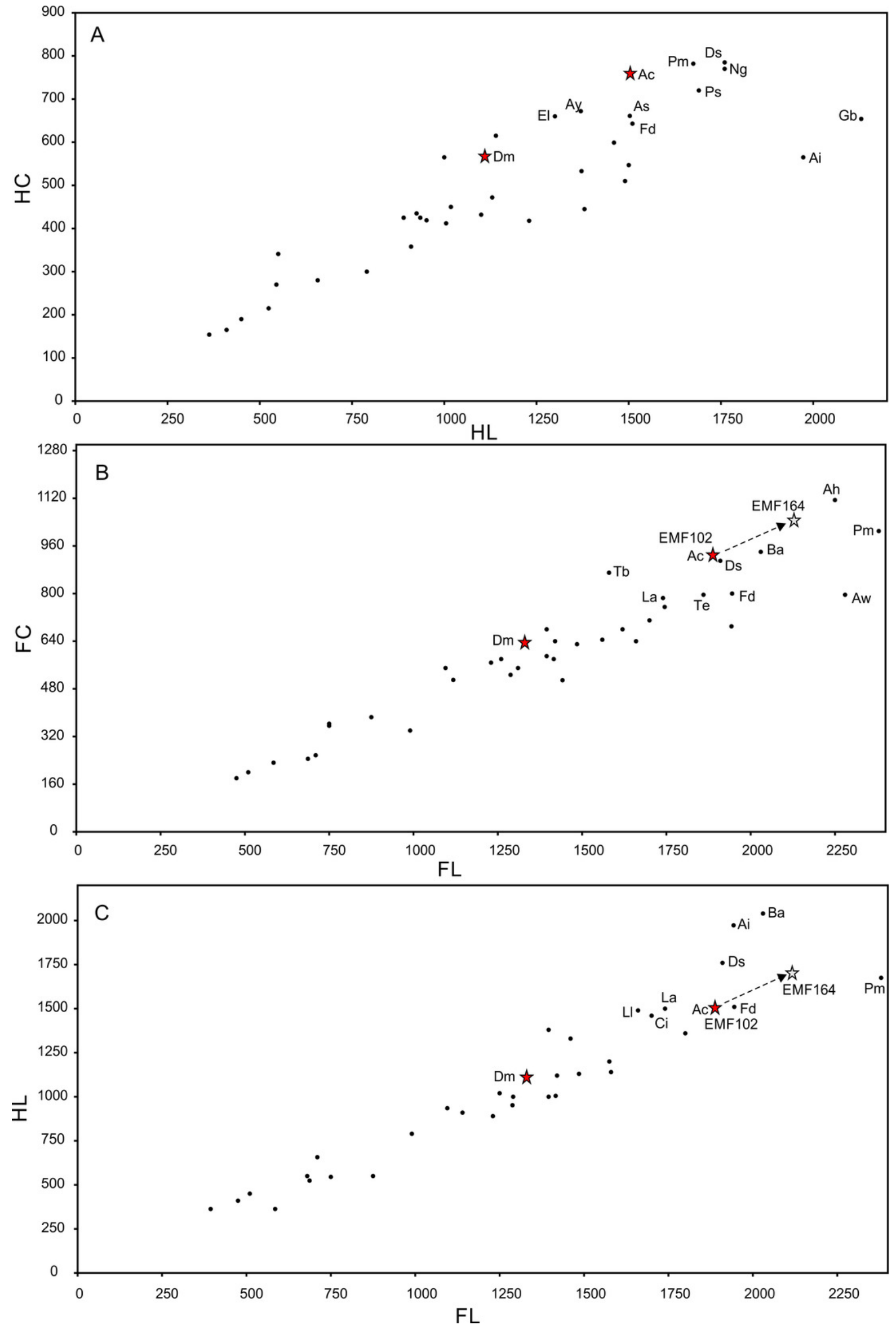

Peer] reviewing PDF | (2020:11:55594:2:1:NEW 28 Mar 2021) 